Portland State University

PDXScholar

\title{
Chehalis River and Tributary Water Quality and Hydrodynamic Modeling: Model Setup, Calibration Analysis for 2013-2015
}

Tel Jensen

Portland State University

Follow this and additional works at: https://pdxscholar.library.pdx.edu/open_access_etds

Part of the Civil and Environmental Engineering Commons Let us know how access to this document benefits you.

Recommended Citation

Jensen, Tel, "Chehalis River and Tributary Water Quality and Hydrodynamic Modeling: Model Setup, Calibration Analysis for 2013-2015" (2020). Dissertations and Theses. Paper 5433.

https://doi.org/10.15760/etd.7306

This Thesis is brought to you for free and open access. It has been accepted for inclusion in Dissertations and Theses by an authorized administrator of PDXScholar. Please contact us if we can make this document more accessible: pdxscholar@pdx.edu. 
Chehalis River and Tributary Water Quality and Hydrodynamic Modeling: Model

Setup, Calibration Analysis for 2013-2015

by

Tel Jensen

A thesis submitted in partial fulfillment of the requirements for the degree of

\author{
Master of Science \\ in \\ Civil and Environmental Engineering
}

Thesis Committee:

Scott Wells, Chair

Chris Berger

Gwynn Johnson

Portland State University

2020 
(C) 2020 Tel Jensen 


\begin{abstract}
The Chehalis River is located in southwest Washington State. Its headwaters are in the Willapa Hills, and it drains parts of the Doty Hills, the western foothills of the Cascade Mountains, and the southern Olympic Mountains. The Chehalis River is over 125 miles long and its basin is over 2000 square miles spanning parts of seven counties and diverse land uses.
\end{abstract}

CE-QUAL-W2 is a widely used two-dimensional (vertical and longitudinal) hydrodynamic and water quality model developed by the US Army Corp of Engineers and the Water Quality Research Group at Portland State University. Version 4.2 includes the ability to run waterbodies in sequence rather than simultaneously, which improves model run times.

This study expands and refines the work of Van Glubt et al. (2017). Model calibration was extended an additional year through 2015. Flow and temperature correlations used to fill model data gaps were updated with new data. 2018 dye study and periphyton data collected by the Washington State Department of Ecology were used to improve model calibration. Temperature and flow models of four large tributaries of the Chehalis River were created.

There remains room for improvement to the mainstem and tributary models. Better characterization of tributary water quality would improve the mainstem model's predictive ability. Model geometry in mainstem and tributary models could be further refined. Measurement of tributary flow rate and temperature at upstream boundaries would improve the utility of the tributary models. 


\section{Acknowledgements}

All the critters, but especially the critter. And Scott. Thanks. 
Table of Contents

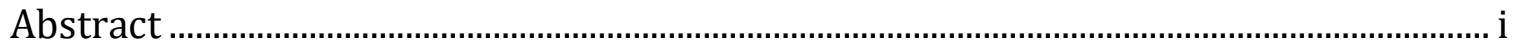

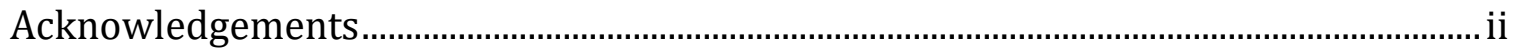

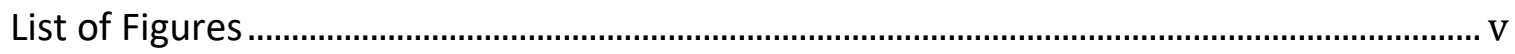

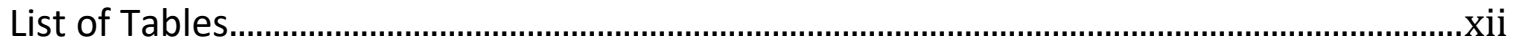

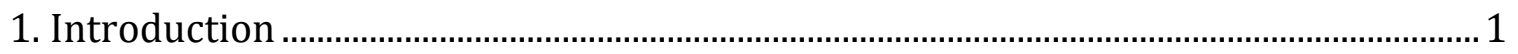

Chehalis River Model Background................................................................................ 1

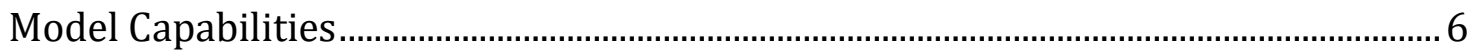

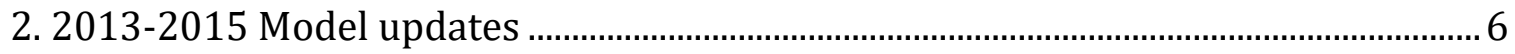

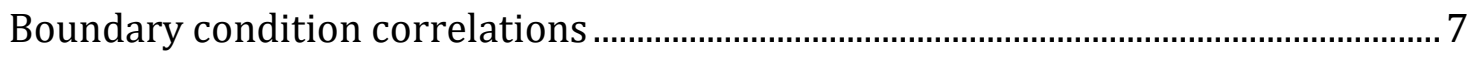

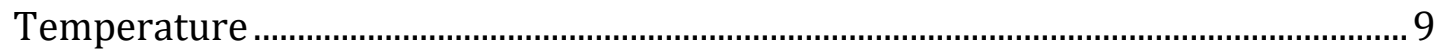

Flow

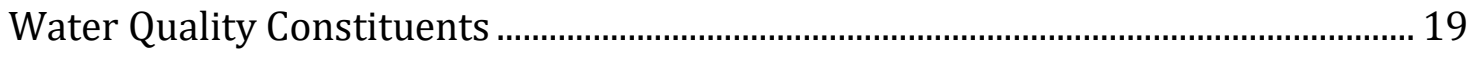

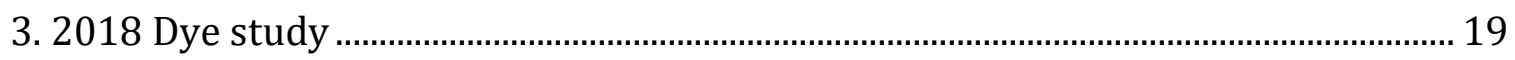

4. Tributaries of the Chehalis: South Fork Chehalis, Newaukum, Skookumchuck, and

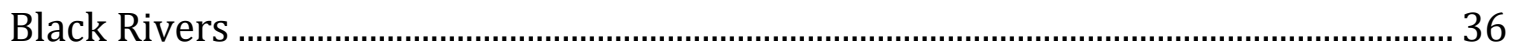

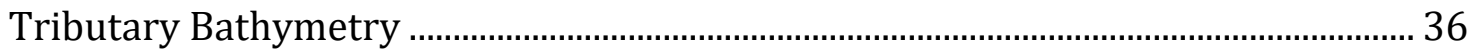

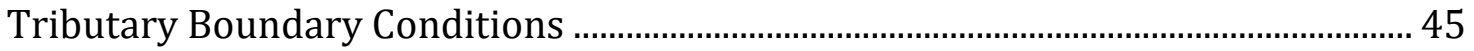

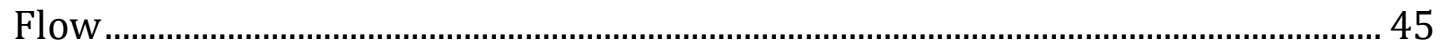

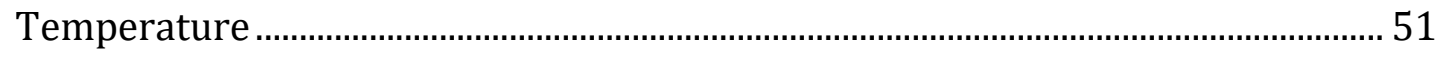

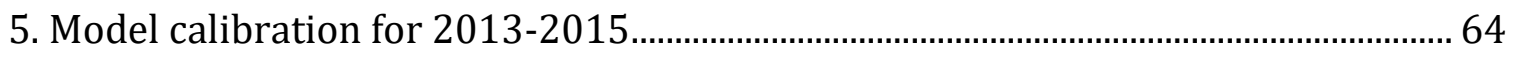

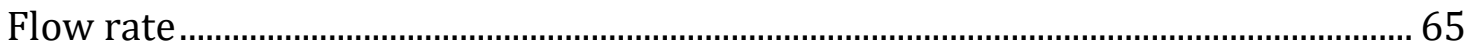

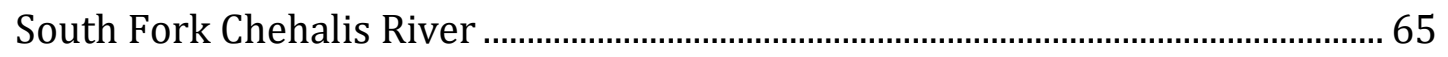

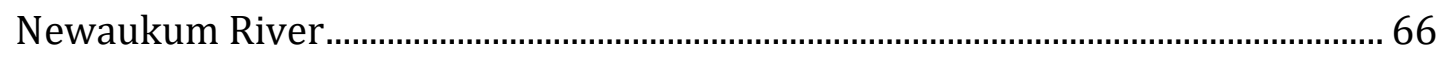

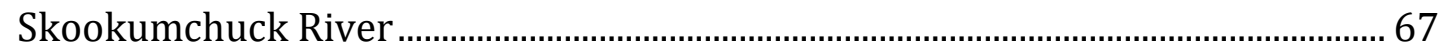

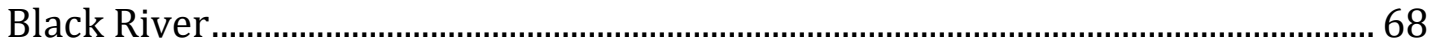

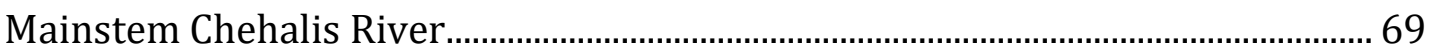

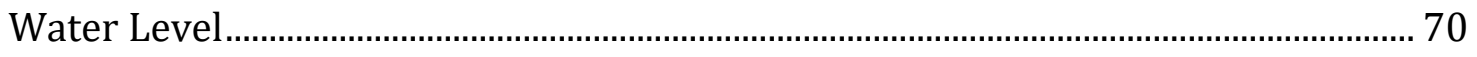

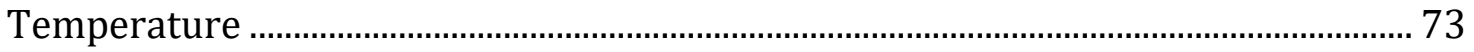

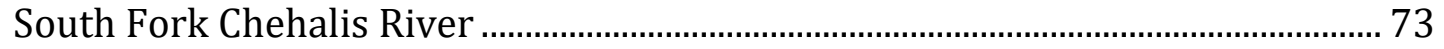

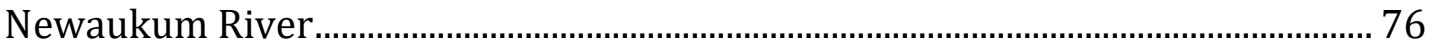

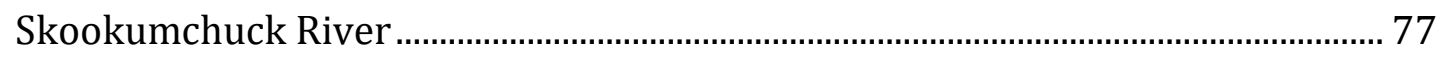




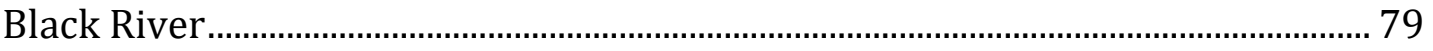

Mainstem Chehalis River..................................................................................... 81

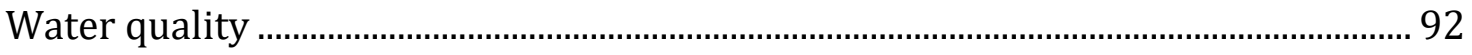

DO, nutrients, chlorophyll $a$, $\mathrm{pH}$ and TSS............................................................... 99

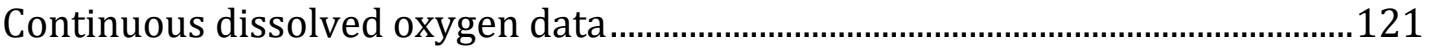

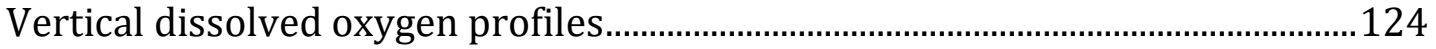

Algae Dynamics............................................................................................................128

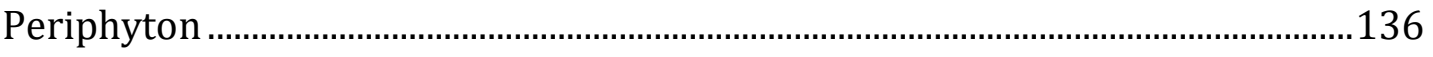

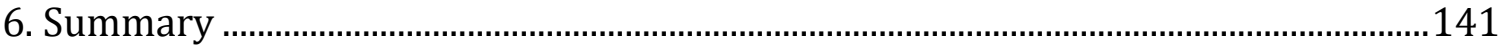

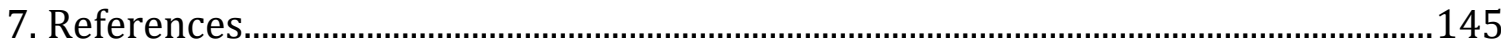

Appendix A: Estimating stream temperatures by the filtered equilibrium technique

The equilibrium temperature..................................................................................146

The filtered equilibrium temperature ..........................................................................148

Appendix B: Washington Department of Ecology Dye Study 2018..............................149

Appendix C: Error Statistics.....................................................................................152

Appendix D: Using Multiple Processors for a Cascade of Waterbodies ..............................153

How to Set up a Simulation .......................................................................................155

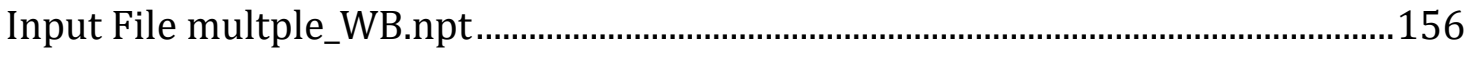

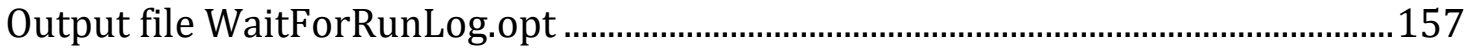

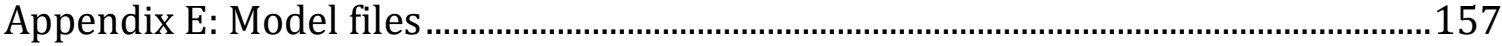

Mainstem Chehalis River .....................................................................................157

South Fork Chehalis River......................................................................................167

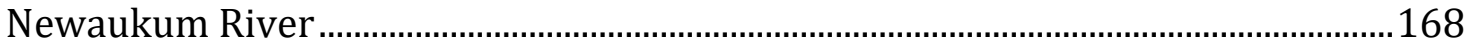

Skookumchuck River ..............................................................................................169

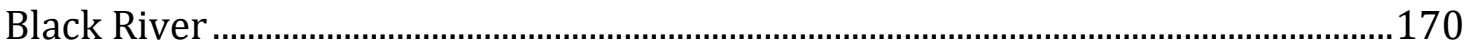

Input file descriptions ..........................................................................................170

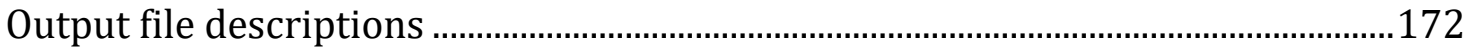




\section{List of Figures}

Figure 1. Chehalis River study area from near Doty, through Centralia to Aberdeen in southwestern Washington State (Google earth, 2017) ............................................... 1 Figure 2. Chehalis River basin and associated tributaries (adapted from Dustin Bilhimer, 2015)

Figure 3. Longitudinal profile of the Chehalis River thalweg (vertical lines show model branch breaks) from Van Glubt et al. (2017). Figure 4. Schematic of tributaries to the model reach of the Chehalis River and their corresponding river miles (WEST Consultants, 2011 and WADOE, 2001). Note: figure is not to scale.

Figure 5. Temperature correlation between the station $4-\mathrm{UCH}$ and the Chehalis River downstream of Darigold WWTP between 2013-2015. 11

Figure 6. Temperature correlation between the station 11-UCH (upstream boundary) and the Chehalis River downstream of Darigold WWTP between 2013-2015. 11 Figure 7. Temperature correlation between the station $13-\mathrm{CH}$ and the Chehalis River downstream of Darigold WWTP between 2013-2015............................................ 12 Figure 8. Temperature correlation between the station $18-\mathrm{CH}$ and the Chehalis River downstream of Darigold WWTP between 2013-2015.............................................. 12 Figure 9. Temperature correlation between the station $22-\mathrm{UCH}$ and the Chehalis River downstream of Darigold WWTP between 2013-2015............................................. 13 Figure 10. Temperature correlation between the station Black River tributary and the Chehalis River downstream of Darigold WWTP between 2013-2015............................ 13 Figure 11. Temperature correlation between the station Elk Creek tributary and the Chehalis River downstream of Darigold WWTP between 2013-2015.......................... 14 Figure 12. Temperature correlation between the station Newaukum tributary and the Chehalis River downstream of Darigold WWTP between 2013-2015............................ 14 Figure 13. Temperature correlation between the station Scatter Creek and the Chehalis River downstream of Darigold WWTP between 2013-2015...................................... 15 Figure 14. Temperature correlation between the station Skookumchuck River and the Chehalis River downstream of Darigold WWTP between 2013-2015............................ 15 Figure 15. Flow correlation between Black River and Chehalis River at Grand Mound between 2013-2015. 17 Figure 16. Flow correlation between Elk Creek and Chehalis River at Doty between 20132015.

Figure 17. Flow correlation between Chehalis River near Mahaffey Creek and Chehalis

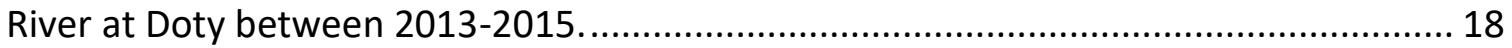
Figure 18. Locations of four dye studies along the Chehalis River mainstem during August 2018.

Figure 19. Flow rate model predictions during August 2018 dye study compared to field data in the mainstem Chehalis River at (a) Doty, (b) Adna, (c) Grand Mound, and (d) Porter. 22

Figure 20. Dye concentration curves at (a) Elk Creek, (b) Hope Creek, (c) Ceres Canyon, and (d) Adna during 2018 dye study..... 24 
Figure 21. Dye concentration curves at (a) Newaukum River, (b) Skookumchuck River, (c) Prather Road, and (d) Oakville Boat Launch during 2018 dye study............................. 25 Figure 22. Modeled dye concentration using two methods compared to dye study field data. The particle concentration was arbitrarily scaled. .............................................. 27 Figure 23. Cumulative mass from dye release compared to model predictions at Elk Creek RM 100.4 29

Figure 24. Cumulative mass from dye release compared to model predictions at Hope Creek RM 94.8 30 Figure 25. Cumulative mass from dye release compared to model predictions at Adna RM 81.5. 30

Figure 26. Cumulative mass from dye release compared to model predictions at

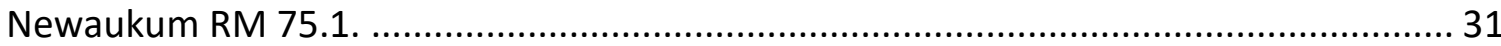
Figure 27. Cumulative mass from dye release compared to model predictions at Skookumchuck RM 67. 31 Figure 28. Cumulative mass from dye release compared to model predictions at Prather Road RM 59.9 32

Figure 29. Cumulative mass from dye release compared to model predictions at Oakville Boat Launch RM 42.4. 33

Figure 30. South Fork Chehalis River HEC-RAS cross sections (black triangles), segment locations (red triangles), and lower model segment locations (blue triangles). Numbers represent CE-QUAL-W2 model segments in the Chehalis River (blue) and in the South Fork Chehalis River (red). 37

Figure 31. Newaukum River HEC-RAS cross sections (black triangles), segment locations (red triangles), and lower model segment locations (blue triangles). Numbers represent CE-QUAL-W2 model segments in the Chehalis River (blue) and in the Newaukum River (red) 38

Figure 32. Skookumchuck River HEC-RAS cross sections (black triangles), segment locations (red triangles), and lower model segment locations (blue triangles). Numbers represent CE-QUAL-W2 model segments in the Chehalis River (blue) and in the Skookumchuck River (red). 39 Figure 33. Black River HEC-RAS cross section locations (black triangles), segment locations (red triangles), and lower Chehalis River model segment locations (blue triangles). Numbers represent CE-QUAL-W2 model segments in the Chehalis River (blue) and in the Black River (red) 40 Figure 34. South Fork Chehalis River thalweg elevations of HEC-RAS cross-sections..... 41 Figure 35. Newaukum River thalweg elevations of HEC-RAS cross-sections. ................ 42 Figure 36. Skookumchuck River thalweg elevations of HEC-RAS cross-sections............. 43 Figure 37. Black River thalweg elevations of HEC-RAS cross-sections. .......................... 44 Figure 38. Flow data from WADOE $23 \mathrm{~K} 060$ gage on the South Fork Chehalis River at Highway 6 showing difference before and after the end of 2017 water year. 47

Figure 39. South Fork Chehalis River flow estimates at Ecology $23 \mathrm{~K} 060$ gage showing regressions to fill in data gaps. Regressions used all the data (all data), those data that passed quality control (good data), or only 2018 and 2019 data (late data). 47 
Figure 40. Estimated South Fork Chehalis River flow rates at upper boundary of model for

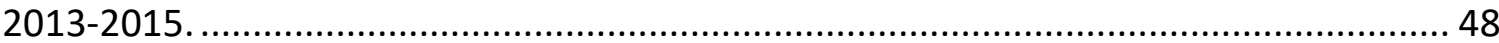

Figure 41. Estimated Newaukum River flow rates at upper bounday of model for 20132015. 49

Figure 42. Estimated Skookumchuck River flow rates at upper boundary of model between 2013-2015. 50 Figure 43. Estimated Black River flow rates at upper boundary of model between 20132015. 51

Figure 44. Filtered equilibrium temperature at 30,60 and 90 day averaging period using meterological data from the Chehalis River model.

Figure 45. Temperature sampling locations in the South Fork River. Red triangles are model segments in the South Fork model. Blue triangles are model segments in the lower Chehalis River mainstem model. 53 Figure 46. Temperature at SFCHEH-2 on the South Fork Chehalis River. ....................... 54 Figure 47. Estimated upstream temperature boundary condition for the South Fork Chehalis River between 2013-2015. 54 Figure 48. Temperature sampling stations (green dots) along the Newaukum River. Red triangles are model segments in the Newaukum model. Blue triangles are model segments in the lower Chehlis River mainstem model. 55 Figure 49. Temperature in the Newaukum River at NEW-1, model segment 60 and NWKMOUTH, model segment 92. 56

Figure 50. Estimated temperature used for Newaukum River upstream boundary condition between 2013-2015.

Figure 51. Temperature sampling stations (green dots) along the Skookumchuck River. Red triangles are model segments in the Skookumchuck model. Blue triangles are model segments in the lower Chehalis River mainstem model.

Figure 52. Skookumchuck River WDFW temperature data from (a) SKOOK-1, (b) SKOOK2, and (c) SKOOK-3. 59 Figure 53. Estimated upstream temperature boundary condition for the Skookumchuck River between 2013-2015. 60 Figure 54. Location of temperature measuring locations (green dots) BLACK-1 and BLACK2 on the Black River. Model segments are in light blue for the lower Chehalis River model

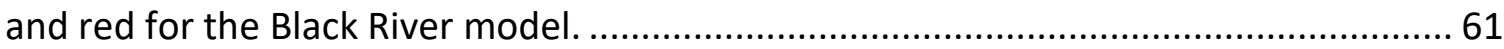
Figure 55. Black River WDFW temperature data from (a) BLACK-1 and (b) BLACK-2 ..... 62 Figure 56. Estimated upstream temperature boundary condition for the Black River between 2013-2015. 63 Figure 57. Using the new CE-QUAL-W2 model framework for running the Chehalis River model. 65

Figure 58. Flow rate comparison between linear regression flow estimate, upstream flow boundary condition, and model predictions for South Fork Chehalis River near the Chehalis mainstem. 66 
Figure 59. Flow rate comparison between field data and model predictions in the Newaukum River at USGS 12025000. Data from this gage was used for the upstream boundary condition and to compare with model output at segment 54 .

Figure 60. Flow rate comparison between field data and model predictions in the Skookumchuck River at USGS 12026400. Flow data from USGS 12026150 was used for the upstream boundary condition. The modeled flow at the mouth of the Skookumchuck River is also included.... 68

Figure 61. Flow rate comparison between field data and model predictions in Black River at $23 \mathrm{E} 060$. 69

Figure 62. Flow rate comparison between field data and model predictions in mainstem Chehalis River at (a) Doty, (b) Grand Mound, and (c) Porter between 2013-2015......... 70 Figure 63. Water level comparison between field data adjusted by mean error and model predictions in the mainstem Chehalis River at (a) Doty, (b) Adna, (c) Chehalis WWTP, and (d) Centralia between 2013-2015 71

Figure 64. Water level comparison between field data adjusted by mean error and model predictions in the mainstem Chehalis River at (a) Grand Mound, (b) Rochester, and (c) Porter between 2013-2015. 72

Figure 65. Temperature comparison between field data and model predictions in South Fork Chehalis River at (a) SFCHEH-1, (b) 23K060, and (c) SF-CHL-MOUTH. ................... 75 Figure 66. Temperature comparison between field data and model predictions in the Newaukum River at (a) NEW-1 and (b) NWK-MOUTH. 77 Figure 67. Temperature comparison between field data and model predictions in Skookumchuck River at (a) SKOOK-1 and (b) SKOOK-2. 79 Figure 68. Temperature comparison between field data and model predictions in Black

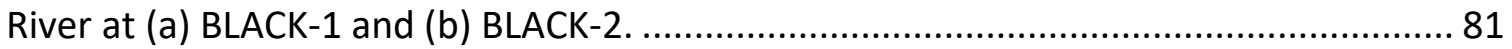
Figure 69. Temperature comparisons between field data and model predictions in the mainstem Chehalis River at (a) 11-UCH, (b) upstream of Pe Ell, (c) downstream of Pe Ell, (d) 13-CH, (e) Woodstead, (f) upstream of Elk Creek, and (g) Doty between 2013-2015.

Figure 70. Temperature comparisons between field data and model predictions in the mainstem Chehalis River at (a) 15-CH, (b) Dryad, (c) Rainbow Falls, (d) 19-CH, (e) Ceres Hills Road, and (f) Adna between 2013-2015. 85 Figure 71. Temperature comparison between field data and model predictions in the mainstem Chehalis River at (a) 21-CH, (b) Newaukum River, (c) 22-CH, (d) upstream of Darigold, (e) downstream of Darigold, and (f) upstream of Skookumchuck River between 2013-2015. 86

Figure 72. Temperature comparison between field data and model predictions in the mainstem Chehalis River at (a) Galvin Bridge, (b) 17-CH, (c) upstream of Black River, (d) 18-CH, (e) Oakville, and (f) Porter between 2013-2015. 87 Figure 73. Vertical temperature profiles of field data and model predictions in the pool area at RM 74.7 (Route 6 Bridge) model segment 149, RM 74.5 (HL-14) model segment 150, and RM 73.75 (HL-13) model segment 153 in 2013 and 2014. 89 
Figure 74. Vertical temperature profiles of field data and model predictions in the pool area at RM 73 (HL-12) model segment 157, RM 72.5 (HL-11) model segment 158, RM 72.25 (HL-10) model segment 160, RM 71.5 (HL-9) model segment 162, and RM 71 (HL-8) model segment 164 in 2014. 90 Figure 75. Vertical temperature profiles of field data and model predictions in the pool area at RM 70.5 (HL-7) model segment 166, RM 70 (HL-6) model segment 168, RM 69.25 (HL-5) model segment 171, RM 68.75 (HL-4) model segment 173, and RM 68.25 (HL-3) model segment 177 in 2014. 91 Figure 76. Vertical temperature profiles of field data and model predictions in the pool area at RM 67.75 (HL-2) model segment 179, RM 67.5 (Mellen Road Bridge) model segment 180, and RM 67.25 (HL-1) model segment 181 in 2013 and 2014. 92 Figure 77. Model dissolved oxygen predictions compared to field data in mainstem Chehalis River at (a) upstream of Pe Ell, (b) Dryad, (c) upstream of South Fork Chehalis River, (d) Adna, (e) upstream of Newaukum River, and (f) Route 6 bridge between 20132015. 101

Figure 78. Model dissolved oxygen predictions compared to field data in the mainstem Chehalis River at (a) upstream of Skookumchuck River, (b) Galvin Road bridge, (c) upstream of Black River, (d) Oakville, and (e) Porter between 2013-2015................... 102 Figure 79. Model ammonia predictions compared to field data in mainstem Chehalis River at (a) upstream of Pe Ell, (b) Dryad, (c) upstream of South Fork Chehalis River, (d) Adna, (e) upstream of Newaukum River, and (f) Route 6 bridge between 2013-2015........... 103 Figure 80. Model ammonia predictions compared to field data in the mainstem Chehalis River at (a) upstream of Skookumchuck River, (b) Galvin Road bridge, (c) upstream of Black River, (d) Oakville, and (e) Porter between 2013-2015. 104 Figure 81. Model NO2-N+NO3-N predictions compared to field data in mainstem Chehalis River at (a) upstream of Pe Ell, (b) Dryad, (c) upstream of South Fork Chehalis River, (d) Adna, (e) upstream of Newaukum River, and (f) Route 6 bridge between 2013-2015. 105 Figure 82. Model NO2-N+NO3-N predictions compared to field data in the mainstem Chehalis River at (a) upstream of Skookumchuck River, (b) Galvin Road bridge, (c) upstream of Black River, (d) Oakville, and (e) Porter between 2013-2015................... 106 Figure 83. Model TKN predictions compared to field data in the mainstem Chehalis River at (a) upstream of Pe Ell, (b) upstream of South Fork Chehalis River, (c) Adna, (d) upstream of Newaukum River, and (e) Route 6 bridge between 2013-2015.............................. 107 Figure 84. Model TKN predictions compared to field data in the mainstem Chehalis River at (a) upstream of Skookumchuck River, (b) Galvin Road bridge, (c) upstream of Black River, and (d) Oakville between 2013-2015. 108 Figure 85. Model PO4-P predictions compared to field data in the mainstem Chehalis River at (a) upstream of Pe Ell, (b) downstream of Pe Ell, (c) Dryad, (d) upstream of South Fork Chehalis River, (e)Adna, and (f) upstream of Newaukum River between 2013-2015... 109 Figure 86. Model PO4-P predictions compared to field data in the mainstem Chehalis River at (a) Route 6 bridge, (b) upstream of Skookumchuck River, (c) Galvin Road bridge, (d) upstream of Black River, (e) Oakville, and (f) Porter between 2013-2015. 110 
Figure 87. Model total phosphorus predictions compared to field data in the mainstem Chehalis River at (a) upstream of Pe Ell, (b) Dryad, (c) upstream of South Fork Chehalis River, (d) Adna, (e) upstream of Newaukum River, and (f) Route 6 bridge between 20132015.

Figure 88. Model total phosphorus predictions compared to field data in the mainstem Chehalis River at (a) upstream of Skookumchuck River, (b) Galvin Road bridge, (c) upstream of Black River, (d) Oakville, and (e) Porter between 2013-2015................... 112 Figure 89. Model chlorophyll a predictions compared to field data in the mainstem Chehalis River at (a) upstream of Pe Ell, (b) upstream of South Fork Chehalis River, (c) Adna, (d) upstream of Newaukum River, and (e) Route 6 bridge between 2013-2015. 113 Figure 90. Model chlorophyll a predictions compared to field data in the mainstem Chehalis River at (a) upstream of Skookumchuck River, (b) Galvin Rd bridge, (c) upstream of Black River, and (d) Oakville between 2013-2015................................................. 114 Figure 91. Model pH predictions compared to field data in the mainstem Chehalis River at (a) upstream of Pe Ell, (b) Dryad, (c) upstream of South Fork Chehalis River, (d) Adna, (e) upstream of Newaukum River, and (f) Route 6 bridge between 2013-2015............... 115 Figure 92. Model pH predictions compared to field data in the mainstem Chehalis River at (a) upstream of Skookumchuck River, (b) Galvin Road bridge, (c) upstream of Black River, (d) Oakville, and (e) Porter between 2013-2015...................................................... 116 Figure 93. Model total suspended solids predictions compared to field data in the mainstem Chehalis River at (a) upstream of Pe Ell, (b) Dryad, (c) upstream of South Fork Chehalis River, (d) Adna, (e) upstream of Newaukum River, and (f) Route 6 bridge between 2013-2015.

Figure 94. Model total suspended solids predictions compared to field data in the mainstem Chehalis River at (a) upstream of Skookumchuck River, (b) Galvin Road bridge, (c) upstream of Black River, (d) Oakville, and (e) Porter between 2013-2015. 118 Figure 95. Model alkalinity predictions in the mainstem Chehalis River at (a) downstream of Pe Ell, (b) downstream of Pe Ell, (c) Dryad, (d) upstream of South Fork Chehalis River, (e) Adna, and ( $f$ ) upstream of Newaukum River between 2013-2015.

Figure 96. Model alkalinity predictions in the mainstem Chehalis River at (a) Route 6 bridge, (b) upstream of Skookumchuck River, (c) Galvin Road bridge, (d) upstream of Black River, (e) Oakville, and (f) Porter between 2013-2015.

Figure 97. Continuous dissolved oxygen model predictions compared to field data in the mainstem Chehalis River at downstream of Pe Ell between 2013-2015. .................... 122 Figure 98. Continuous dissolved oxygen model predictions compared to field data in the mainstem Chehalis River at Route 6 bridge between 2013-2015............................. 123 Figure 99. Continuous dissolved oxygen model predictions compared to field data in the mainstem Chehalis River at Mellen Road bridge between 2013-2015......................... 124 Figure 100. Vertical dissolved oxygen model predictions compared to field data in the mainstem Chehalis River pool area in 2013 and 2014 in the pool area....................... 125 Figure 101. Vertical dissolved oxygen model predictions compared to field data in the mainstem Chehalis River pool area in 2014. 126 
Figure 102. Vertical dissolved oxygen model predictions compared to field data in the mainstem Chehalis River pool area in 2014.

Figure 103. Vertical dissolved oxygen model predictions compared to field data in the mainstem Chehalis River pool area in 2013 and 2014.

Figure 104. Model predicted nitrogen limitation for algal growth in the mainstem Chehalis River at (a) upstream of Pe Ell, (b) downstream of Pe Ell, (c) Dryad, (d) upstream of South Fork Chehalis River, (e) Adna, and (f) upstream of Newaukum River between 2013-2015. A value of 1 shows it is not limiting. Whichever value $(N, P$, or light) is the lowest is the limiting nutrient. 129

Figure 105. Model predicted nitrogen limitation for algal growth in the mainstem Chehalis River at (a) Route 6 bridge, (b) upstream of Skookumchuck River, (c) Galvin Road bridge, (d) upstream of Black River, (e) Oakville, and (f) Porter between 2013-2015. A value of 1 shows it is not limiting. Whichever value $(N, P$, or light) is the lowest is the limiting nutrient. 131

Figure 106. Model predicted phosphorus limitation for algal growth in the mainstem Chehalis River at (a) upstream of Pe Ell, (b) downstream of Pe Ell, (c) Dryad, (d) upstream of South Fork Chehalis River, (e) Adna, and ( $f$ ) upstream of Newaukum River between 2013-2015. A value of 1 shows it is not limiting. Whichever value (N, P, or light) is the lowest is the limiting nutrient. 133 Figure 107. Model predicted phosphorus limitation for algal growth in the mainstem Chehalis River at (a) Route 6 bridge, (b) upstream of Skookumchuck River, (c) Galvin Road bridge, (d) upstream of Black River, (e) Oakville, and (f) Porter between 2013-2015. A value of 1 shows it is not limiting. Whichever value ( $N, P$, or light) is the lowest is the limiting nutrient. 135

Figure 108. Model periphyton density predictions in the mainstem Chehalis River at (a) upstream of Pe Ell, (b) downstream of Pe Ell, (c) Dryad, (d) upstream of South Fork Chehalis River, (e) Adna, and (f) upstream of Newaukum River between 2013-2015. . 137 Figure 109. Model periphyton density predictions in the mainstem Chehalis River at (a) Route 6 bridge, (b) upstream of Skookumchuck River, (c) Galvin Road bridge, (d) upstream of Black River, (e) Oakville, and (f) Porter between 2013-2015. 138 Figure 110. Periphyton field data for 2018 compared with model average periphyton output in the mainstem Chehalis River at model segments $11,36,59,90,111$, and 137 for 2013-2015. 140 


\section{List of Tables}

Table 1. River mile and segment locations for upstream boundary, tributaries, dischargers, and groundwater inputs to the Chehalis River (Van Glubt et al. 2017)

Table 2. Temperature Regression Relationships for tributaries along the Chehalis mainstem at the upstream boundary, Elk Creek, South Fork Chehalis River, Newaukum River, Skookumchuck River, Scatter Creek, and Black River. Other station correlations at Darigold, 22-CH (river mile 75.3), and 18-CH (river mile 50.5) were used for distributed un-gaged flow inputs. Old refers to those regressions used in Van Glubt et al. 2017, while new refers to the updated one used in this study. Where multiple regressions for one tributary are shown, the regressions were used in order of proximity to the tributary for which temperature is being estimated...... 10 Table 3. Tributary flow correlations that were updated from the work of Van Glubt et al. (2017) using new data from 2015. "Old" refers to those regressions used in Van Glubt et al. 2017, while "new" refers to the updated one used in this study. 16 Table 4. Flow rate errors (see Appendix $\mathrm{C}$ ) between model predictions and field data for flow rate at Doty, Grand Mound, and Porter for August 2018 during the dye study of Mathieu (2018). 21 Table 5. First-order decay constants applied to model particles to approximate dye loss.

Table 6. Adjustments in CE-QUAL-W2 model adjusted hydraulic equivalent slope (SLOPEC) from the Van Glubt et al. (2017) model based on the results of the dye study..... 34 Table 7. Adjustments in CE-QUAL-W2 model reference bottom elevation (EBOT) from the Van Glubt et al. (2017) model based on the results of the dye study.

Table 8. Adjustments in CE-QUAL-W2 model adjusted elevation of the spillway between branches (ESP) from the Van Glubt et al. (2017) model based on the results of the dye study.

Table 9. Adjustments in CE-QUAL-W2 model dispersion coefficient (DX) from the Van Glubt et al. (2017) model based on the results of the dye study.................................. 35

Table 10. Characteristics of tributary grids.

Table 11. Flow rate error statistics (see Appendix C) of field data compared to model predictions at model segment 38 at South Fork Chehalis River near the mainstem Chehalis.

Table 12. Flow rate error statistics (see Appendix C) of field data compared to model predictions at model segment 93 at Newaukum River near the mainstem Chehalis...... 66 Table 13. Flow rate error statistics (see Appendix C) of field data compared to model predictions at model segment 111 at Skookumchuck River near the mainstem Chehalis.

Table 14. Flow rate error statistics (see Appendix C) of field data compared to model predictions at model segment 53 at Black River near the mainstem Chehalis. 68 Table 15. Model errors (see Appendix C) of flow rate at Doty, Grand Mound, and Porter between 2013-2015. 70 
Table 16. Temperature error statistics (see Appendix C) of field data compared to model predictions at SFCHEH-1 and 23K060 in South Fork Chehalis River

Table 17. Temperature error statistics (see Appendix C) of field data compared to model predictions at model segment 92 at Newaukum River near the mainstem Chehalis..... 76 Table 18. Temperature error statistics (see Appendix C) of field data compared to model predictions in the Skookumchuck River at SKOOK-1 and SKOOK-2.

Table 19. Temperature error statistics (see Appendix C) of field data compared to model predictions at BLACK-1 and BLACK- 2 in the Black River. 80 Table 20. Temperature errors (see Appendix C) along the mainstem Chehalis River between 2013-2015. 82 Table 21. CE-QUAL-W2 model water quality parameters in the Chehalis River Model... 93 Table 22. Model coefficients used in the CE-QUAL-W2 model of the tributaries. WSC is the wind sheltering coefficient, TSEDF is a factor that accounts for absorption of heat into the bed sediment, AFW, BFW and CFW were evaporation coefficients, EXH2O is the light extinction coefficient for water in $\mathrm{m}^{-1}$, and BETA is the fraction of short wave solar absorbed on the surface. 


\section{Introduction}

\section{Chehalis River Model Background}

Van Glubt et al. (2017) developed a hydrodynamic and water quality model of the upper Chehalis River in southwest Washington State for the years 2013-2014 that was used to evaluate scenarios associated with flood hazard reduction and aquatic species restoration and enhancement. The Chehalis River Basin is located in southwest Washington State (see Figure 1). The upper Chehalis River basin covers 1,293 square miles, including parts of five counties: Lewis, Thurston, Grays Harbor, Pacific, and Cowlitz (WADOE, 2001). The Chehalis River originates in the Willapa Hills of the Coast Range east of Willapa Bay, and also drains the western foothills of the Cascades and the southern Olympic Mountains. The Chehalis ultimately flows into Grays Harbor and the Pacific Ocean, totaling over 125 miles in length.

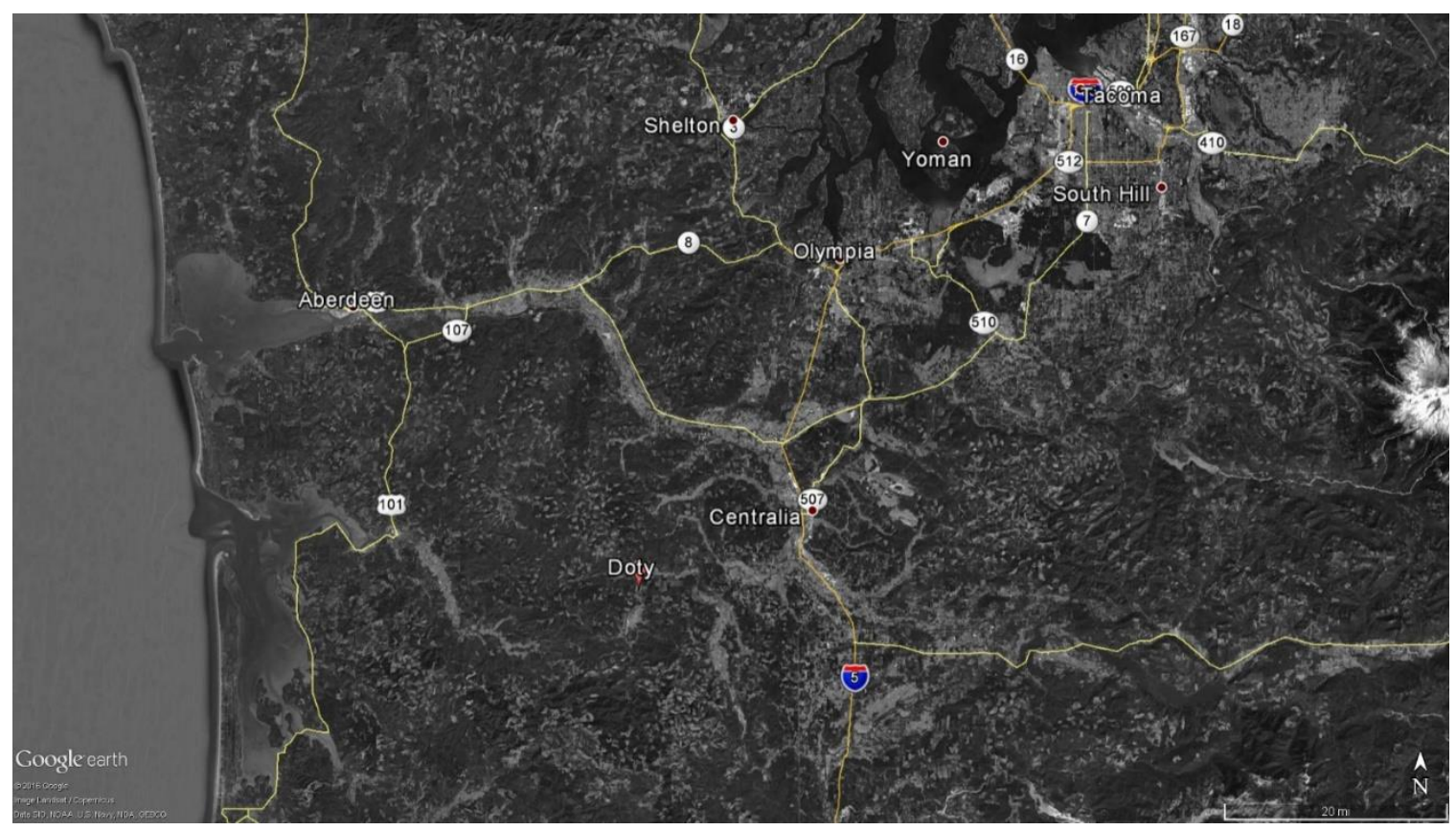

Figure 1. Chehalis River study area from near Doty, through Centralia to Aberdeen in southwestern Washington State (Google earth, 2017). 
The larger tributaries of the Chehalis River include the South Fork Chehalis River, Newaukum River, Skookumchuck River, and Black River (see Figure 2). Smaller tributaries include many creeks, such as Elk, Bunker, Mill, Stearns, Salzer, China, Scammon, Lincoln, Prairie, Scatter, Independence, Garrard, Cedar, Rock, Gibson, and Porter.

The land uses in the Chehalis river basin are diverse, including residential, agricultural, industrial, and logging and forest (WADOE, 2001). The river passes through urban areas, including the cities Centralia and Chehalis. In the study area, four municipal wastewater treatment plants (Pe Ell, Chehalis, Centralia, and Grand Mound) and one industrial wastewater treatment plant (Darigold) discharge to the river. Wastewater land application is required as an alternative for the Chehalis and Darigold wastewater treatment plant during periods of low river flows. National Frozen Foods has a state waste discharge permit to land apply wastewater in fields bordering the river between Chehalis and Centralia. 


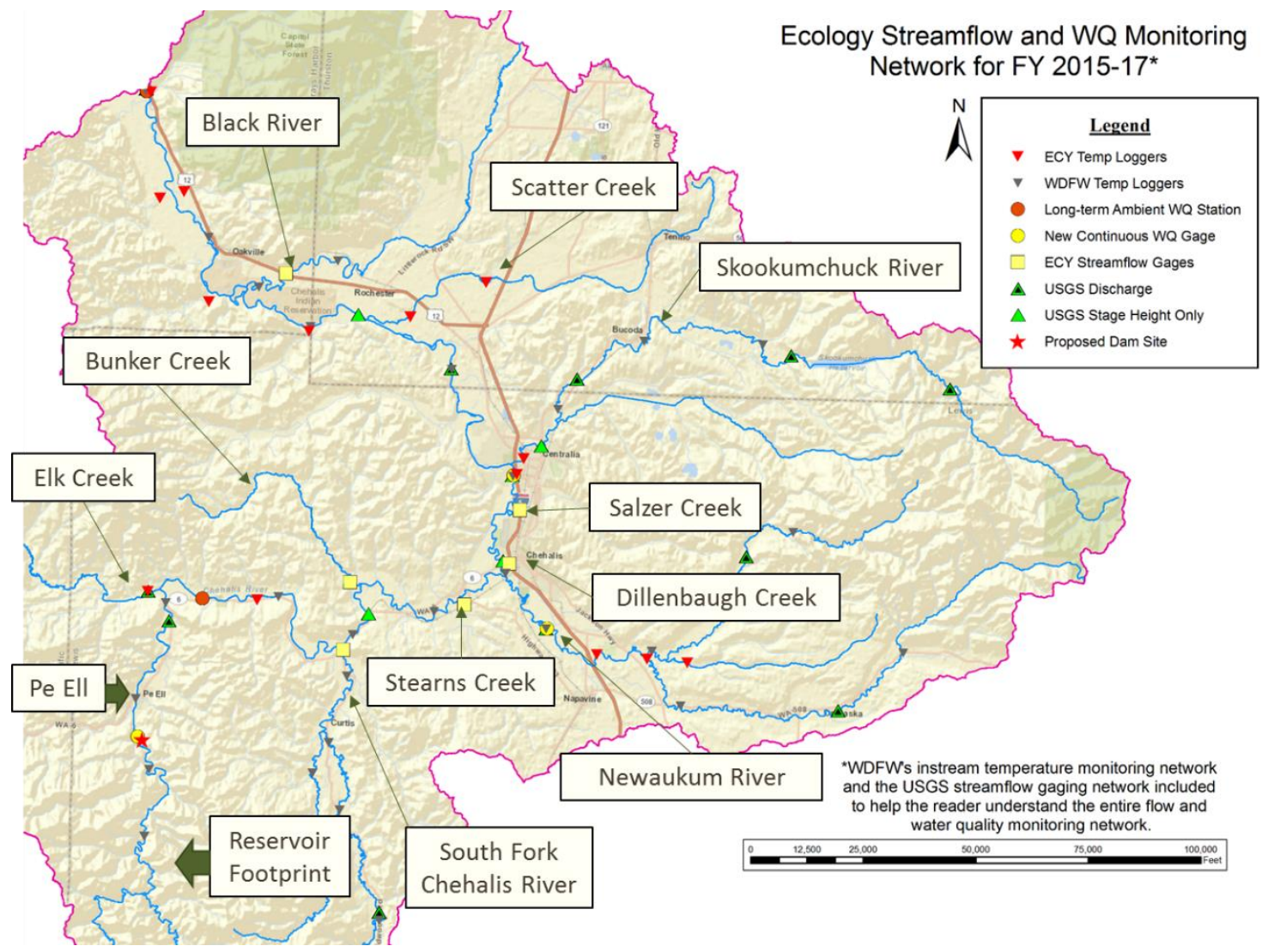

Figure 2. Chehalis River basin and associated tributaries (adapted from Dustin Bilhimer, 2015)

The mainstem Chehalis River in the study area has three distinct reaches based on their unique physical characteristics of slope and depth. The upper reach, beginning upstream of Pe Ell and extending to Chehalis, WA, has steep gradients with riffles and pools. The middle reach, beginning just below the Newaukum River near Chehalis, WA and extending to the just above the Skookumchuck River, has slow, deep, lake-like conditions that at times exhibit stratification. The lower reach, beginning near the Skookumchuck River and extending to Porter, WA, is similar to the upper reach, with faster velocities and riffles and pools (Pickett, 1994). 
The model used by Van Glubt et al. (2017) was the CE-QUAL-W2 Version 4 and it was used to assess flow, water level, temperature, and water quality conditions along the Chehalis River.

The model grid reflected the character of the Chehalis River channel (see Figure 3) and was made up of 302 segments in 10 branches (collections of model segments with similar channel slope) and nine waterbodies (collections of model branches with similar water level fluctuations and different meteorological conditions).

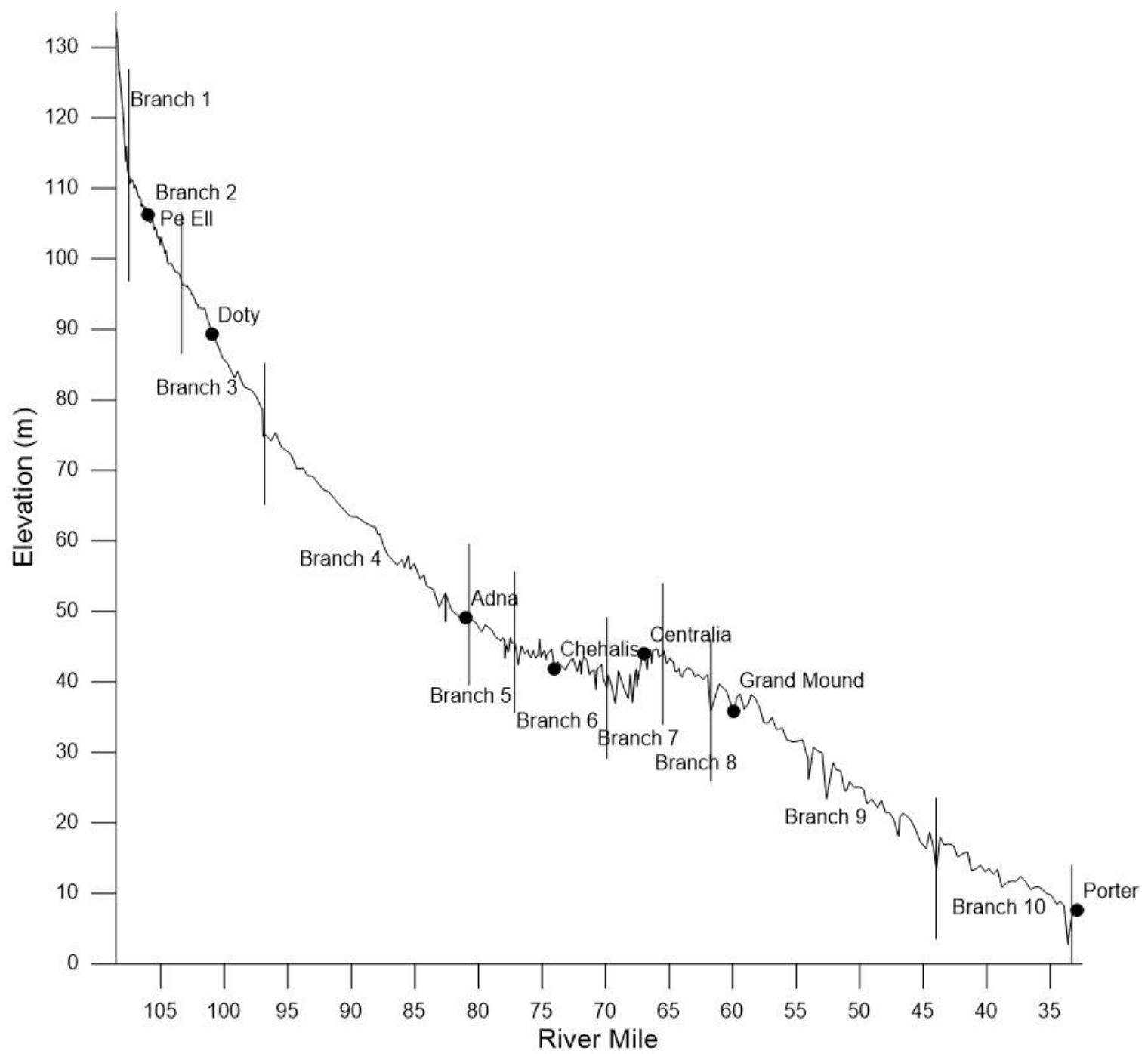


Figure 3. Longitudinal profile of the Chehalis River thalweg (vertical lines show model branch breaks) from Van Glubt et al. (2017).

The model grid was based on more than 350 river cross sections provided by Anchor QEA (2011). Three weather monitoring stations were used for meteorological data. 21 tributaries were included as well as discharges from five wastewater treatment plants and groundwater inputs along the whole length of the model. Data gaps were filled with linear regressions to nearby monitoring stations where feasible. Several tributaries were entirely un-gaged. Flow in these un-gaged tributaries was estimated using a ratio of the tributaries' catchment area to that of a gaged flow and assuming the ratio of flow between the two is the same.

Temperatures in un-gaged tributaries were assumed to be the same as temperatures measured in a tributary with similar flow.

This current study expands on the work of Van Glubt et al. (2017) by performing the following additional tasks:

- Extend the original model calibration from 2013-2014 to include 2015. Hence, all boundary conditions were developed for the low-flow critical year of 2015.

- Develop and calibrate flow and temperature models of 4 tributaries: South Fork Chehalis, Newaukum, Skookumchuck, and Black Rivers for 2013-2015.

- Use field data from Washington Department of Ecology from 2018 to inform the 2013-2015 model calibration. These field data include a dye study to assess travel times and a periphyton study to assess biomass densities. These data were used to compare to model results of travel time and periphyton densities and to adjust the model calibration as needed for the 2013-2015 period.

This report is divided into the following sections:

1. Chehalis River model updates for the 2013-2015 period

2. Results of the 2018 time-of-travel dye study and application to the Chehalis River 
3. Development of models for the tributaries of the Chehalis: Newaukum, Skookumchuck, South Fork and Black Rivers for 2013-2015

4. Model calibration for the mainstem Chehalis, South Fork Chehalis, Newaukum, Skookumchuck, and Black Rivers for 2013-2015 for temperature and flow. Model calibration of the mainstem Chehalis River for water quality (dissolved oxygen, nutrients such as NH4-N, NO2+NO3-N, P04, TP, TN, algae, periphyton, suspended solids)

Model Capabilities

CE-QUAL-W2 is a two-dimensional, laterally averaged hydrodynamic and water quality numerical model (Cole and Wells, 2018). CE-QUAL-W2 was developed by the US Army Corps of Engineers and the Water Quality Research Group at Portland State University. The model predicts the following hydrodynamic variables:

- water surface elevation

- longitudinal and vertical velocities

- temperature

A wide variety of water quality constituents can be simulated using CE-QUAL-W2. 47 state variables are included, along with more than 60 derived variables. Any combination of these constituents can be simulated.

\section{2013-2015 Model updates}

2015 boundary conditions were added to extend the 2013-2014 model an

additional year. The summer of 2015 was warm and dry, leading to low flow and high temperature conditions in the river, making it useful for calibrating the model to these extreme conditions.

Existing boundary condition correlations that were used to fill in data gaps were adjusted to include additional field data that was collected after the 2013-2014 model was developed. This led to many updates to the correlations used for the 
earlier model. Hence, all model boundary conditions from Van Glubt et al. (2017)

were re-evaluated and re-done.

\section{Boundary condition correlations}

The model tributaries in the Chehalis River model are shown in Table 1. These are shown schematically in Figure 4.

Table 1. River mile and segment locations for upstream boundary, tributaries, dischargers, and groundwater inputs to the Chehalis River (Van Glubt et al. 2017)

\begin{tabular}{|l|c|c|}
\hline Description & Model Segment & River Mile \\
\hline Upstream boundary & 2 & 108 \\
\hline Pe Ell WWTP & 15 & 107 \\
\hline Elk Creek & 38 & 100 \\
\hline South Fork Chehalis River & 89 & 88 \\
\hline Bunker Creek & 105 & 85 \\
\hline Stearns Creek & 134 & 78.1 \\
\hline Mill Creek & 135 & 78 \\
\hline Newaukum River & 145 & 75.2 \\
\hline Darigold WWTP & 150 & 75 \\
\hline Dillenbaugh Creek & 150 & 74.4 \\
\hline Chehalis WWTP & 150 & 74.3 \\
\hline Salzer Creek & 171 & 69.2 \\
\hline China Creek & 181 & 67.5 \\
\hline Skookumchuck River & 182 & 66.8 \\
\hline Scammon Creek & 187 & 65.5 \\
\hline Lincoln Creek & 205 & 61.8 \\
\hline Centralia WWTP & 207 & 61.25 \\
\hline Grand Mound WWTP & 218 & 59.17 \\
\hline Prairie Creek & 222 & 58.2 \\
\hline Scatter Creek & 236 & 55.2 \\
\hline Independence Creek & 250 & 50 \\
\hline Black River & 267 & 47 \\
\hline Garrard Creek & 275 & 44.9 \\
\hline Rock Creek & 300 & 39.3 \\
\hline Cedar Creek & 302 & 38.7 \\
\hline Gibson Creek & 321 & 37.3 \\
\hline Porter Creek & & 33.3 \\
\hline
\end{tabular}




\begin{tabular}{|l|c|c|}
\hline Description & Model Segment & River Mile \\
\hline $\begin{array}{l}\text { Groundwater - Upstream of Elk } \\
\text { Creek to downstream Boundary at } \\
\text { Porter }\end{array}$ & $35-321$ & $101.9-33.3$ \\
\hline
\end{tabular}

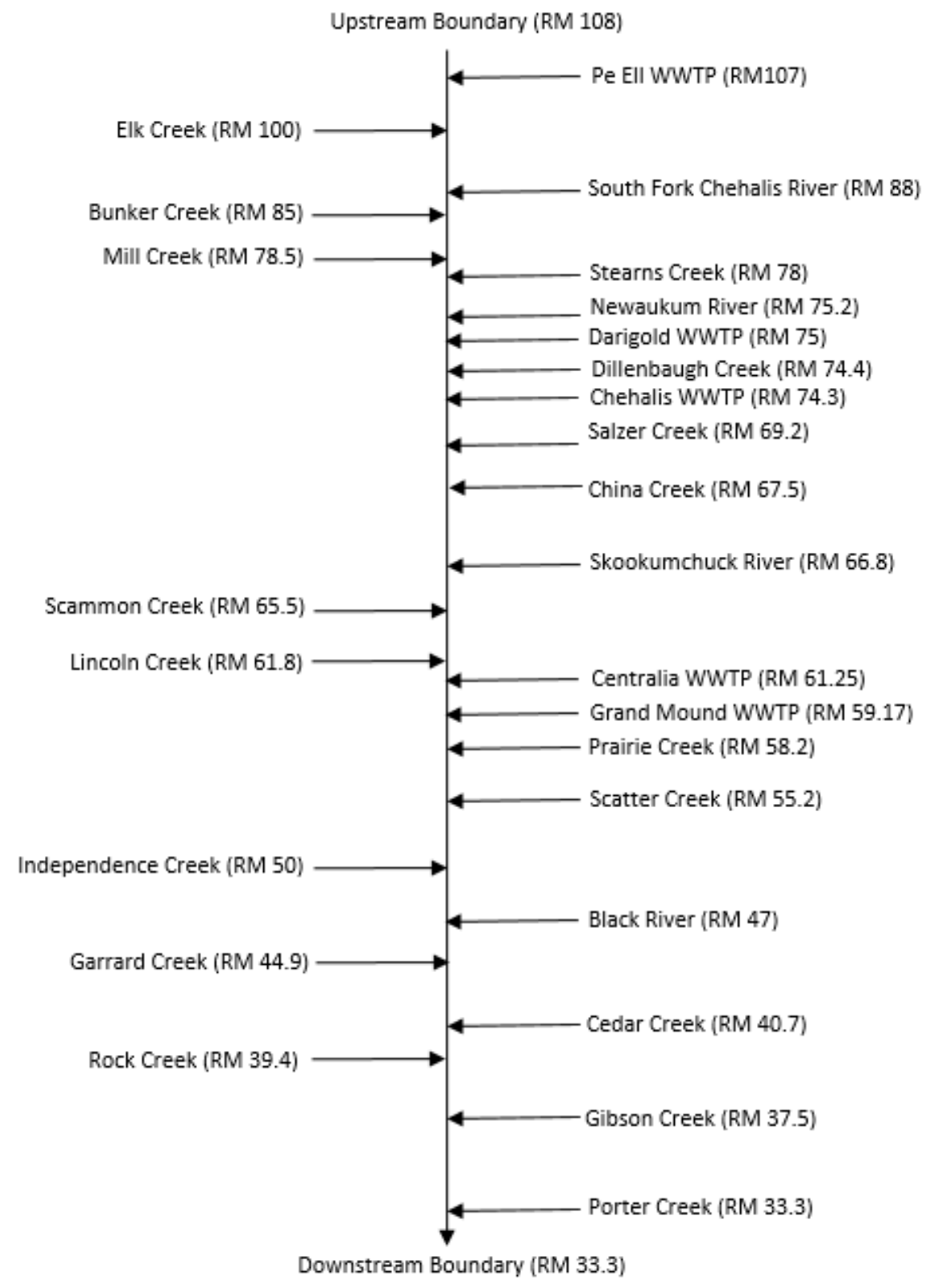

Figure 4. Schematic of tributaries to the model reach of the Chehalis River and their corresponding river miles (WEST Consultants, 2011 and WADOE, 2001). Note: figure is not to scale. 


\section{Temperature}

Since many of the tributaries in the model did not have complete temperature data from 2013-2015, these were estimated by correlating known data to other more complete temperature records. These temperature correlations with field data are summarized in Table 2. Temperature correlations for the following stations: 4-UCH, 11-UCH, 13-CH, 18-CH, 22-UCH, the Black River, Elk Creek, Newaukum, Scatter Creek, Skookumchuck River and the Chehalis River downstream of Darigold WWTP are shown in Figure 5, Figure 6, Figure 7, Figure 8, Figure 9, Figure 10, Figure 11, Figure 12, Figure 13, and Figure 14, respectively. The temperature records from the Darigold WWTP were the most complete and were used to fill in several data gaps. Of the two gages there (upstream and downstream of the WWTP discharge), regressions to data from the downstream gage (Ch R.DS Darigold) gave better coefficients of correlation than did data from the upstream gage. Where temperature data from a gage closer to the tributary than the Darigold gages were available, they were used regardless of which data gave the best coefficient of correlation. Where two or more regressions are given in Table 2, the regression using data from the gage nearest the tributary was used first and the Ch R.DS Darigold regression was used to fill in the remaining gaps. 
Table 2. Temperature Regression Relationships for tributaries along the Chehalis mainstem at the upstream boundary, Elk Creek, South Fork Chehalis River, Newaukum River, Skookumchuck River, Scatter Creek, and Black River. Other station correlations at Darigold, 22-CH (river mile 75.3), and 18$\mathrm{CH}$ (river mile 50.5) were used for distributed un-gaged flow inputs. Old refers to those regressions used in Van Glubt et al. 2017, while new refers to the updated one used in this study. Where multiple regressions for one tributary are shown, the regressions were used in order of proximity to the tributary for which temperature is being estimated.

\begin{tabular}{|c|c|c|c|}
\hline Tributary & \multicolumn{2}{|r|}{ Regression Equation } & $\mathrm{R}^{2}$ \\
\hline $\begin{array}{l}\text { Chehalis River } \\
\text { Downstream of } \\
\text { Darigold }\end{array}$ & old & $T_{\text {Ch R.DS Darigold }}=1.048 * T_{\text {Ch R.Porter }}-1.135$ & 0.988 \\
\hline \multirow{5}{*}{$\begin{array}{l}\text { Upstream boundary } \\
\text { (station 11-UCH) }\end{array}$} & old & $T_{C h R .(11-U C H)}=1.0191 * T_{C H L-P E L-U S \& 3-U C H}-0.5085$ & 0.978 \\
\hline & new & $T_{C h R .(11-U C H)}=1.0250 * T_{C H L-P E L-U S}-0.6180$ & 0.934 \\
\hline & new & $T_{C h R .(11-U C H)}=1.0230 * T_{3-U C H}-0.5430$ & 0.977 \\
\hline & old & $T_{C h R .(11-U C H)}=0.8186 * T_{C h R . D S}$ Darigold +1.0174 & 0.954 \\
\hline & new & $T_{C h R .(11-U C H)}=0.8222 * T_{C h R . D S \text { Darigold }}+0.7120$ & 0.955 \\
\hline \multirow{4}{*}{ Elk Creek } & old & $T_{\text {Elk Creek }}=0.7681 * T_{\text {Ch } R(4-U C H)}+1.7319$ & 0.974 \\
\hline & new & $T_{\text {Elk Creek }}=0.6501 * T_{C h R(4-U C H)}+3.7124$ & 0.958 \\
\hline & old & $T_{\text {Elk Creek }}=0.7383 * T_{\text {Ch R.DS Darigold }}+1.6909$ & 0.979 \\
\hline & new & $T_{\text {Elk Creek }}=0.7320 * T_{\text {Ch R.DS Darigold }}+1.7934$ & 0.977 \\
\hline \multirow{2}{*}{$\begin{array}{l}\text { South Fork Chehalis } \\
\text { River } \\
\end{array}$} & old & $T_{S F \text { Chehalis }}=0.9627 * T_{\text {Ch R.DS Darigold }}+0.583$ & 0.988 \\
\hline & new & $T_{S F \text { Chehalis }}=0.9544 * T_{\text {Ch R.DS Darigold }}+0.7173$ & 0.987 \\
\hline \multirow{2}{*}{ Newaukum River } & old & $T_{\text {Newaukum }}=0.9521 * T_{\text {Ch R.DS Darigold }}+0.5257$ & 0.978 \\
\hline & new & $T_{\text {Newaukum }}=0.9502 * T_{\text {Ch R.DS Darigold }}+0.4918$ & 0.987 \\
\hline \multirow{2}{*}{$\begin{array}{l}\text { Skookumchuck } \\
\text { River }\end{array}$} & old & $T_{\text {Skookumchuck }}=0.67 * T_{\text {Ch R.DS Darigold }}+4.7899$ & 0.969 \\
\hline & new & $T_{\text {Skookumchuck }}=0.6438 * T_{\text {Ch R.DS Darigold }}+5.2135$ & 0.952 \\
\hline \multirow{4}{*}{ Black River } & old & $T_{\text {Black }}=0.7406 * T_{\text {Ch R.(18-CH) }}+3.2796$ & 0.836 \\
\hline & new & $T_{\text {Black }}=0.7405 * T_{\text {Ch R.(18-CH })}+3.2827$ & 0.836 \\
\hline & old & $T_{\text {Black }}=0.8222 * T_{\text {Ch R.DS Darigold }}+2.3484$ & 0.967 \\
\hline & new & $T_{\text {Black }}=0.8138 * T_{\text {Ch R.DS Darigold }}+2.4735$ & 0.965 \\
\hline Scatter Creek & new & $T_{\text {Scatter Creek }}=0.8599 * T_{\text {Ch R.DS Darigold }}+1.7380$ & 0.947 \\
\hline $22-\mathrm{CH}$ & new & $T_{C H-22}=0.9974 * T_{C h \text { R.DS Darigold }}+0.2083$ & 0.996 \\
\hline $18-\mathrm{CH}$ & new & $T_{C H-18}=0.9258 * T_{C h R . D S \text { Darigold }}+1.2311$ & 0.983 \\
\hline
\end{tabular}




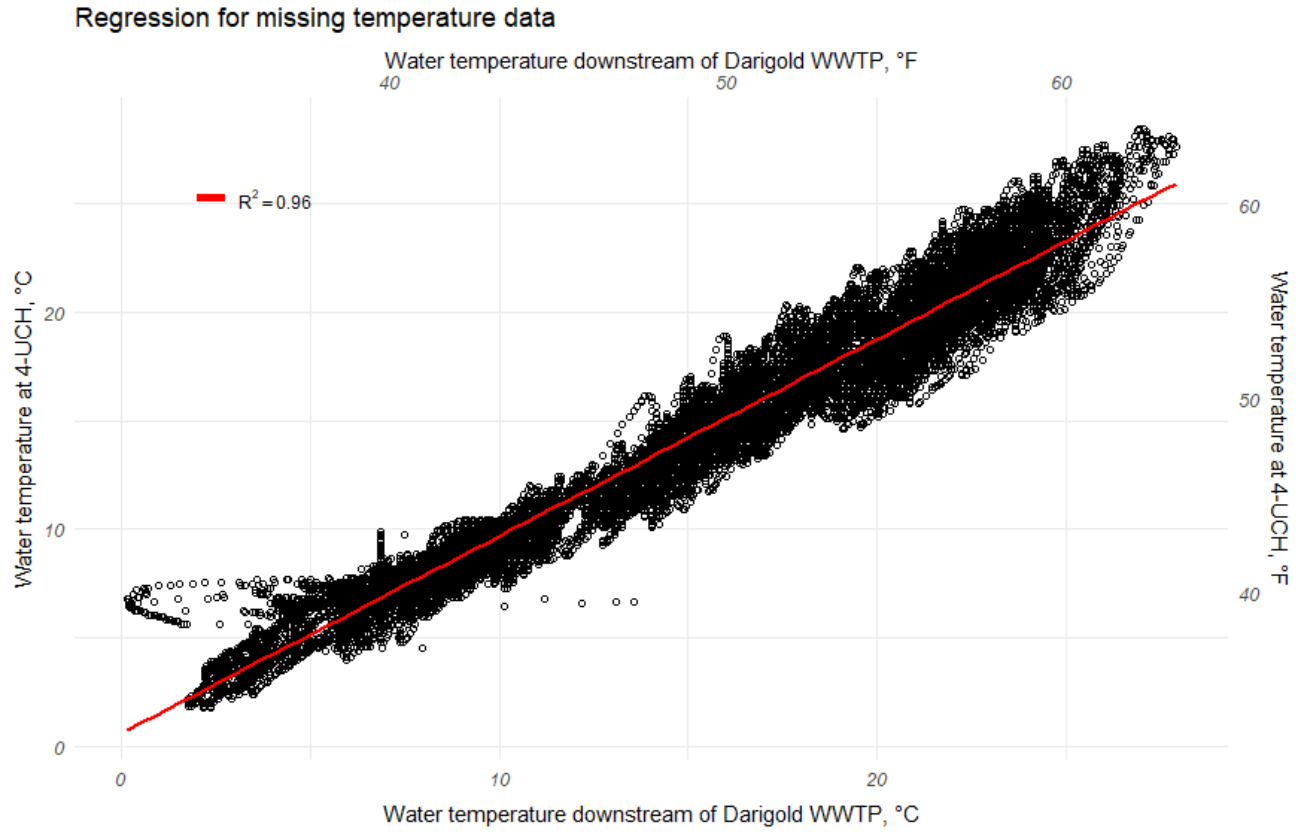

Figure 5. Temperature correlation between the station 4-UCH and the Chehalis River downstream of Darigold WWTP between 2013-2015.

Regression for missing temperature data

Water temperature downstream of Darigold WWTP, ${ }^{\circ} \mathrm{F}$

${ }_{50}$ Darigold WWTP, 60

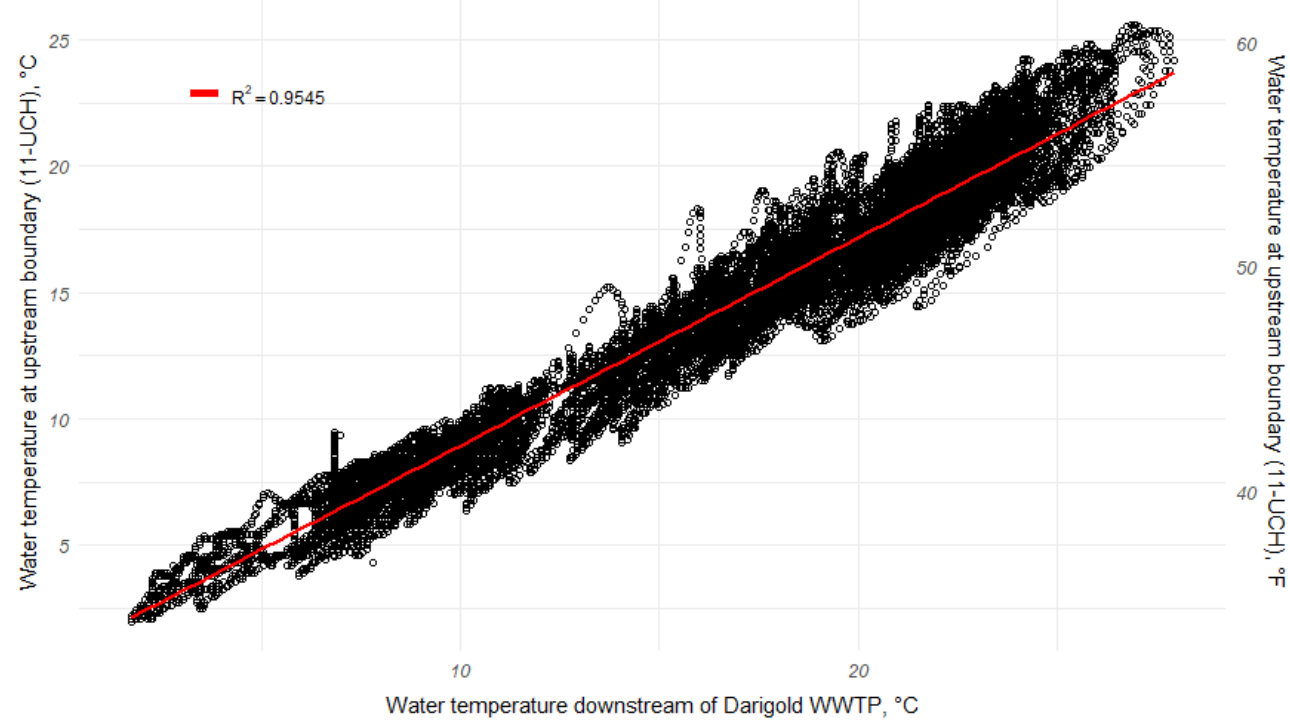

Figure 6. Temperature correlation between the station 11-UCH (upstream boundary) and the Chehalis River downstream of Darigold WWTP between 2013-2015. 
Regression for missing temperature data

Water temperature downstream of Darigold WWTP, ${ }^{\circ} \mathrm{F}$

$$
50
$$

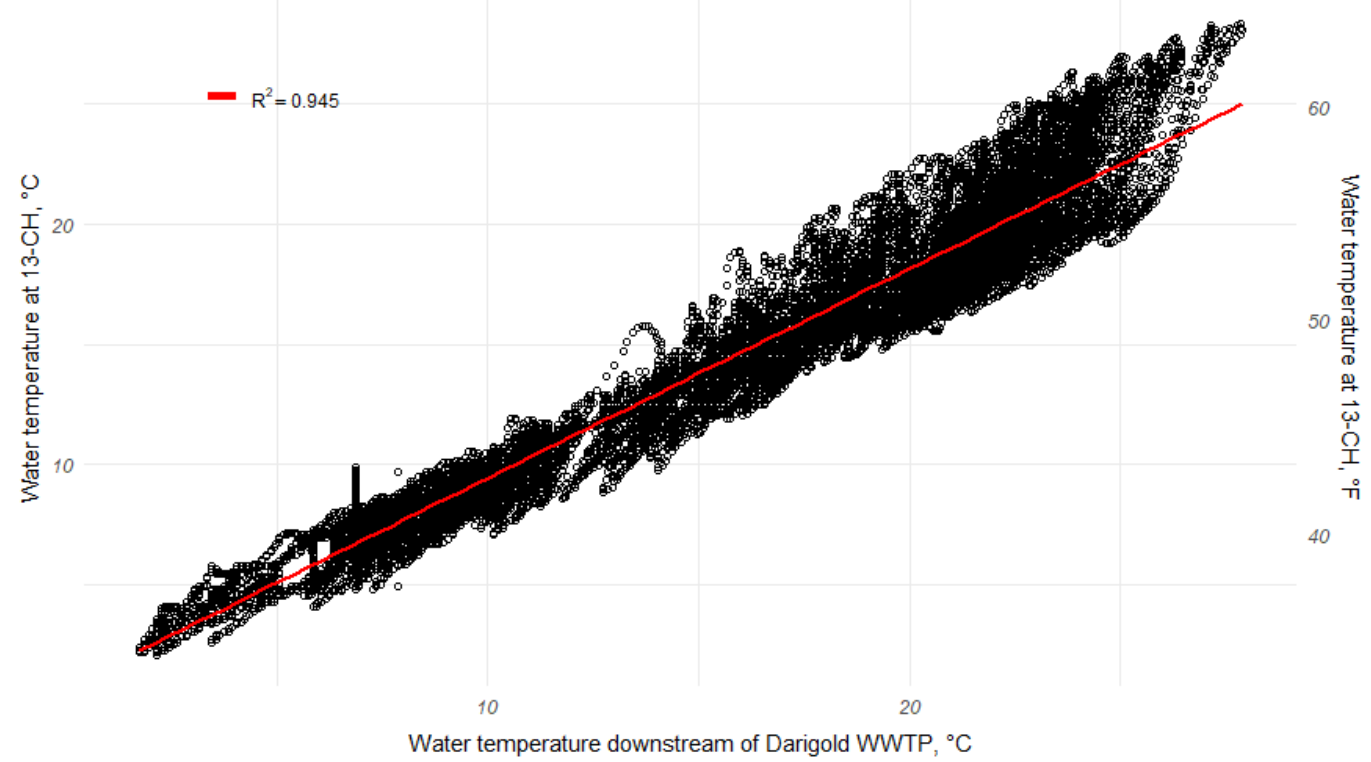

Figure 7. Temperature correlation between the station 13-CH and the Chehalis River downstream of Darigold WWTP between 2013-2015.

\section{Regression for missing temperature data}

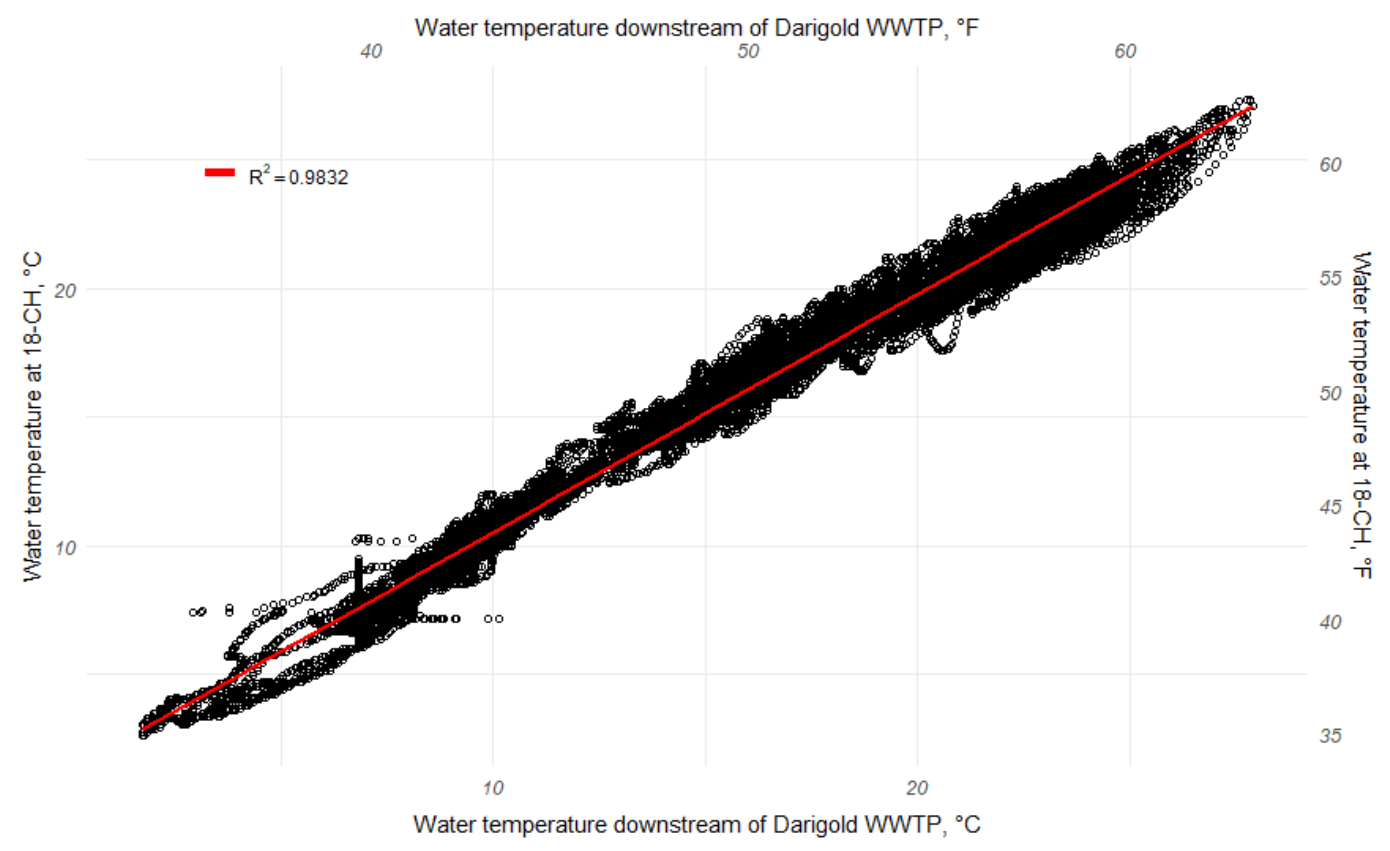

Figure 8. Temperature correlation between the station 18-CH and the Chehalis River downstream of Darigold WWTP between 2013-2015. 


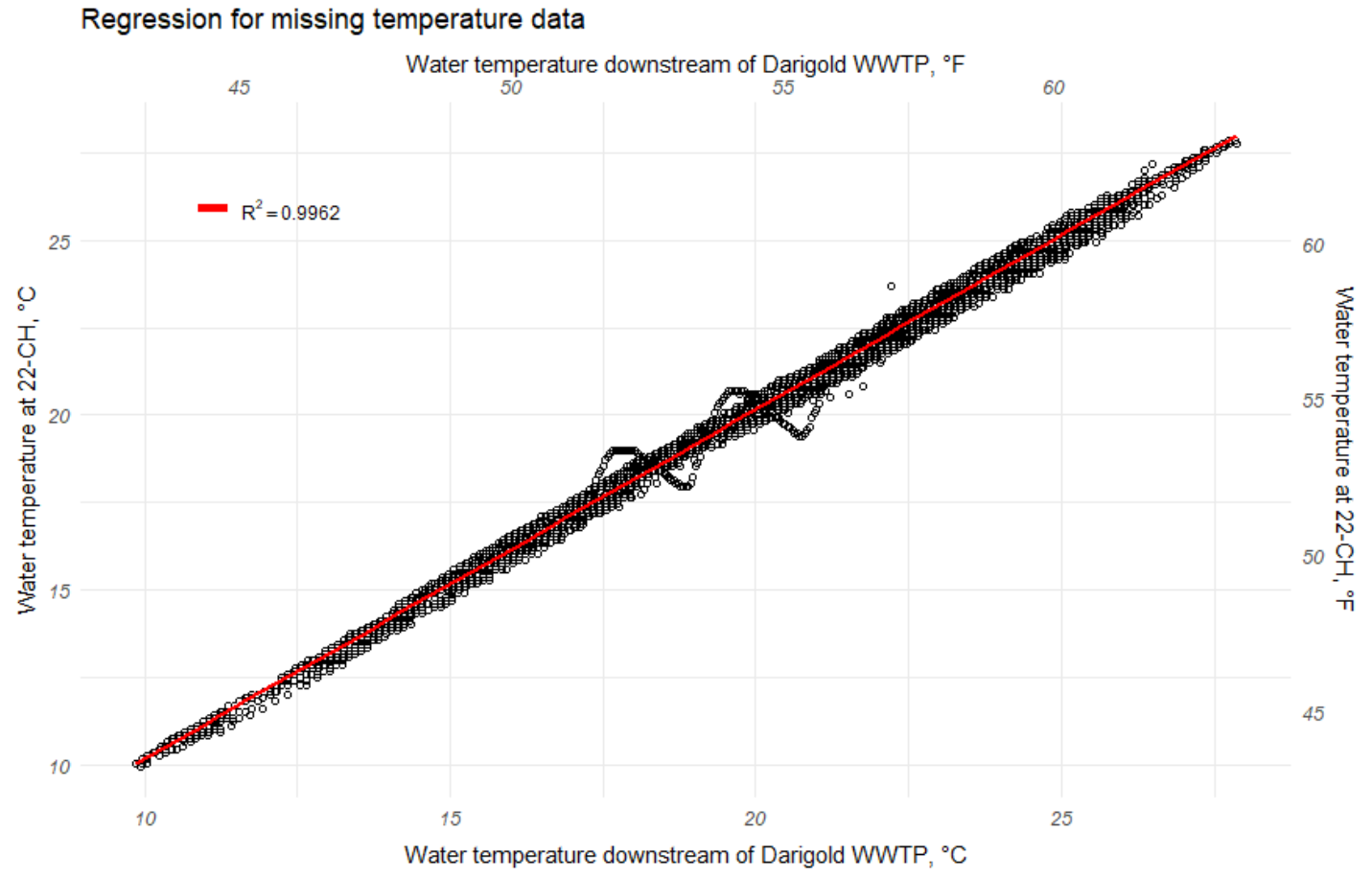

Figure 9. Temperature correlation between the station 22-UCH and the Chehalis River downstream of Darigold WWTP between 2013-2015.

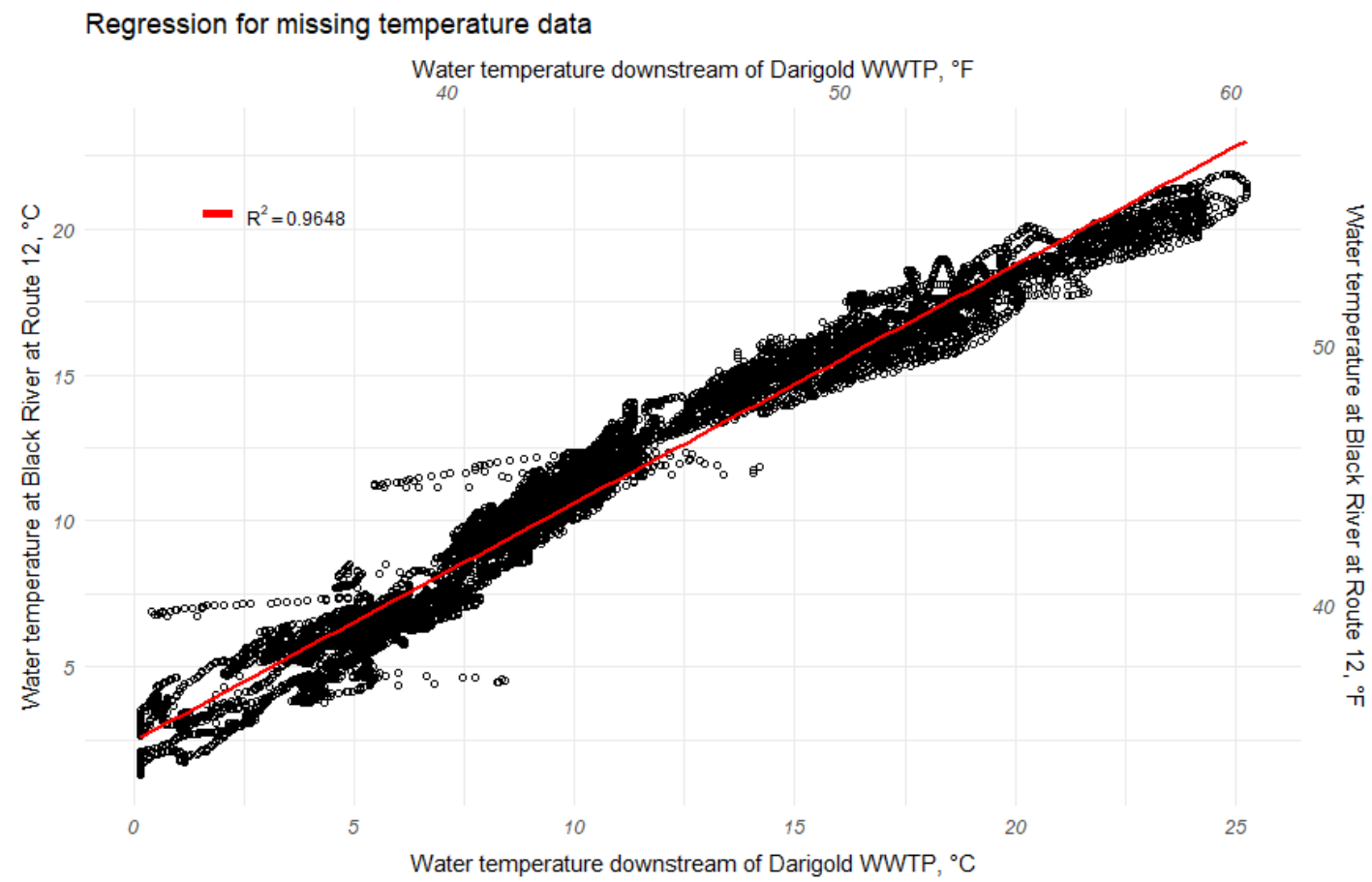

Figure 10. Temperature correlation between the station Black River tributary and the Chehalis River downstream of Darigold WWTP between 2013-2015. 


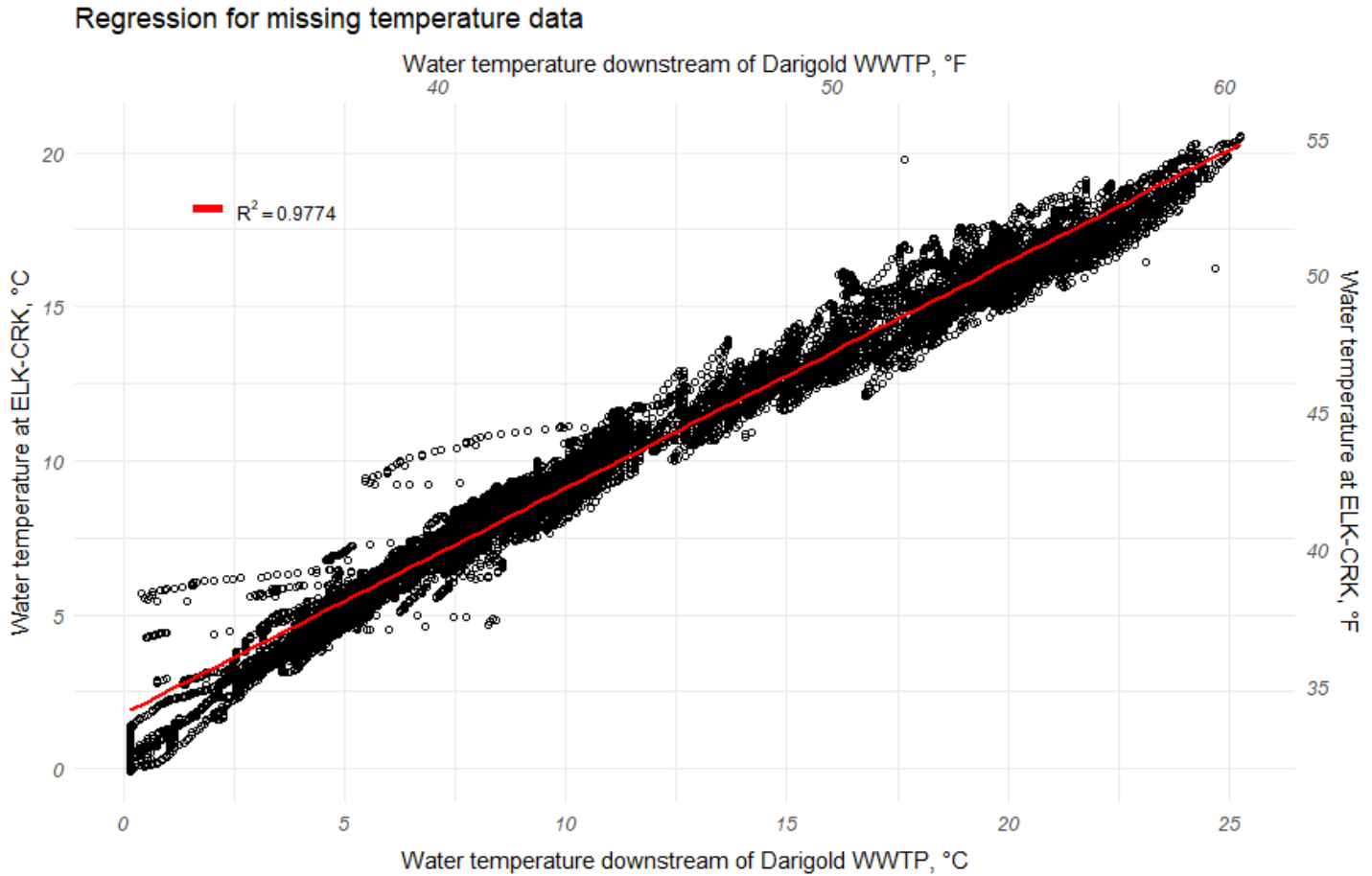

Figure 11. Temperature correlation between the station Elk Creek tributary and the Chehalis River downstream of Darigold WWTP between 2013-2015.

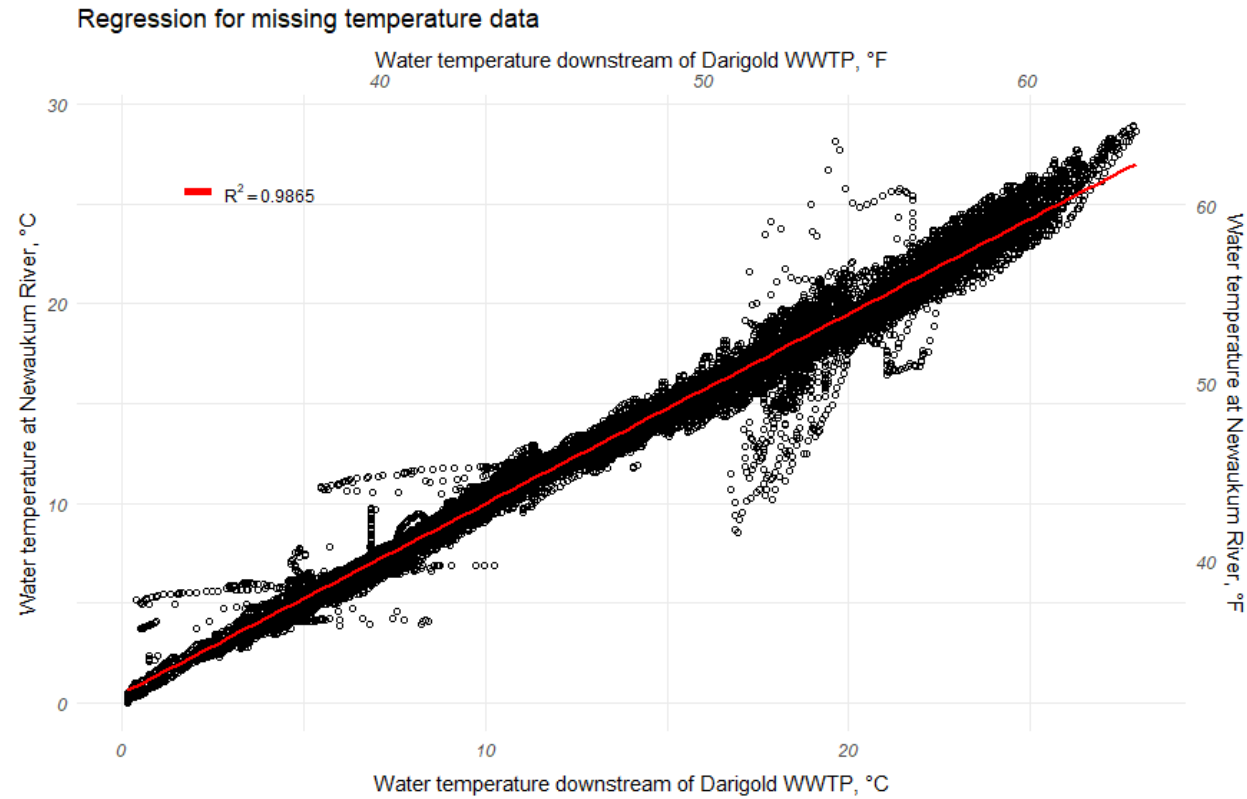

Figure 12. Temperature correlation between the station Newaukum tributary and the Chehalis River downstream of Darigold WWTP between 2013-2015. 
Regression for missing temperature data

Water temperature downstream of Darigold WWTP, ${ }^{\circ} \mathrm{F}$

$40-60$

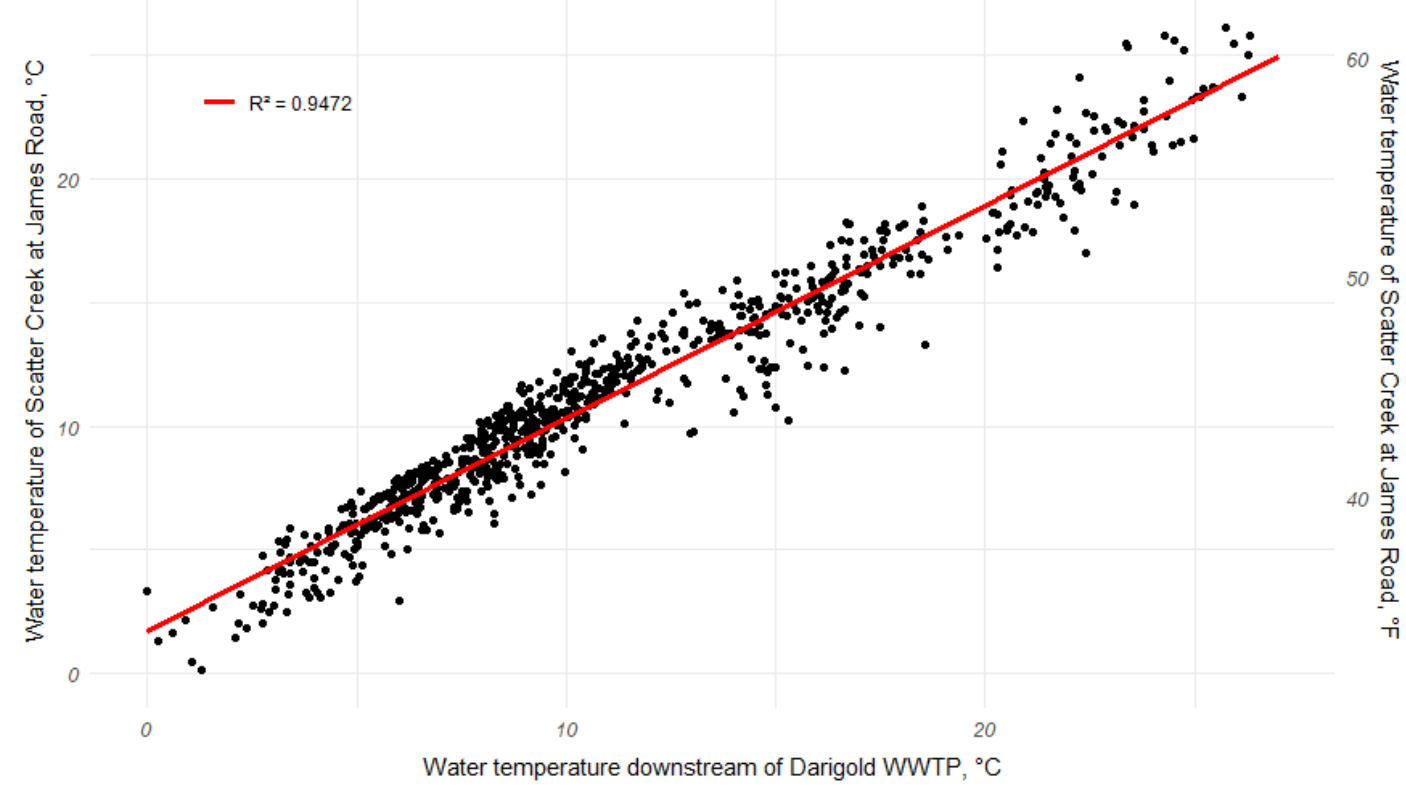

Figure 13. Temperature correlation between the station Scatter Creek and the Chehalis River downstream of Darigold WWTP between 2013-2015.

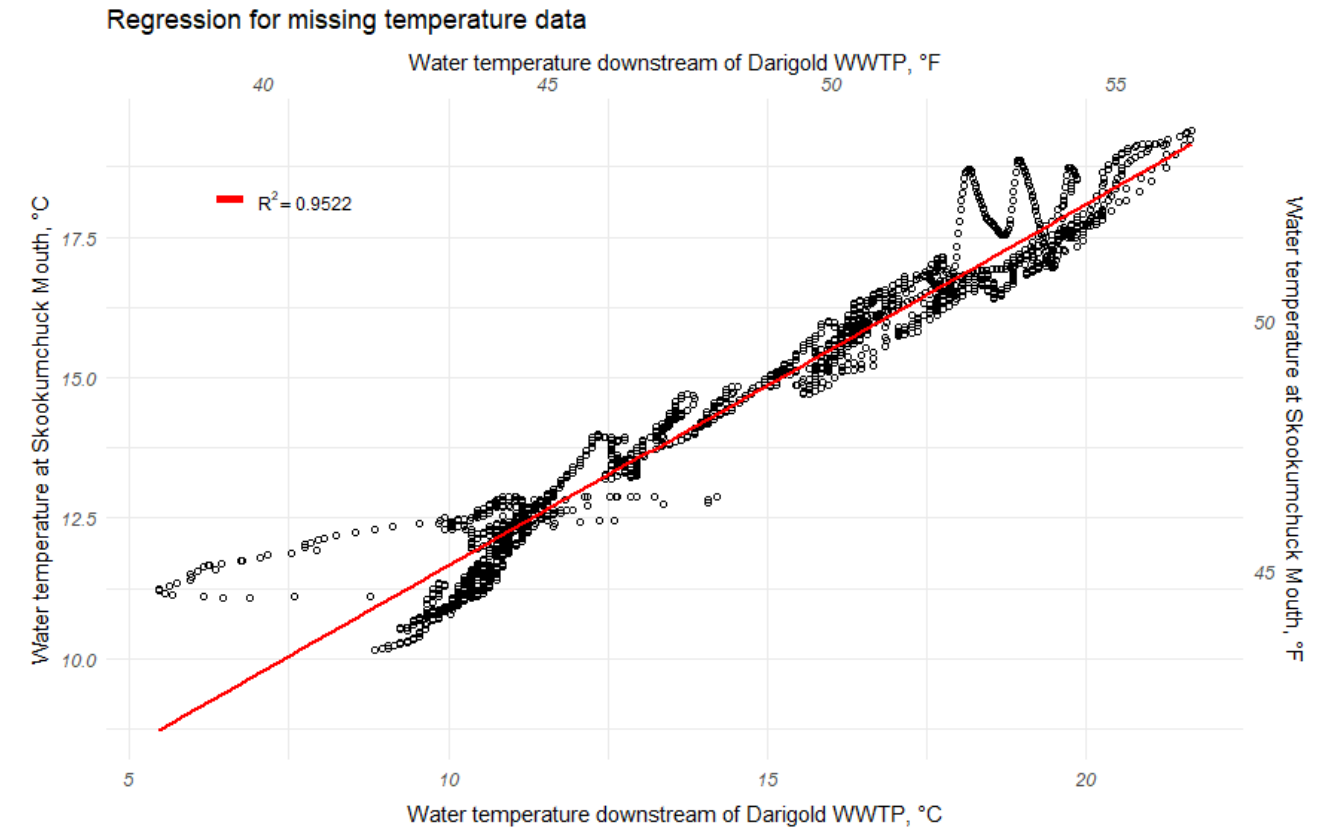

Figure 14. Temperature correlation between the station Skookumchuck River and the Chehalis River downstream of Darigold WWTP between 2013-2015. 
Flow

When flow data were missing, the missing data were filled in using field data correlations with flow rates at another monitoring station. In updating the correlations from Van Glubt et al. (2017) with new data in 2015, some of these correlations were adjusted for the entire time period. A summary of these correlations is shown in Table 3.

Table 3. Tributary flow correlations that were updated from the work of Van Glubt et al. (2017) using new data from 2015. "Old" refers to those regressions used in Van Glubt et al. 2017, while "new" refers to the updated one used in this study.

\begin{tabular}{|l|l|l|l|}
\hline \multicolumn{2}{|l|}{ Tributary } & Regression & $r^{2}$ \\
\hline \multirow{2}{*}{$\begin{array}{l}\text { Chehalis at } \\
\text { Mahaffey Creek }\end{array}$} & old & $Q_{\text {ChR.Mahaffey }}=0.8262 * Q_{\text {Chehalis@Doty }}-0.3337$ & 0.980 \\
\cline { 2 - 4 } & new & $Q_{\text {ChR.Mahaffey }}=0.7635 * Q_{\text {Chehalis@Doty }}-0.1505$ & 0.973 \\
\hline \multirow{3}{*}{ Elk Creek } & old & $Q_{\text {Elk Creek }}=0.3254 * Q_{\text {Chehalis@Doty }}$ & 0.765 \\
\cline { 2 - 4 } & new & $Q_{\text {Elk Creek }}=0.3218 * Q_{\text {Chehalis@Doty }}$ & 0.900 \\
\hline \multirow{2}{*}{$\begin{array}{l}\text { South Fork } \\
\text { Chehalis }\end{array}$} & old & $Q_{\text {SF Chehalis }}=0.1818 * Q_{\text {Chehalis@Doty }}$ & 0.845 \\
\cline { 2 - 4 } & new & $Q_{\text {SF Chehalis }}=0.2239 * Q_{\text {Chehalis@Doty }}$ & 0.915 \\
\hline \multirow{3}{*}{ Black River } & old & $Q_{\text {Black }}=0.0956 * Q_{\text {Chehalis@Grand Mound }}$ & 0.469 \\
\cline { 2 - 4 } & new & $Q_{\text {Black }}=0.09242 * Q_{\text {Chehalis@Grand Mound }}$ & 0.775 \\
\hline
\end{tabular}

Figure 15 shows flow rate correlations between the Black River and the mainstem Chehalis River at Grand Mound; Figure 16 shows flow rate correlations between Elk Creek and the mainstem Chehalis River at Doty; and Figure 17 shows flow correlations between the mainstem Chehalis River near Mahaffey Creek and the mainstem Chehalis River at Doty. 


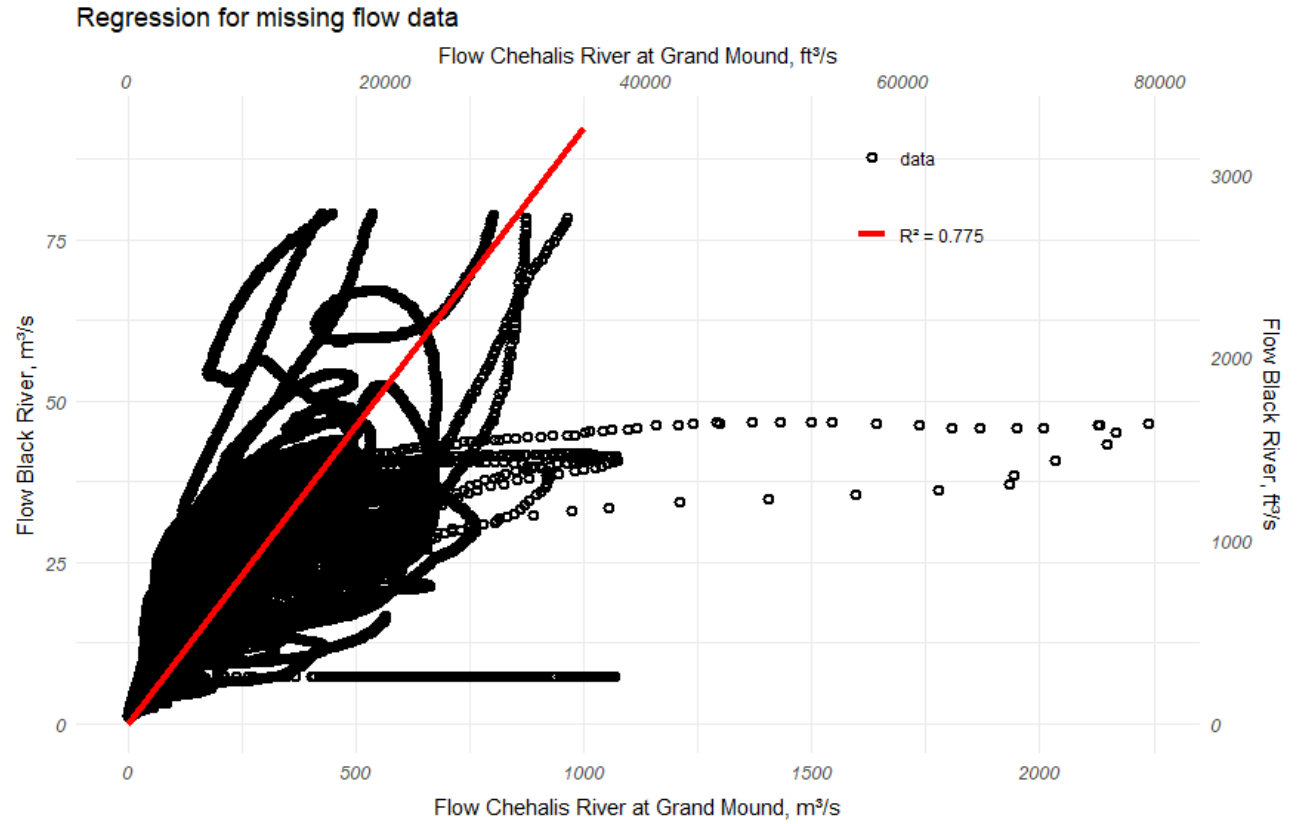

Figure 15. Flow correlation between Black River and Chehalis River at Grand Mound between 20132015.

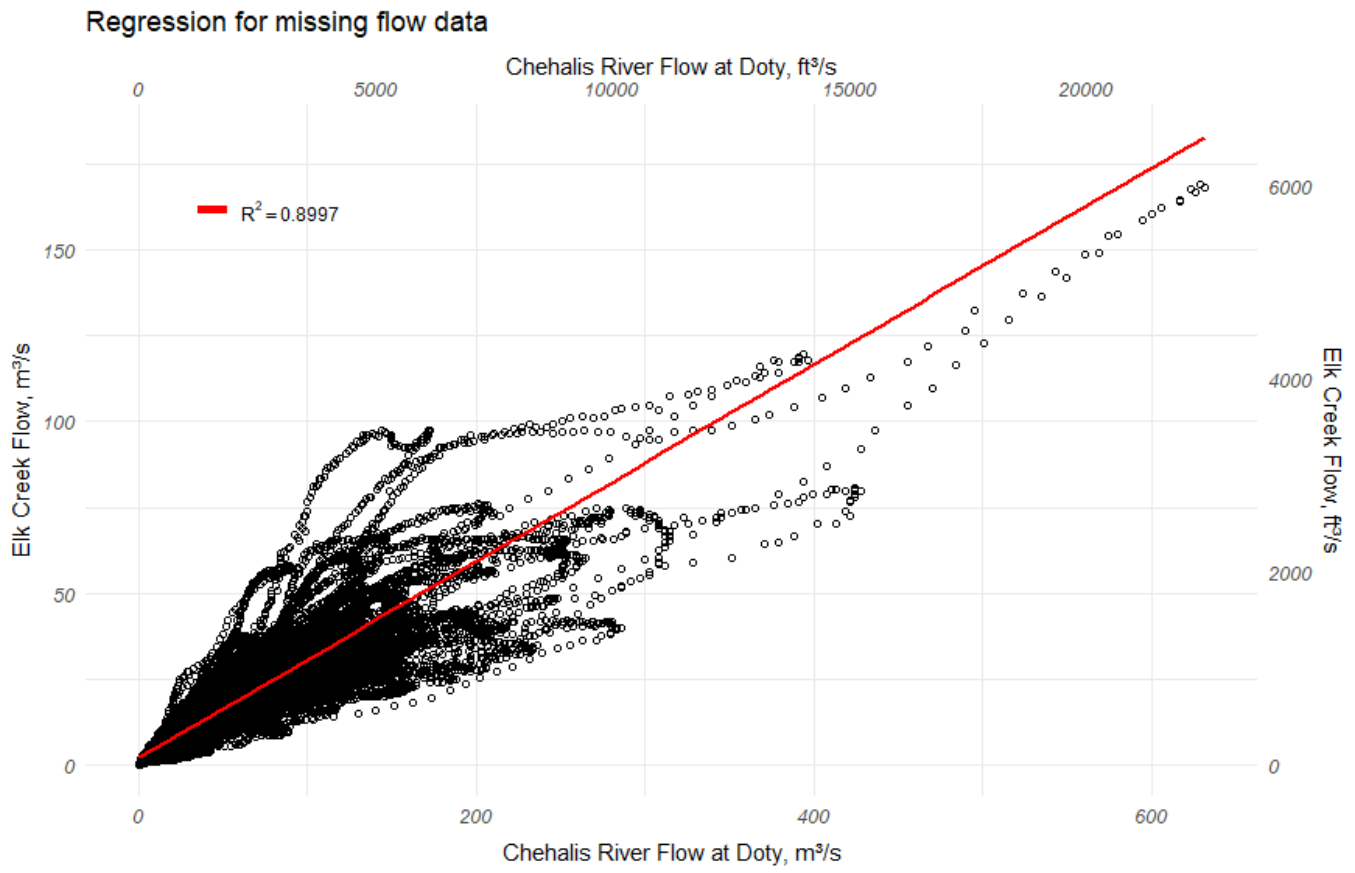

Figure 16. Flow correlation between Elk Creek and Chehalis River at Doty between 2013-2015. 


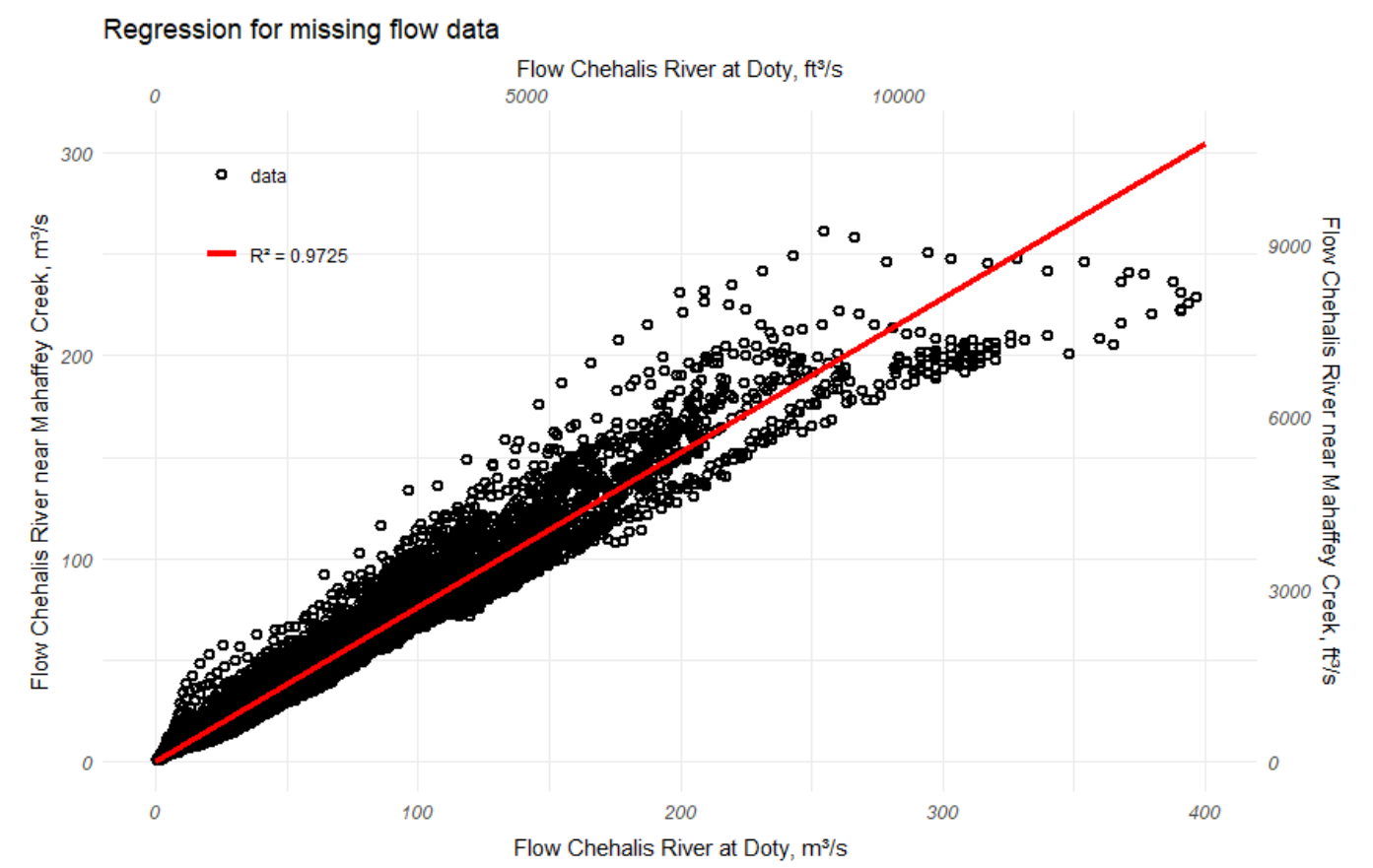

Figure 17. Flow correlation between Chehalis River near Mahaffey Creek and Chehalis River at Doty between 2013-2015. 


\section{Water Quality Constituents}

Changes to Van Glubt's (2017) water quality constituent input files are limited to wastewater treatment plant discharges and groundwater tributaries in waterbody 3. A sensitivity analysis lead to decreasing the $\mathrm{PO}_{4^{3-}}$ concentration from $0.09 \mathrm{mg} / \mathrm{l}$ by half to $0.045 \mathrm{mg} / \mathrm{l}$ in groundwater tributaries $27-51$. This improved model phosphorus and algae predictions. Treatment plant discharge files were updated with 2015 water quality data. Very little tributary water quality data was available for 2015, so 2013 and 2014 data were averaged to extend constituent files through 2015.

\section{2018 Dye study}

The Washington Department of Ecology performed dye studies along the Chehalis mainstem during 2018. Details of these studies were provided by Nuri Mathieu (2019) from Washington Department of Ecology and are shown in Appendix B. The regions of the Chehalis mainstem where the dye studies were conducted are shown in Figure 18. 


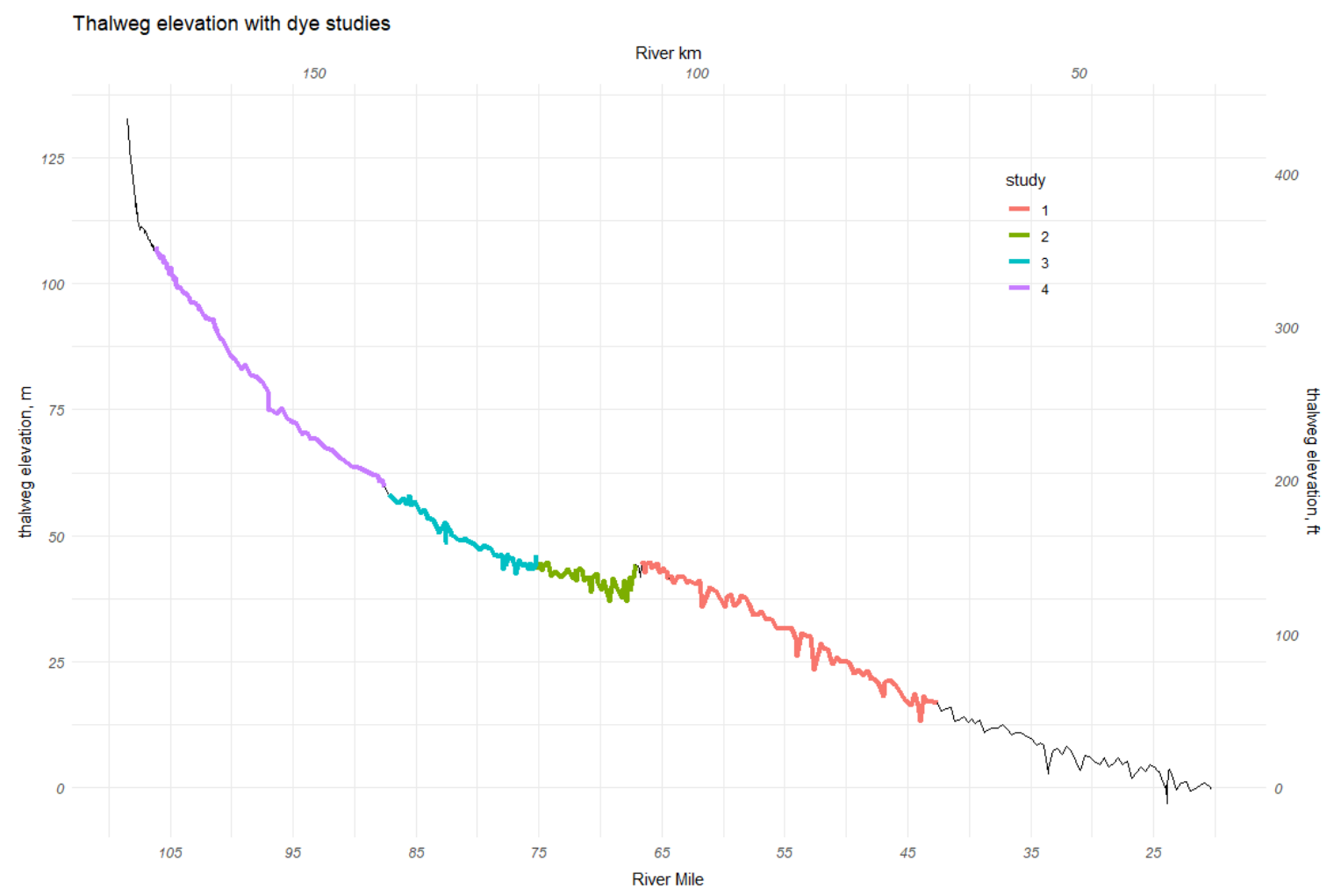

Figure 18. Locations of four dye studies along the Chehalis River mainstem during August 2018.

In order to run the model for the August 2018 dye study, the flow regime had to be adjusted to that measured at the USGS gages during the dye study. We used the temperatures from the 2015 time period with flows from 2018 . Hence, flows had to be developed for the 2018 period of the dye study. Also, in 2018 a new flow monitoring location was added at Adna that was not available for the 2013-2015 flow comparisons.

The 2018 model prediction of flow rates at Doty, Adna, Grand Mound, and Porter gage stations compared to field data are shown in Figure 19. Table 4 shows excellent mean error (ME, goal of $0 \mathrm{~m}^{3} / \mathrm{s}$ ) and low absolute mean error (AME) relative to the flow rate. For example, at Porter, the average flow rate during the dye 
study was about $8.5 \mathrm{~m}^{3} / \mathrm{s}$, hence the AME error divided by the average flow rate was about $1.4 \%$.

Table 4. Flow rate errors (see Appendix C) between model predictions and field data for flow rate at Doty, Grand Mound, and Porter for August 2018 during the dye study of Mathieu (2018).

\begin{tabular}{|l|r|r|r|r|}
\hline Gage & Number of comparisons & ME, $\mathrm{m}^{3} / \mathrm{s}$ & $\mathrm{AME}, \mathrm{m}^{3} / \mathrm{s}$ & $\mathrm{RMS}, \mathrm{m}^{3} / \mathrm{s}$ \\
\hline Doty & 970 & 0.00042 & 0.01336 & 0.02027 \\
\hline Adna & 970 & 0.00664 & 0.04766 & 0.06167 \\
\hline Grand Mound & 783 & 0.02781 & 0.03468 & 0.04793 \\
\hline Porter & 783 & 0.05199 & 0.11679 & 0.15159 \\
\hline weighted & 3506 & 0.01978 & 0.05071 & 0.06723 \\
\hline
\end{tabular}




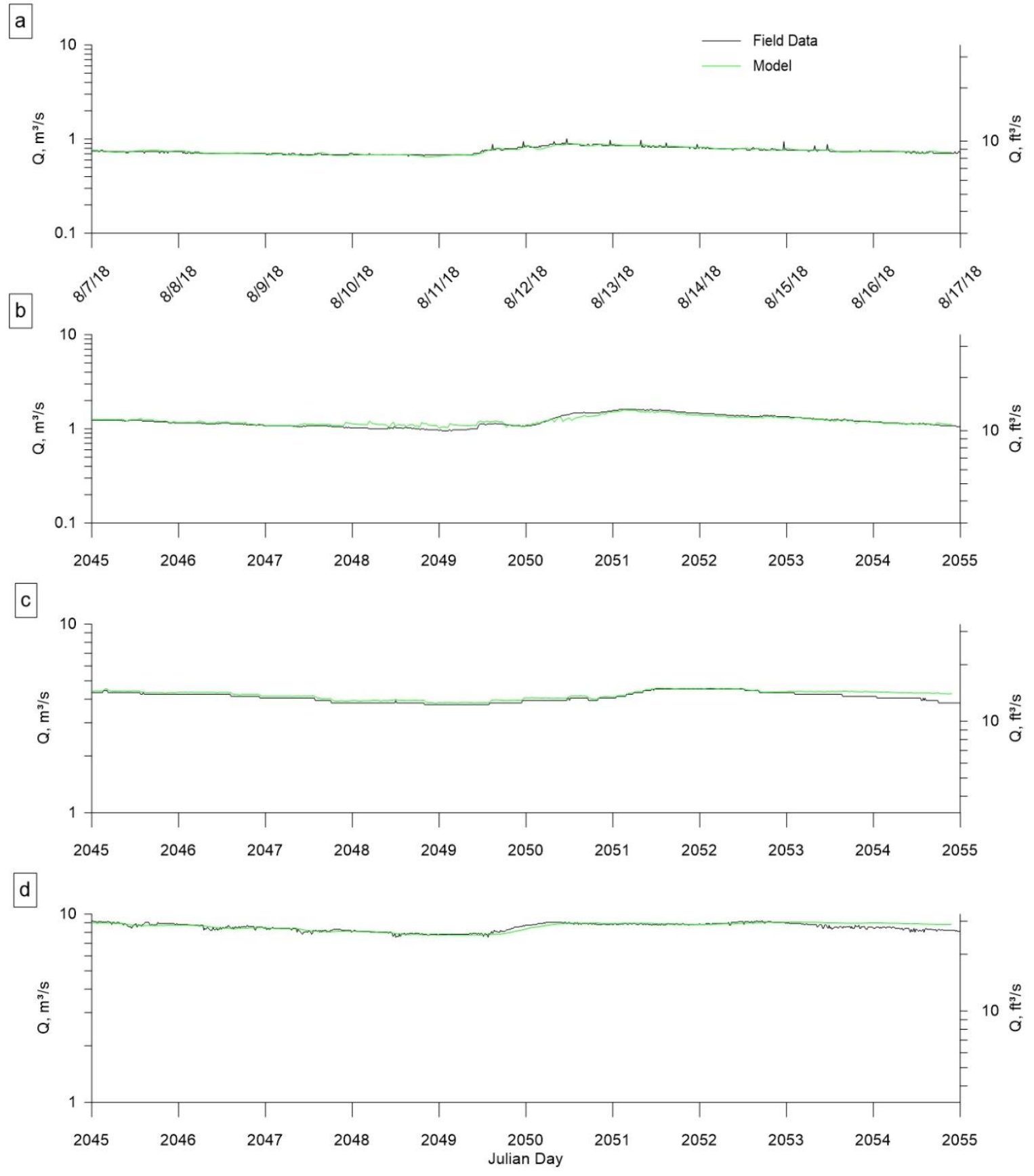

Figure 19. Flow rate model predictions during August 2018 dye study compared to field data in the mainstem Chehalis River at (a) Doty, (b) Adna, (c) Grand Mound, and (d) Porter.

The dye was modeled as particles representing the dye mass. The particle transport algorithm (Cole and Wells, 2018) allows particles to move through the system without being constrained by segment boundaries rather than as a continuum, 
which would increase numerical spreading. This algorithm moves particles based on fluid motion and random motion based on turbulence intensity in the $\mathrm{x}, \mathrm{y}$ and $\mathrm{z}$ directions.

There were 4 dye releases as shown in Figure 18 and in Appendix A. The resulting dye concentrations (data from Mathieu, 2019) measured at each sampling site are shown in the following Figure 20 and Figure 21. Mathieu did not have confidence in the data from Ceres Canyon, so it was excluded from further analysis. The primary goal of this modeling effort was to obtain similar travel time of the peak and particle spread (dispersion). Figure 23, Figure 24, Figure 25, Figure 26, Figure 27, Figure 28, and Figure 29 show cumulative dye mass compared to modeled cumulative particle mass fraction at each of the monitoring points. As evident from these graphs, some sites (such as at Newaukum) did not exhibit expected dye response behavior either because of missing the peak during sampling or flow complexities. 


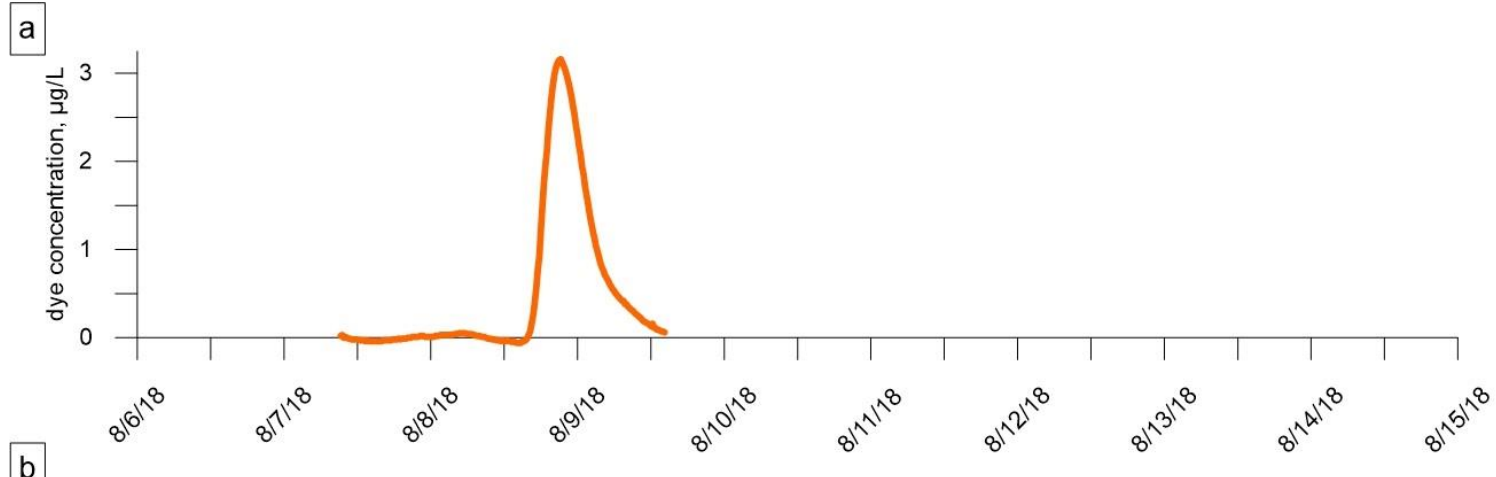

b

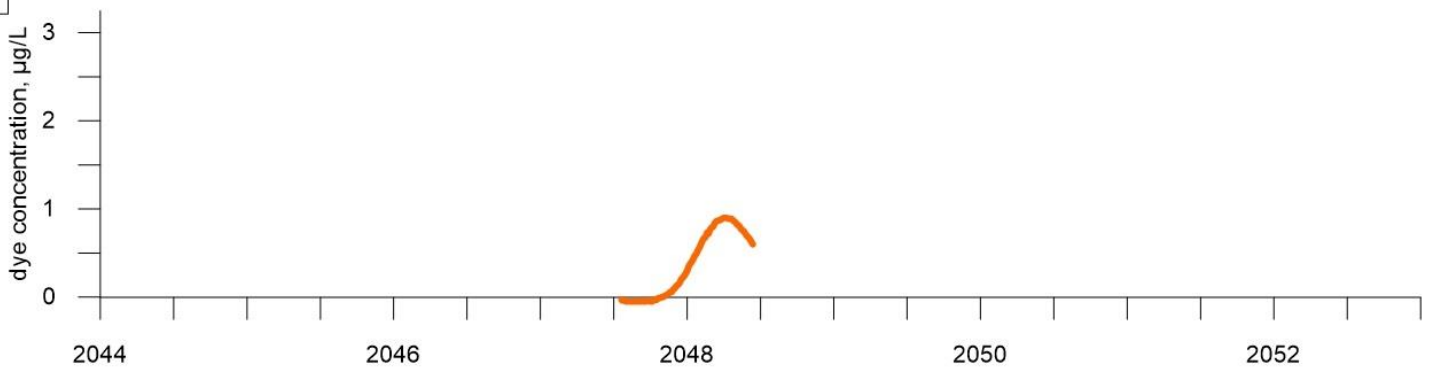

c

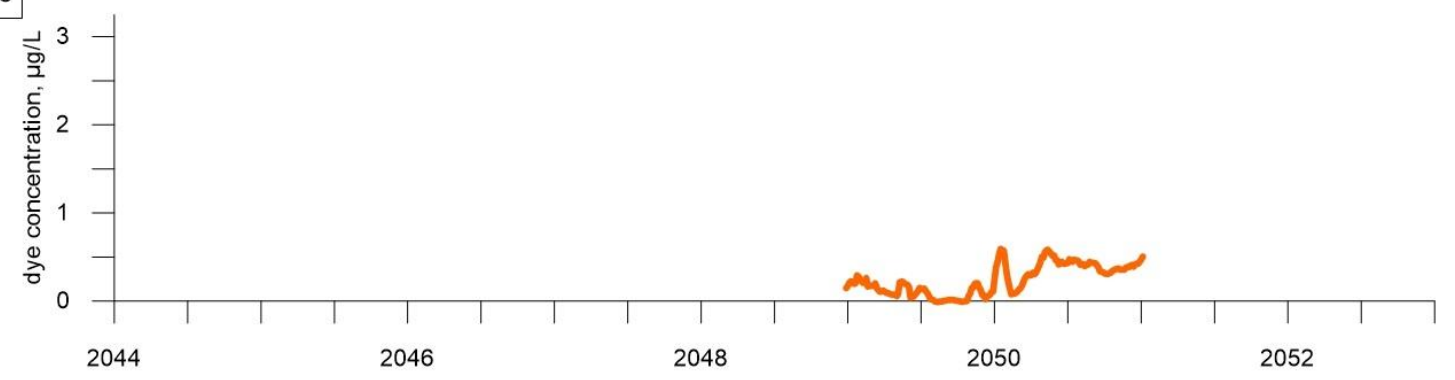

d

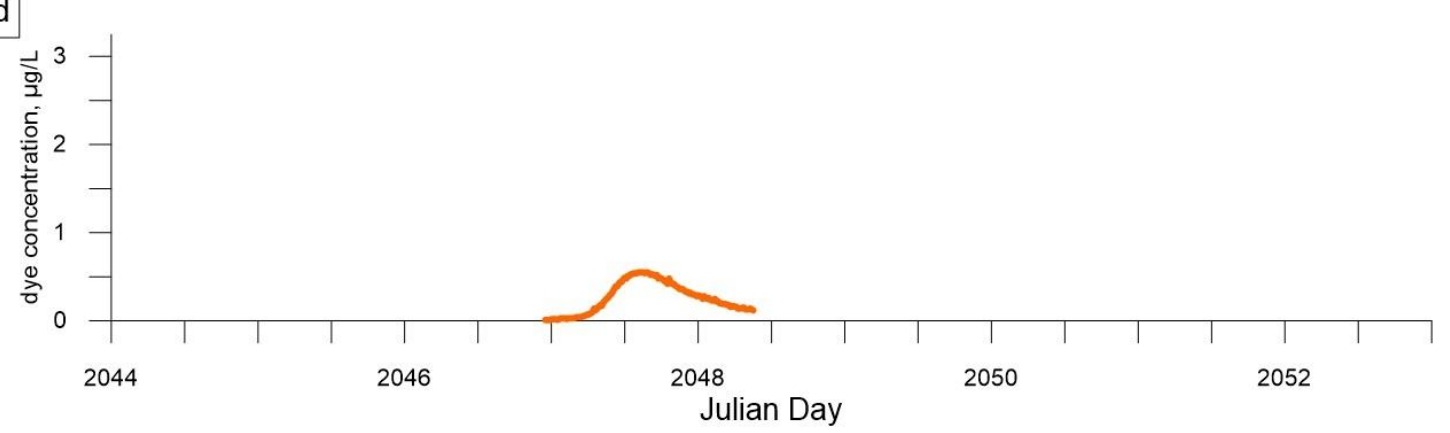

Figure 20. Dye concentration curves at (a) Elk Creek, (b) Hope Creek, (c) Ceres Canyon, and (d) Adna during 2018 dye study. 


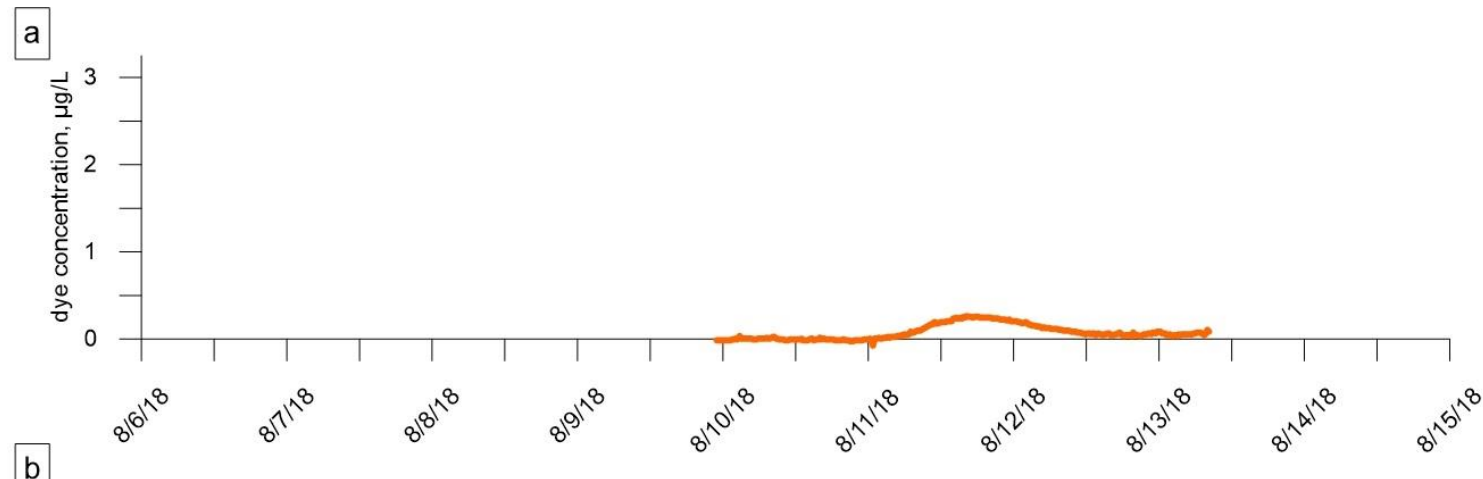

b

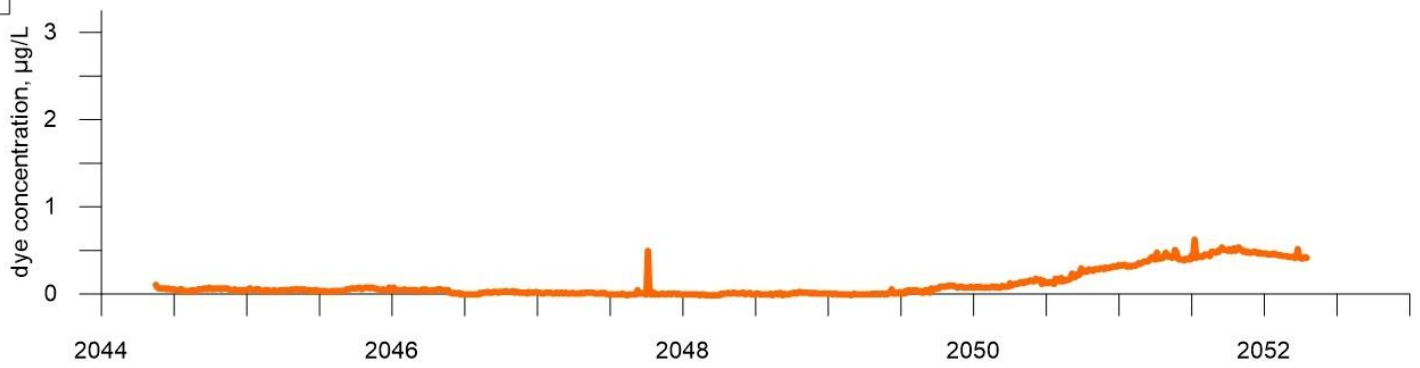

C

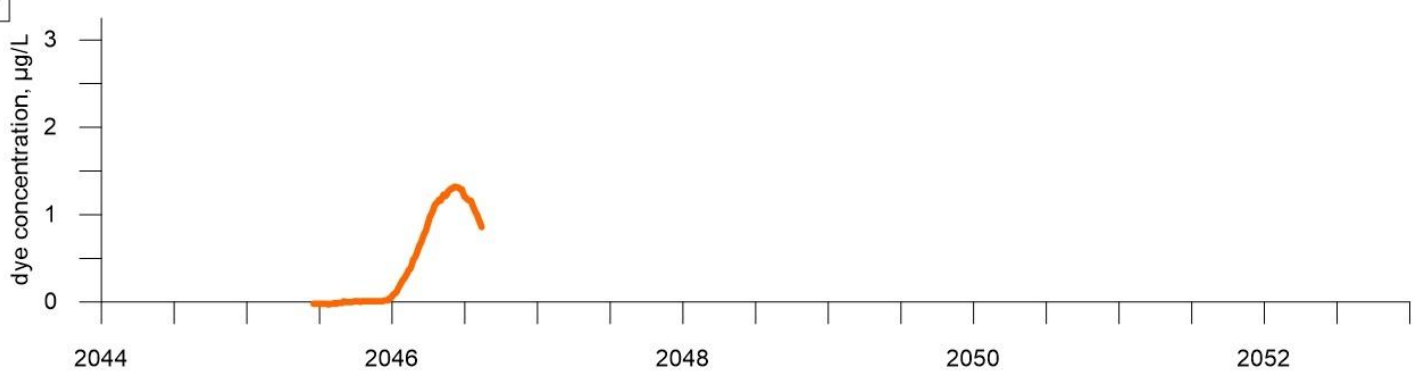

d

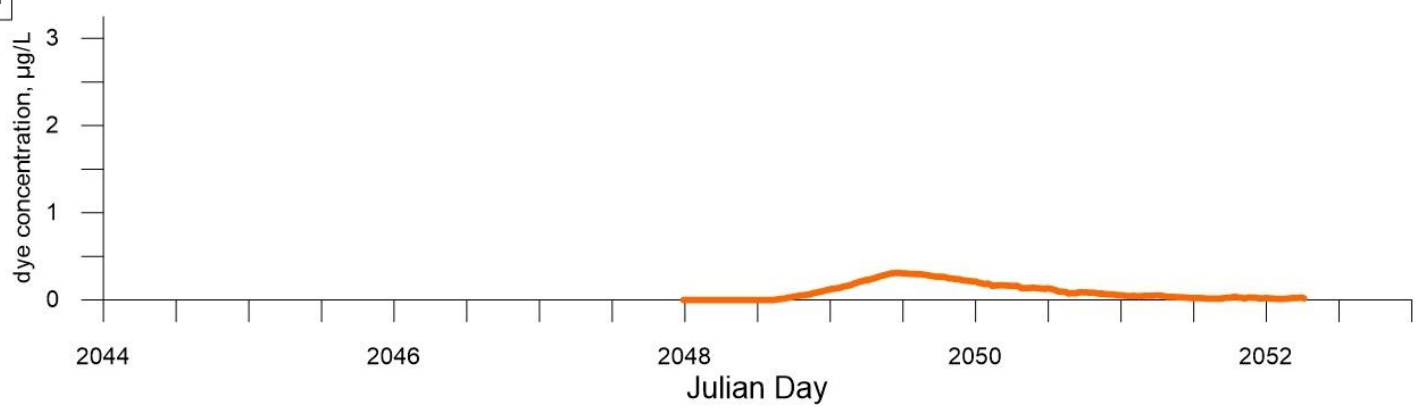

Figure 21. Dye concentration curves at (a) Newaukum River, (b) Skookumchuck River, (c) Prather Road, and (d) Oakville Boat Launch during 2018 dye study.

Modeling dye transport by adding particles instead of adding a mass of dye to a model cell allows greater resolution of the dye transport. Converting particles to 
concentration in order to compare to field data was based on the following conversion:

$$
C=\frac{M}{\# \text { particles released }} \frac{1}{Q \Delta t} \sum \text { particles }
$$

where particles represent those particles passing a sensor location during a time period $\Delta t, Q$ is the flow rate, $M$ is the total mass of dye released, and \#particles released is the total number released to represent the dye study. This method did not allow easy comparison of model results and field data, because of the difficulty in estimating a volume for converting from modeled particle mass to concentration. Figure 22 shows dye modeled as both a conservative tracer and as particles compared to field data. Modeling dye as a conservative tracer caused to much dispersion, while converting particle paths to concentrations required arbitrarily 
scaling to match field data.

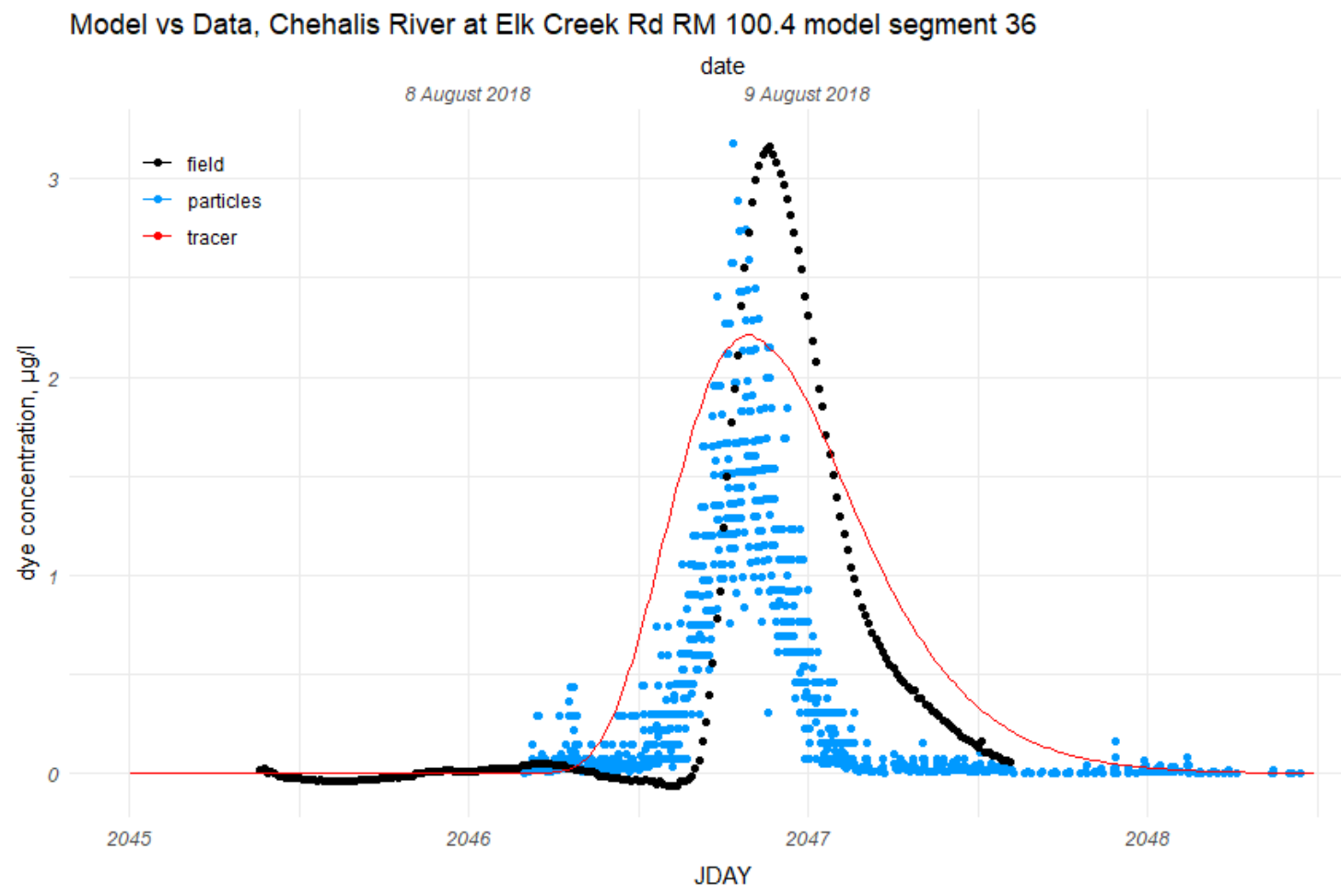

Figure 22. Modeled dye concentration using two methods compared to dye study field data. The particle concentration was arbitrarily scaled.

Instead of comparing concentration versus time with the field data, the cumulative dye mass measured in the field was compared to cumulative particle mass in the model. The cumulative mass was computed from the model particle release as

$$
\text { CumulativeMass }=\frac{M}{\# \text { particles released }} \sum \text { particles }
$$

The dye study data were converted to cumulative mass using the following:

$$
\text { CumulativeMass }=\sum C Q \Delta t
$$

Where $C$ is the dye concentration, $Q$ is the flow rate, and $\Delta t$ is the time interval between measurements. 
With the exception of the Skookumchuck sample site, the mass of dye calculated to have passed the probe was lower than the mass of dye released for the study. To account for this mass loss, first-order decay was assumed for particles in the model as in

$$
\frac{\partial M}{\partial t}=-M k
$$

where $\frac{\partial M}{\partial t}$ is the time rate of change of dye mass and $k$ is a first-order decay constant. Integrating this equation and solving for $k$ gives

$$
k=\frac{\ln \frac{M_{0}}{M}}{t-t_{0}}
$$

where $M_{0}$ is the mass of dye released and $t_{0}$ is the time of dye release.

If it appeared that most of the dye plume had been captured in the field data, the total mass calculated was used for $M$ and the time that half of the mass had passed the sample site was used for $t$. If it did not appear that the whole plume had been captured, the time of peak concentration was used for $t$, and twice the cumulative mass at that point was used for $M$. The decay constants calculated this way are shown in Table 5. No decay constant was used for Skookumchuck, because more dye mass was measured there than was released. 
Table 5. First-order decay constants applied to model particles to approximate dye loss.

\begin{tabular}{|l|l|}
\hline Station & $k$, day-1 \\
\hline Elk Creek Rd & 0.30 \\
\hline Hope Creek & 0.29 \\
\hline Adna & 0.47 \\
\hline Newaukum & 0.23 \\
\hline Prather Rd & 0.15 \\
\hline Oakville Boat Launch & 0.098 \\
\hline
\end{tabular}

Model vs Data, Chehalis River at Elk Creek Rd RM 100.4 model segment 36 release 4

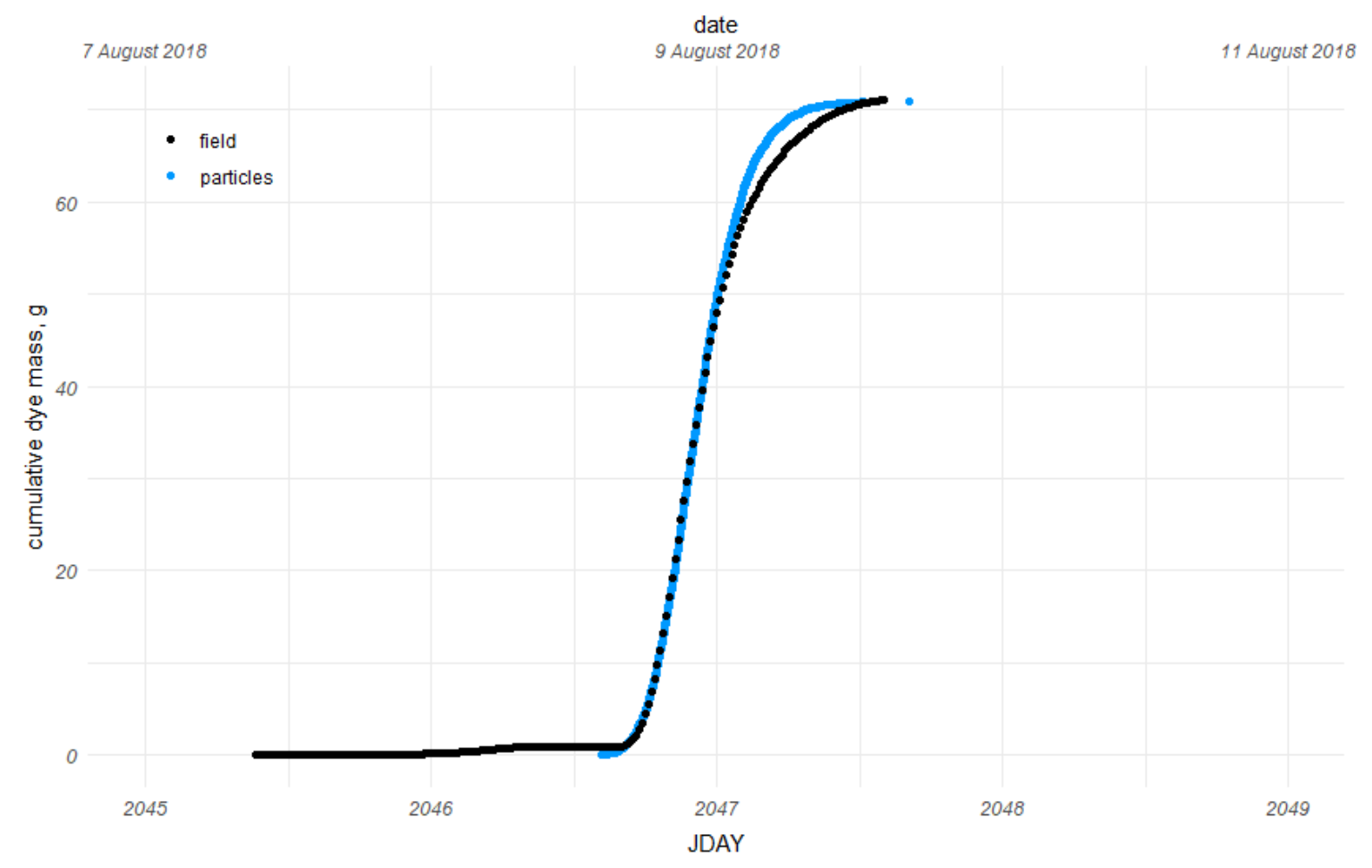

Figure 23. Cumulative mass from dye release compared to model predictions at Elk Creek RM 100.4. 


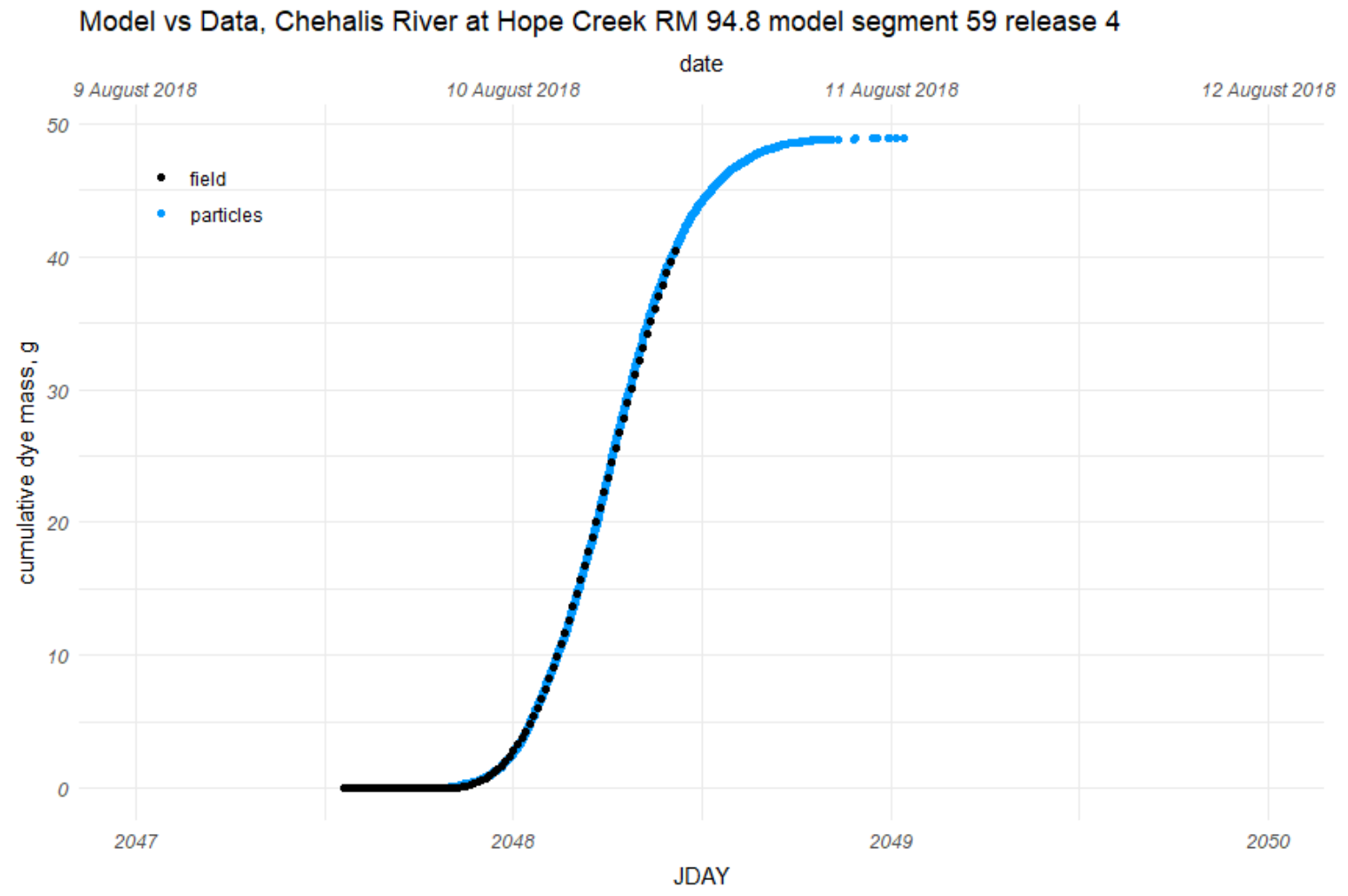

Figure 24. Cumulative mass from dye release compared to model predictions at Hope Creek RM 94.8.

Model vs Data, Chehalis River at Adna RM 81.5 model segment 114 release 3

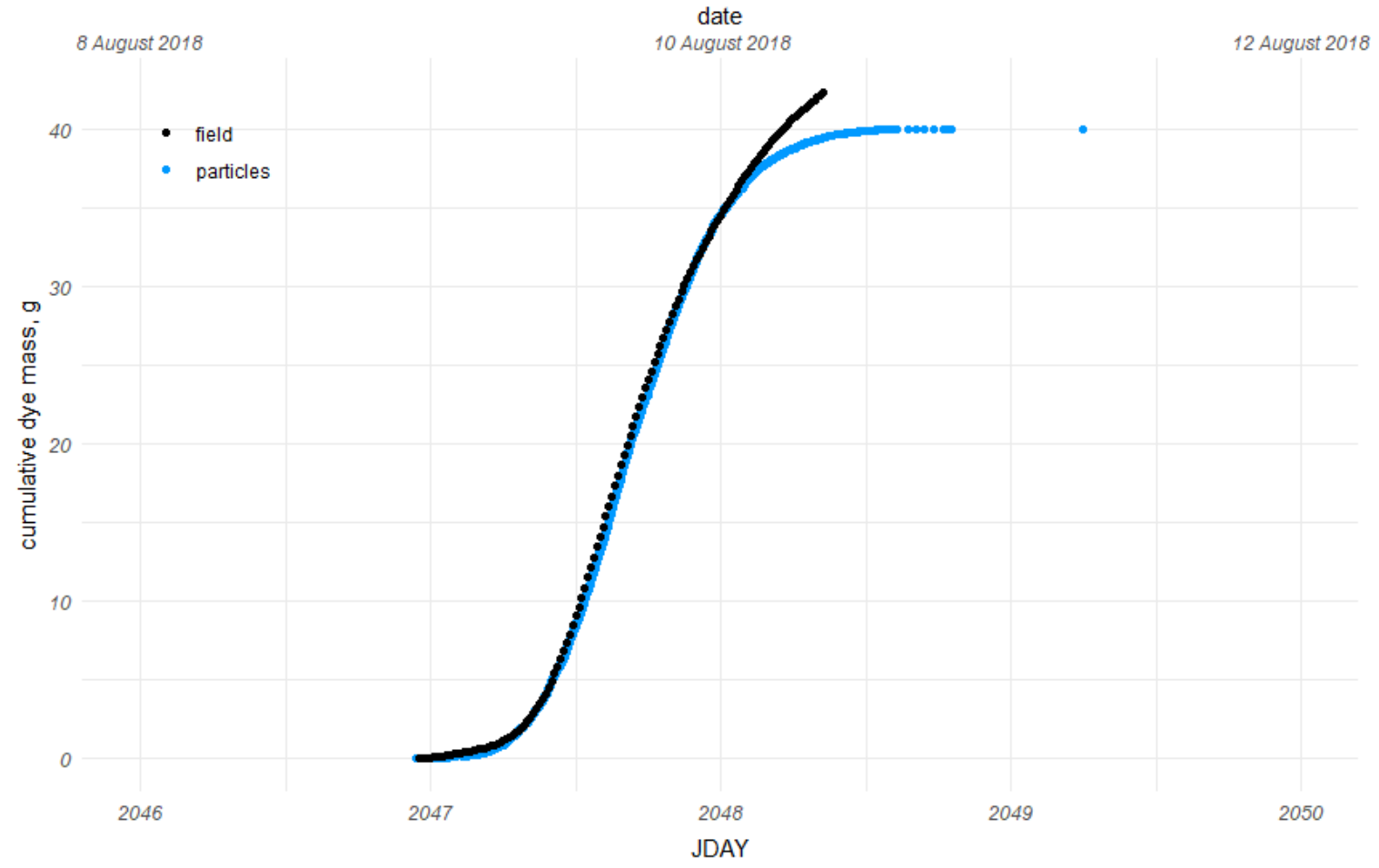

Figure 25. Cumulative mass from dye release compared to model predictions at Adna RM 81.5. 
Model vs Data, Chehalis River at Newaukum RM 75.1 model segment 142 release 3

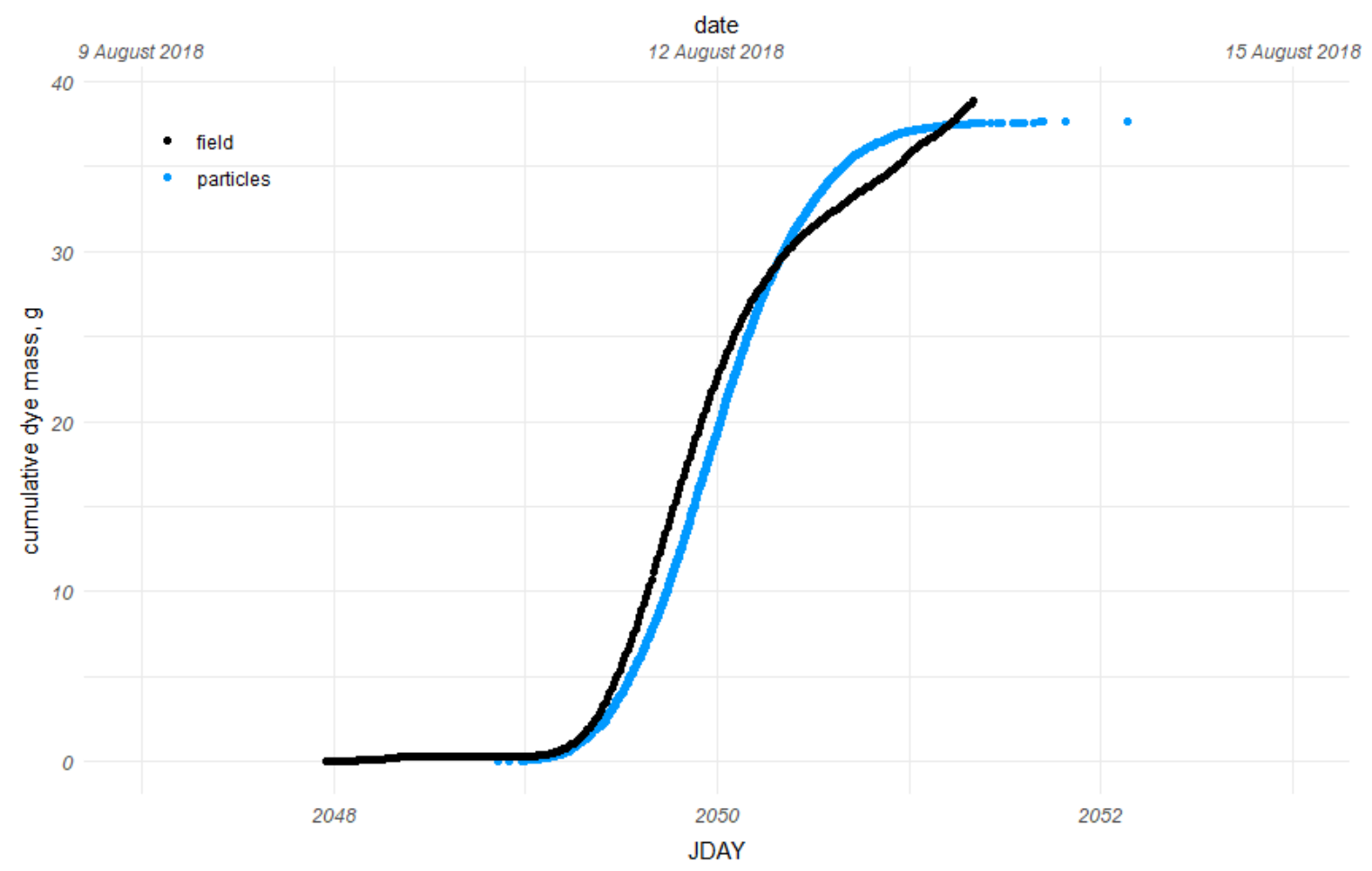

Figure 26. Cumulative mass from dye release compared to model predictions at Newaukum RM 75.1.

Model vs Data, Chehalis River at Skookumchuck RM 67 model segment 178 release 2

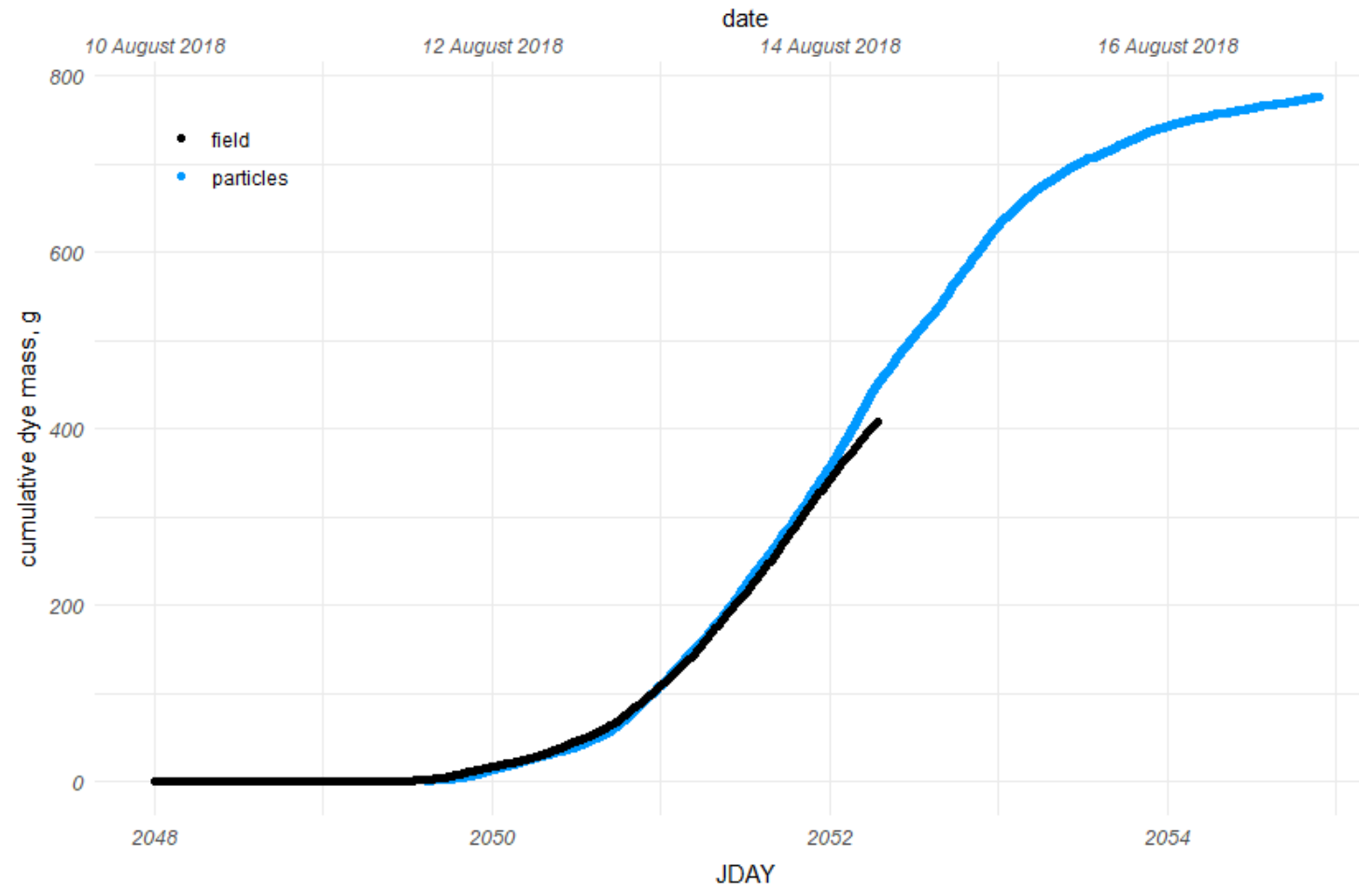

Figure 27. Cumulative mass from dye release compared to model predictions at Skookumchuck RM 67. 


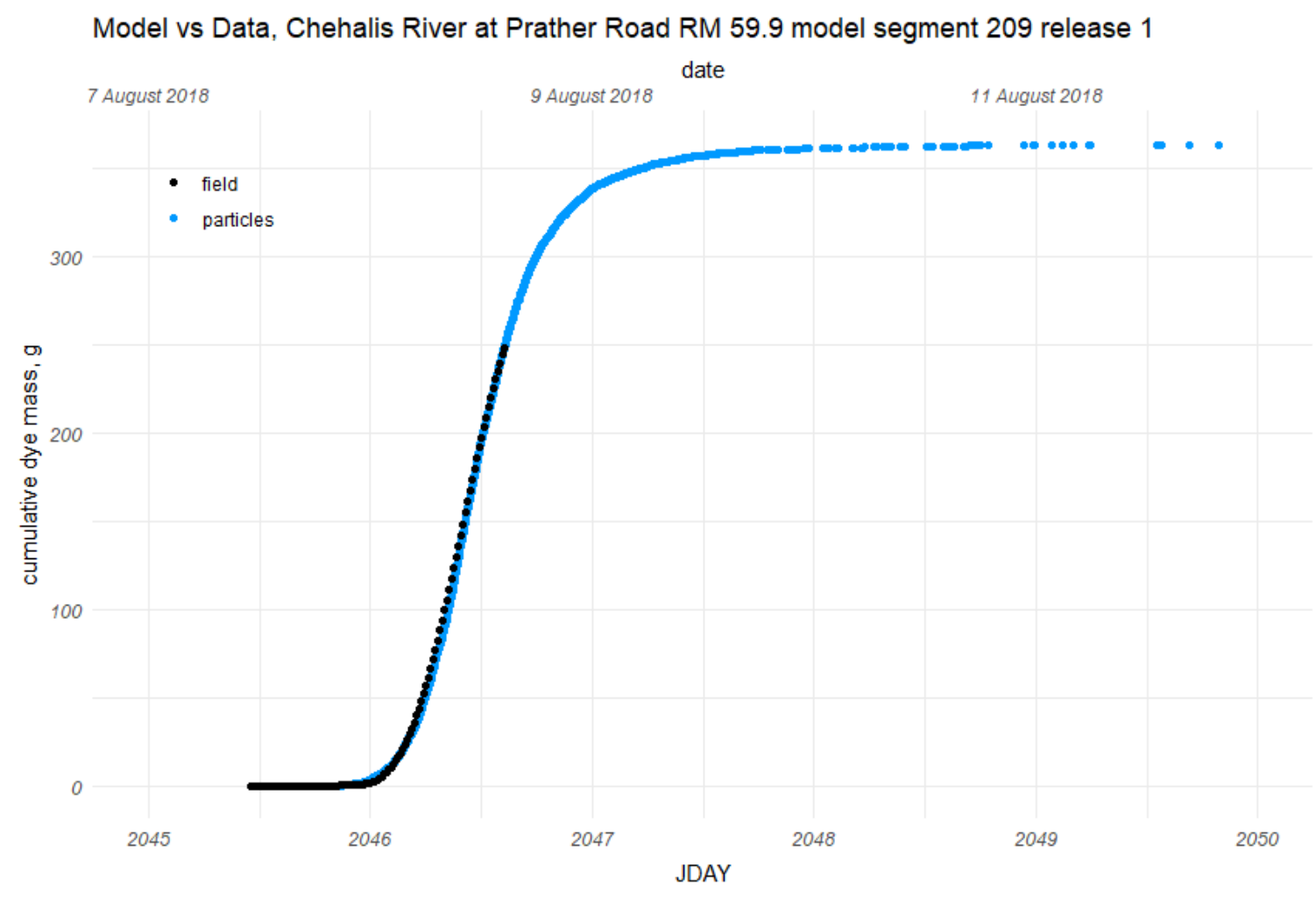

Figure 28. Cumulative mass from dye release compared to model predictions at Prather Road RM 59.9. 


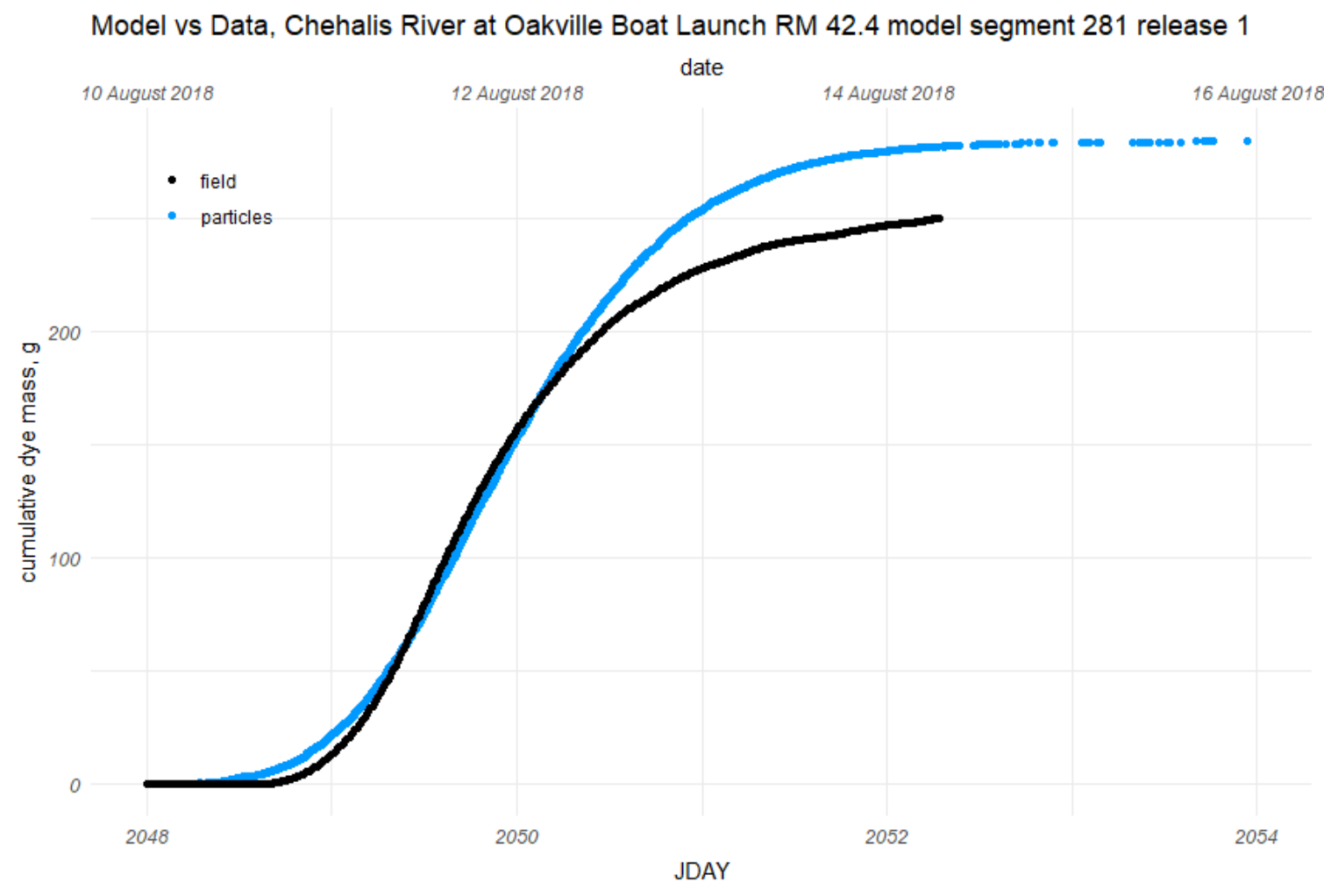

Figure 29. Cumulative mass from dye release compared to model predictions at Oakville Boat Launch RM 42.4 .

Four parameters were adjusted to match the results of the dye study conducted in August 2018: hydraulic equivalent branch slope (Table 6), waterbody bottom elevation (Table 7), spillway elevation (Table 8), and longitudinal eddy diffusivity (Table 9). In most cases the dye results showed that transport of mass and heat downstream in the Van Glubt et al. (2017) model was too fast and did not allow enough dispersion. 
Table 6. Adjustments in CE-QUAL-W2 model adjusted hydraulic equivalent slope (SLOPEC) from the Van Glubt et al. (2017) model based on the results of the dye study.

\begin{tabular}{|c|l|c|}
\hline \multirow{2}{*}{ model branch } & \multicolumn{2}{|c|}{ SLOPEC } \\
\cline { 2 - 3 } & \multicolumn{1}{|c|}{ old } & new \\
\hline 1 & 0.003 & 0.001600 \\
\hline 2 & 0.0004 & 0.000216 \\
\hline 3 & 0.0006 & 0.000294 \\
\hline 4 & 0.00095 & 0.000048 \\
\hline 5 & 0.00055 & 0.000496 \\
\hline 6 & 0.000001 & 0.000001 \\
\hline 7 & 0.000001 & 0.000001 \\
\hline 8 & 0.00055 & 0.000081 \\
\hline 9 & 0.000769 & 0.000127 \\
\hline 10 & 0.00077 & 0.000077 \\
\hline
\end{tabular}

Table 7. Adjustments in CE-QUAL-W2 model reference bottom elevation (EBOT) from the Van Glubt et al. (2017) model based on the results of the dye study.

\begin{tabular}{|c|l|l|}
\hline \multirow{2}{*}{ waterbody } & \multicolumn{2}{|c|}{ EBOT, meters } \\
\cline { 2 - 3 } & old & new \\
\hline 1 & 111.06 & 111.06 \\
\hline 2 & 93.34 & 93.34 \\
\hline 3 & 71.15 & 71.15 \\
\hline 4 & 46.68 & 46.68 \\
\hline 5 & 39.77 & 39.77 \\
\hline 6 & 38.08 & 36.207 \\
\hline 7 & 35.32 & 35.32 \\
\hline 8 & 14.96 & 14.96 \\
\hline 9 & 3.28 & 3.280 \\
\hline
\end{tabular}

Table 8. Adjustments in CE-QUAL-W2 model adjusted elevation of the spillway between branches (ESP) from the Van Glubt et al. (2017) model based on the results of the dye study.

\begin{tabular}{|c|c|c|}
\hline \multirow{2}{*}{ Spillway } & \multicolumn{2}{|c|}{ ESP, meters } \\
\cline { 2 - 3 } & old & new \\
\hline 1 & 8.770 & 8.770 \\
\hline 2 & 95.84 & 96.34 \\
\hline 3 & 112.55 & 111.00 \\
\hline 4 & n/a & 46.557 \\
\hline 5 & n/a & 48.905 \\
\hline 6 & n/a & 73.25 \\
\hline 7 & n/a & 43.55 \\
\hline 8 & n/a & 28.50 \\
\hline 9 & n/a & 21.96 \\
\hline
\end{tabular}


Table 9. Adjustments in CE-QUAL-W2 model dispersion coefficient (DX) from the Van Glubt et al. (2017) model based on the results of the dye study.

\begin{tabular}{|c|l|l|}
\hline \multirow{2}{*}{ Waterbody } & \multicolumn{2}{|c|}{ DX, $\mathrm{m}^{2} \mathrm{sec}^{-1}$} \\
\cline { 2 - 3 } & old & new \\
\hline 1 & 1.00 & 10.0 \\
\hline 2 & 1.00 & 6.50 \\
\hline 3 & 1.00 & 1.27 \\
\hline 4 & 1.00 & 4.50 \\
\hline 5 & 1.00 & 3.70 \\
\hline 6 & 1.00 & 2.65 \\
\hline 7 & 1.00 & 90.0 \\
\hline 8 & 1.00 & 41.0 \\
\hline 9 & 1.00 & 10.0 \\
\hline
\end{tabular}


4. Tributaries of the Chehalis: South Fork Chehalis, Newaukum, Skookumchuck, and Black Rivers

Models were developed for the four largest tributaries in the mainstem Chehalis River model domain.

\section{Tributary Bathymetry}

Bathymetry for the South Fork Chehalis, Newaukum, Skookumchuck and Black Rivers was developed using existing HEC-RAS cross-sections. The grids were developed from the most upstream HEC-RAS cross-section downstream to the confluence with the Chehalis River. Figure 30 through Figure 33 show the model segments of the tributary grids and the HEC-RAS cross-section locations for the South Fork Chehalis, Newaukum, Skookumchuck, and Black Rivers, respectively. The thalweg elevations of the tributary HEC-RAS cross-sections are plotted in Figure 34 through Figure 37. Layer thicknesses were $1 \mathrm{~m}$, and segment length varies from $174.52 \mathrm{~m}$ to $282.22 \mathrm{~m}$. Table 10 lists the grid characteristics for each tributary. 


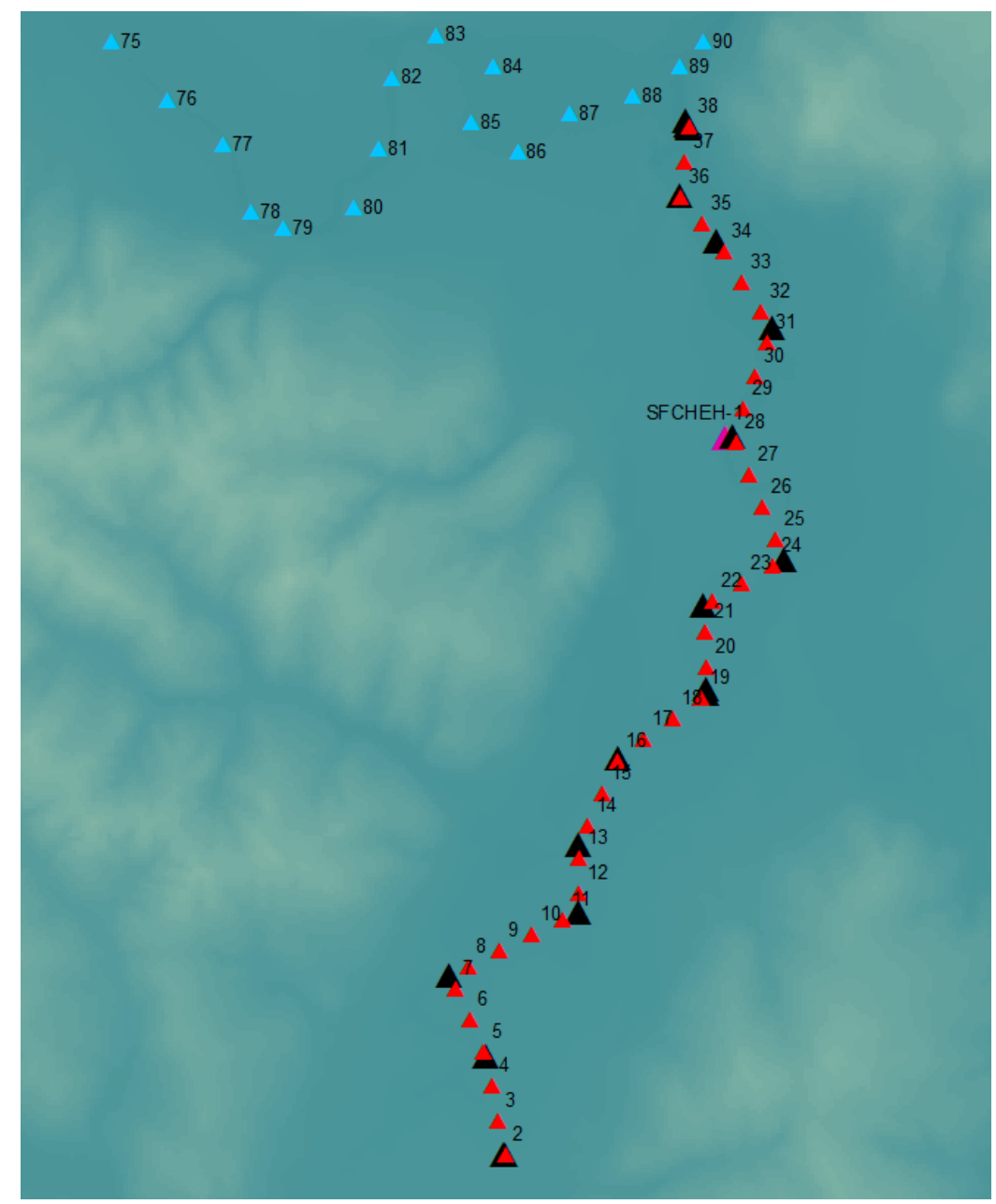

Figure 30. South Fork Chehalis River HEC-RAS cross sections (black triangles), segment locations (red triangles), and lower model segment locations (blue triangles). Numbers represent CE-QUAL-W2 model segments in the Chehalis River (blue) and in the South Fork Chehalis River (red). 


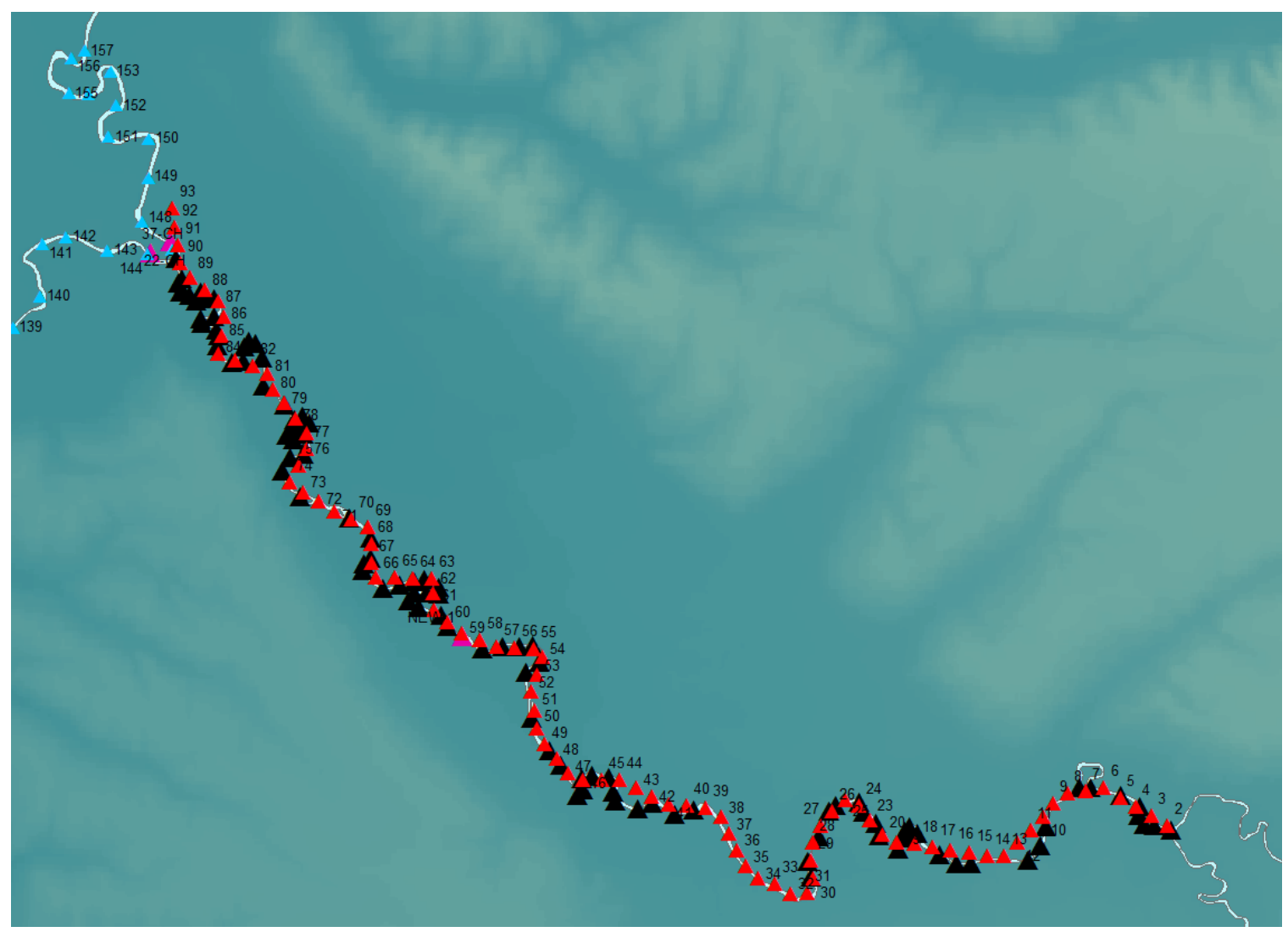

Figure 31. Newaukum River HEC-RAS cross sections (black triangles), segment locations (red triangles), and lower model segment locations (blue triangles). Numbers represent CE-QUAL-W2 model segments in the Chehalis River (blue) and in the Newaukum River (red). 


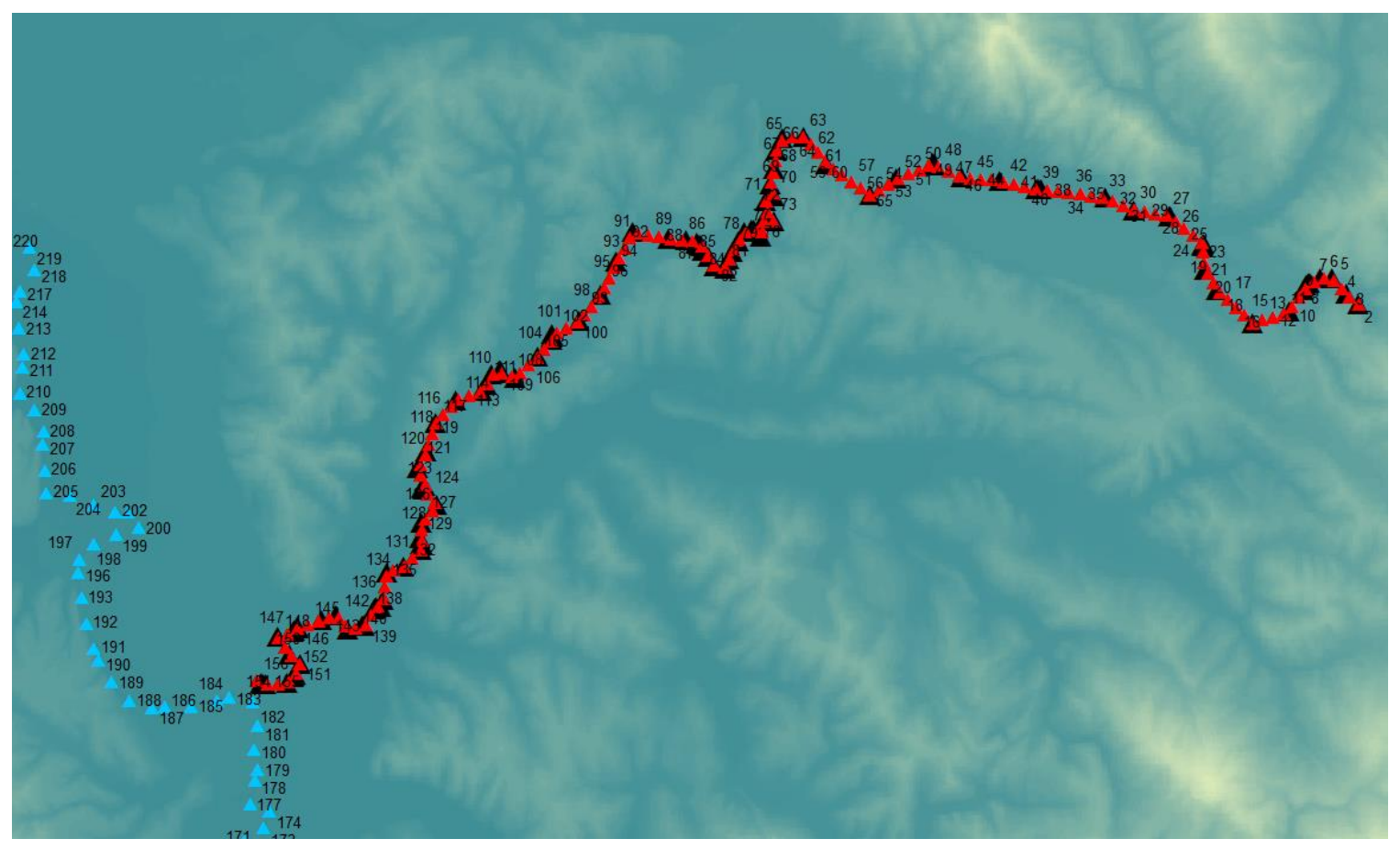

Figure 32. Skookumchuck River HEC-RAS cross sections (black triangles), segment locations (red triangles), and lower model segment locations (blue triangles). Numbers represent CE-QUAL-W2 model segments in the Chehalis River (blue) and in the Skookumchuck River (red). 


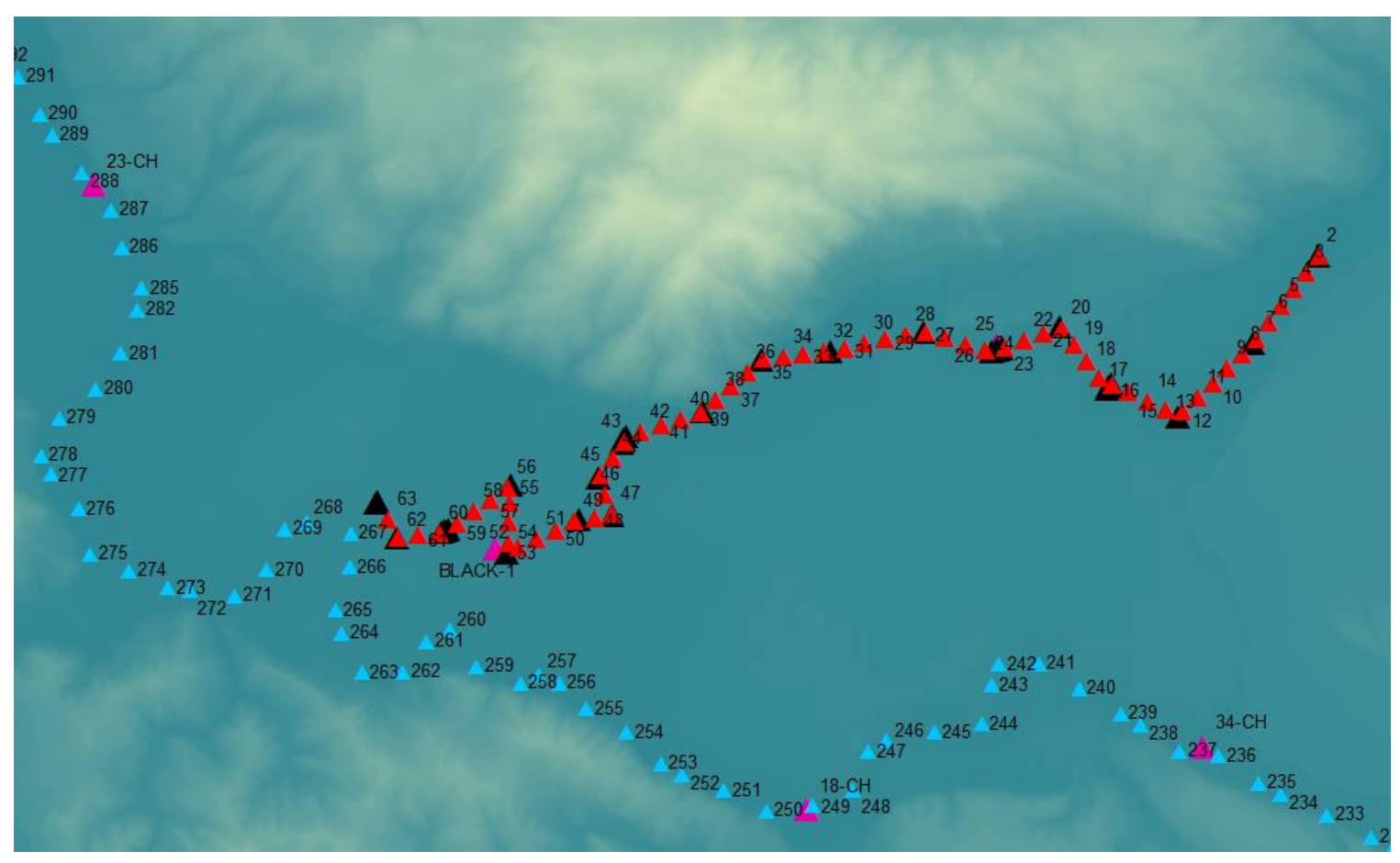

Figure 33. Black River HEC-RAS cross section locations (black triangles), segment locations (red triangles), and lower Chehalis River model segment locations (blue triangles). Numbers represent CEQUAL-W2 model segments in the Chehalis River (blue) and in the Black River (red). 


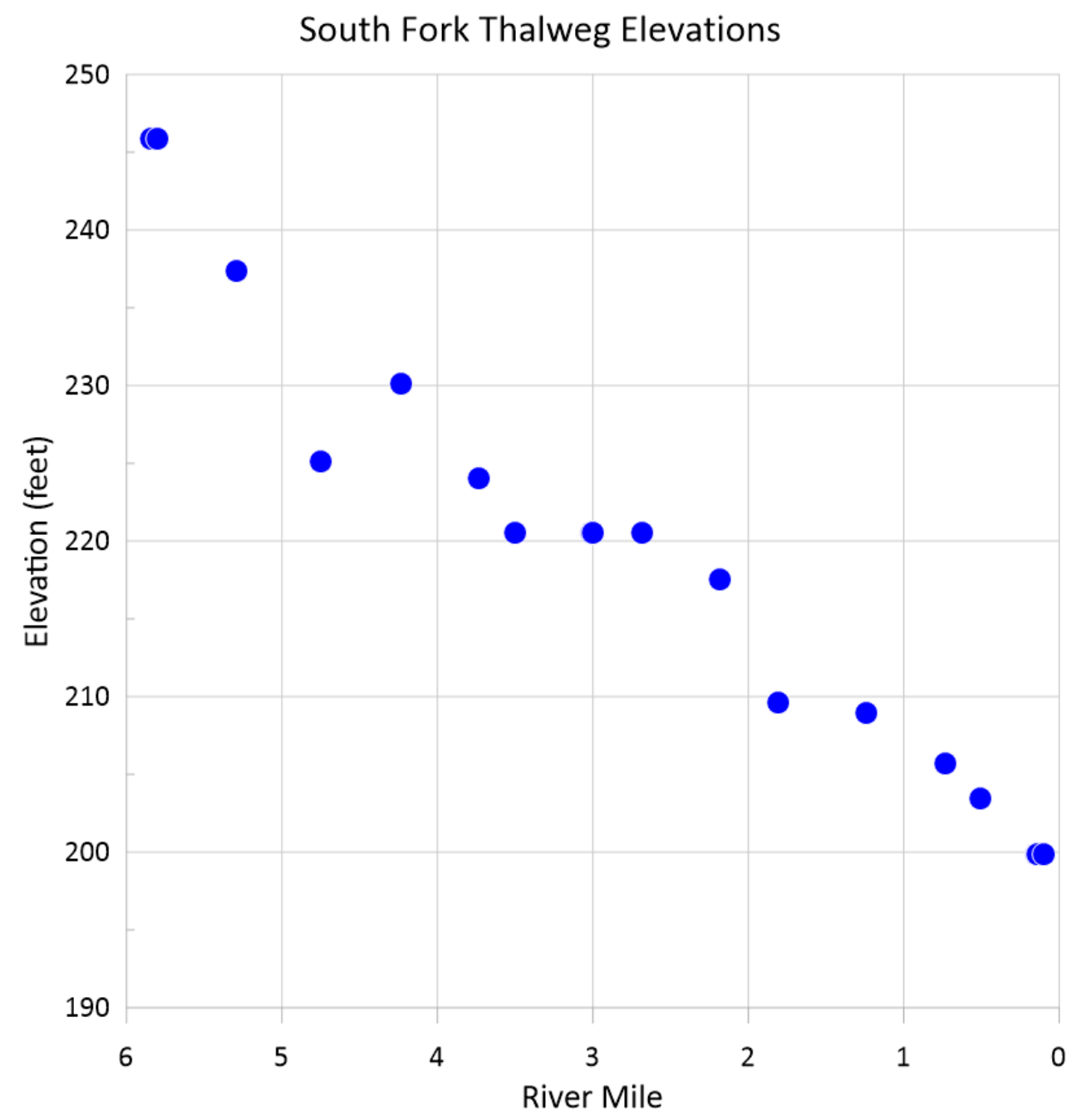

Figure 34. South Fork Chehalis River thalweg elevations of HEC-RAS cross-sections. 


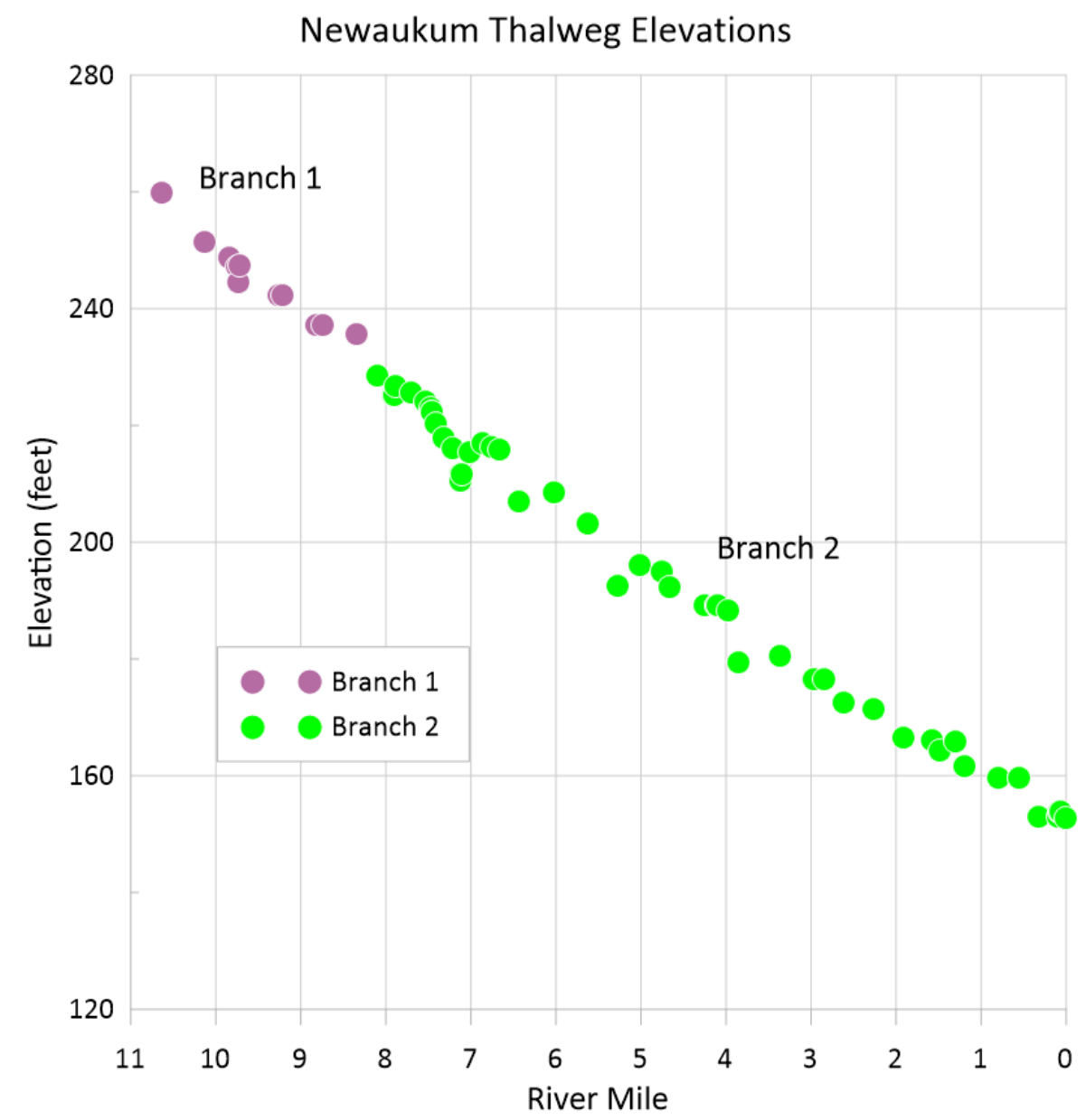

Figure 35. Newaukum River thalweg elevations of HEC-RAS cross-sections. 


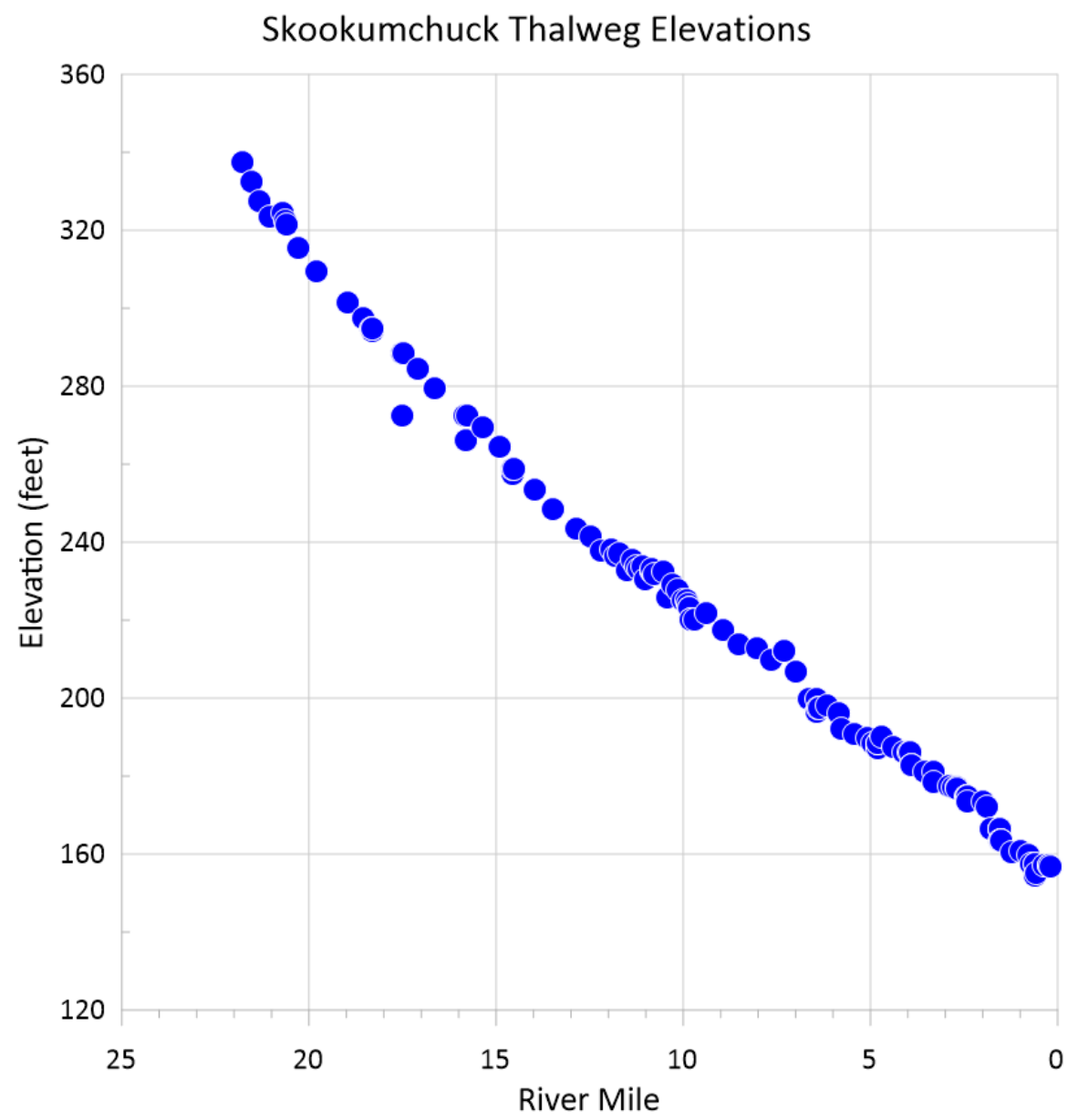

Figure 36. Skookumchuck River thalweg elevations of HEC-RAS cross-sections. 


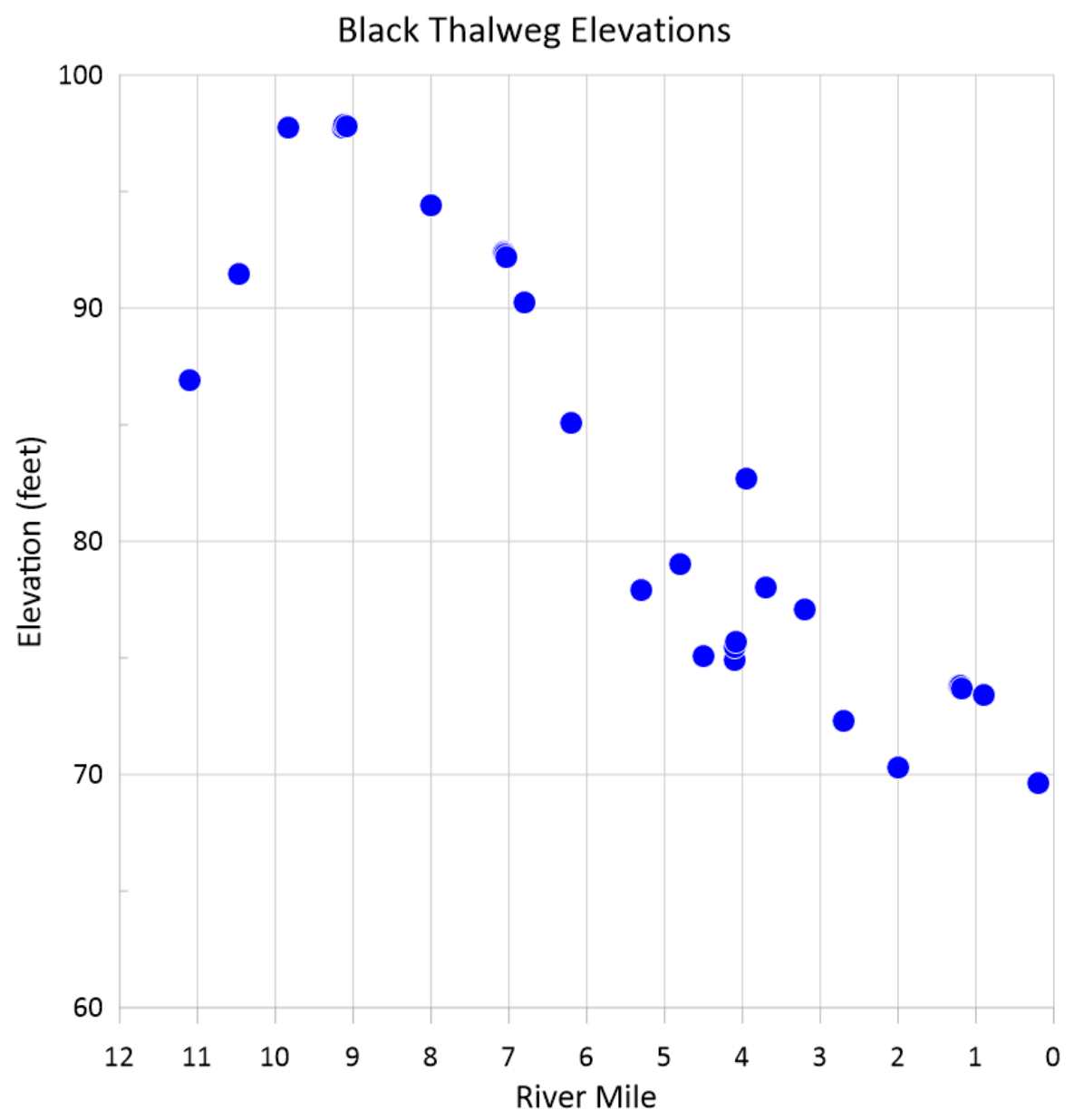

Figure 37. Black River thalweg elevations of HEC-RAS cross-sections.

Table 10. Characteristics of tributary grids.

\begin{tabular}{|l|c|c|c|c|}
\hline Parameter & $\begin{array}{c}\text { South Fork } \\
\text { Chehalis River }\end{array}$ & $\begin{array}{c}\text { Newaukum } \\
\text { River }\end{array}$ & $\begin{array}{c}\text { Skookumchuck } \\
\text { River }\end{array}$ & Black River \\
\hline Grid length & $\begin{array}{c}5.84 \mathrm{miles} \\
(9,399 \mathrm{~m})\end{array}$ & $\begin{array}{c}9.76 \mathrm{miles} \\
(15,707 \mathrm{~m})\end{array}$ & $\begin{array}{c}21.77 \mathrm{miles} \\
(35,036 \mathrm{~m})\end{array}$ & $\begin{array}{c}10.87 \\
\text { miles, } \\
(17,498 \mathrm{~m})\end{array}$ \\
\hline $\begin{array}{l}\text { Number of active } \\
\text { segments }\end{array}$ & 37 & 90 & 155 & 62 \\
\hline $\begin{array}{l}\text { Longitudinal grid } \\
\text { spacing }\end{array}$ & $254.02 \mathrm{~m}$ & $174.52 \mathrm{~m}$ & $226.04 \mathrm{~m}$ & $282.22 \mathrm{~m}$ \\
\hline $\begin{array}{l}\text { Number of } \\
\text { branches/waterbodies }\end{array}$ & $1 / 1$ & $2 / 1$ & $1 / 1$ & $1 / 1$ \\
\hline Vertical layer thickness & $1 \mathrm{~m}$ & $1 \mathrm{~m}$ & $1 \mathrm{~m}$ & $1 \mathrm{~m}$ \\
\hline
\end{tabular}




\section{Tributary Boundary Conditions}

Data from a number of gages in the Upper Chehalis Basin (Figure 2) were available, including flow and temperature data useful for this project for calibration. In many cases, though, the location of the gages and time of their deployment meant that when temperature data were available, flow data were not and vice versa.

The upstream boundary conditions for flow rate and temperature for the South Fork Chehalis, Newaukum, Skookumchuck, and Black Rivers were absent in most cases. Hence, we tried to estimate upstream conditions when they were missing by using downstream data to infer upstream conditions or by using data from above the upstream model boundary. This meant that the model calibrations for the rivers over three years were largely approximate since detailed boundary conditions were usually not available.

Flow

Where flow data from more than one gage were available for a tributary, the furthest downstream data were used for flow calibration and upstream data were used for the upstream boundary condition. Where flow data were only available from one gage (usually near the mouth of the Lower Chehalis mainstem), those data were used for both calibration and the upstream boundary condition.

\section{South Fork Chehalis}

There are a number of tributaries of the South Fork Chehalis River between the USGS 12020800 gage at river mile 16.2 and the WSDOE 23K060 gage at river mile 0.1 near the confluence of the South Fork Chehalis with the mainstem Chehalis 
River. Because these tributaries are not gaged and their catchments are not wellcharacterized, their flow was estimated using a single distributed tributary that added flow to each of the model segments scaled to the segment's surface area. The distributed tributary flow was the difference between the modeled flow without a distributed tributary and the estimated flow at the end of the model before entering the Chehalis mainstem. Flow at the confluence was estimated using a regression of flow data from WSDOE gage 23K060 to flow data from the USGS gage at Doty (USGS 12020000).

Different rating tables appear to have been used for the Ecology 23K060 data before and after water year 2017 (Figure 38). A considerable amount of these data also had QC flags indicating that they are outside the range of the gage's rating table. Three flow estimates were created using Doty data with subsets of the 23K060 data: all available data, all data tagged with either "Good quality REVIEWED data" or "Good quality provisional data", and all data from the 2018 water year onward termed "late" data (see Figure 39). These flow estimates (using the "late" data) were used during the calibration to assess model performance near the mouth.

The estimated flow rate used in the South Fork model upstream boundary was from USGS 12020800 gage at river mile 16.2 and is shown in Figure 40. 


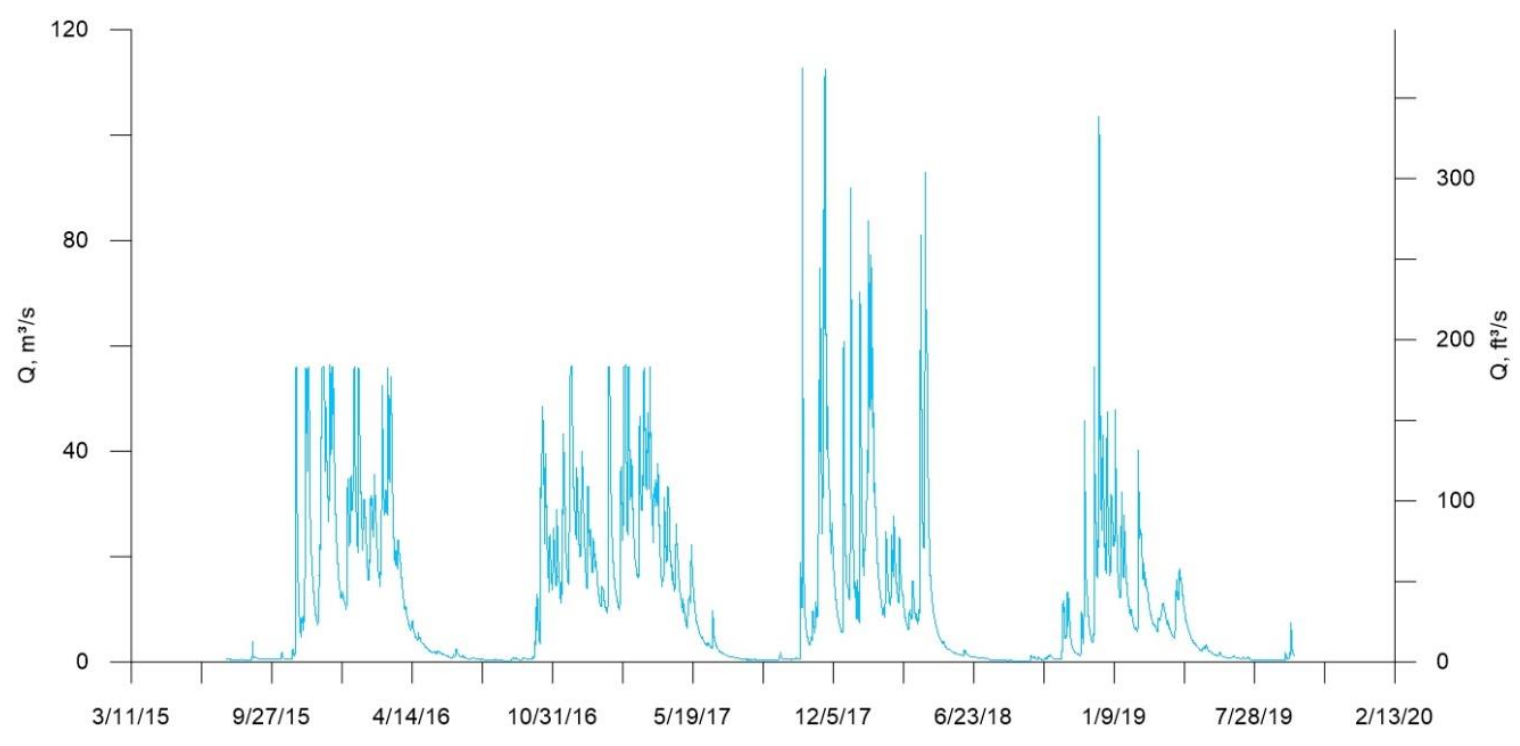

Figure 38. Flow data from WADOE 23K060 gage on the South Fork Chehalis River at Highway 6 showing difference before and after the end of 2017 water year.

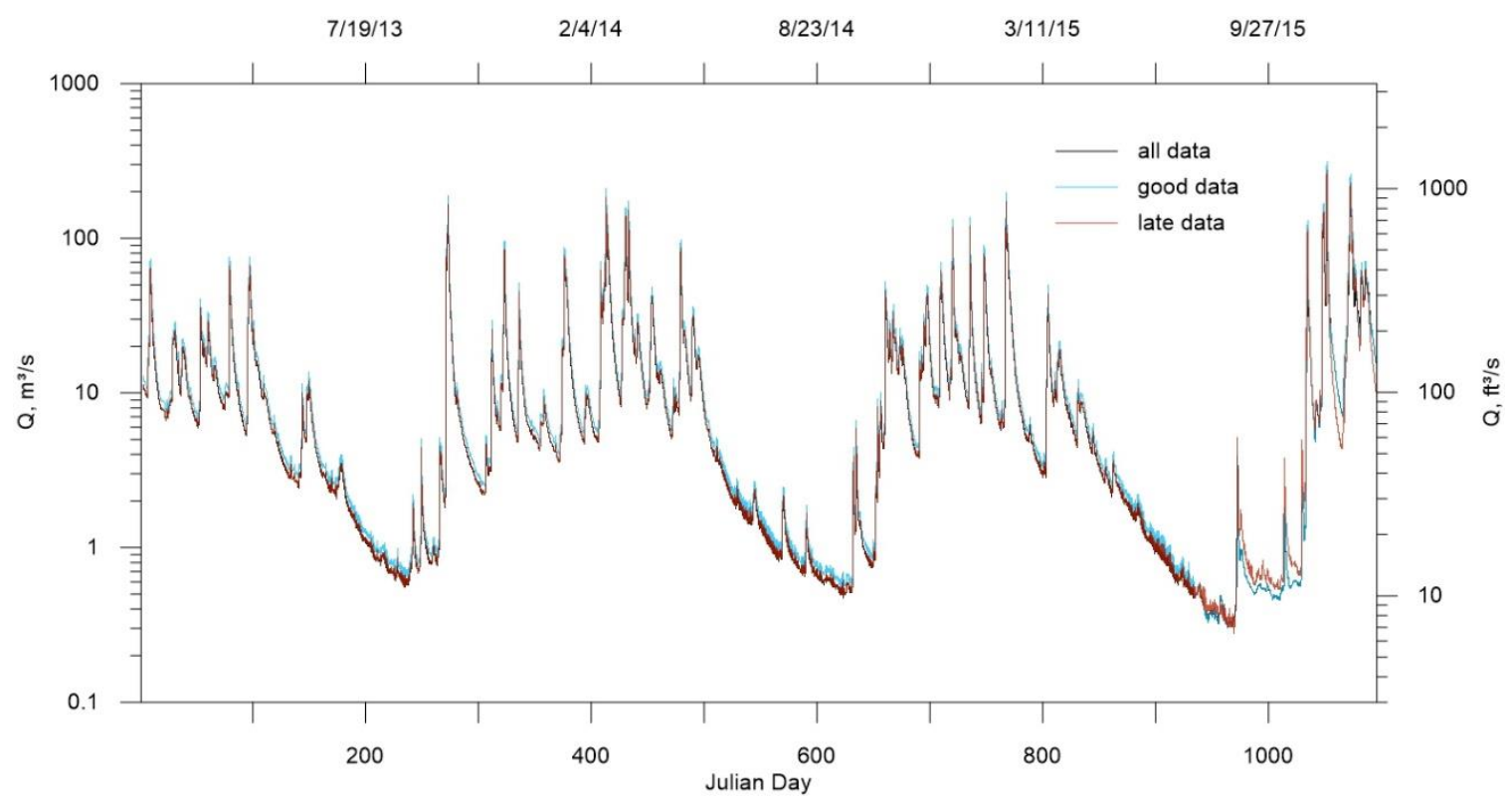

Figure 39. South Fork Chehalis River flow estimates at Ecology 23 K060 gage showing regressions to fill in data gaps. Regressions used all the data (all data), those data that passed quality control (good data), or only 2018 and 2019 data (late data). 


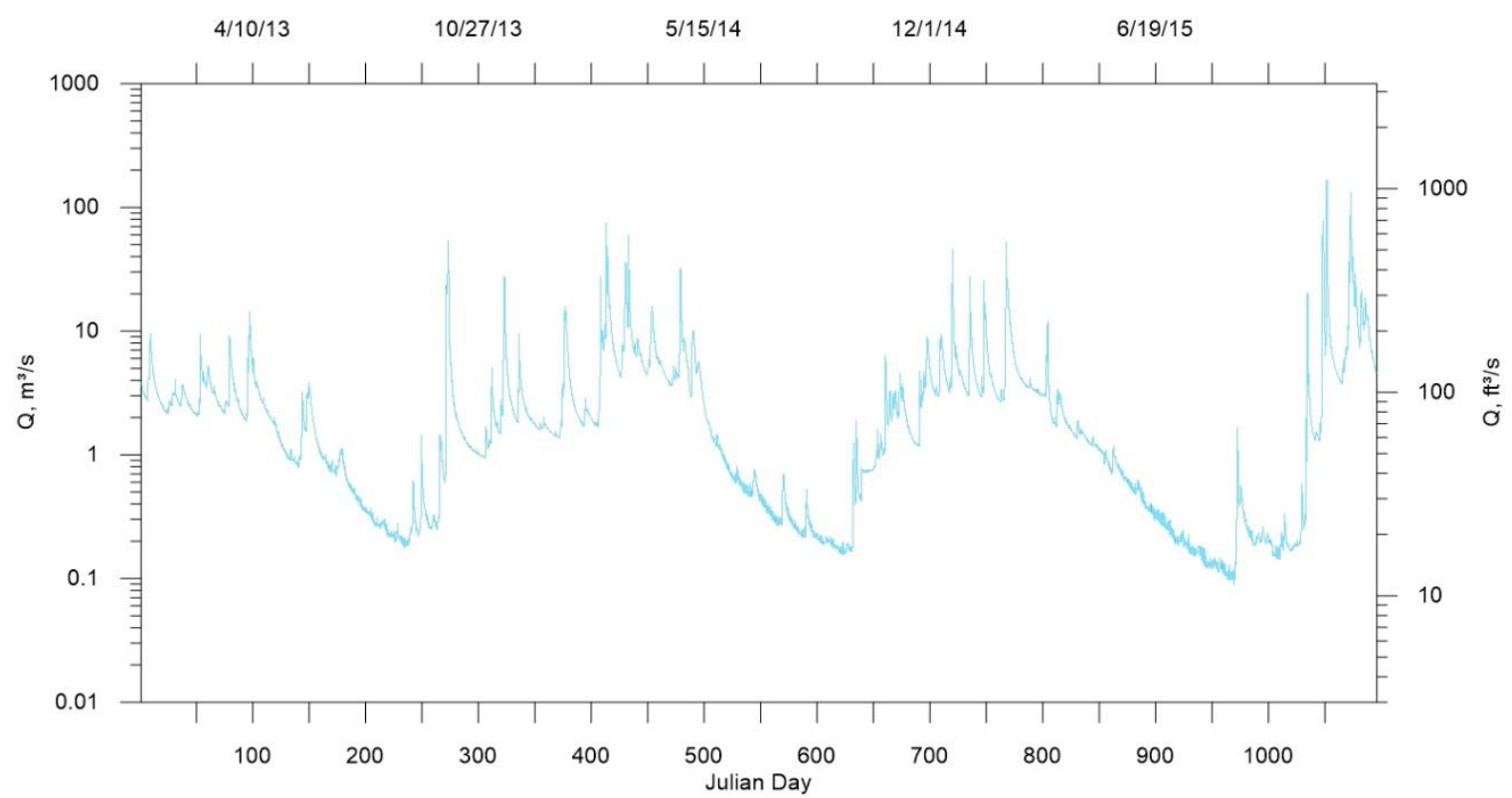

Figure 40. Estimated South Fork Chehalis River flow rates at upper boundary of model for 2013-2015.

\section{Newaukum River}

The USGS 12025000 gage is at river mile 4.1 in model segment 54. There are additional USGS gages in the North Fork Newaukum River (river mile 7.7) and South Fork Newaukum River (river mile 22.8). These are too far upstream from both the fork at Newaukum river mile 10.9 and the upstream end of the model at Newaukum river mile 9.76 to be used for an upstream boundary condition. The estimated flow rate used in the Newaukum model upstream boundary is shown in Figure 41 which is based on the USGS gage at RM 4.1 with data gaps filled by regression. 


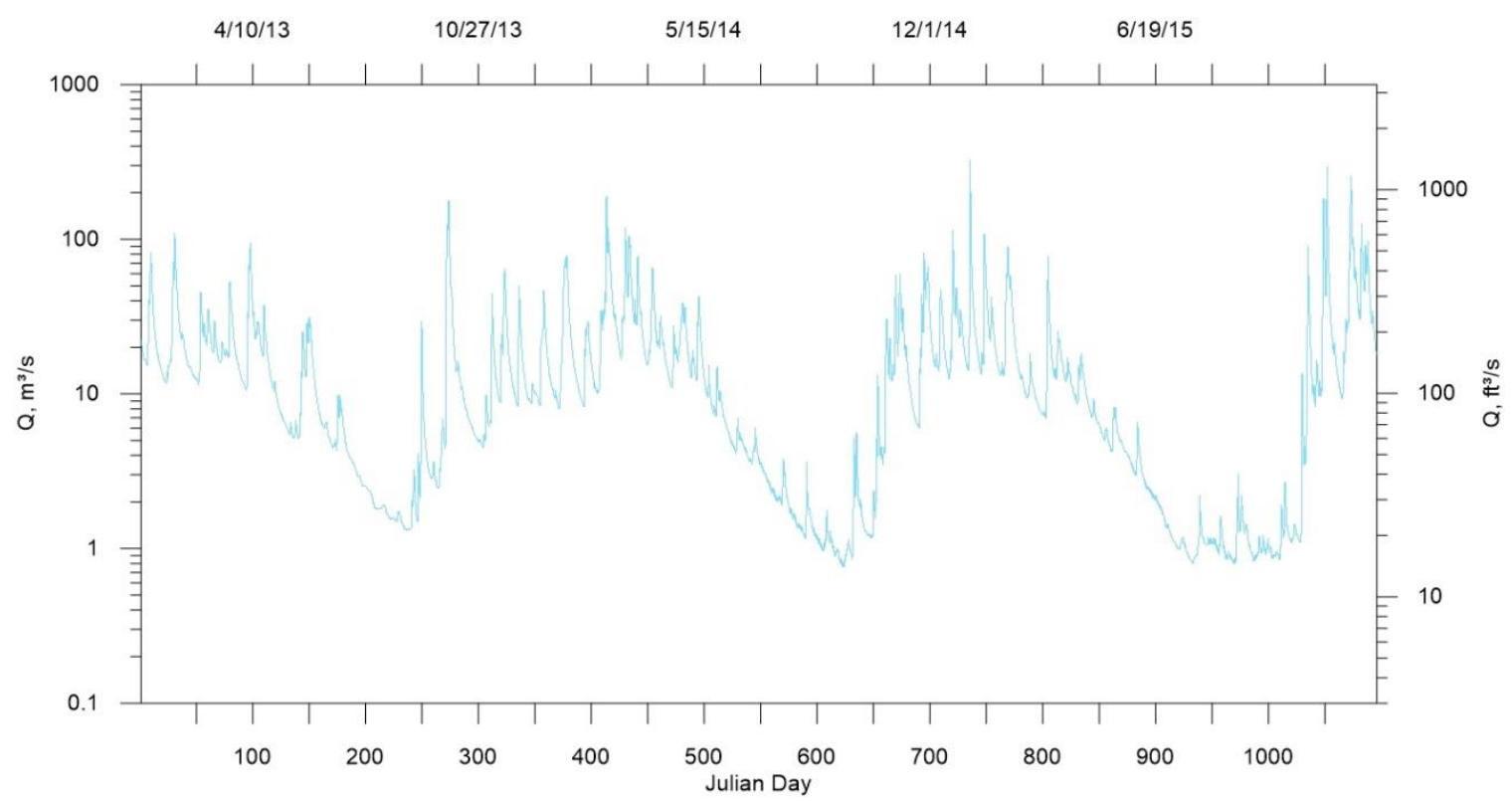

Figure 41. Estimated Newaukum River flow rates at upper bounday of model for 2013-2015.

\section{Skookumchuck River}

The USGS 12026400 gage is at river mile 6.4 in model segment 111. USGS 12026150 is at river mile 20.7 in model segment 9, about one mile downstream from the upstream end of the model. The estimated flow rate used in the Skookumchuck model upstream boundary is based on USGS 12026150 at RM 20.7 and is shown in Figure 42 with data gaps filled by regression. 


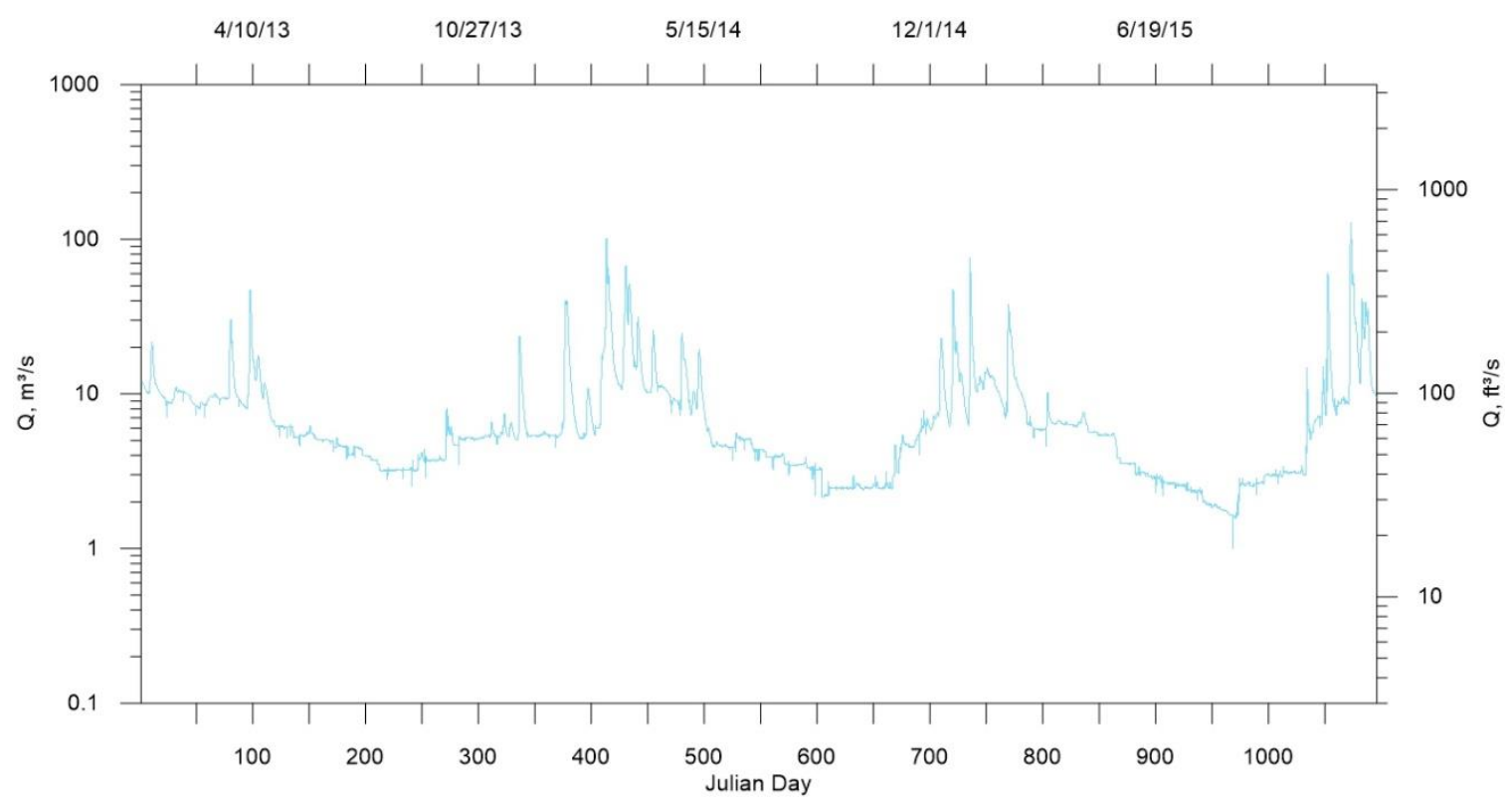

Figure 42. Estimated Skookumchuck River flow rates at upper boundary of model between 2013-2015.

\section{Black River}

The WADOE 23E060 gage is at river mile 2.0 in model segment 53 . No flow data from the 2014 water year was available from this gage. This data gap was filled in using a regression to USGS 12027500 on the mainstem Chehalis River near Grand Mound. The estimated flow rate used in the Black River model upstream boundary is shown in Figure 43 and is the WADOE 23E060 gage with data gaps filled by regression. 


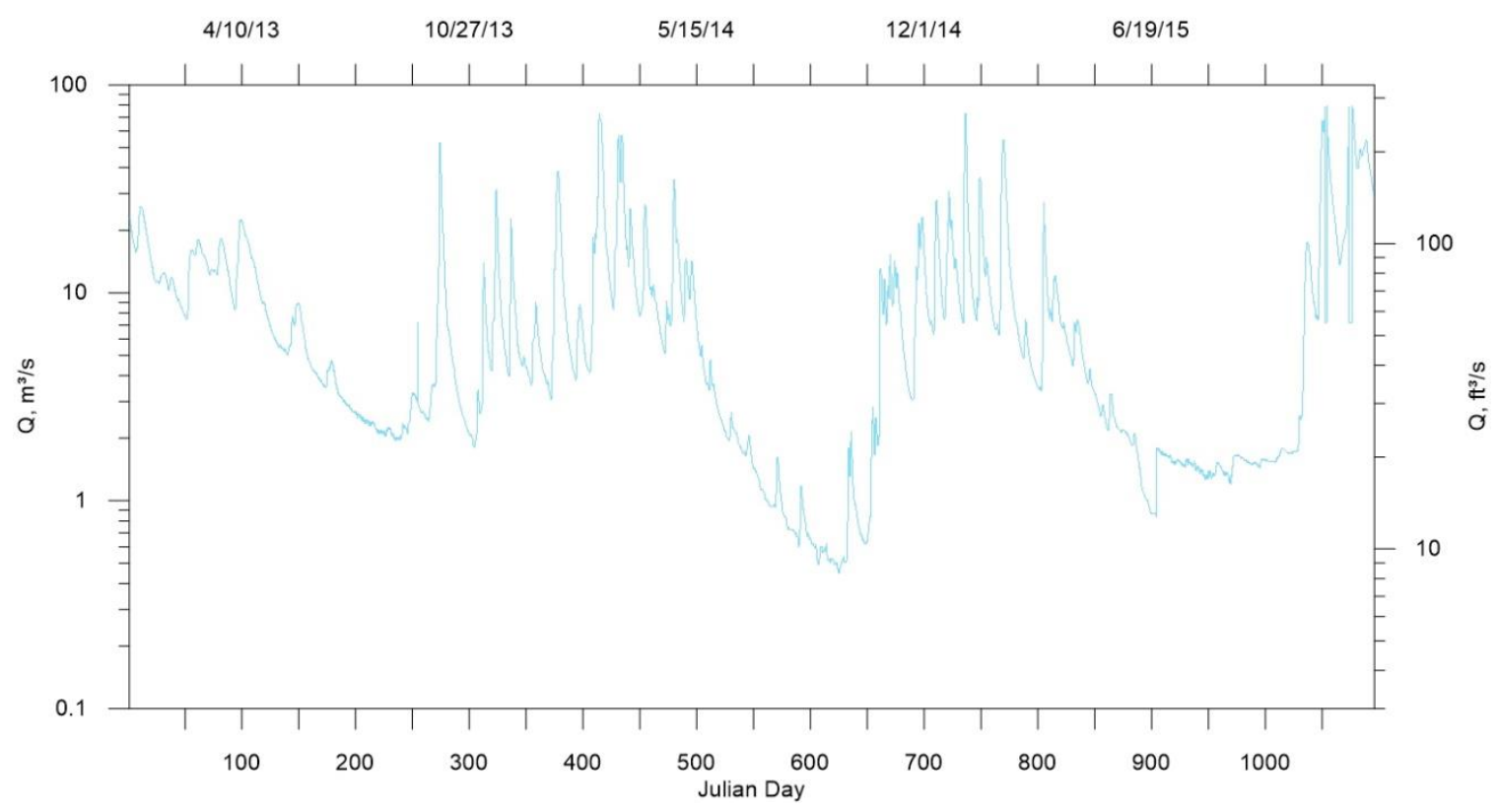

Figure 43. Estimated Black River flow rates at upper boundary of model between 2013-2015.

\section{Temperature}

No direct measurements of water temperature at the upstream boundary were available for any of the tributaries for the 2013-2015 time period. What temperature data did exist did not cover the entire model period. Hence, we explored using nearby field data, using in-model domain temperatures, and using a synthetic approach based on the meteorological data. We attempted to develop synthetic input temperatures based on a filtered equilibrium approach of Adams and Wells (1984). This technique is shown in Appendix A. But this technique usually needs some field data to assess its efficacy. An example of this approach using 30, 60 and 90-day averages of the filtered equilibrium temperature are shown in Figure 44. The averaging period reflected the weighted average of the meteorological data, meaning stream temperature memory extended back in time over the weighted averaging period. These often were inadequate to predict downstream 
temperatures accurately. Hence, in some cases, when available, field data measured near the downstream boundaries were used for the upstream boundary when available.

The next sections show the available field data and the temperatures used for the upper boundary for each tributary.



Figure 44. Filtered equilibrium temperature at 30, 60 and 90 day averaging period using meterological data from the Chehalis River model.

\section{South Fork Chehalis River}

There were temperature data from both WDFW and WADOE gages on the South Fork Chehalis River. The WDFW SFCHEH-2 gage was closest to the upstream model boundary. The location of temperature sampling locations on the South Fork is shown in Figure 45. The data available from this gage overlapped with the model period from 30 April 2015 to 31 December 2015 and are shown in Figure 46. 
The final estimated upstream temperatures were the data collected nearest the upstream boundary (for 2015 WDFW SFCHEH-2 gage and for parts of 2013-2014 WADOE gage nearer the mouth) with data gaps filled in using 90-day filtered equilibrium temperatures and are shown in Figure 47.

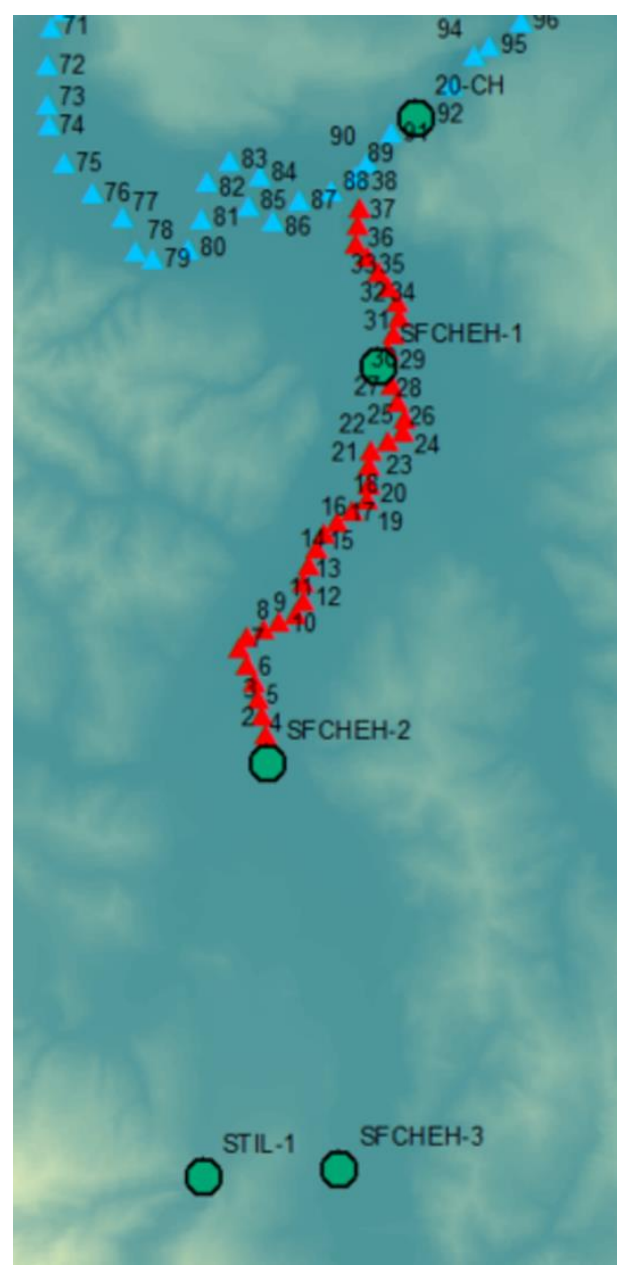

Figure 45. Temperature sampling locations in the South Fork River. Red triangles are model segments in the South Fork model. Blue triangles are model segments in the lower Chehalis River mainstem model. 


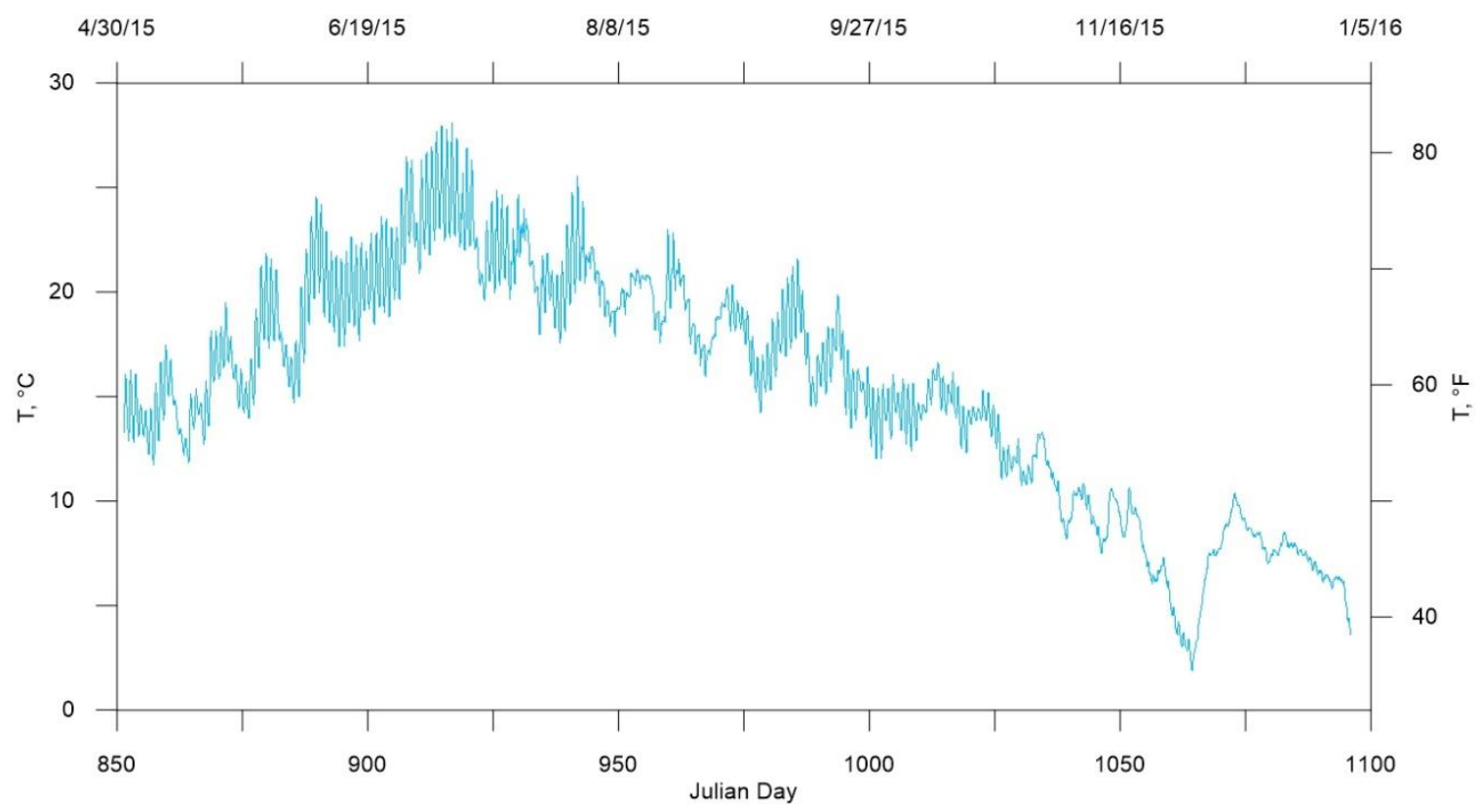

Figure 46. Temperature at SFCHEH-2 on the South Fork Chehalis River.

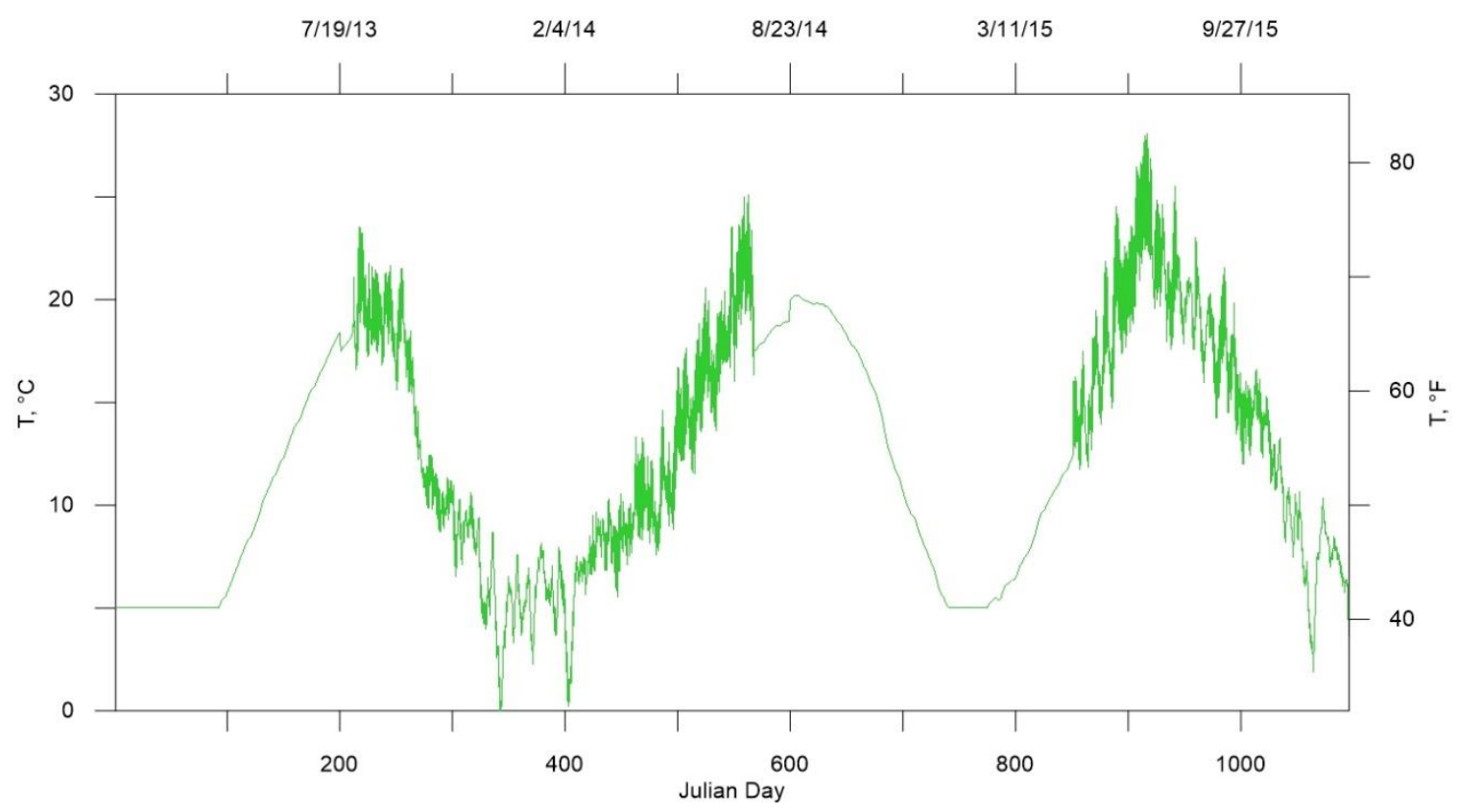

Figure 47. Estimated upstream temperature boundary condition for the South Fork Chehalis River between 2013-2015.

\section{Newaukum River}

There were several temperature monitoring locations at different time periods in the Newaukum River as shown in Figure 48. The WDFW NEW-1 gage is in model 
segment 60 and field data existed between August 2014 through fall of 2015 (see Figure 49). NWK-MOUTH is in model segment 92 and data were available between the summer of 2013 and the summer of 2014 (see Figure 49). Also, there were upstream temperature data at NFNEW2.

The final estimated upstream temperatures were NFNEW-2 data where it existed filled in with NWK-MOUTH data (gaps in this time series were filled in using a regression to Darigold temperatures from the mainstem) and are shown in Figure 50.

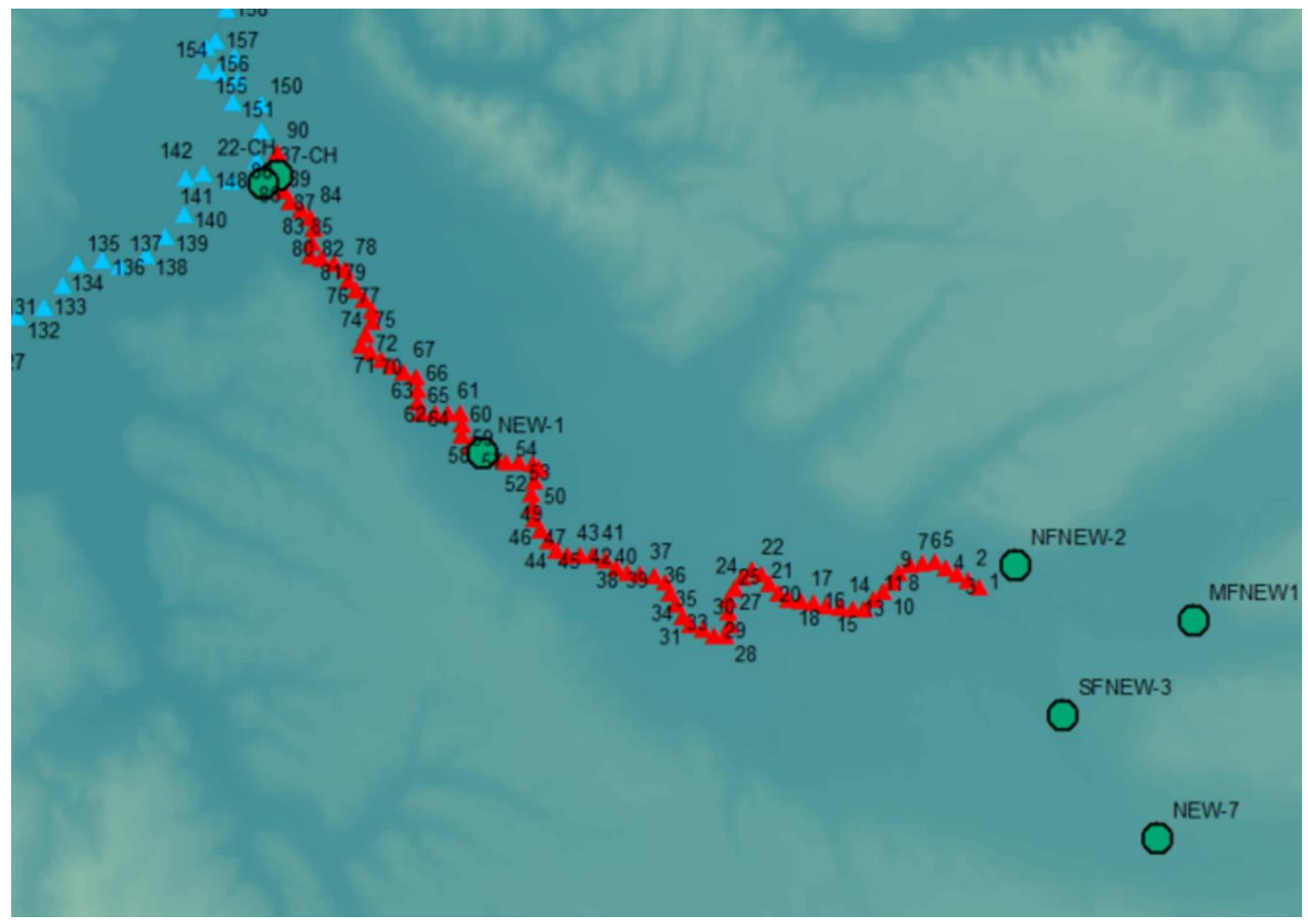

Figure 48. Temperature sampling stations (green dots) along the Newaukum River. Red triangles are model segments in the Newaukum model. Blue triangles are model segments in the lower Chehlis River mainstem model. 


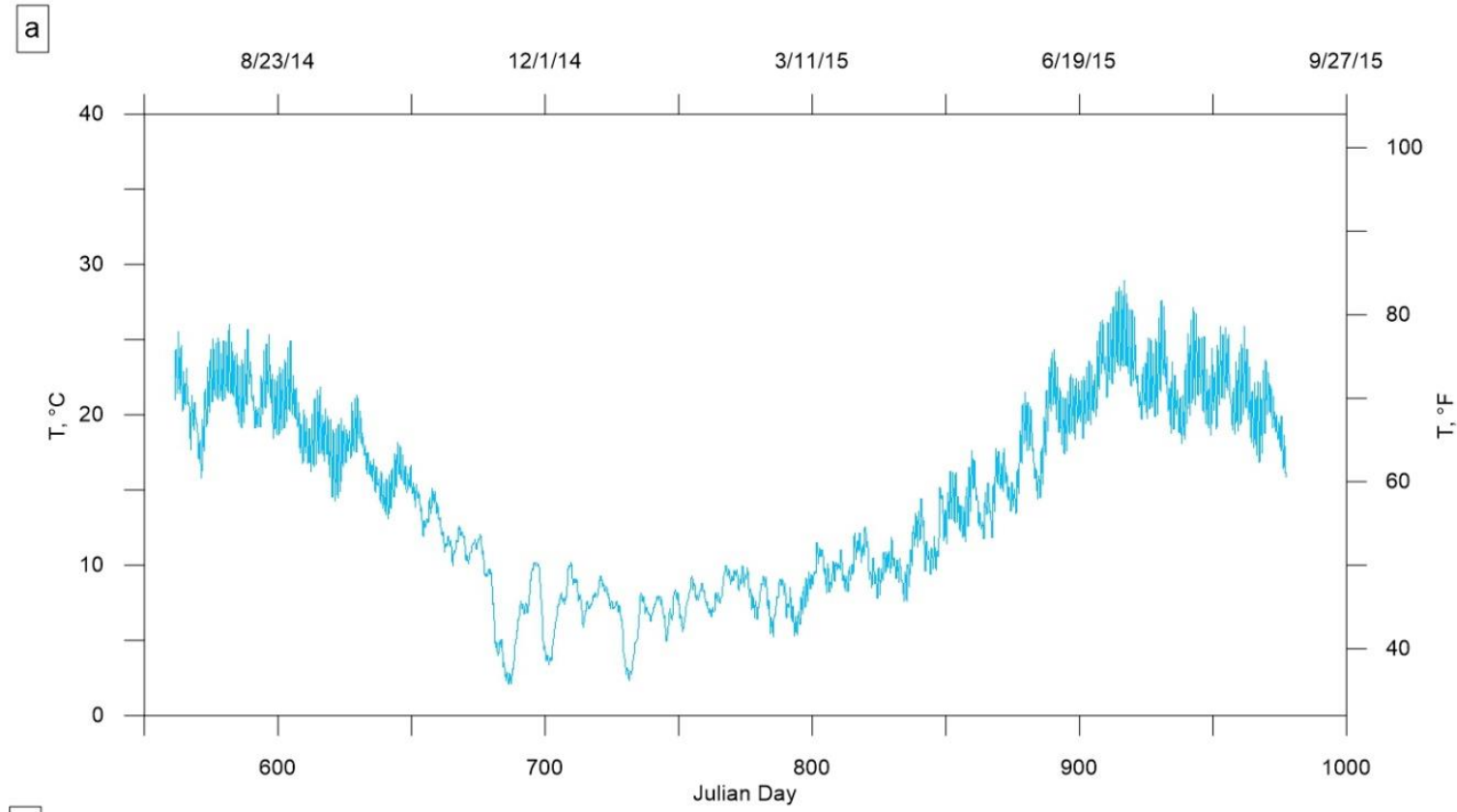

$\mathrm{b}$

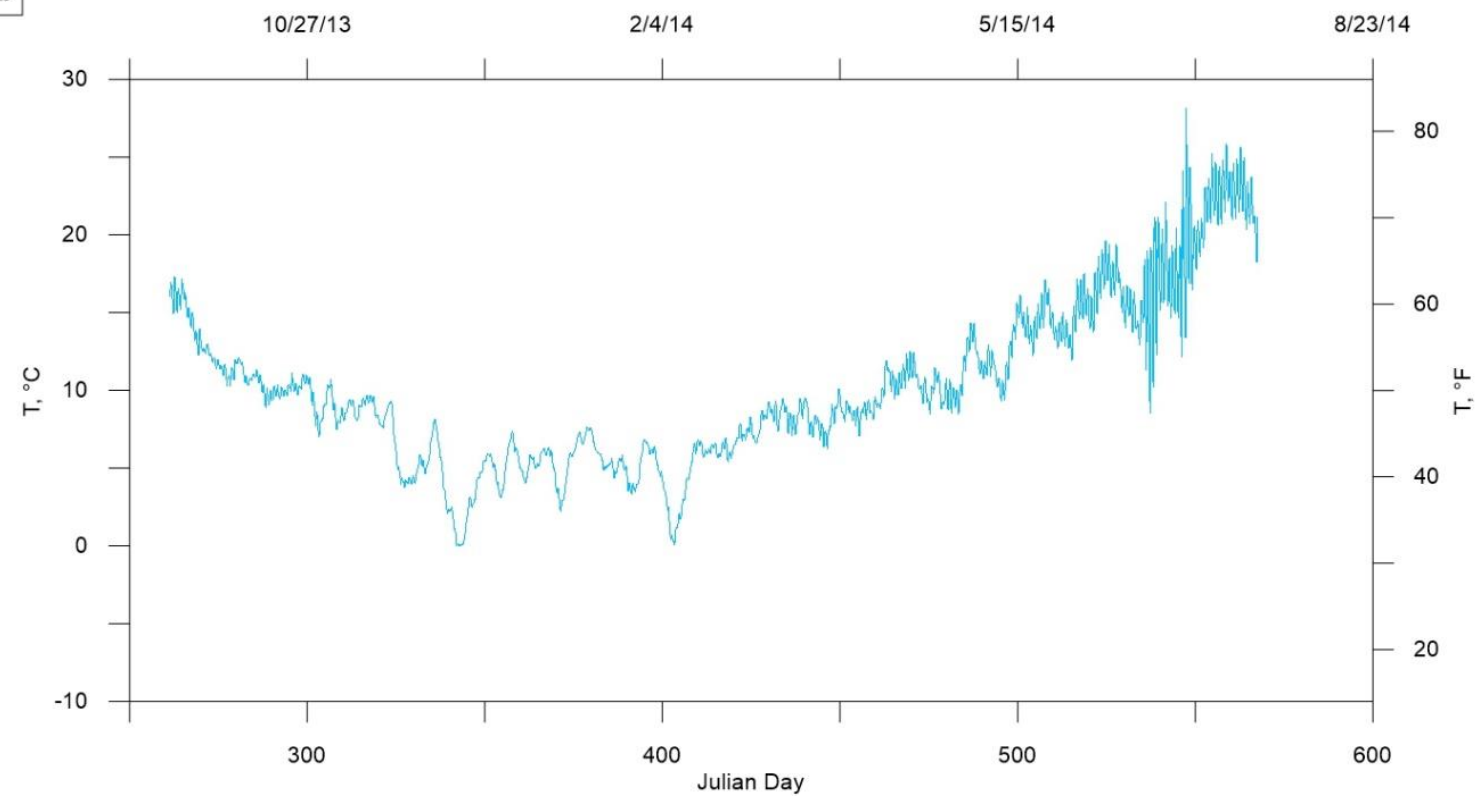

Figure 49. Temperature in the Newaukum River at NEW-1, model segment 60 and NWK-MOUTH, model segment 92. 


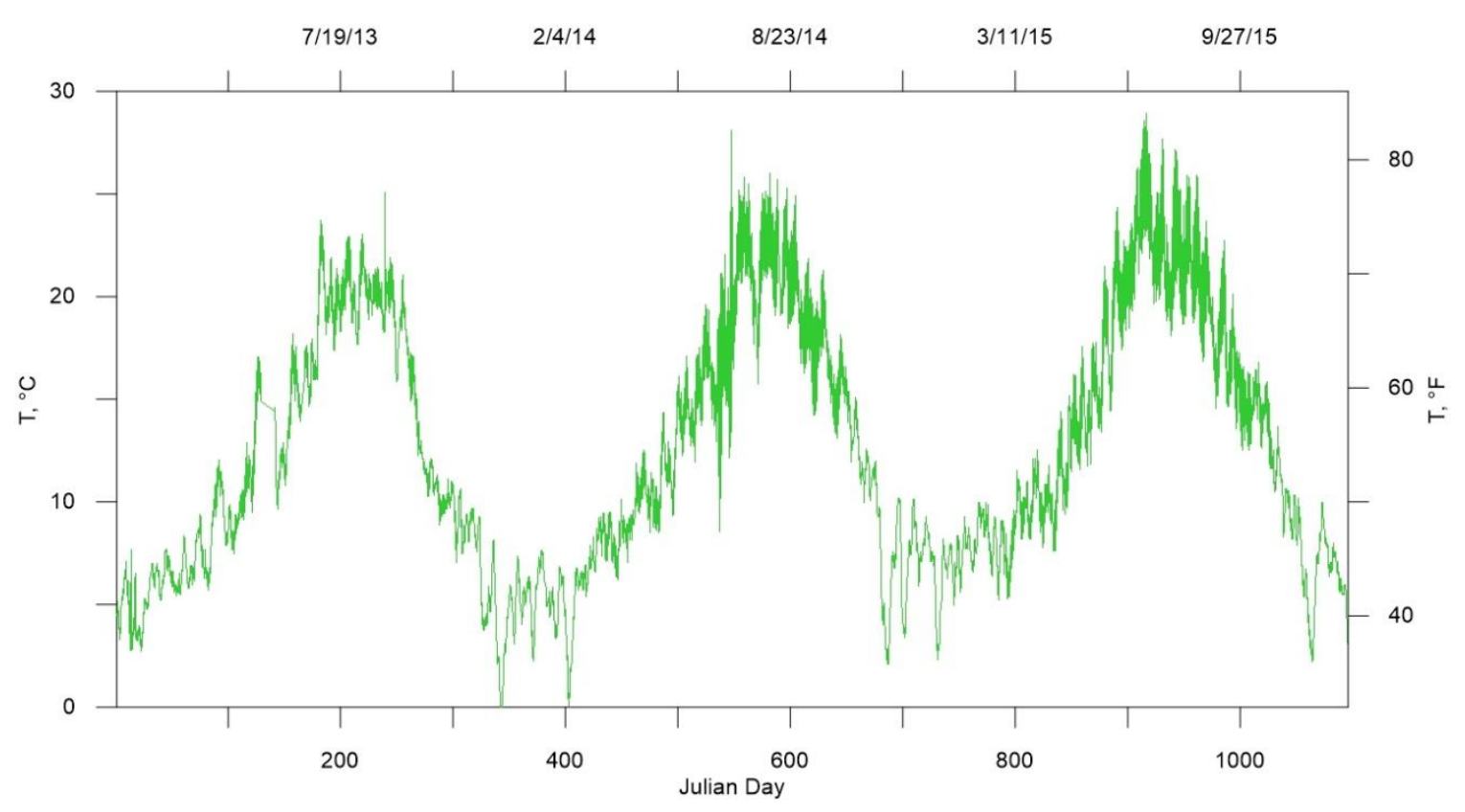

Figure 50. Estimated temperature used for Newaukum River upstream boundary condition between 2013-2015.

\section{Skookumchuck River}

There were 3 sets of temperature data in the model domain for the Skookumchuck River from WDFW gages: SKOOK-1 near model segment 124 measured between May 2015 to October 2015, SKOOK-2 near model segment 78 measured between May 2015 and October 2015, and SKOOK-3 near model segment 24 measured between May 2015 to December 2015 (Figure 51). These temperature data are shown in Figure 52.

The final estimated upstream temperatures were the data collected nearest the upstream boundary with data gaps filled using 90-day filtered equilibrium temperatures and are shown in Figure 53. 


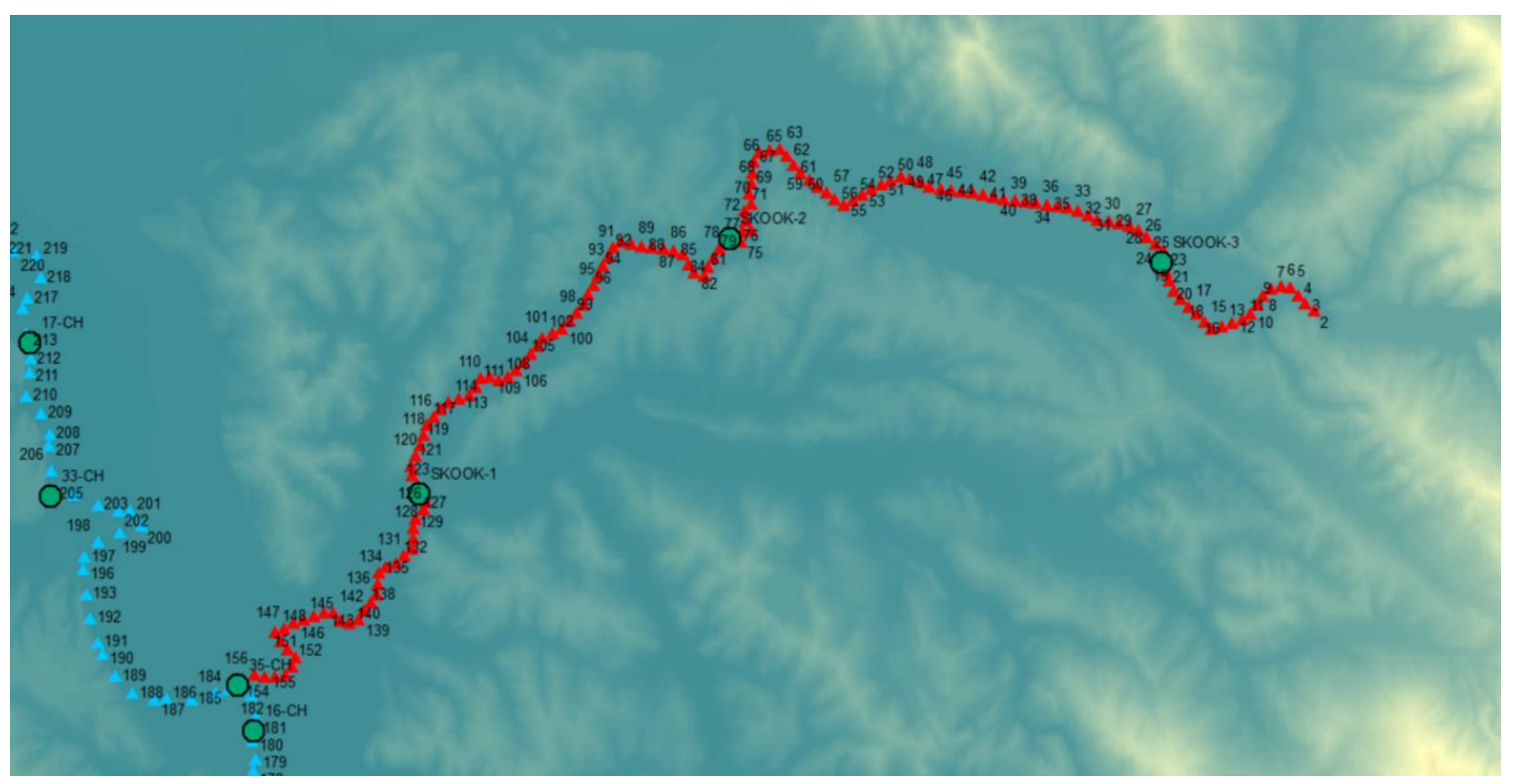

Figure 51. Temperature sampling stations (green dots) along the Skookumchuck River. Red triangles are model segments in the Skookumchuck model. Blue triangles are model segments in the lower Chehalis River mainstem model. 


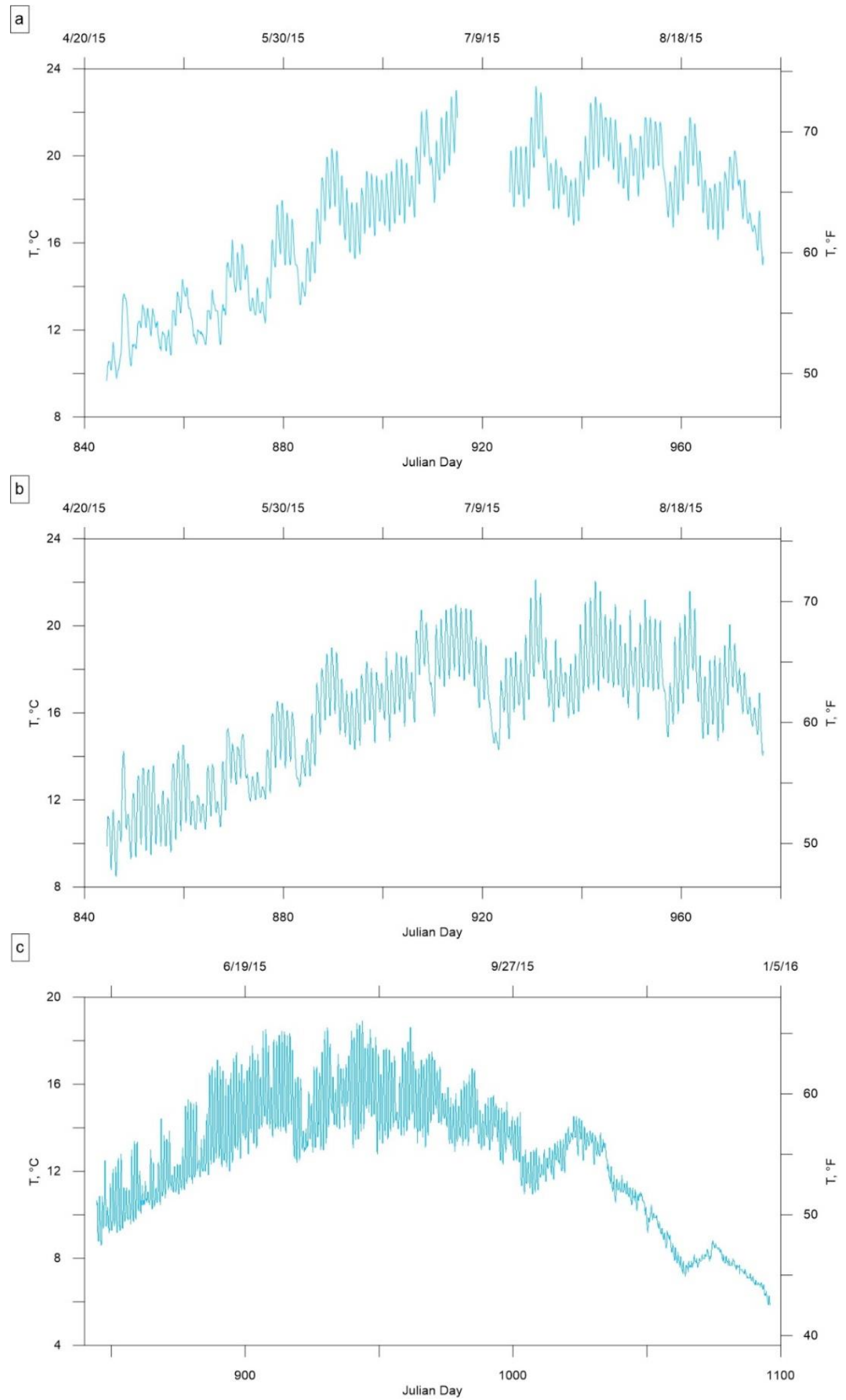

Figure 52. Skookumchuck River WDFW temperature data from (a) SKOOK-1, (b) SKOOK-2, and (c) SKOOK-3. 


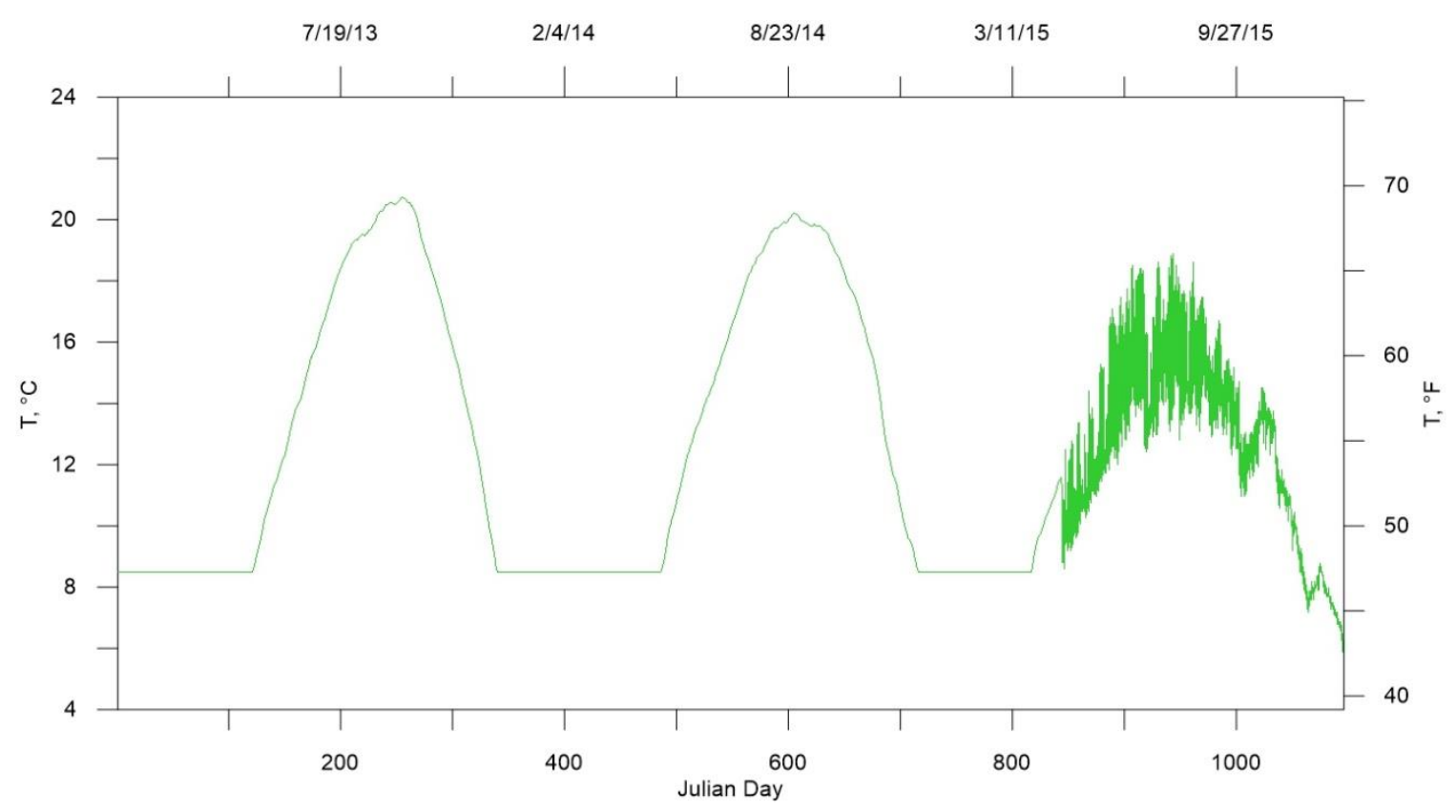

Figure 53. Estimated upstream temperature boundary condition for the Skookumchuck River between 2013-2015.

\section{Black River}

There were 2 sets of temperature data for the Black River: WDFW BLACK-1 in model segment 53 between July 2014 and December 2014 and between May 2015 to August 2015; and BLACK-2 at model segment 21 between May 2015 and October 2015. The locations of these gages are shown in Figure 54, and the temperature field data are shown in Figure 55.

The estimated upstream temperatures for the Black River were the data collected nearest the upstream boundary with data gaps were filled in using 60-day filtered equilibrium temperatures and are shown in Figure 56. 


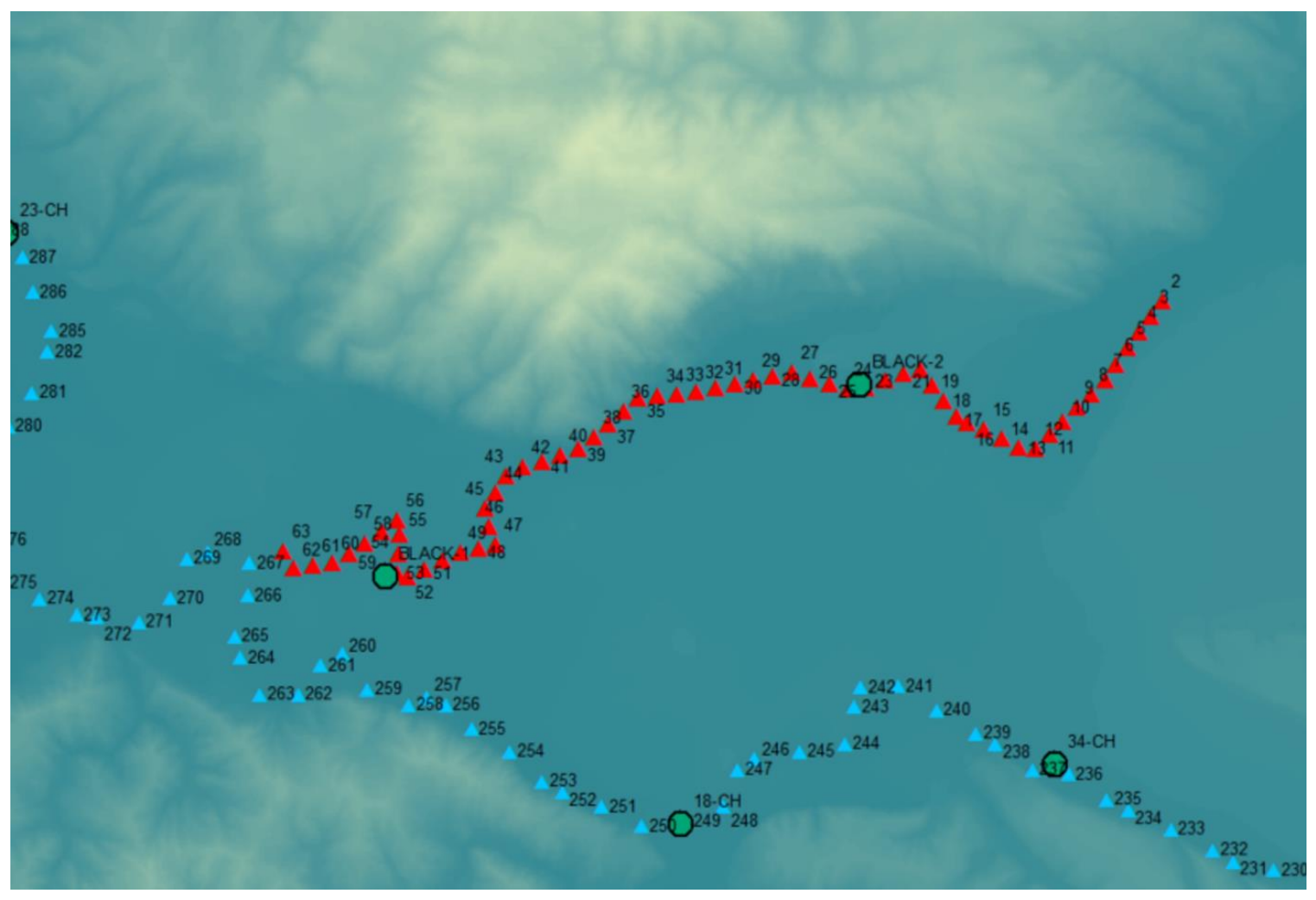

Figure 54. Location of temperature measuring locations (green dots) BLACK-1 and BLACK-2 on the Black River. Model segments are in light blue for the lower Chehalis River model and red for the Black River model. 
a

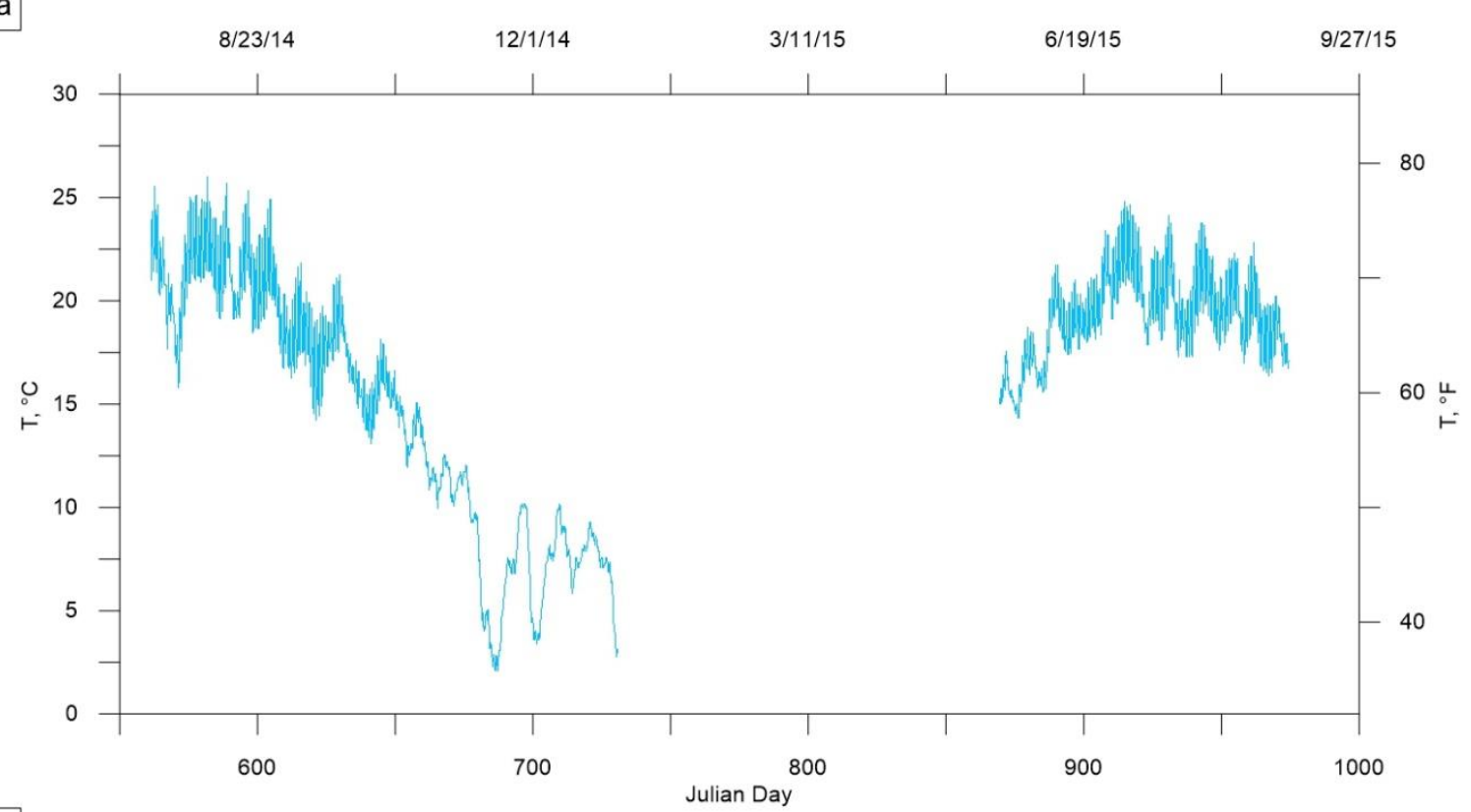

b

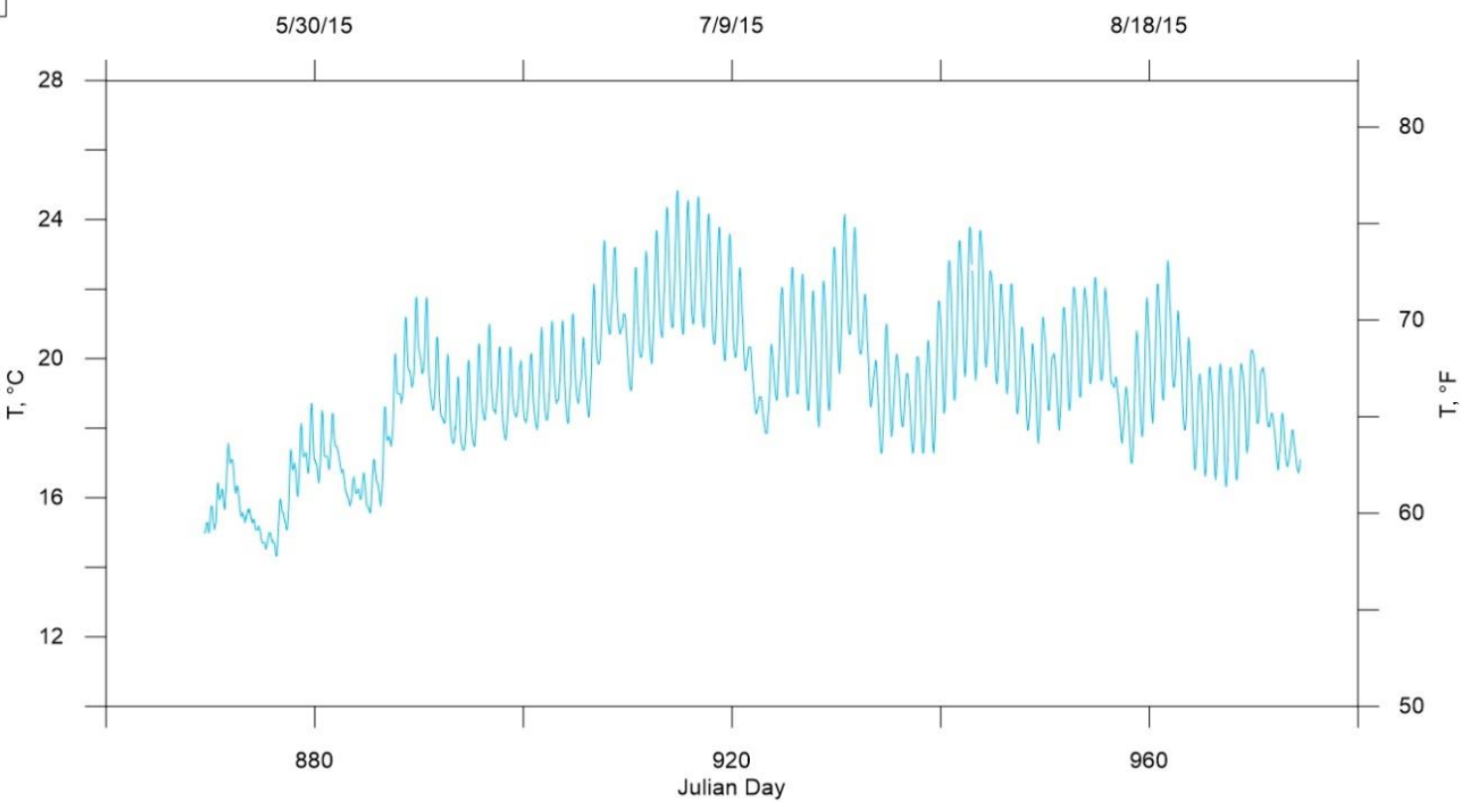

Figure 55. Black River WDFW temperature data from (a) BLACK-1 and (b) BLACK-2. 


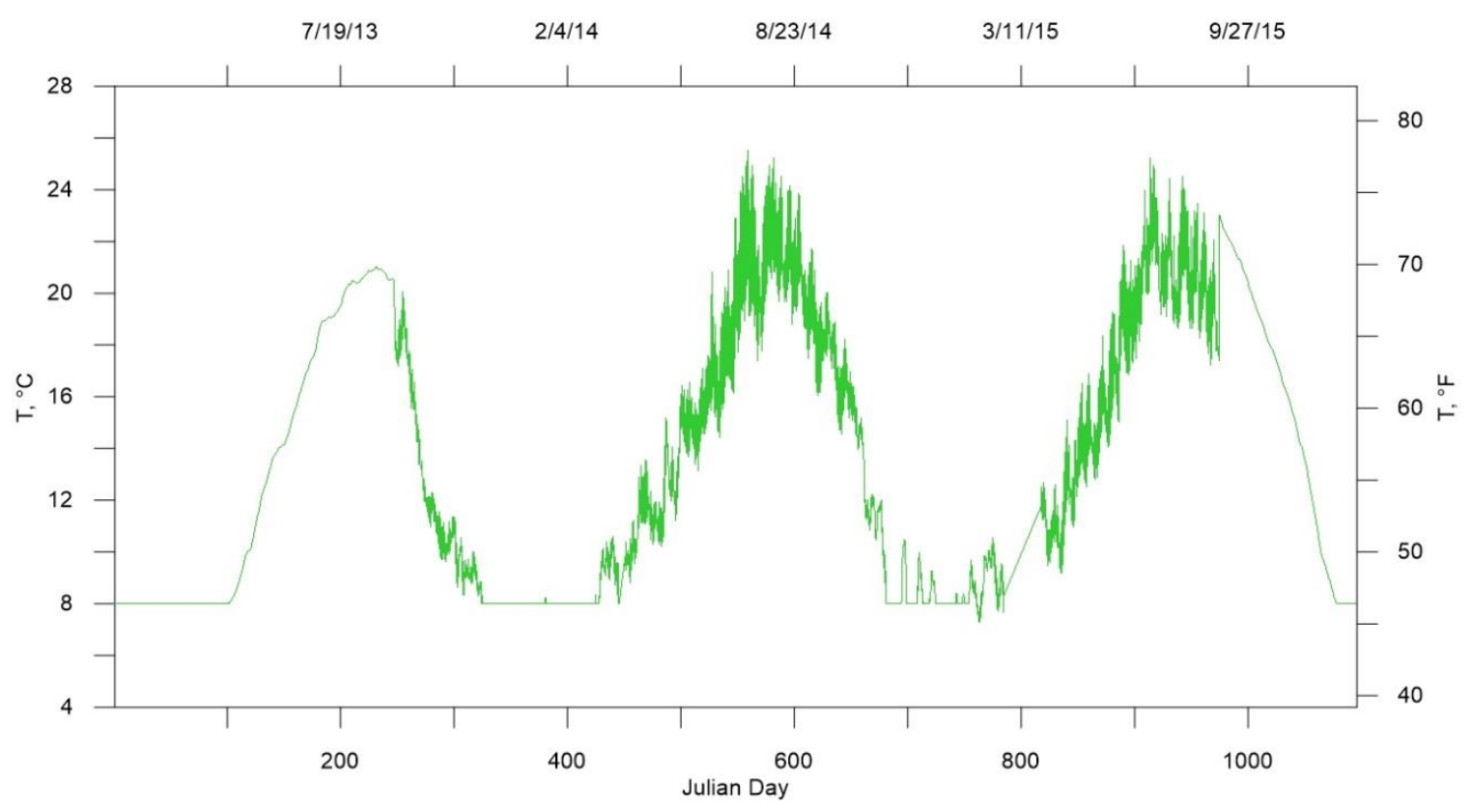

Figure 56. Estimated upstream temperature boundary condition for the Black River between 20132015. 


\section{Model calibration for 2013-2015}

Following the work of Van Glubt et al. (2017), the model calibration was assessed by evaluating the errors between model predictions and field data. Appendix $\mathrm{C}$ shows the definitions of the error statistics used in these model-data comparisons. Modeldata comparisons were made for flow rate, water level, temperature, and water quality for the Chehalis mainstem. For the tributary models (South Fork Chehalis, Newaukum, Skookumchuck, and Black Rivers), only model-data flow rate and temperature comparisons were made.

Also, a new version of CE-QUAL-W2 was used (Version 4.2), that allowed for a reduction in model run times by up to $90 \%$. This required splitting the 9 waterbodies in the model into separate directories as shown in Figure 57. Running the model for temperature for 3 years used to take about 250 min of time, but with the new version this was reduced to about $25 \mathrm{~min}$. Similar reductions were noted running water quality simulations, even though it still took a working day to complete a full water quality run for the 3 year period. A description of this process is shown in Appendix D. 
- Convert 1 model to multiple WB models

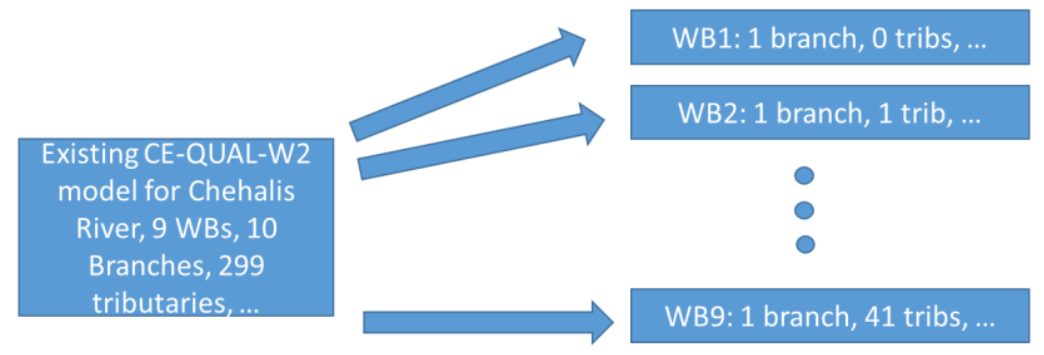

- Debug each WB by using preprocessor to check for errors

- Note: each WB must have a downstream spillway or gate to pass $Q, T$, and $C$ to the downstream WB

Figure 57. Using the new CE-QUAL-W2 model framework for running the Chehalis River model.

Flow rate

In general, the model calibration for flow rate followed this approach: using

estimated upstream boundary flow rates, the model predicted flow at a downstream

gaging station was compared to field data. The error in flow was ascribed to

distributed flows (either positive or negative) between the gage locations. This

distributed flow was then added back to the model to match flow rate field data.

\section{South Fork Chehalis River}

In Figure 58, the model predicted flow rate of the South Fork Chehalis River near the mainstem of the Chehalis was compared to flow estimated based on a regression with field data in 2018 and 2019 (termed the "late" data). The flow rate error statistics at South Fork are shown in Table 11.

Table 11. Flow rate error statistics (see Appendix C) of field data compared to model predictions at model segment 38 at South Fork Chehalis River near the mainstem Chehalis.

\begin{tabular}{|c|c|c|c|}
\hline Count & $\mathrm{ME}, \mathrm{m}^{3} / \mathrm{s}$ & $\mathrm{AME}, \mathrm{m}^{3} / \mathrm{s}$ & $\mathrm{RMS}, \mathrm{m}^{3} / \mathrm{s}$ \\
\hline 104700 & -0.0003 & 0.651 & 2.696 \\
\hline
\end{tabular}




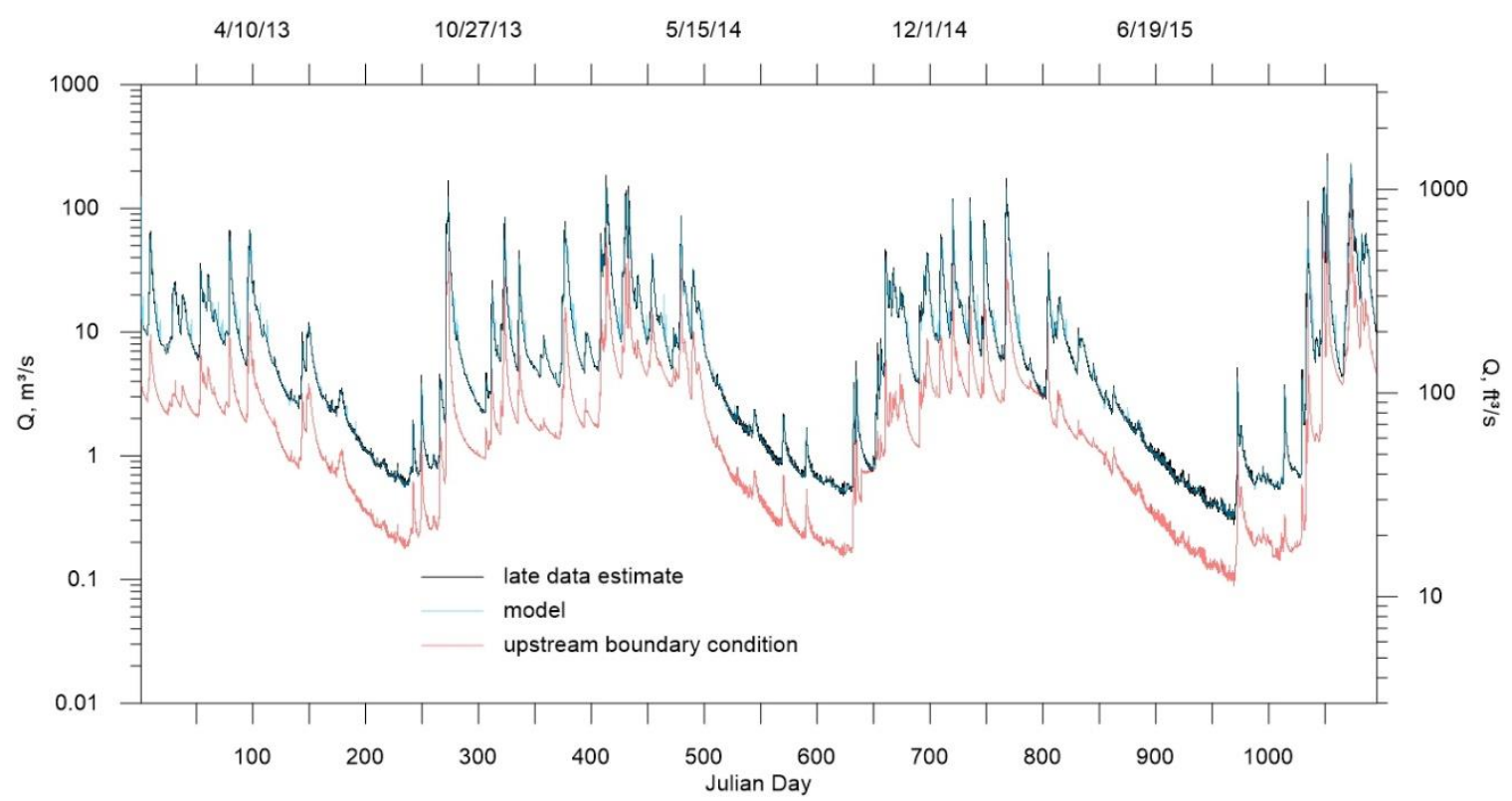

Figure 58. Flow rate comparison between linear regression flow estimate, upstream flow boundary condition, and model predictions for South Fork Chehalis River near the Chehalis mainstem.

Newaukum River

The model predicted flow rate in the Newaukum River near the confluence with the mainstem of the lower Chehalis River was compared to field data in Figure 59. The flow rate error statistics at model segment 93 are shown in Table 12.

Table 12. Flow rate error statistics (see Appendix C) of field data compared to model predictions at model segment 93 at Newaukum River near the mainstem Chehalis.

\begin{tabular}{|l|r|r|r|}
\hline Count & ME, $\mathrm{m}^{3} / \mathrm{s}$ & $\mathrm{AME}, \mathrm{m}^{3} / \mathrm{s}$ & $\mathrm{RMS}, \mathrm{m}^{3} / \mathrm{s}$ \\
\hline 104122 & -0.070 & 1.520 & 4.555 \\
\hline
\end{tabular}




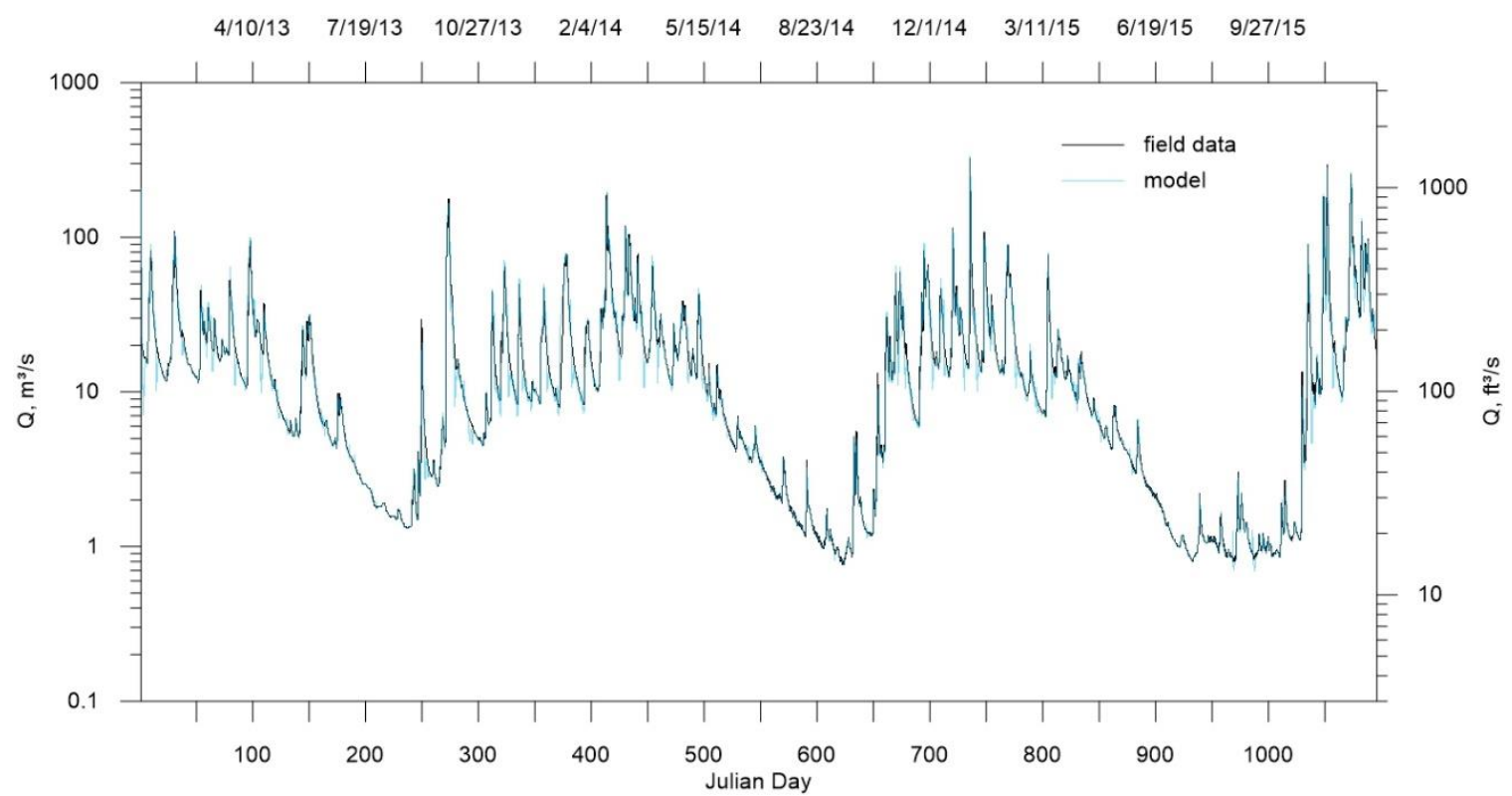

Figure 59. Flow rate comparison between field data and model predictions in the Newaukum River at USGS 12025000. Data from this gage was used for the upstream boundary condition and to compare with model output at segment 54.

Skookumchuck River

The model predicted flow rate at the Skookumchuck River near the mainstem of the

Chehalis was compared to field data in Figure 60. The flow rate error statistics for the

\section{Skookumchuck model are shown in Table 13.}

Table 13. Flow rate error statistics (see Appendix C) of field data compared to model predictions at model segment 111 at Skookumchuck River near the mainstem Chehalis.

\begin{tabular}{|c|r|r|r|}
\hline Count & ME, $\mathrm{m}^{3} / \mathrm{s}$ & \multicolumn{1}{|c|}{ AME, $\mathrm{m}^{3} / \mathrm{s}$} & $\mathrm{RMS}, \mathrm{m}^{3} / \mathrm{s}$ \\
\hline 87493 & 0.180 & 0.768 & 3.104 \\
\hline
\end{tabular}




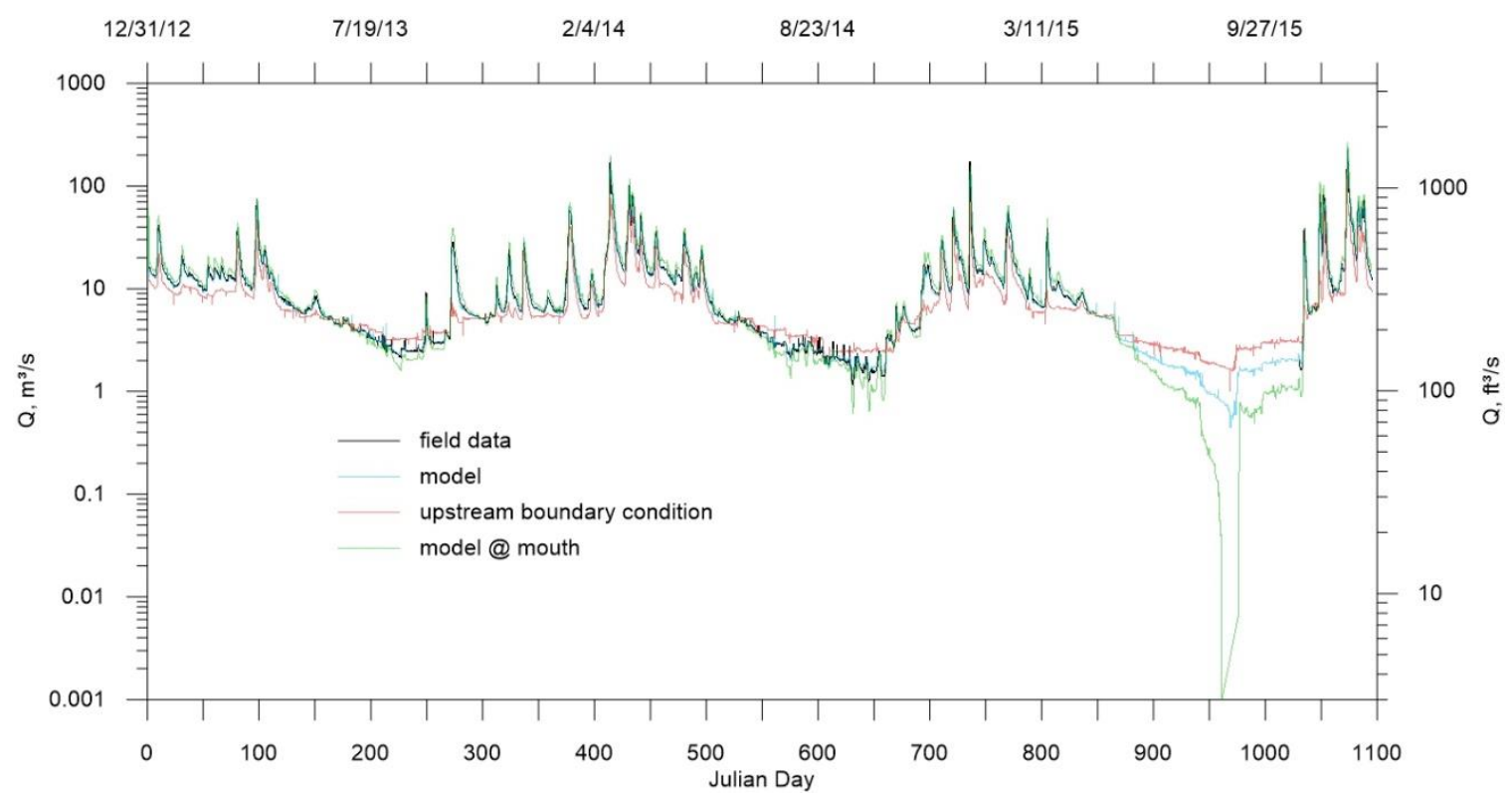

Figure 60. Flow rate comparison between field data and model predictions in the Skookumchuck River at USGS 12026400. Flow data from USGS 12026150 was used for the upstream boundary condition. The modeled flow at the mouth of the Skookumchuck River is also included.

Black River

The model predicted flow rate at the Black River near the mainstem of the Chehalis was compared to field data (Gage 23E060) in Figure 61. The flow rate error statistics of this comparison are shown in Table 14.

Table 14. Flow rate error statistics (see Appendix C) of field data compared to model predictions at model segment 53 at Black River near the mainstem Chehalis.

\begin{tabular}{|c|r|r|r|}
\hline Count & ME, $\mathrm{m}^{3} / \mathrm{s}$ & \multicolumn{1}{c|}{$A M E, \mathrm{~m}^{3} / \mathrm{s}$} & $\mathrm{RMS}, \mathrm{m}^{3} / \mathrm{s}$ \\
\hline 104624 & -0.010 & 0.445 & 2.106 \\
\hline
\end{tabular}




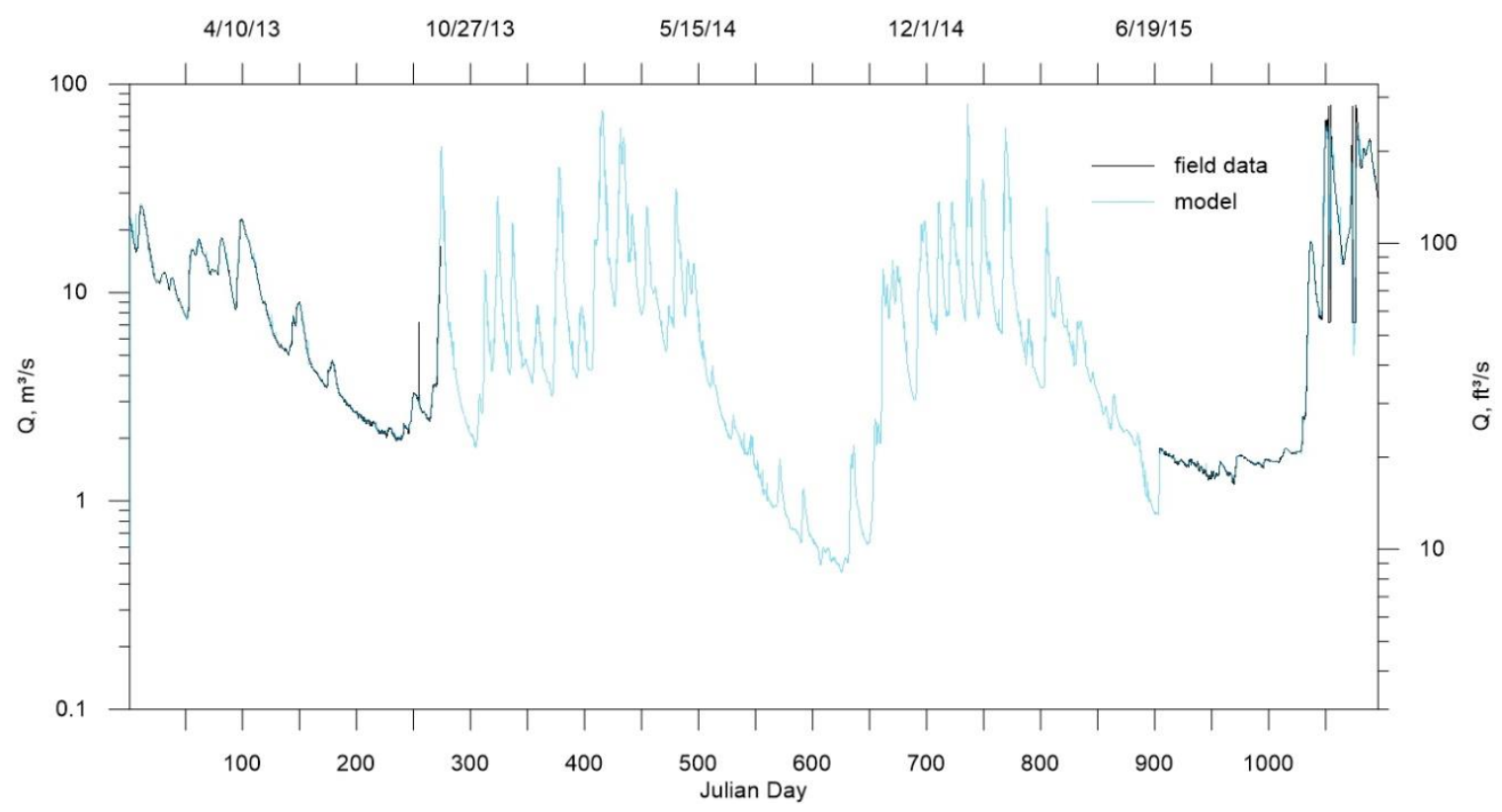

Figure 61. Flow rate comparison between field data and model predictions in Black River at 23E060.

Mainstem Chehalis River

Flow rates predicted by the model were compared to the 3 main flow gages on the Chehalis River at Doty, Grand Mound, and Porter in Figure 62. Table 15 shows the associated flow prediction errors at Doty, Grand Mound, and Porter gage locations for 2013-2015. The mean errors at the Doty, Grand Mound, and Porter gages were $0.007 \%, 0.084 \%$, and $0.052 \%$ of the average flow during the model period at these gages, respectively. Absolute mean errors were 5.06\%, 3.50\%, and 6.14\% of average flow. 


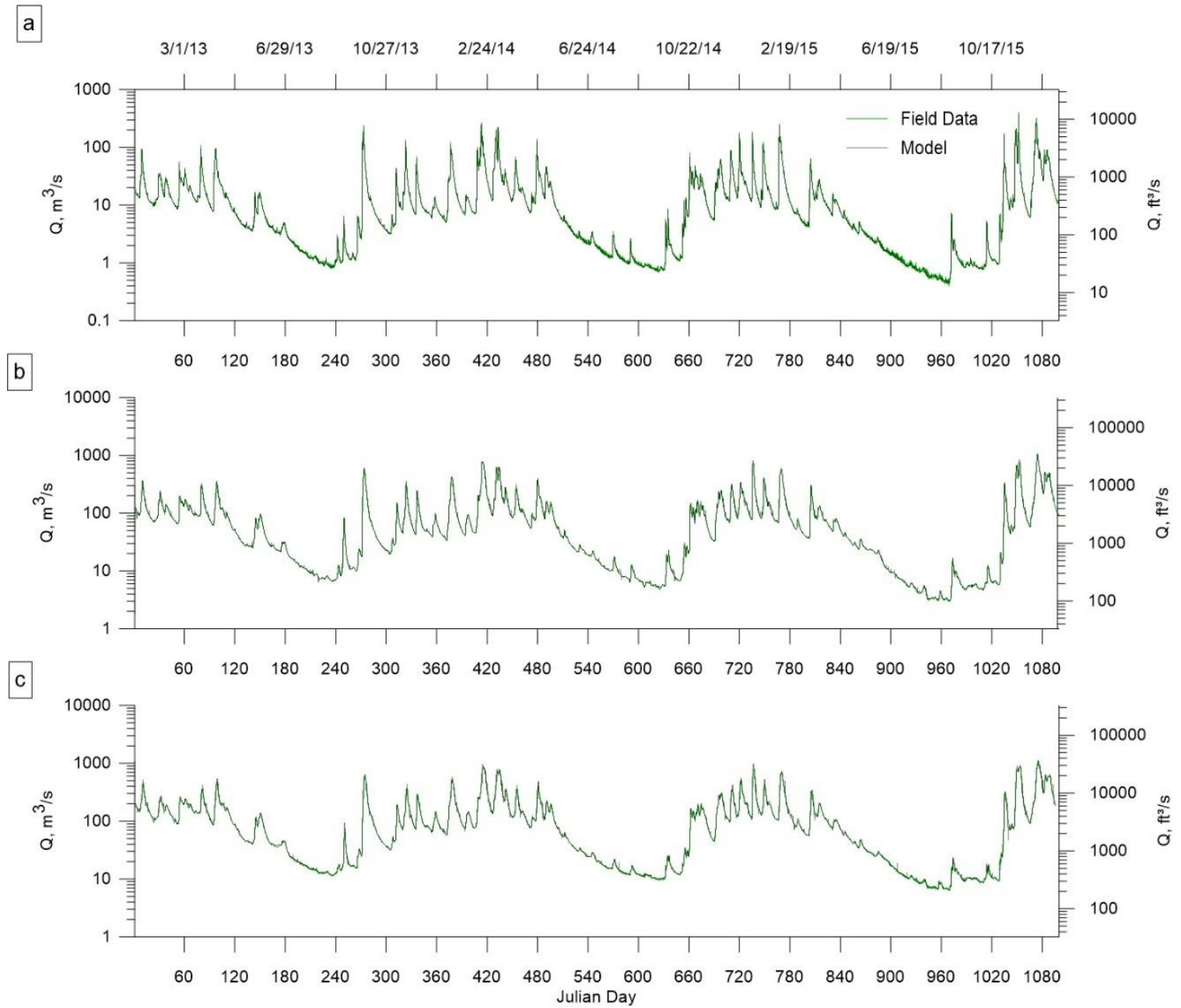

Figure 62. Flow rate comparison between field data and model predictions in mainstem Chehalis River at (a) Doty, (b) Grand Mound, and (c) Porter between 2013-2015.

Table 15. Model errors (see Appendix C) of flow rate at Doty, Grand Mound, and Porter between 20132015.

\begin{tabular}{|l|r|r|r|r|}
\hline Gage & \multicolumn{1}{|c|}{ Count } & \multicolumn{1}{c|}{$\mathrm{ME}^{3} / \mathrm{s}$} & \multicolumn{1}{c|}{$\mathrm{AME}^{3} \mathrm{~m}^{3} / \mathrm{s}$} & \multicolumn{1}{c|}{$\mathrm{RMS}, \mathrm{m}^{3} / \mathrm{s}$} \\
\hline Doty & 104698 & 0.0016 & 0.7701 & 3.1872 \\
\hline Grand Mound & 103444 & -0.0161 & 2.9592 & 8.95255 \\
\hline Porter & 103794 & -0.0265 & 7.3106 & 19.2839 \\
\hline Weighted errors & 311936 & -0.0136 & 3.6723 & 10.4462 \\
\hline
\end{tabular}

Water Level

Model predictions of water level to field data are shown in Figure 63 and Figure 64 for Doty, Adna, Chehalis WWTP, Centralia, Grand Mound, Rochester, and Porter. As 
was done in Van Glubt et al. (2017), the datum was adjusted based on the mean

model elevation since there was uncertainty over the exact position of the datum.

a

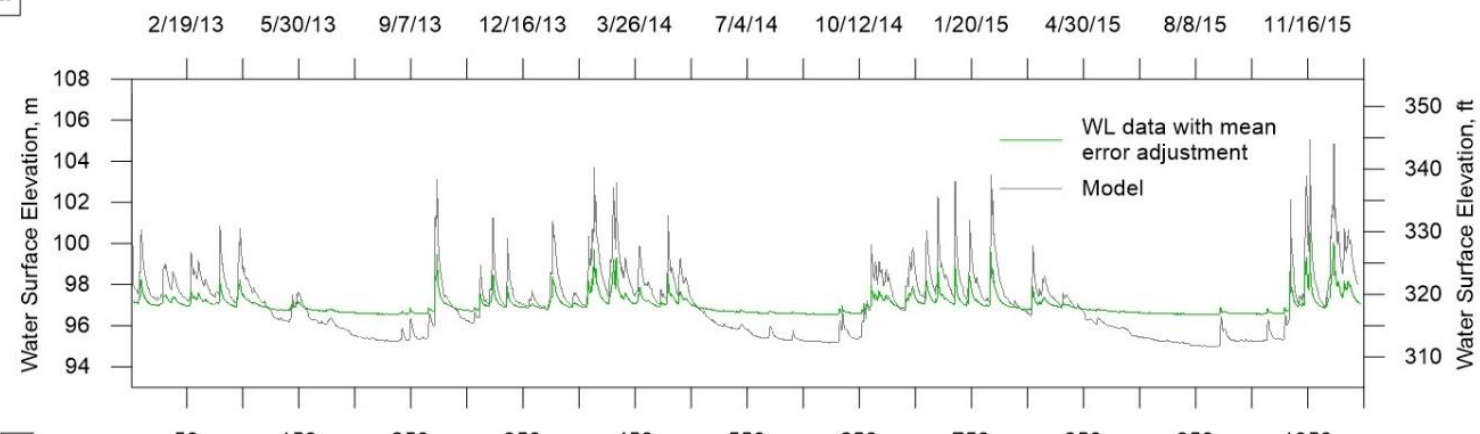

b

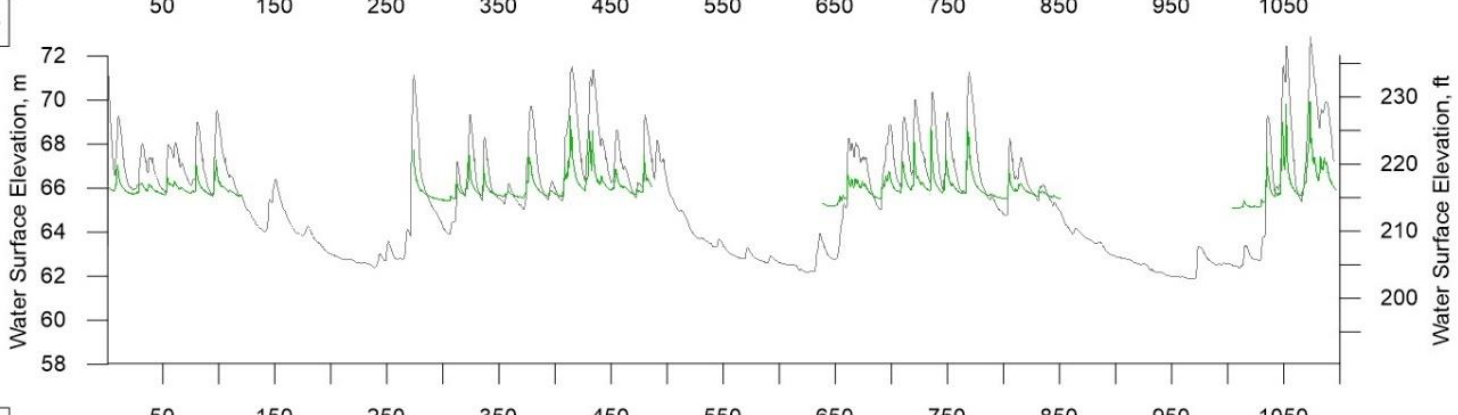

c
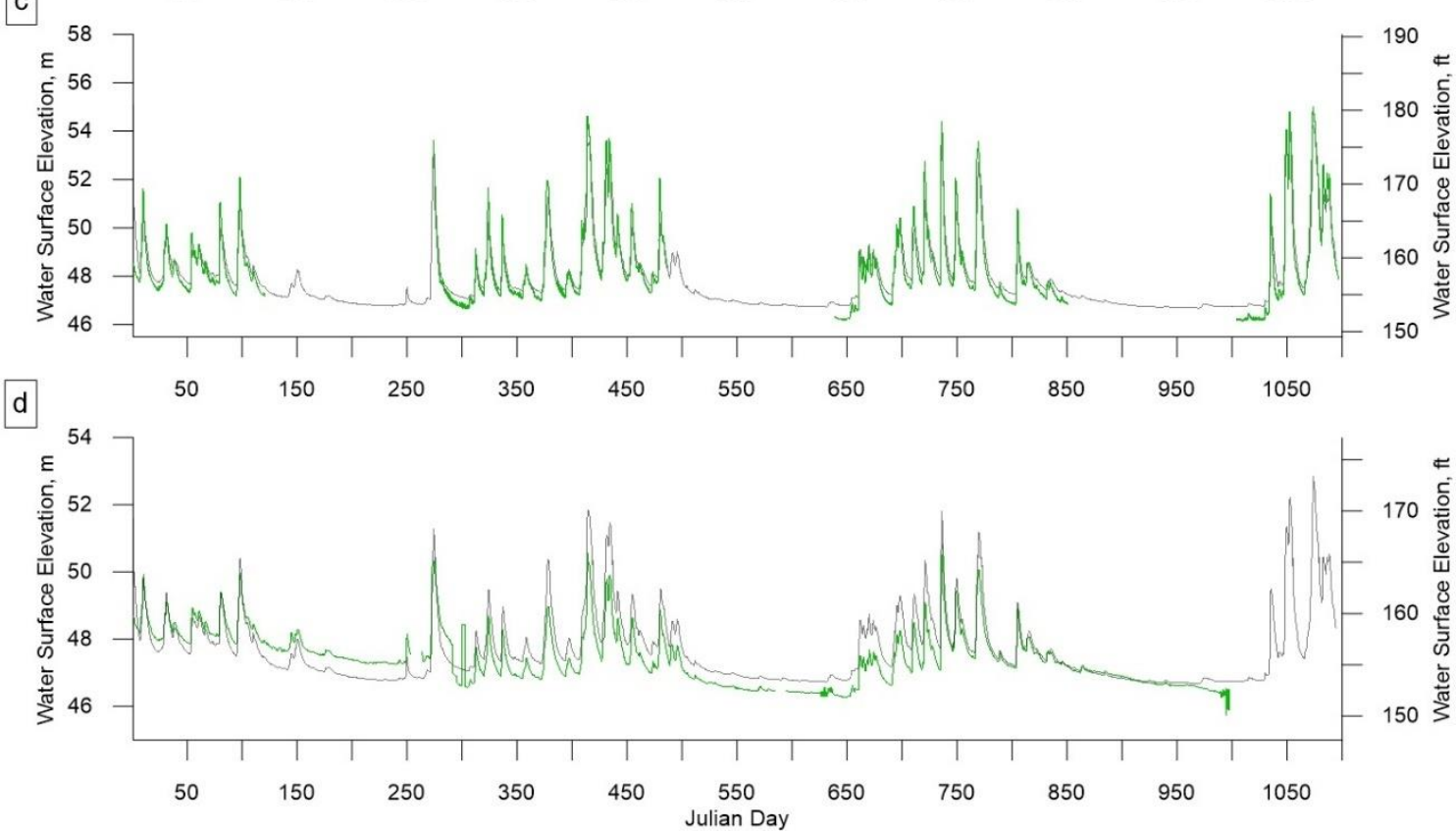

Figure 63. Water level comparison between field data adjusted by mean error and model predictions in the mainstem Chehalis River at (a) Doty, (b) Adna, (c) Chehalis WWTP, and (d) Centralia between 2013 2015. 


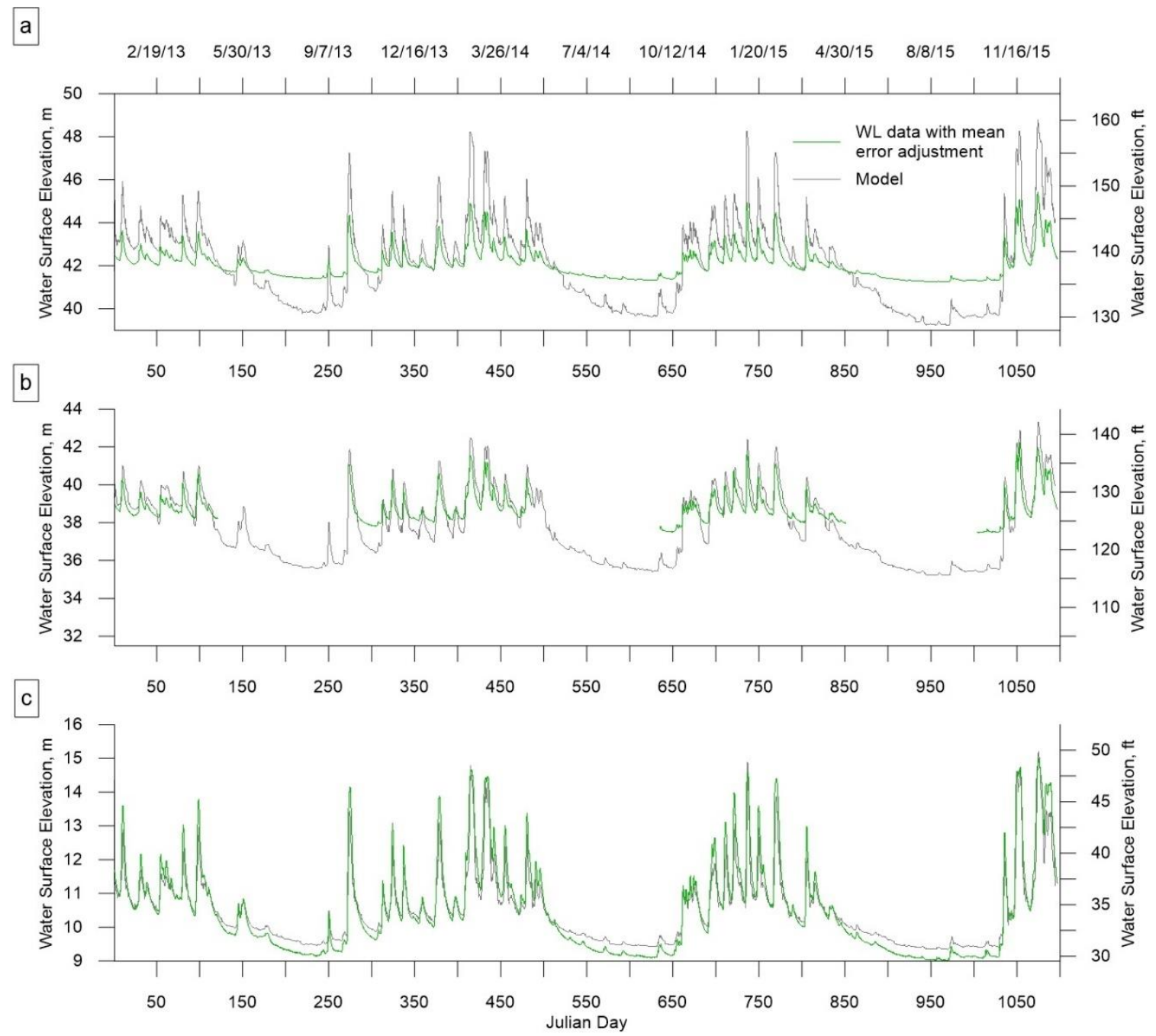

Figure 64. Water level comparison between field data adjusted by mean error and model predictions in the mainstem Chehalis River at (a) Grand Mound, (b) Rochester, and (c) Porter between 2013-2015.

Model water elevations did not match field data well at all gauges. In the upper reach at Doty, the error may be a result of not accurately modeling the pool-andriffle nature of the river channel. To more accurately model pools and riffles, finer resolution bathymetry data would be required than was available. The model grid would also need to be divided into many more water bodies, complicating model development. Instead, adjustments to SLOPEC (hydraulic equivalent slope) were used to approximate this channel structure. The model grid also does not include 
flood storage in the upper reaches, leading to modeled water levels exceeding gauge data during high flow events.

The poor match at Grand Mound may be due to omitting off-channel flood storage, other mismatches between modeled and actual channel geometry, and/or datum issues. We were unable to resolve this issue in the current study, but further investigation is warranted.

\section{Temperature}

The variation of temperature in the Chehalis River tributaries was most often controlled by water depth predicted by the hydrodynamic model, light extinction, shading and how much of the heat went into the bed substrate. These models used meteorological data that were developed for the Chehalis mainstem model (see Wells et al., 2019). The results that follow show model-field data comparisons of temperature between January 1, 2013 and December 31, 2015 for the South Fork Chehalis River, Newaukum River, Skookumchuck River, Black River, and mainstem Chehalis River.

\section{South Fork Chehalis River}

The predicted temperature at the South Fork Chehalis River at WDFW SFCHEH-1 and near the mainstem of the Chehalis River was compared to field data in Figure 65. The temperature error statistics at South Fork Chehalis are shown in Table 16. From the limited temperature field data and the lack of boundary conditions for upstream temperatures, the model predicts the mean temperature over the period with a ME under to $0.5^{\circ} \mathrm{C}$ at each gage. The AME is close to $1^{\circ} \mathrm{C}$ even though we have no upstream temperature boundary conditions. 
Table 16. Temperature error statistics (see Appendix C) of field data compared to model predictions at SFCHEH-1 and 23 KO60 in South Fork Chehalis River.

\begin{tabular}{|r|r|r|r|r|}
\hline \multicolumn{1}{|l|}{ Gage } & \multicolumn{1}{c|}{ Count } & \multicolumn{1}{l|}{$\mathrm{ME},{ }^{\circ} \mathrm{C}$} & \multicolumn{1}{c|}{$\mathrm{AME}^{\circ} \mathrm{C}$} & \multicolumn{1}{c|}{ RMS, ${ }^{\circ} \mathrm{C}$} \\
\hline SFCHEH-1 & 6488 & -0.224 & 0.996 & 1.294 \\
\hline 23K060 & 12484 & 0.415 & 1.049 & 1.570 \\
\hline SF-CHL-MOUTH & 17049 & -0.020 & 0.802 & 1.083 \\
\hline
\end{tabular}


a

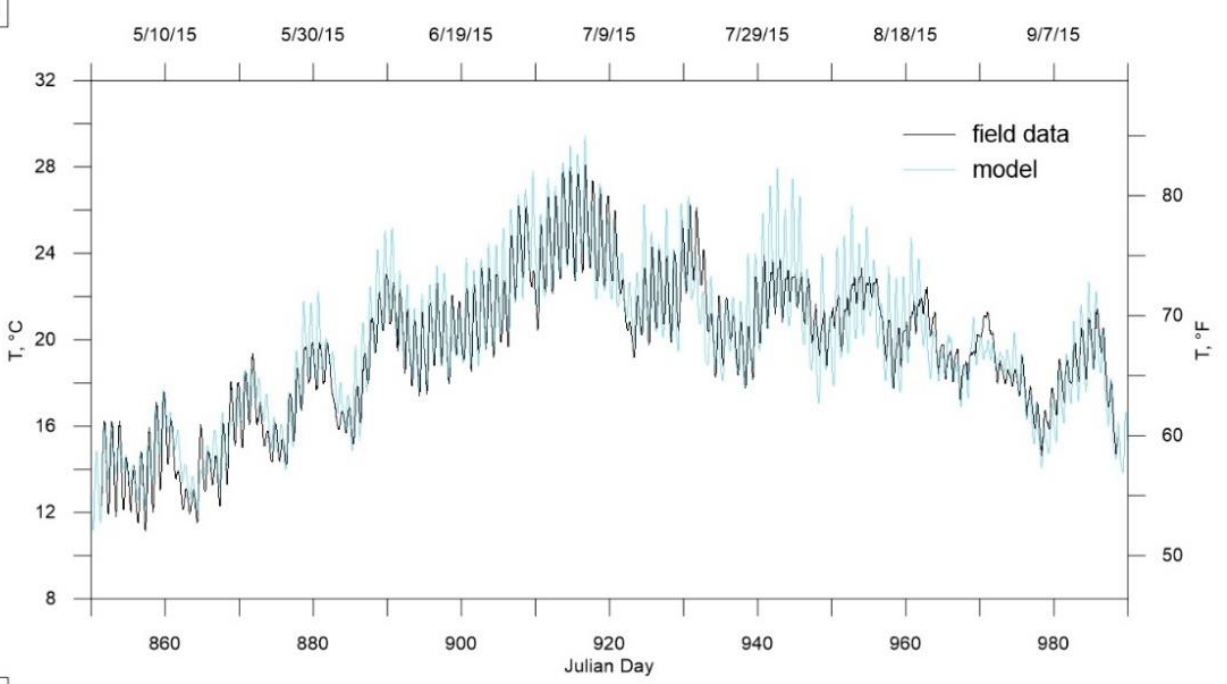

b
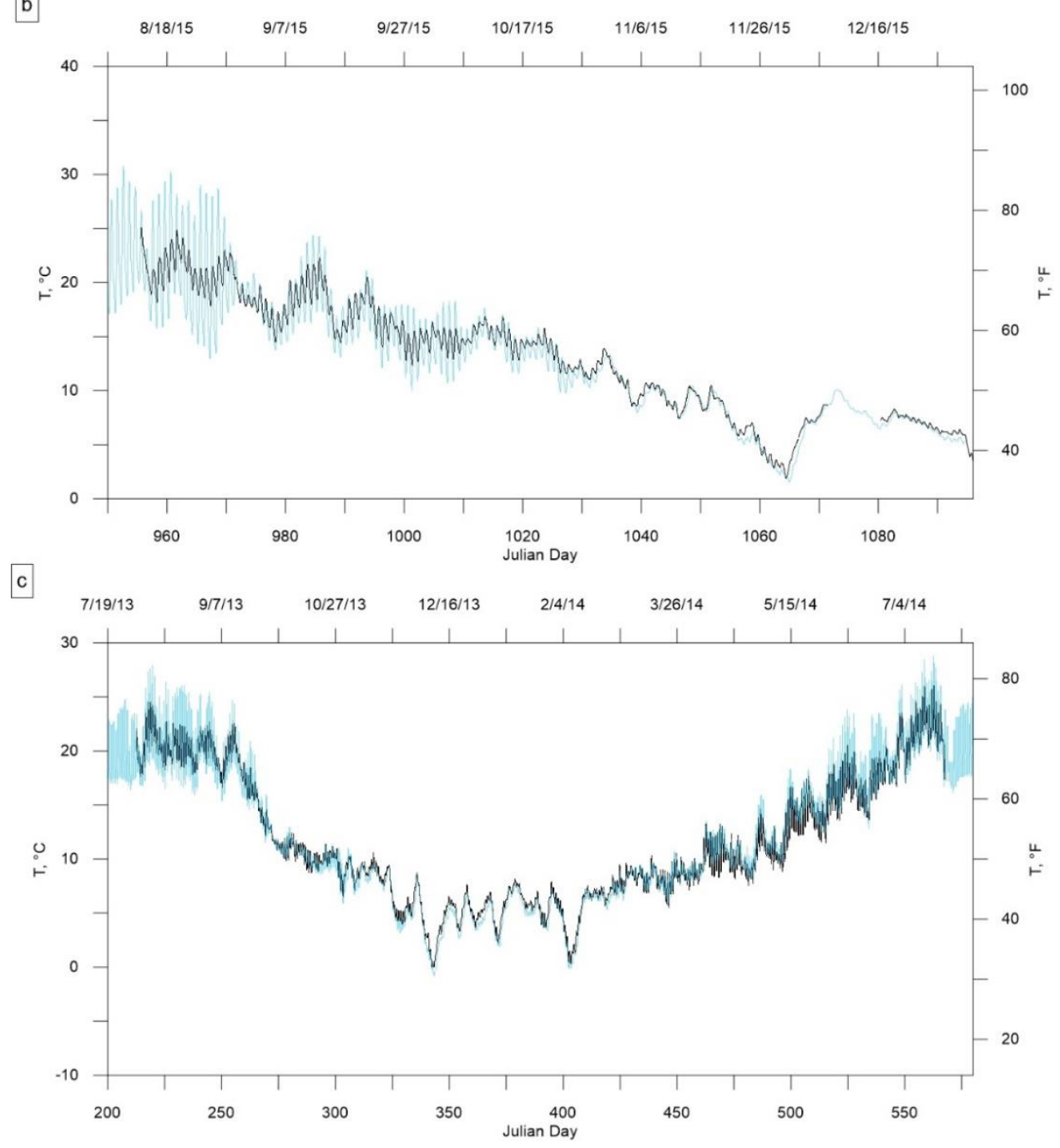

Figure 65. Temperature comparison between field data and model predictions in South Fork Chehalis River at (a) SFCHEH-1, (b) 23K060, and (c) SF-CHL-MOUTH. 


\section{Newaukum River}

The predicted temperature at the Newuakum River near the mainstem of the Chehalis was compared to field data in Figure 66. The temperature error statistics at Newaukum are shown in Table 17. From the limited temperature field data and the lack of boundary conditions for upstream temperatures, the model predicts the mean temperature over the period with a ME close to $0{ }^{\circ} \mathrm{C}$ and an AME close to $1^{\circ} \mathrm{C}$.

Table 17. Temperature error statistics (see Appendix C) of field data compared to model predictions at model segment 92 at Newaukum River near the mainstem Chehalis.

\begin{tabular}{|r|c|c|r|r|}
\hline \multicolumn{1}{|l|}{ Gage } & \multicolumn{1}{|c|}{ Count } & \multicolumn{1}{c|}{$\mathrm{ME}^{\circ}{ }^{\circ} \mathrm{C}$} & \multicolumn{1}{c|}{ AME, ${ }^{\circ} \mathrm{C}$} & \multicolumn{1}{c|}{$\mathrm{RMS}^{\circ}{ }^{\circ} \mathrm{C}$} \\
\hline NEW-1 & 19965 & 0.139 & 1.008 & 1.331 \\
\hline NWK-MOUTH & 14696 & 0.142 & 0.995 & 1.269 \\
\hline
\end{tabular}




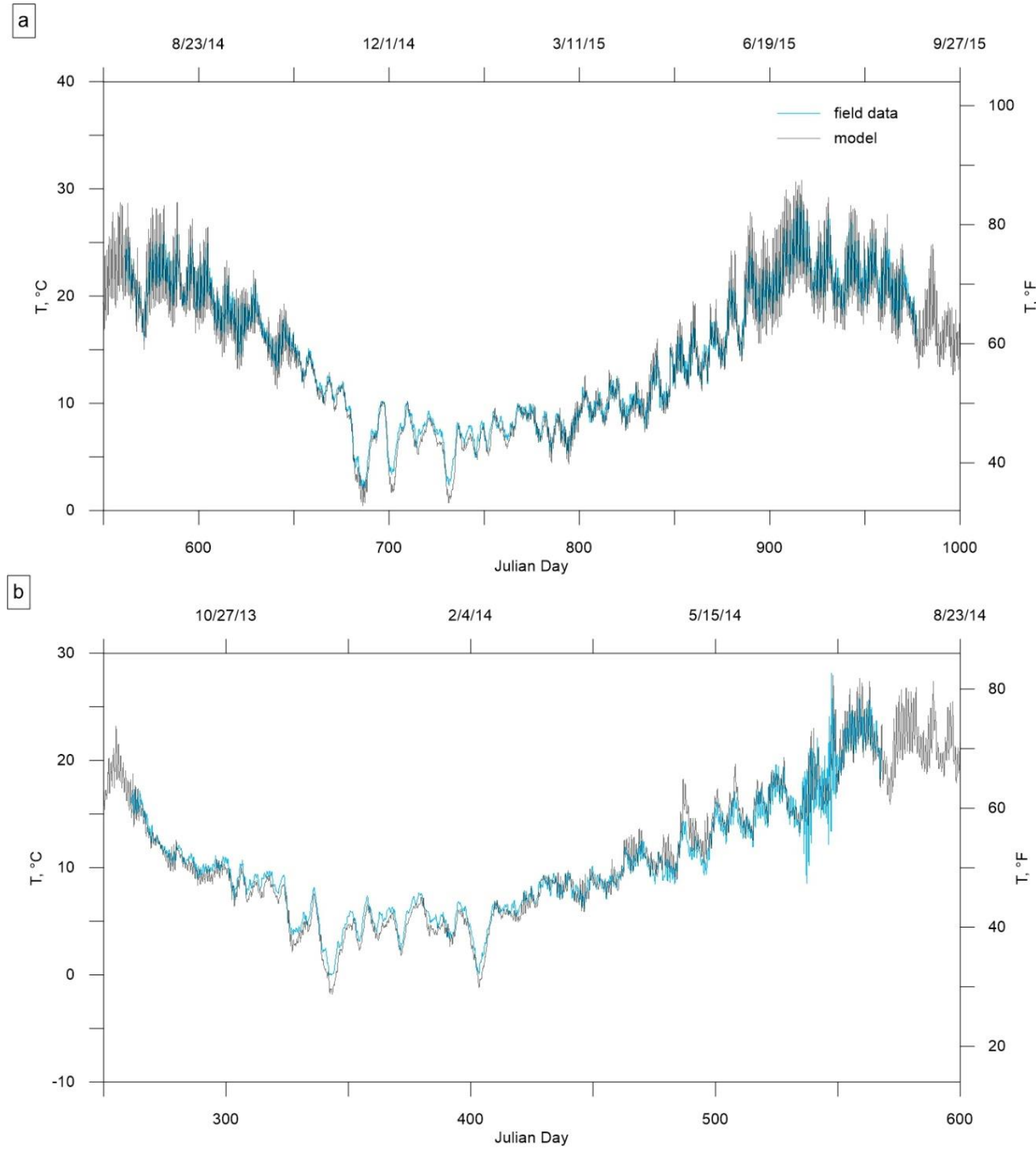

Figure 66. Temperature comparison between field data and model predictions in the Newaukum River at (a) NEW-1 and (b) NWK-MOUTH.

Skookumchuck River

The predicted temperature at the Skookumchuck River near the mainstem of the Chehalis was compared to field data in Figure 67. The temperature error statistics at Skookumchuck are shown in Table 18. From the limited temperature field data and 
the lack of boundary conditions for upstream temperatures, the model predicts the mean temperature over the period with a low ME. Since there were no temperature field data during the peak summer period, little can be said about the summer temperature dynamics.

Table 18. Temperature error statistics (see Appendix C) of field data compared to model predictions in the Skookumchuck River at SKOOK-1 and SKOOK-2.

\begin{tabular}{|l|r|r|r|r|}
\hline Gage & \multicolumn{1}{|c|}{ Count } & \multicolumn{1}{c|}{ ME, ${ }^{\circ} \mathrm{C}$} & \multicolumn{1}{c|}{ AME, ${ }^{\circ} \mathrm{C}$} & \multicolumn{1}{c|}{ RMS, ${ }^{\circ} \mathrm{C}$} \\
\hline SKOOK-1 & 5834 & 0.127 & 0.897 & 1.169 \\
\hline SKOOK-2 & 6332 & -0.523 & 1.273 & 1.728 \\
\hline
\end{tabular}




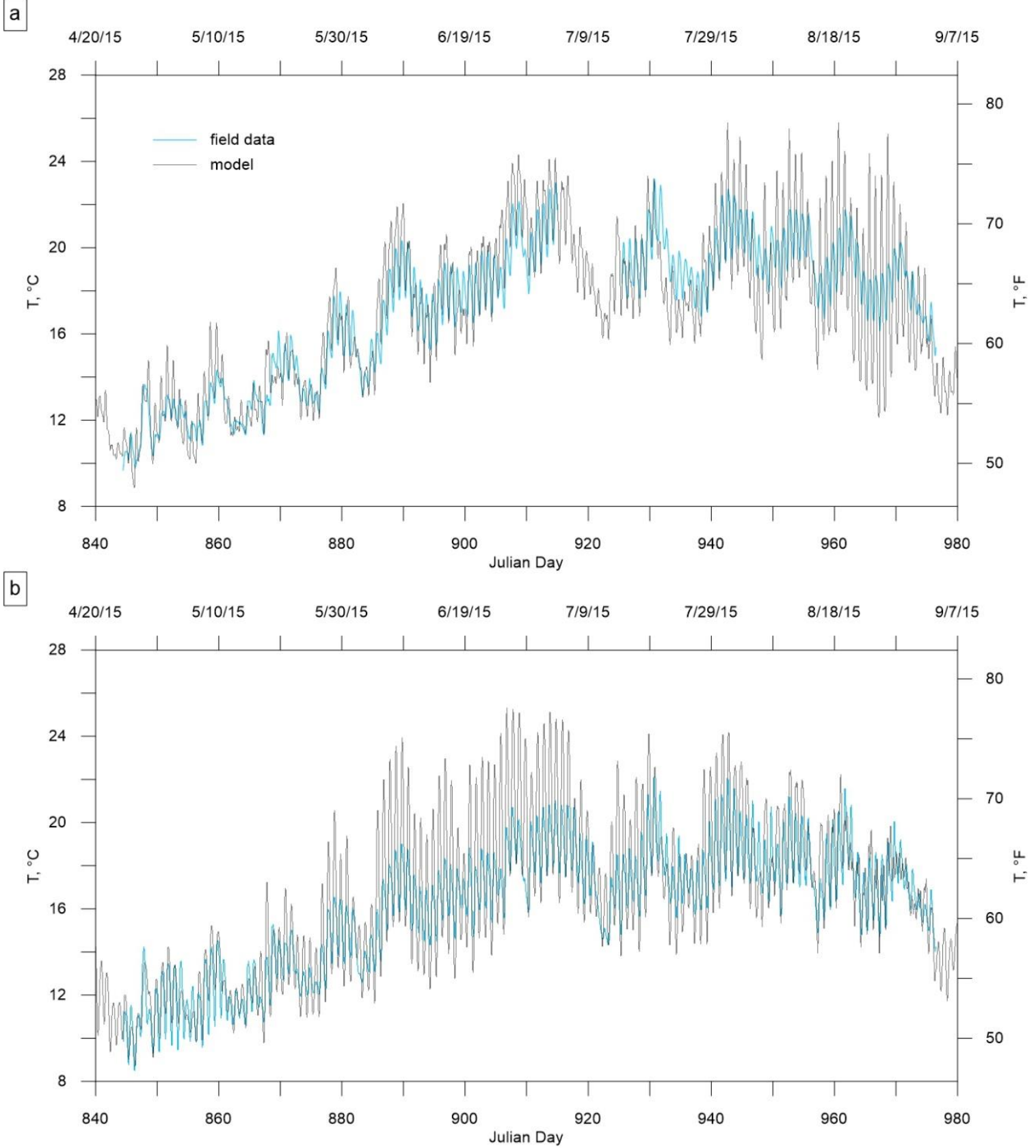

Figure 67. Temperature comparison between field data and model predictions in Skookumchuck River at (a) SKOOK-1 and (b) SKOOK-2.

Black River

The predicted temperature at the Black River near the mainstem of the Chehalis was compared to field data in Figure 68. The temperature error statistics at Black River are shown in Table 19. From the limited temperature field data and the lack of 
boundary conditions for upstream temperatures, the model predicts a low ME over the model period. The AME is under $1{ }^{\circ} \mathrm{C}$ even though we have no upstream temperature boundary conditions. Much of the bias and error is a result of the model systematically being too cool during the winter of 2014-2015.

Table 19. Temperature error statistics (see Appendix C) of field data compared to model predictions at BLACK-1 and BLACK-2 in the Black River.

\begin{tabular}{|l|r|r|r|r|}
\hline Gage & \multicolumn{1}{|c|}{ Count } & \multicolumn{1}{c|}{$\mathrm{ME},{ }^{\circ} \mathrm{C}$} & \multicolumn{1}{c|}{$\mathrm{AME},{ }^{\circ} \mathrm{C}$} & \multicolumn{1}{c|}{$\mathrm{RMS},{ }^{\circ} \mathrm{C}$} \\
\hline BLACK-1 & 13181 & 0.128 & 0.983 & 1.330 \\
\hline BLACK-2 & 5044 & -0.509 & 0.885 & 1.155 \\
\hline
\end{tabular}



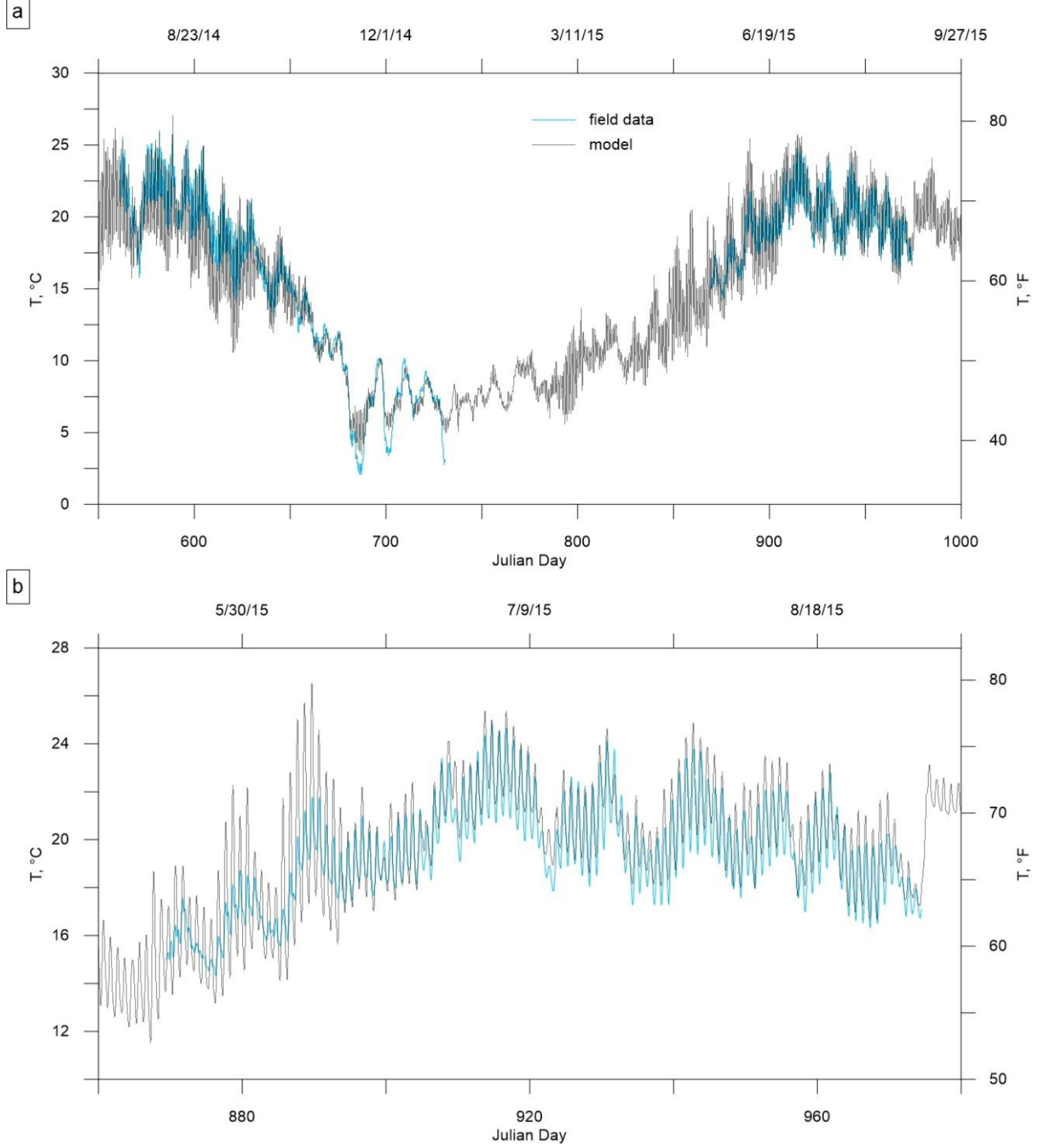

Figure 68. Temperature comparison between field data and model predictions in Black River at (a) $B L A C K-1$ and (b) BLACK-2.

Mainstem Chehalis River

The variation of temperature in the Chehalis River was most often controlled by water depth predicted by the hydrodynamic model, light extinction, shading and how much of the heat went into the bed substrate. The results that follow show 
model-field data comparisons of temperature between January 1, 2013 and December 31, 2015.

The Chehalis River model of Van Glubt et al. (2017) was adjusted to include 2015, updated boundary conditions, and bathymetry and other adjustments after the dye study calibration. The wind sheltering coefficient was set to 0.25 for model water bodies $1,2,3,4$, and 5 , and 0.5 for water bodies $6,7,8$, and 9 . Table 20 shows the model errors (see Appendix C) for each sampling station along the Chehalis River mainstem. In general, our goal was to have less than a $1{ }^{\circ} \mathrm{C}$ absolute mean error (AME) error for all these aggregate stations and a mean error (ME) approaching 0.0 ${ }^{\circ} \mathrm{C}$. The model is performing adequately for the entire system with a ME of $-0.01{ }^{\circ} \mathrm{C}$ and an AME error of $0.74{ }^{\circ} \mathrm{C}$ using over 688,000 model-data comparisons.

Table 20. Temperature errors (see Appendix C) along the mainstem Chehalis River between 2013-2015.

\begin{tabular}{|l|r|r|r|r|}
\hline Gage & \multicolumn{1}{|c|}{ Count } & \multicolumn{1}{c|}{ ME, ${ }^{\circ} \mathrm{C}$} & \multicolumn{1}{c|}{ AME, ${ }^{\circ} \mathrm{C}$} & \multicolumn{1}{l|}{ RMS, ${ }^{\circ} \mathrm{C}$} \\
\hline 11-UCH & 22219 & 0.058 & 0.146 & 0.215 \\
\hline 3-UCH & 23417 & -0.094 & 0.461 & 0.578 \\
\hline CHL-PEL-US & 17052 & -0.301 & 0.503 & 0.610 \\
\hline CHL-PEL-DS & 17487 & -0.153 & 1.038 & 1.335 \\
\hline 13-CH & 22177 & -0.265 & 0.810 & 1.070 \\
\hline CHL-WOODSTEAD & 11373 & -0.200 & 0.776 & 0.989 \\
\hline 4-UCH & 22076 & -0.373 & 0.869 & 1.111 \\
\hline CHL-DOTY & 10108 & -0.321 & 1.002 & 1.255 \\
\hline 23A160 & 8167 & -0.682 & 1.051 & 1.291 \\
\hline 15-CH & 6037 & -0.898 & 1.141 & 1.378 \\
\hline CHL-RAINBOW-FALLS & 30620 & -0.386 & 0.777 & 0.946 \\
\hline 19-CH & 9207 & -0.359 & 0.961 & 1.227 \\
\hline CHL-CERES-HILLS & 10114 & 0.313 & 0.939 & 1.265 \\
\hline CHL-ADNA & 17044 & 0.044 & 0.905 & 1.125 \\
\hline 21-CH & 13538 & -0.345 & 1.044 & 1.242 \\
\hline CHL-US-NWK & 17083 & -0.032 & 0.842 & 1.037 \\
\hline 22-CH & 39837 & 0.029 & 0.682 & 0.873 \\
\hline Darigold Upstream & 98034 & -0.259 & 0.627 & 0.811 \\
\hline
\end{tabular}




\begin{tabular}{|l|r|r|r|r|}
\hline Gage & \multicolumn{1}{|c|}{ Count } & \multicolumn{1}{c|}{ ME, ${ }^{\circ} \mathrm{C}$} & \multicolumn{1}{|c|}{ AME, ${ }^{\circ} \mathrm{C}$} & \multicolumn{1}{r|}{ RMS, ${ }^{\circ} \mathrm{C}$} \\
\hline Darigold Downstream & 98421 & 0.221 & 0.598 & 0.778 \\
\hline 16-CH & 36099 & 0.518 & 0.878 & 1.144 \\
\hline CHL-GLV & 17091 & 0.455 & 0.757 & 1.063 \\
\hline 17-CH & 7277 & 0.462 & 0.885 & 1.070 \\
\hline CHL-US-BLK & 17143 & 0.321 & 0.720 & 0.887 \\
\hline 18-CH & 19656 & 0.042 & 0.872 & 1.087 \\
\hline CHL-OAK & 16895 & 0.219 & 0.779 & 0.970 \\
\hline 23-CH & 42395 & 0.411 & 0.872 & 1.054 \\
\hline 23A70 Porter & 37938 & 0.275 & 0.768 & 0.960 \\
\hline Weighted error & 688505 & 0.014 & 0.735 & 0.933 \\
\hline
\end{tabular}

Figure 69 shows temperature field data compared to model predictions at the mainstem Chehalis River stations: 11-UCH, upstream of Pe Ell, downstream of Pe Ell, 13-CH, Woodstead, upstream of Elk Creek, and Doty. Figure 70 shows model temperature predictions compared to field data at the mainstem Chehalis River stations: 15-CH, Dryad, Rainbow Falls, 19-CH, Ceres Hills Road, and Adna. Figure 71 shows model temperature predictions compared to field data at the mainstem Chehalis River stations: 21-CH, near Newaukum confluence, 22-CH, upstream of Darigold, downstream of Darigold, and upstream of Skookumchuck. Figure 72 shows model temperature predictions compared to field data at the mainstem Chehalis River stations: Galvin Bridge, 17-CH, upstream of Black River, 18-CH, Oakville and Porter. 
a
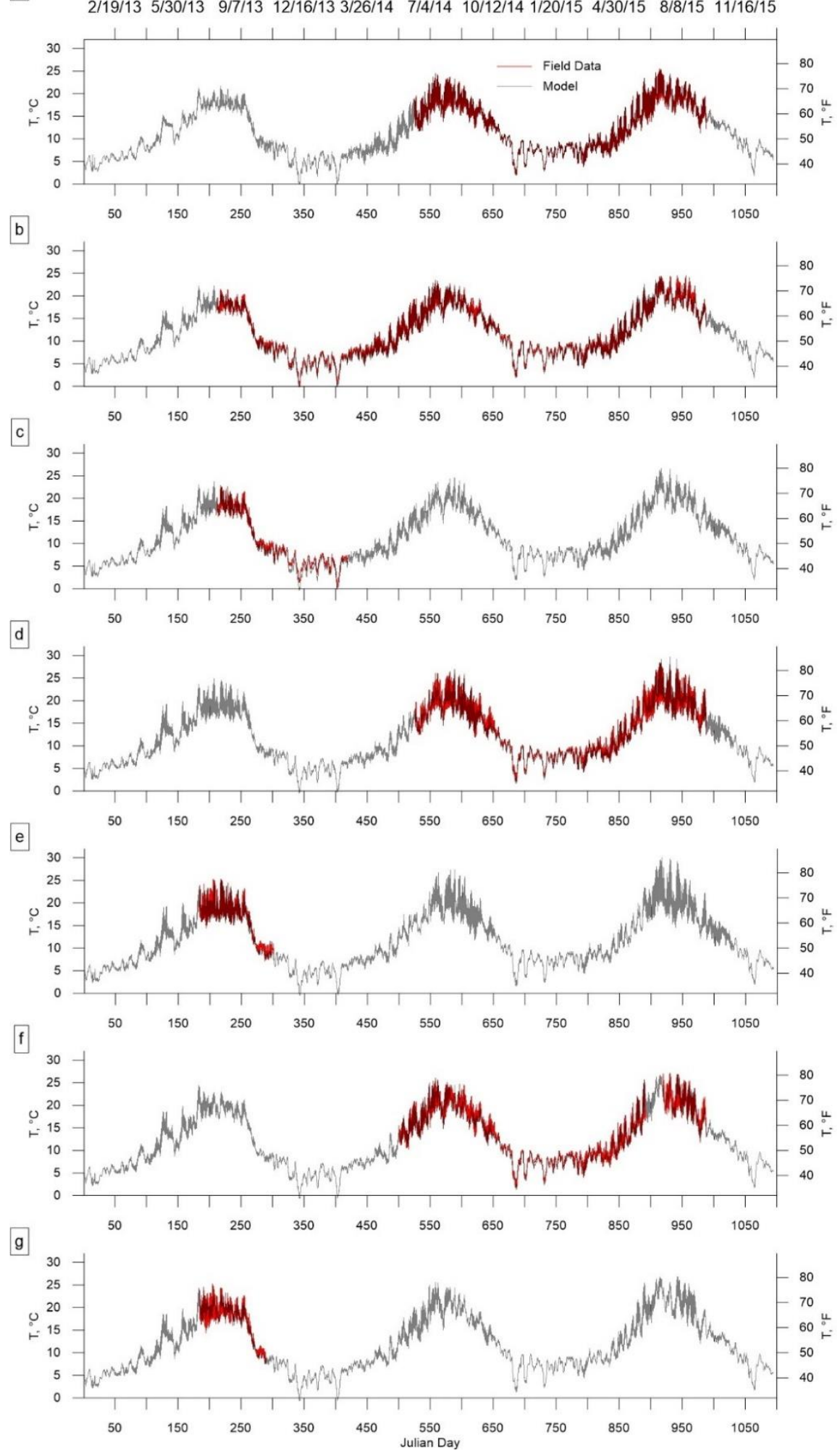

Figure 69. Temperature comparisons between field data and model predictions in the mainstem Chehalis River at (a) 11-UCH, (b) upstream of Pe Ell, (c) downstream of Pe Ell, (d) 13-CH, (e) Woodstead, (f) upstream of Elk Creek, and (g) Doty between 2013-2015. 
a

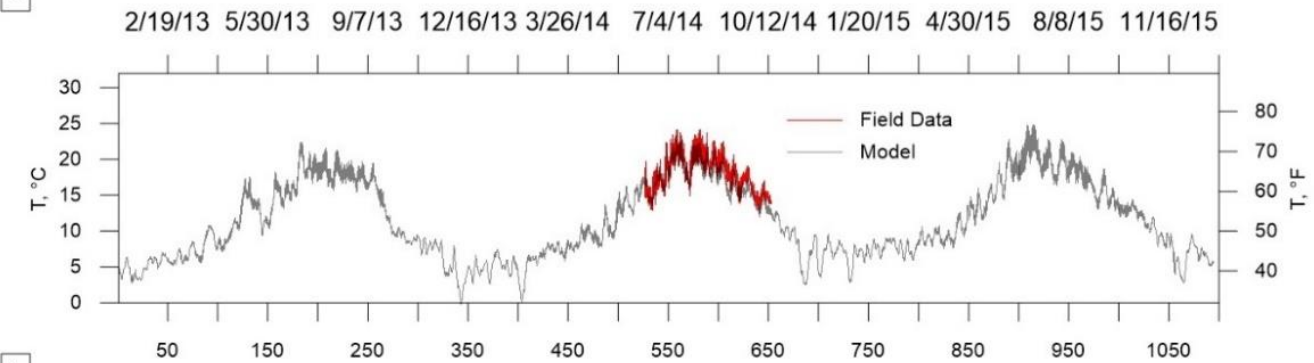

b

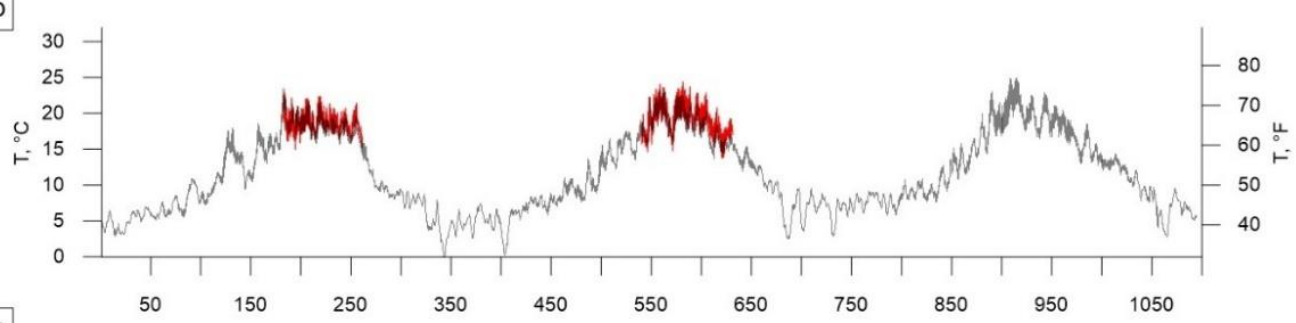

c

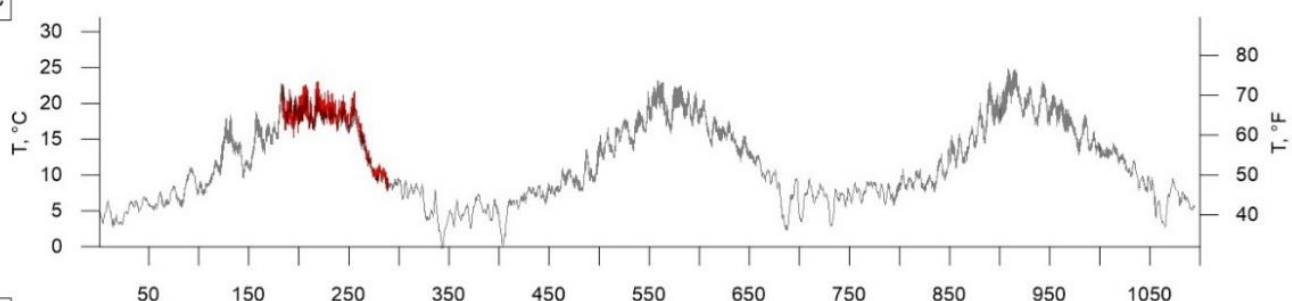

d

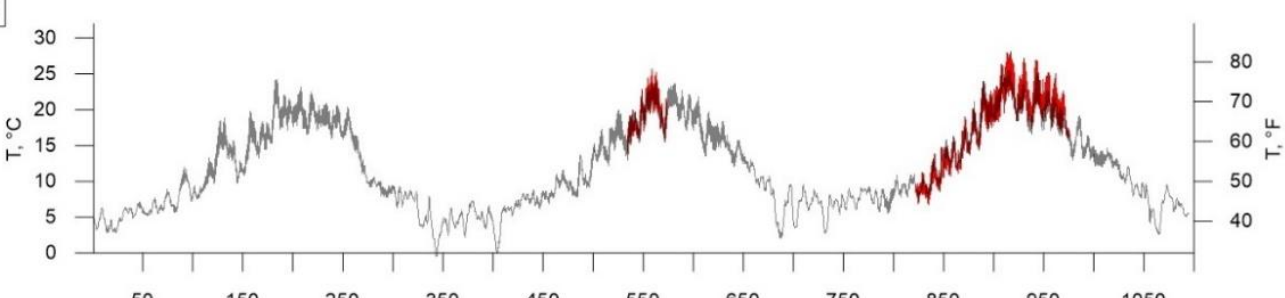

e

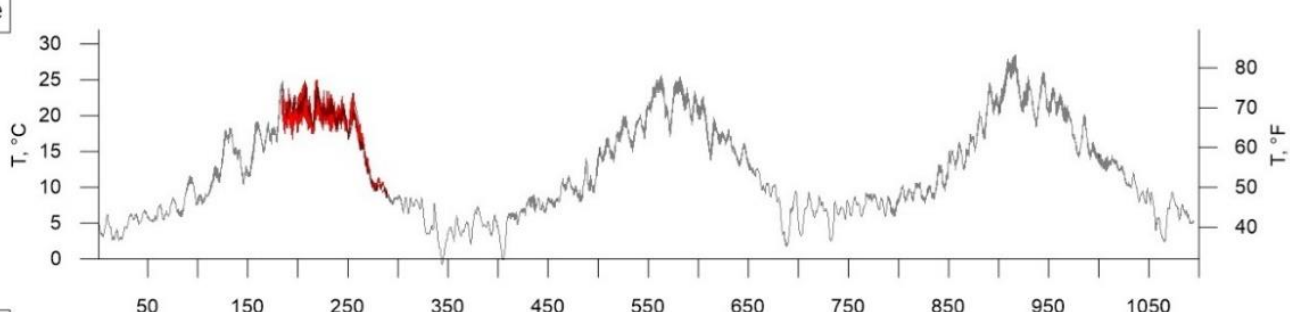

$$
\text { f }
$$

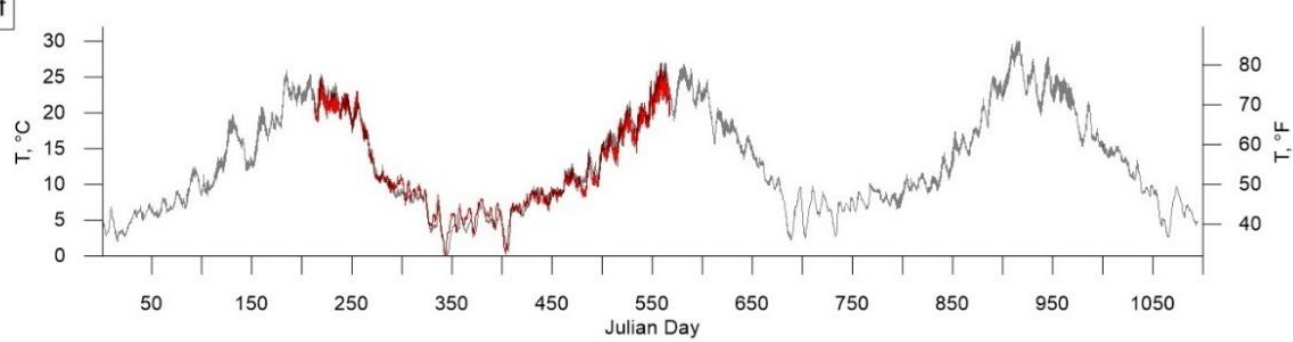

Figure 70. Temperature comparisons between field data and model predictions in the mainstem Chehalis River at (a) 15-CH, (b) Dryad, (c) Rainbow Falls, (d) 19-CH, (e) Ceres Hills Road, and (f) Adna between 2013-2015. 


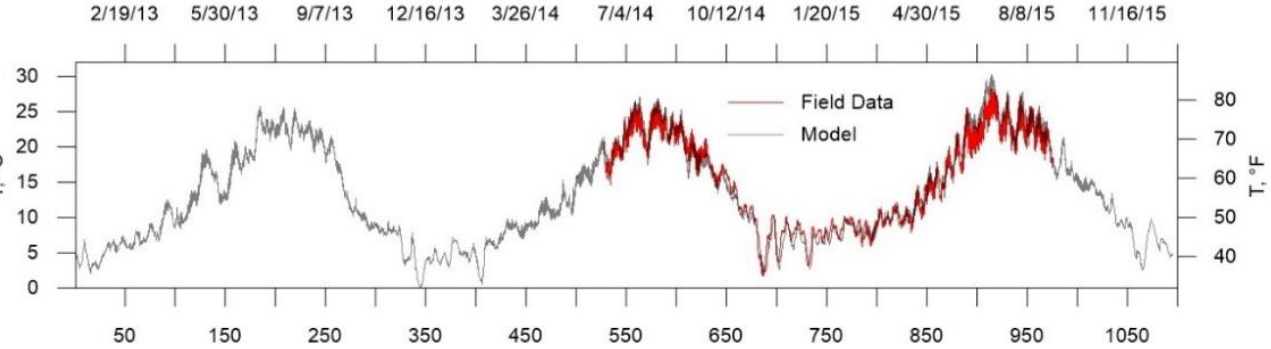

b

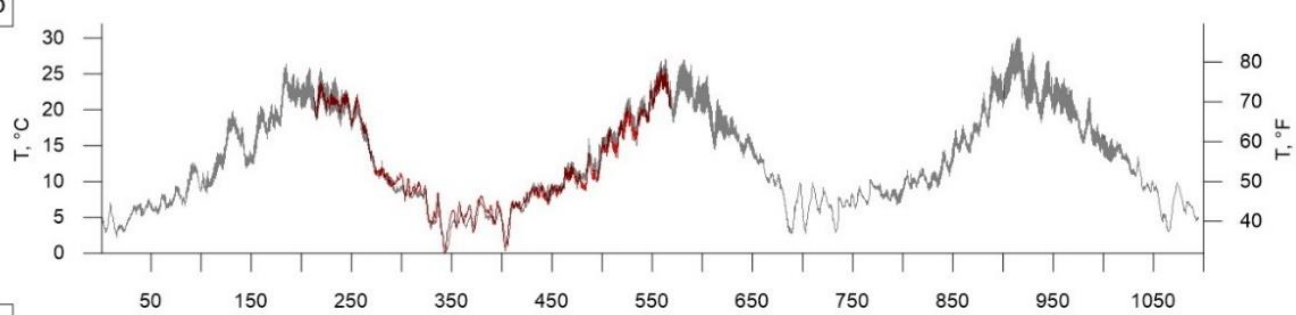

c

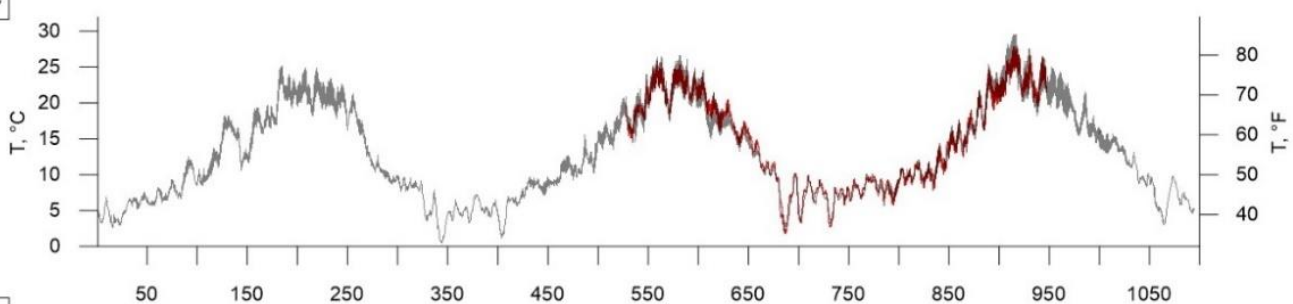

d

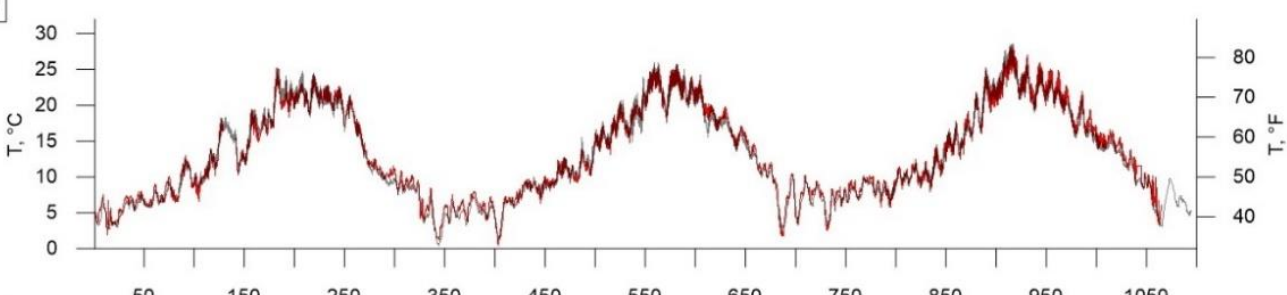

$\mathrm{e}$

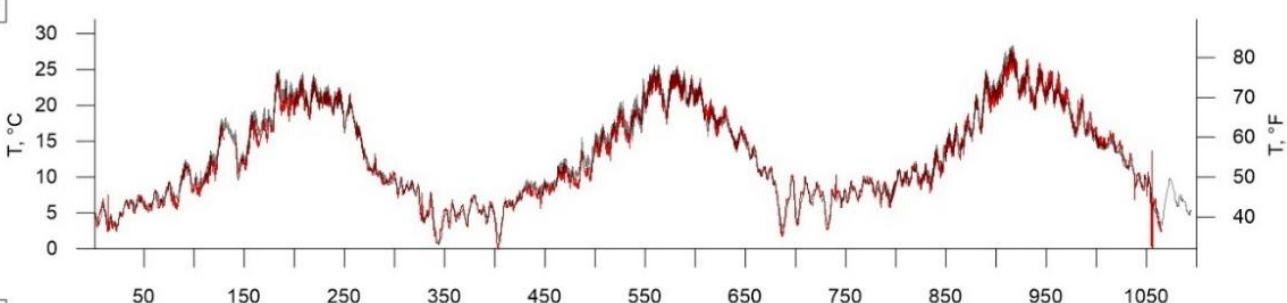

f

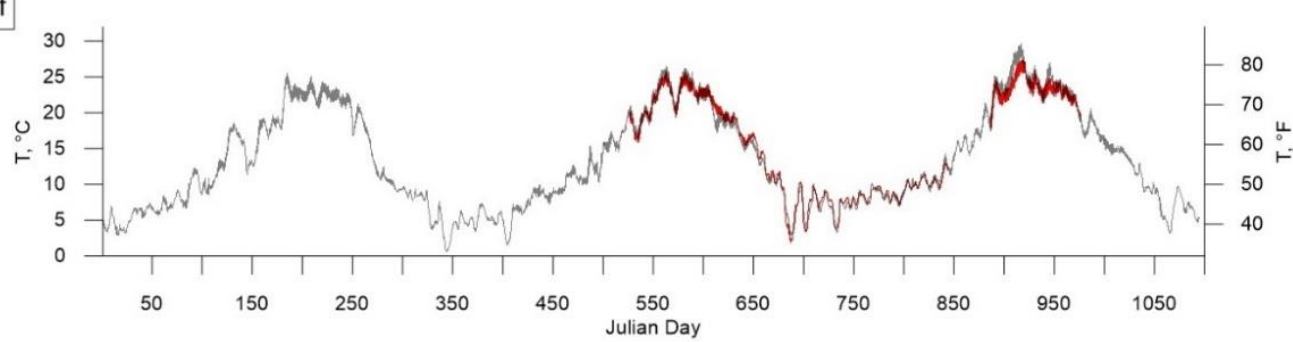

Figure 71. Temperature comparison between field data and model predictions in the mainstem Chehalis River at (a) 21-CH, (b) Newaukum River, (c) 22-CH, (d) upstream of Darigold, (e) downstream of Darigold, and (f) upstream of Skookumchuck River between 2013-2015. 
a

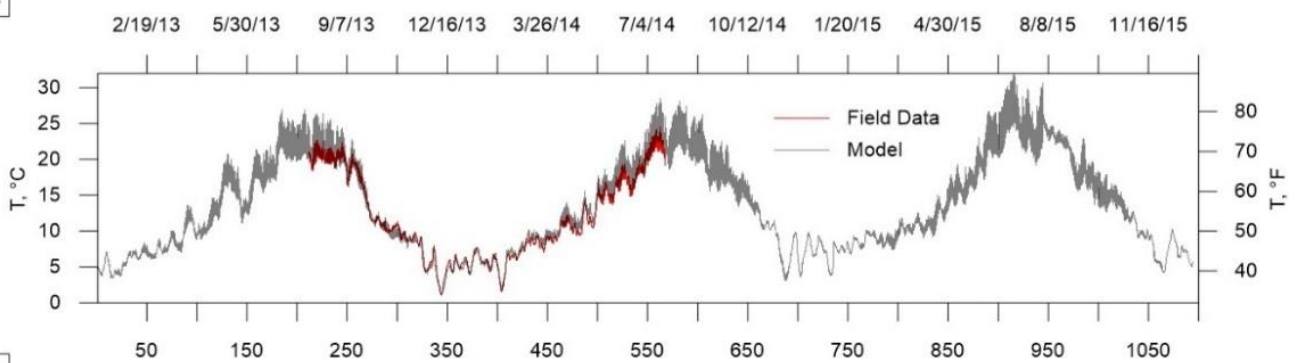

b

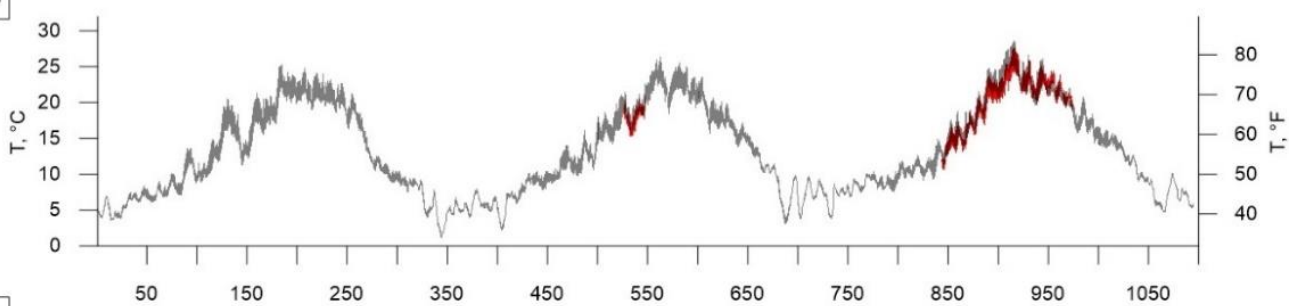

c

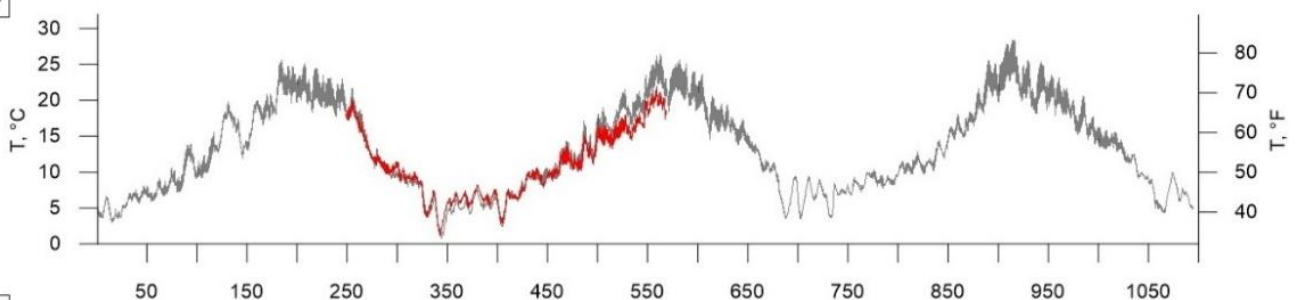

d

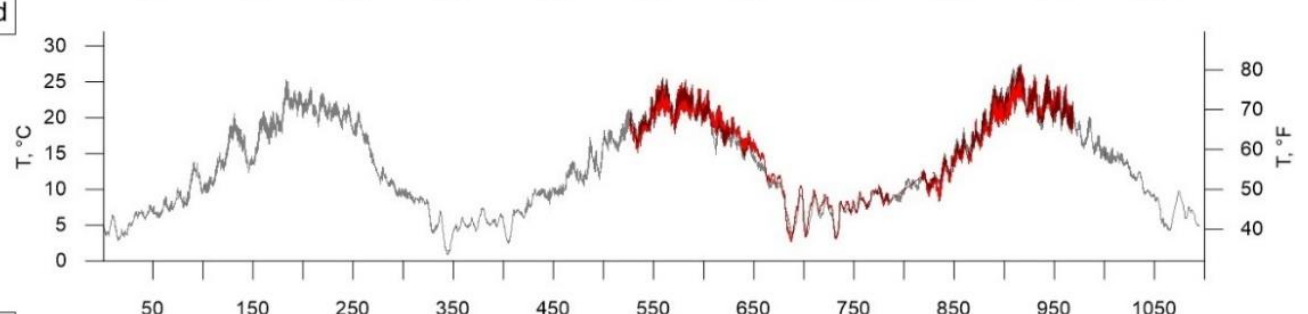

e

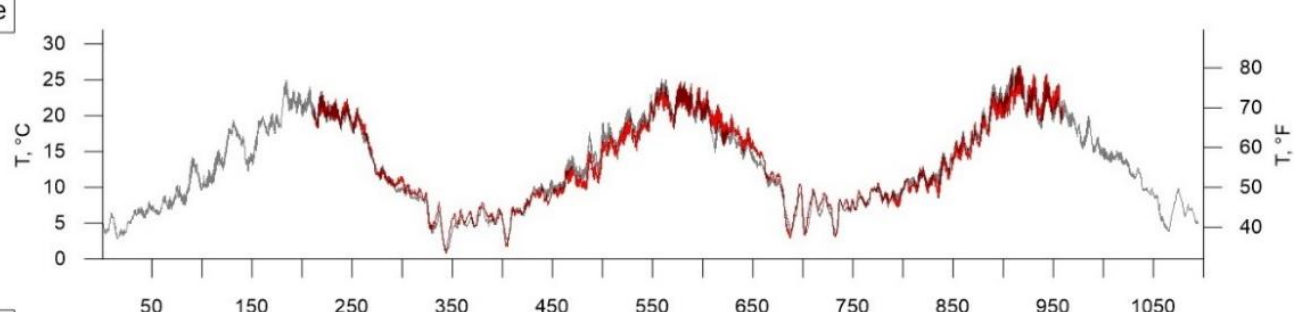

$\mathrm{f}$

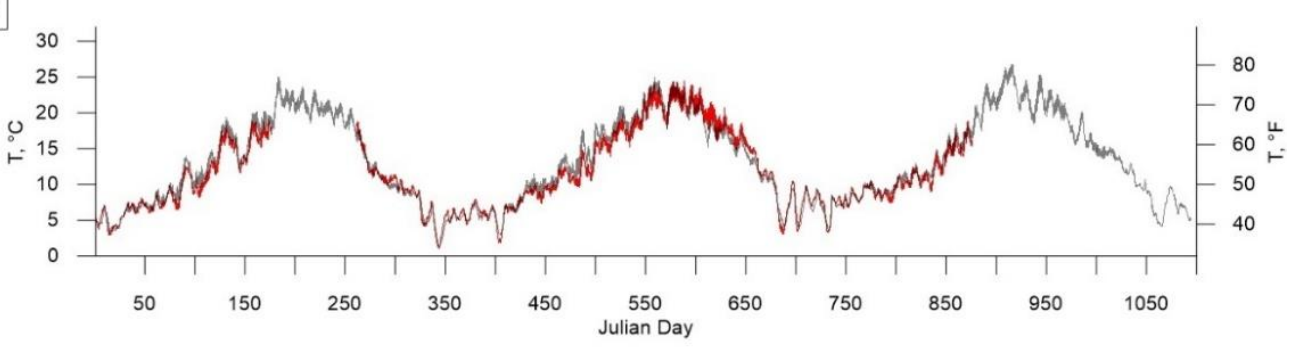

Figure 72. Temperature comparison between field data and model predictions in the mainstem Chehalis River at (a) Galvin Bridge, (b) 17-CH, (c) upstream of Black River, (d) 18-CH, (e) Oakville, and (f) Porter between 2013-2015. 
In the pool area of the Chehalis River, vertical temperature profiles were obtained in 2014. The CE-QUAL-W2 model comparisons to temperature profiles in the pool area are shown in Figure 73, Figure 74, Figure 75, and Figure 76. In many comparisons the model reasonably predicts stratification in the pool. In others it is clear the model fails to mix vertically when it should. The primary goal in this section was to ensure that stratification was predicted reasonably since stratification affects water quality dynamics shown later in this report. The mixing in the pool is very dependent on the wind in the vicinity, and there were no wind data in the pool area. Hence, we did not excessively tune the model wind to reproduce the temperature dynamics day by day. 


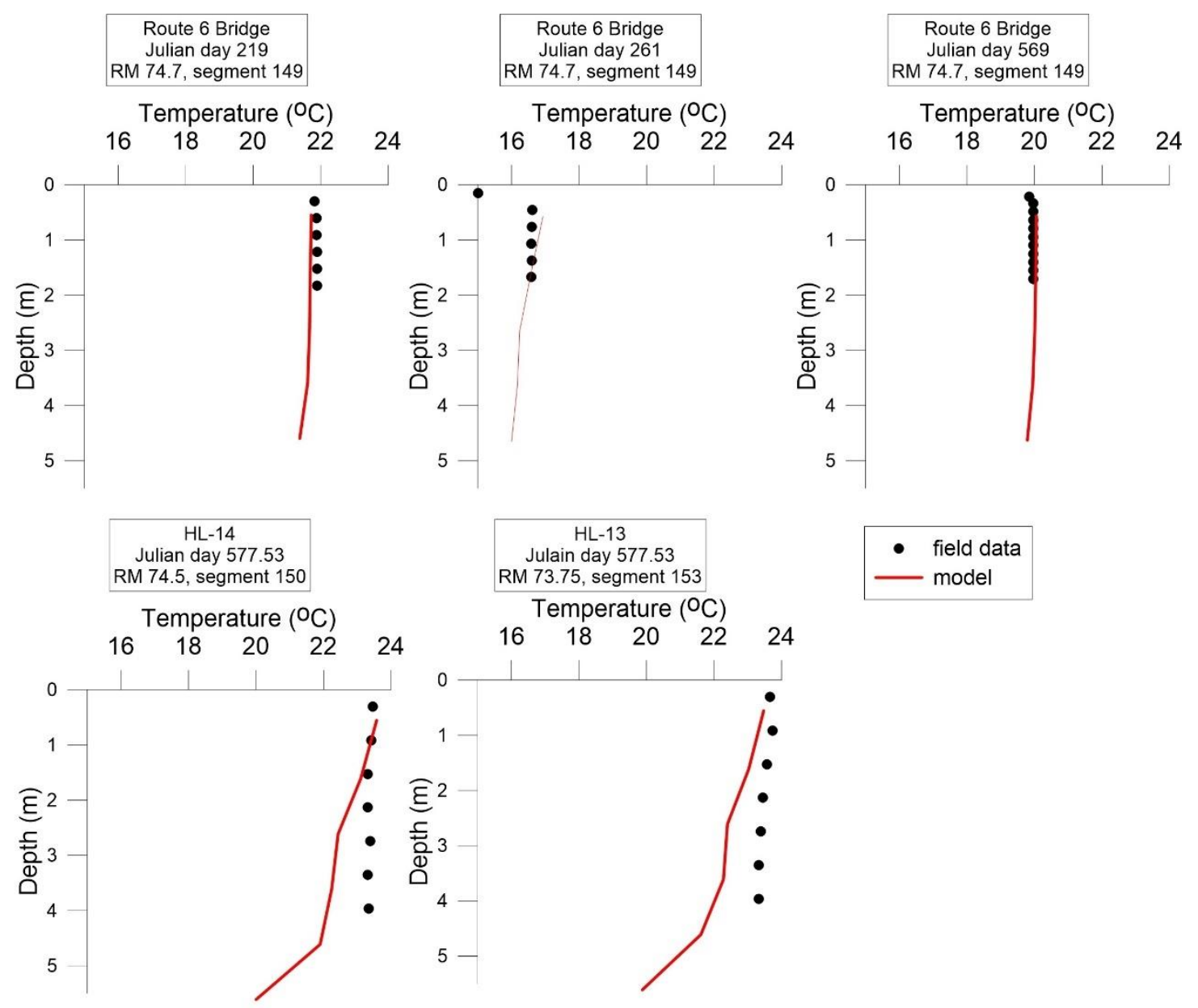

Figure 73. Vertical temperature profiles of field data and model predictions in the pool area at RM 74.7 (Route 6 Bridge) model segment 149, RM 74.5 (HL-14) model segment 150, and RM 73.75 (HL-13) model segment 153 in 2013 and 2014. 


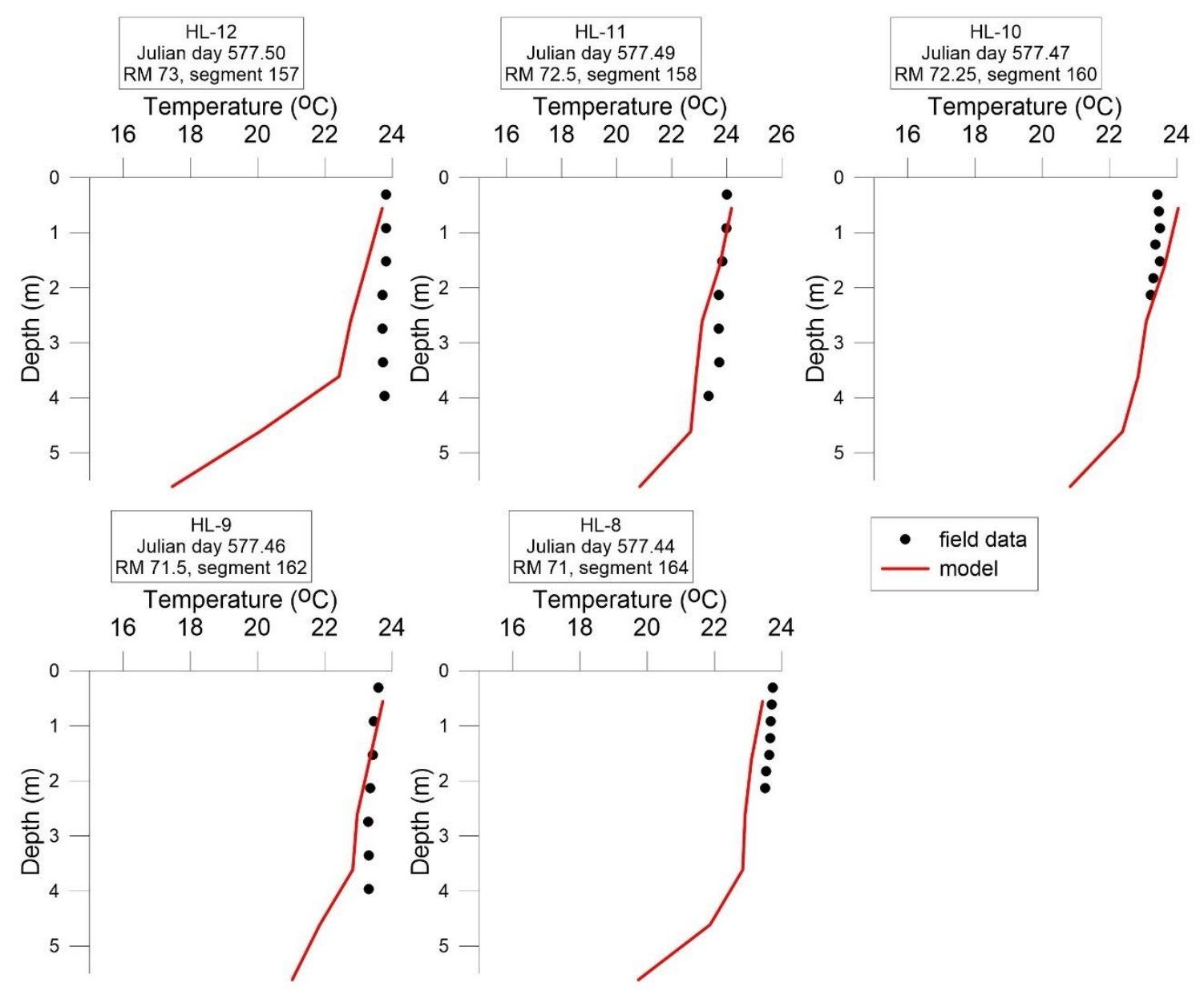

Figure 74. Vertical temperature profiles of field data and model predictions in the pool area at RM 73 (HL-12) model segment 157, RM 72.5 (HL-11) model segment 158, RM 72.25 (HL-10) model segment 160, RM 71.5 (HL-9) model segment 162, and RM 71 (HL-8) model segment 164 in 2014. 


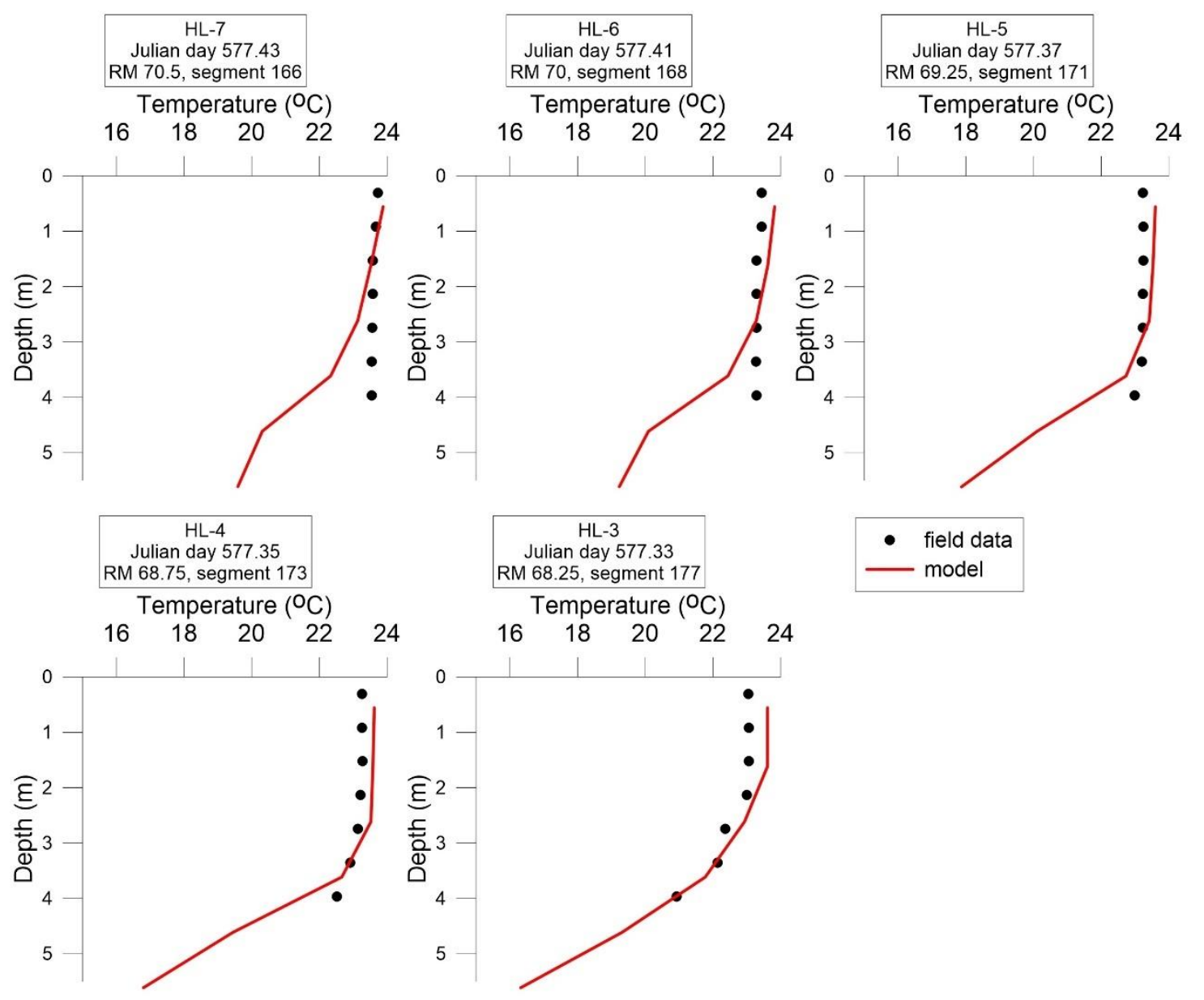

Figure 75. Vertical temperature profiles of field data and model predictions in the pool area at RM 70.5 (HL-7) model segment 166, RM 70 (HL-6) model segment 168, RM 69.25 (HL-5) model segment 171, RM 68.75 (HL-4) model segment 173, and RM 68.25 (HL-3) model segment 177 in 2014. 


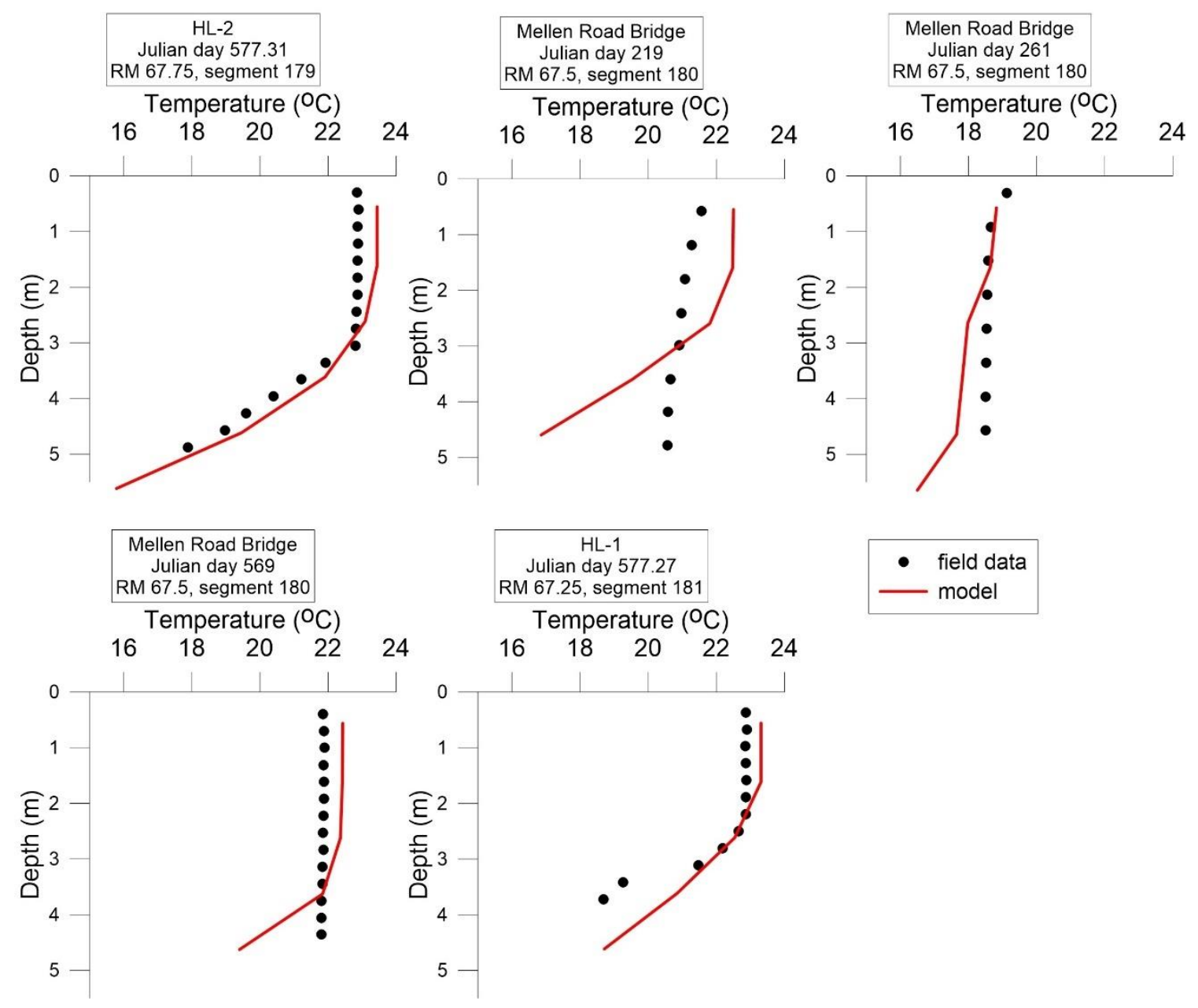

Figure 76. Vertical temperature profiles of field data and model predictions in the pool area at RM 67.75 (HL-2) model segment 179, RM 67.5 (Mellen Road Bridge) model segment 180, and RM 67.25 (HL-1) model segment 181 in 2013 and 2014.

\section{Water quality}

Water quality model predictions between 2013 and 2015 were compared to field data for dissolved oxygen, NO2+NO3-N, PO4-P, TP, TN, TSS, and chlorophyll $a$. Also, periphyton field data from 2018 were compared to model predictions of averaged periphyton for 2013-2015 to assess whether the model is predicting the correct order of magnitude of the periphyton impact on the Chehalis River.

The water quality parameters used in the model calibration are shown in Table 21. 
Table 21. CE-QUAL-W2 model water quality parameters in the Chehalis River Model.

\begin{tabular}{|c|c|c|c|c|c|}
\hline Variable & Description & Units & $\begin{array}{l}\text { Typical } \\
\text { values* }\end{array}$ & $\begin{array}{c}\text { Value from } \\
\text { Glubt et al. } \\
\text { (2017) }\end{array}$ & $\begin{array}{l}\text { Value used } \\
\text { in this } \\
\text { study }\end{array}$ \\
\hline AX & $\begin{array}{l}\text { Longitudinal eddy } \\
\text { viscosity (for } \\
\text { momentum } \\
\text { dispersion) }\end{array}$ & $\mathrm{m}^{2} / \mathrm{sec}$ & 1 & 1 & $\begin{array}{c}\text { Variable } \\
\text { between 1- } \\
10\end{array}$ \\
\hline DX & $\begin{array}{l}\text { Longitudinal eddy } \\
\text { diffusivity (for } \\
\text { dispersion of heat } \\
\text { and constituents) }\end{array}$ & $\mathrm{m}^{2} / \mathrm{sec}$ & 1 & 1 & $\begin{array}{c}\text { Variable } \\
\text { between 1- } \\
90\end{array}$ \\
\hline CBHE & $\begin{array}{l}\text { Coefficient of bottom } \\
\text { heat exchange }\end{array}$ & $\mathrm{Wm}^{2} / \mathrm{sec}$ & 0.30 & 0.30 & 0.30 \\
\hline TSED & $\begin{array}{l}\text { Sediment (ground) } \\
\text { temperature }\end{array}$ & ${ }^{\circ} \mathrm{C}$ & & 11.5 & 11.5 \\
\hline WSC & $\begin{array}{l}\text { Wind sheltering } \\
\text { coefficient }\end{array}$ & & 0.85 & 0.25 & $\begin{array}{c}0.25 \text { and } \\
0.5\end{array}$ \\
\hline BETA & $\begin{array}{l}\text { Fraction of incident } \\
\text { solar radiation } \\
\text { absorbed at the water } \\
\text { surface }\end{array}$ & & 0.45 & 0.45 & 0.45 \\
\hline EXH20 & Extinction for water & $/ \mathrm{m}$ & $0.25-0.45$ & 0.25 & 0.25 \\
\hline AG1 & $\begin{array}{l}\text { Algal growth rate for } \\
\text { group \#1 }\end{array}$ & /day & $1-3$ & 1.5 & 1.25 \\
\hline AM1 & $\begin{array}{l}\text { Algal mortality rate } \\
\text { for group \#1 }\end{array}$ & /day & & 0.1 & 0.1 \\
\hline AE1 & $\begin{array}{l}\text { Algal excretion rate } \\
\text { for group \#1 }\end{array}$ & /day & $\begin{array}{l}0.014- \\
0.044\end{array}$ & 0.04 & 0.04 \\
\hline AR1 & $\begin{array}{l}\text { Algal dark respiration } \\
\text { for group \#1 }\end{array}$ & /day & $0.01-0.92$ & 0.04 & 0.04 \\
\hline AS1 & $\begin{array}{l}\text { Algal settling rate for } \\
\text { group \#1 }\end{array}$ & /day & $0.02-1.00$ & 0.1 & 0.1 \\
\hline ASAT1 & $\begin{array}{l}\text { Algae Saturation } \\
\text { intensity at maximum } \\
\text { photosynthetic rate } \\
\text { for group \#1 }\end{array}$ & $\mathrm{W} / \mathrm{m}^{2}$ & $10-170$ & 150 & 150 \\
\hline
\end{tabular}




\begin{tabular}{|c|c|c|c|c|c|}
\hline Variable & Description & Units & $\begin{array}{l}\text { Typical } \\
\text { values* }\end{array}$ & $\begin{array}{c}\text { Value from } \\
\text { Glubt et al. } \\
\text { (2017) }\end{array}$ & $\begin{array}{l}\text { Value used } \\
\text { in this } \\
\text { study }\end{array}$ \\
\hline APOM1 & $\begin{array}{l}\text { Fraction of algal } \\
\text { biomass lost by } \\
\text { mortality to detritus } \\
\text { for algae for group \#1 }\end{array}$ & & 0.8 & 0.8 & 0.8 \\
\hline AT1_1 & $\begin{array}{l}\text { Lower temperature } \\
\text { for algal growth for } \\
\text { group \#1 }\end{array}$ & ${ }^{\circ} \mathrm{C}$ & & 3 & 3 \\
\hline AT2_1 & $\begin{array}{l}\text { Lower temperature } \\
\text { for maximum algal } \\
\text { growth for group \#1 }\end{array}$ & ${ }^{\circ} \mathrm{C}$ & & 7 & 7 \\
\hline AT3_1 & $\begin{array}{l}\text { Upper temperature } \\
\text { for maximum algal } \\
\text { growth for group \#1 }\end{array}$ & ${ }^{\circ} \mathrm{C}$ & & 20 & 20 \\
\hline AT4_1 & $\begin{array}{l}\text { Upper temperature } \\
\text { for algal growth for } \\
\text { group \#1 }\end{array}$ & ${ }^{\circ} \mathrm{C}$ & & 30 & 30 \\
\hline AK1_1 & $\begin{array}{l}\text { Fraction of algal } \\
\text { growth rate at AT1 } \\
\text { for group \#1 }\end{array}$ & & 0.1 & 0.1 & 0.1 \\
\hline AK2_1 & $\begin{array}{l}\text { Fraction of maximum } \\
\text { algal growth rate at } \\
\text { AT2 for group \#1 }\end{array}$ & & 0.99 & 0.99 & 0.99 \\
\hline AK3_1 & $\begin{array}{l}\text { Fraction of maximum } \\
\text { algal growth rate at } \\
\text { AT3 for group \#1 }\end{array}$ & & 0.99 & 0.99 & 0.99 \\
\hline AK4_1 & $\begin{array}{l}\text { Fraction of algal } \\
\text { growth rate at AT4 } \\
\text { for group \#1 }\end{array}$ & & 0.1 & 0.1 & 0.1 \\
\hline ALGP1 & $\begin{array}{l}\text { Stoichiometric } \\
\text { equivalent between } \\
\text { organic matter and } \\
\text { phosphorus for algae } \\
\text { group \#1 }\end{array}$ & & 0.005 & 0.01 & 0.01 \\
\hline ALGN1 & $\begin{array}{l}\text { Stoichiometric } \\
\text { equivalent between } \\
\text { organic matter and } \\
\text { nitrogen for algae } \\
\text { group \#1 }\end{array}$ & & 0.08 & 0.08 & 0.08 \\
\hline
\end{tabular}




\begin{tabular}{|c|c|c|c|c|c|}
\hline Variable & Description & Units & $\begin{array}{l}\text { Typical } \\
\text { values* }\end{array}$ & $\begin{array}{c}\text { Value from } \\
\text { Glubt et al. } \\
\text { (2017) }\end{array}$ & $\begin{array}{l}\text { Value used } \\
\text { in this } \\
\text { study }\end{array}$ \\
\hline ALGC1 & $\begin{array}{l}\text { Stoichiometric } \\
\text { equivalent between } \\
\text { organic matter and } \\
\text { carbon for algae } \\
\text { group \#1 }\end{array}$ & & $0.4-0.5$ & 0.5 & 0.5 \\
\hline AG2 & $\begin{array}{l}\text { Algal growth rate for } \\
\text { group \#2 }\end{array}$ & /day & $1-3$ & 2 & 2 \\
\hline AM2 & $\begin{array}{l}\text { Algal mortality rate } \\
\text { for group \#2 }\end{array}$ & /day & & 0.1 & 0.1 \\
\hline AE2 & $\begin{array}{l}\text { Algal excretion rate } \\
\text { for group \#2 }\end{array}$ & /day & $\begin{array}{l}0.014- \\
0.044\end{array}$ & 0.04 & 0.04 \\
\hline AR2 & $\begin{array}{l}\text { Algal dark respiration } \\
\text { for group \#2 }\end{array}$ & /day & $0.01-0.92$ & 0.04 & 0.04 \\
\hline AS2 & $\begin{array}{l}\text { Algal settling rate for } \\
\text { group \#2 }\end{array}$ & /day & $0.02-1.00$ & 0.1 & 0.1 \\
\hline ASAT2 & $\begin{array}{l}\text { Algae Saturation } \\
\text { intensity at maximum } \\
\text { photosynthetic rate } \\
\text { for group } \# 2\end{array}$ & $\mathrm{~W} / \mathrm{m}^{2}$ & $10-170$ & 150 & 150 \\
\hline APOM2 & $\begin{array}{l}\text { Fraction of algal } \\
\text { biomass lost by } \\
\text { mortality to detritus } \\
\text { for algae for group \#2 }\end{array}$ & & 0.8 & 0.8 & 0.8 \\
\hline AT1_2 & $\begin{array}{l}\text { Lower temperature } \\
\text { for algal growth for } \\
\text { group \#2 }\end{array}$ & ${ }^{\circ} \mathrm{C}$ & & 7 & 7 \\
\hline AT2_2 & $\begin{array}{l}\text { Lower temperature } \\
\text { for maximum algal } \\
\text { growth for group \#2 }\end{array}$ & ${ }^{\circ} \mathrm{C}$ & & 15 & 15 \\
\hline AT3_2 & $\begin{array}{l}\text { Upper temperature } \\
\text { for maximum algal } \\
\text { growth for group \#2 }\end{array}$ & ${ }^{\circ} \mathrm{C}$ & & 30 & 30 \\
\hline AT4_2 & $\begin{array}{l}\text { Upper temperature } \\
\text { for algal growth for } \\
\text { group \#2 }\end{array}$ & ${ }^{\circ} \mathrm{C}$ & & 35 & 35 \\
\hline
\end{tabular}




\begin{tabular}{|c|c|c|c|c|c|}
\hline Variable & Description & Units & $\begin{array}{l}\text { Typical } \\
\text { values* }\end{array}$ & $\begin{array}{c}\text { Value from } \\
\text { Glubt et al. } \\
\text { (2017) }\end{array}$ & $\begin{array}{l}\text { Value used } \\
\text { in this } \\
\text { study }\end{array}$ \\
\hline AK1_2 & $\begin{array}{l}\text { Fraction of algal } \\
\text { growth rate at AT1 } \\
\text { for group \#2 }\end{array}$ & & 0.1 & 0.1 & 0.1 \\
\hline AK2_2 & $\begin{array}{l}\text { Fraction of maximum } \\
\text { algal growth rate at } \\
\text { AT2 for group \#2 }\end{array}$ & & 0.99 & 0.99 & 0.99 \\
\hline AK3_2 & $\begin{array}{l}\text { Fraction of maximum } \\
\text { algal growth rate at } \\
\text { AT3 for group \#2 }\end{array}$ & & 0.99 & 0.99 & 0.99 \\
\hline AK4_2 & $\begin{array}{l}\text { Fraction of algal } \\
\text { growth rate at AT4 } \\
\text { for group \#2 }\end{array}$ & & 0.1 & 0.1 & 0.1 \\
\hline ALGP2 & $\begin{array}{l}\text { Stoichiometric } \\
\text { equivalent between } \\
\text { organic matter and } \\
\text { phosphorus for algae } \\
\text { group \#2 }\end{array}$ & & 0.005 & 0.01 & 0.01 \\
\hline ALGN2 & $\begin{array}{l}\text { Stoichiometric } \\
\text { equivalent between } \\
\text { organic matter and } \\
\text { nitrogen for algae } \\
\text { group \#2 }\end{array}$ & & 0.08 & 0.08 & 0.08 \\
\hline ALGC2 & $\begin{array}{l}\text { Stoichiometric } \\
\text { equivalent between } \\
\text { organic matter and } \\
\text { carbon for algae } \\
\text { group \#2 }\end{array}$ & & $0.4-0.5$ & 0.5 & 0.5 \\
\hline LDOMDK & $\begin{array}{l}\text { Labile DOM decay } \\
\text { rate }\end{array}$ & /day & 0.04-0.12 & 0.08 & 0.08 \\
\hline LRDDK & $\begin{array}{l}\text { Labile to refractory } \\
\text { decay rate }\end{array}$ & /day & 0.001 & 0.01 & 0.01 \\
\hline RDOMDK & $\begin{array}{l}\text { Maximum refractory } \\
\text { decay rate }\end{array}$ & /day & 0.001 & 0.001 & 0.001 \\
\hline LPOMDK & $\begin{array}{l}\text { Labile Detritus decay } \\
\text { rate }\end{array}$ & /day & $0.04-0.1$ & 0.06 & 0.06 \\
\hline POMS & Detritus settling rate & $\mathrm{m} /$ day & $0.2-2$ & 0.75 & 0.75 \\
\hline
\end{tabular}




\begin{tabular}{|c|c|c|c|c|c|}
\hline Variable & Description & Units & $\begin{array}{l}\text { Typical } \\
\text { values* }\end{array}$ & $\begin{array}{c}\text { Value from } \\
\text { Glubt et al. } \\
\text { (2017) }\end{array}$ & $\begin{array}{l}\text { Value used } \\
\text { in this } \\
\text { study }\end{array}$ \\
\hline RPOMDK & $\begin{array}{l}\text { Refractory detritus } \\
\text { decay rate }\end{array}$ & /day & 0.001 & 0.001 & 0.001 \\
\hline 0MT1 & $\begin{array}{l}\text { Lower temperature } \\
\text { for organic matter } \\
\text { decay }\end{array}$ & ${ }^{\circ} \mathrm{C}$ & 4 & 4 & 4 \\
\hline ОMT2 & $\begin{array}{l}\text { Lower temperature } \\
\text { for maximum organic } \\
\text { matter decay }\end{array}$ & ${ }^{\circ} \mathrm{C}$ & 30 & 25 & 25 \\
\hline OMK1 & $\begin{array}{l}\text { Fraction of organic } \\
\text { matter decay rate at } \\
\text { OMT1 }\end{array}$ & & 0.1 & 0.1 & 0.1 \\
\hline OMK2 & $\begin{array}{l}\text { Fraction of organic } \\
\text { matter decay rate at } \\
\text { OMT2 }\end{array}$ & & 0.99 & 0.99 & 0.99 \\
\hline P04R & $\begin{array}{l}\text { Anaerobic sediment } \\
\text { release rate of } \\
\text { phosphorus as } \\
\text { fraction of SOD }\end{array}$ & & & 0.001 & 0.001 \\
\hline AHSP1 & $\begin{array}{l}\text { Algal half-saturation } \\
\text { constant for } \\
\text { phosphorus for group } \\
\# 1\end{array}$ & $\mathrm{~g} / \mathrm{m}^{3}$ & $\begin{array}{c}0.002- \\
0.01\end{array}$ & 0.003 & 0.003 \\
\hline AHSP2 & $\begin{array}{l}\text { Algal half-saturation } \\
\text { constant for } \\
\text { phosphorus for group } \\
\# 2\end{array}$ & $\mathrm{~g} / \mathrm{m}^{3}$ & $\begin{array}{c}0.002- \\
0.01\end{array}$ & 0.003 & 0.003 \\
\hline NH4DK & $\begin{array}{l}\text { Ammonia decay rate } \\
\text { (nitrification rate) }\end{array}$ & /day & $0.001-1.3$ & 0.8 & 0.8 \\
\hline AHSN1 & $\begin{array}{l}\text { Algal half-saturation } \\
\text { constant for nitrogen } \\
\text { for group \#1 }\end{array}$ & $\mathrm{g} / \mathrm{m}^{3}$ & 0.014 & 0.014 & 0.014 \\
\hline AHSN2 & $\begin{array}{l}\text { Algal half-saturation } \\
\text { constant for nitrogen } \\
\text { for group \#2 }\end{array}$ & $\mathrm{g} / \mathrm{m}^{3}$ & 0.014 & 0.014 & 0.014 \\
\hline NH4T1 & $\begin{array}{l}\text { Lower temperature } \\
\text { for ammonia decay }\end{array}$ & ${ }^{\circ} \mathrm{C}$ & 5 & 5 & 5 \\
\hline
\end{tabular}




\begin{tabular}{|c|c|c|c|c|c|}
\hline Variable & Description & Units & $\begin{array}{l}\text { Typical } \\
\text { values* }\end{array}$ & $\begin{array}{c}\text { Value from } \\
\text { Glubt et al. } \\
\text { (2017) }\end{array}$ & $\begin{array}{l}\text { Value used } \\
\text { in this } \\
\text { study }\end{array}$ \\
\hline NH4T2 & $\begin{array}{l}\text { Lower temperature } \\
\text { for maximum } \\
\text { ammonia decay }\end{array}$ & ${ }^{\circ} \mathrm{C}$ & 20 & 25 & 25 \\
\hline NH4K1 & $\begin{array}{l}\text { Fraction of } \\
\text { nitrification rate at } \\
\text { NH4T1 }\end{array}$ & & 0.1 & 0.1 & 0.1 \\
\hline NH4K2 & $\begin{array}{l}\text { Fraction of } \\
\text { nitrification rate at } \\
\text { NH4T2 }\end{array}$ & & 0.99 & 0.99 & 0.99 \\
\hline NO3DK & $\begin{array}{l}\text { Nitrate decay rate } \\
\text { (denitrification rate) }\end{array}$ & /day & $0.05-0.15$ & 0.03 & 0.03 \\
\hline N03T1 & $\begin{array}{l}\text { Lower temperature } \\
\text { for nitrate decay }\end{array}$ & ${ }^{\circ} \mathrm{C}$ & 5 & 5 & 5 \\
\hline N03T2 & $\begin{array}{l}\text { Lower temperature } \\
\text { for maximum nitrate } \\
\text { decay }\end{array}$ & ${ }^{\circ} \mathrm{C}$ & 20 & 25 & 25 \\
\hline N03K1 & $\begin{array}{l}\text { Fraction of } \\
\text { denitrification rate at } \\
\text { NO3T1 }\end{array}$ & & 0.1 & 0.1 & 0.1 \\
\hline N03K2 & $\begin{array}{l}\text { Fraction of } \\
\text { denitrification rate at } \\
\text { NO3T2 }\end{array}$ & & 0.99 & 0.99 & 0.99 \\
\hline O2NH4 & $\begin{array}{l}\text { Oxygen } \\
\text { stoichiometric } \\
\text { equivalent for } \\
\text { ammonia decay }\end{array}$ & & 4.57 & 4.57 & 4.57 \\
\hline O20M & $\begin{array}{l}\text { Oxygen } \\
\text { stoichiometric } \\
\text { equivalent for organic } \\
\text { matter decay }\end{array}$ & & 1.4 & 1.4 & 1.4 \\
\hline 02AR1 & $\begin{array}{l}\text { Oxygen } \\
\text { stoichiometric } \\
\text { equivalent for dark } \\
\text { respiration for group } \\
\# 1\end{array}$ & & 1.1 & 1.1 & 1.1 \\
\hline
\end{tabular}




\begin{tabular}{|c|c|c|c|c|c|}
\hline Variable & Description & Units & $\begin{array}{l}\text { Typical } \\
\text { values* }\end{array}$ & $\begin{array}{c}\text { Value from } \\
\text { Glubt et al. } \\
\text { (2017) }\end{array}$ & $\begin{array}{l}\text { Value used } \\
\text { in this } \\
\text { study }\end{array}$ \\
\hline O2AR2 & $\begin{array}{l}\text { Oxygen } \\
\text { stoichiometric } \\
\text { equivalent for dark } \\
\text { respiration for group } \\
\# 2\end{array}$ & & 1.1 & 1.1 & 1.1 \\
\hline 02AG1 & $\begin{array}{l}\text { Oxygen } \\
\text { stoichiometric } \\
\text { equivalent for algal } \\
\text { growth for group \#1 }\end{array}$ & & 1.4 & 1.6 & 1.6 \\
\hline 02AG2 & $\begin{array}{l}\text { Oxygen } \\
\text { stoichiometric } \\
\text { equivalent for algal } \\
\text { growth for group \#2 }\end{array}$ & & 1.4 & 1.6 & 1.6 \\
\hline 02LIM & $\begin{array}{l}\text { Dissolved oxygen } \\
\text { concentration at } \\
\text { which anaerobic } \\
\text { processes begin }\end{array}$ & $\mathrm{g} / \mathrm{m}^{3}$ & 0.1 & 0.07 & 0.07 \\
\hline SEDK & $\begin{array}{l}\text { First order sediment } \\
\text { compartment decay } \\
\text { rate }\end{array}$ & /day & & 0.03 & 0.1 \\
\hline SOD & $\begin{array}{c}\text { Zeroth order } \\
\text { sediment oxygen } \\
\text { demand }\end{array}$ & $\mathrm{g} / \mathrm{m}^{2} /$ day & $0.3-6$ & $0.3-1.9$ & $0.3-1.9$ \\
\hline$\overline{\text { SEDBR }}$ & Sediment burial rate & /day & & 0.01 & 0.01 \\
\hline \multicolumn{6}{|c|}{ * Cole and Wells (2018) } \\
\hline
\end{tabular}

DO, nutrients, chlorophyll $a, \mathrm{pH}$ and TSS

Figure 77 through Figure 94 show the model results for dissolved oxygen, ammonia,

nitrates, TKN, phosphate, total phosphorus, chlorophyll $a, \mathrm{pH}$, and TSS at the

Chehalis River stations: upstream of Pe Ell, downstream of Pe Ell, Dryad, upstream

of the South Fork Chehalis River, Adna, upstream of the Newaukum River, Route 6

bridge, upstream of Skookumchuck River, Galvin Road bridge, upstream of Black 
River, Oakville, and Porter. Model predictions of alkalinity (there were no field data comparisons) are shown in Figure 95 and Figure 96. 
a
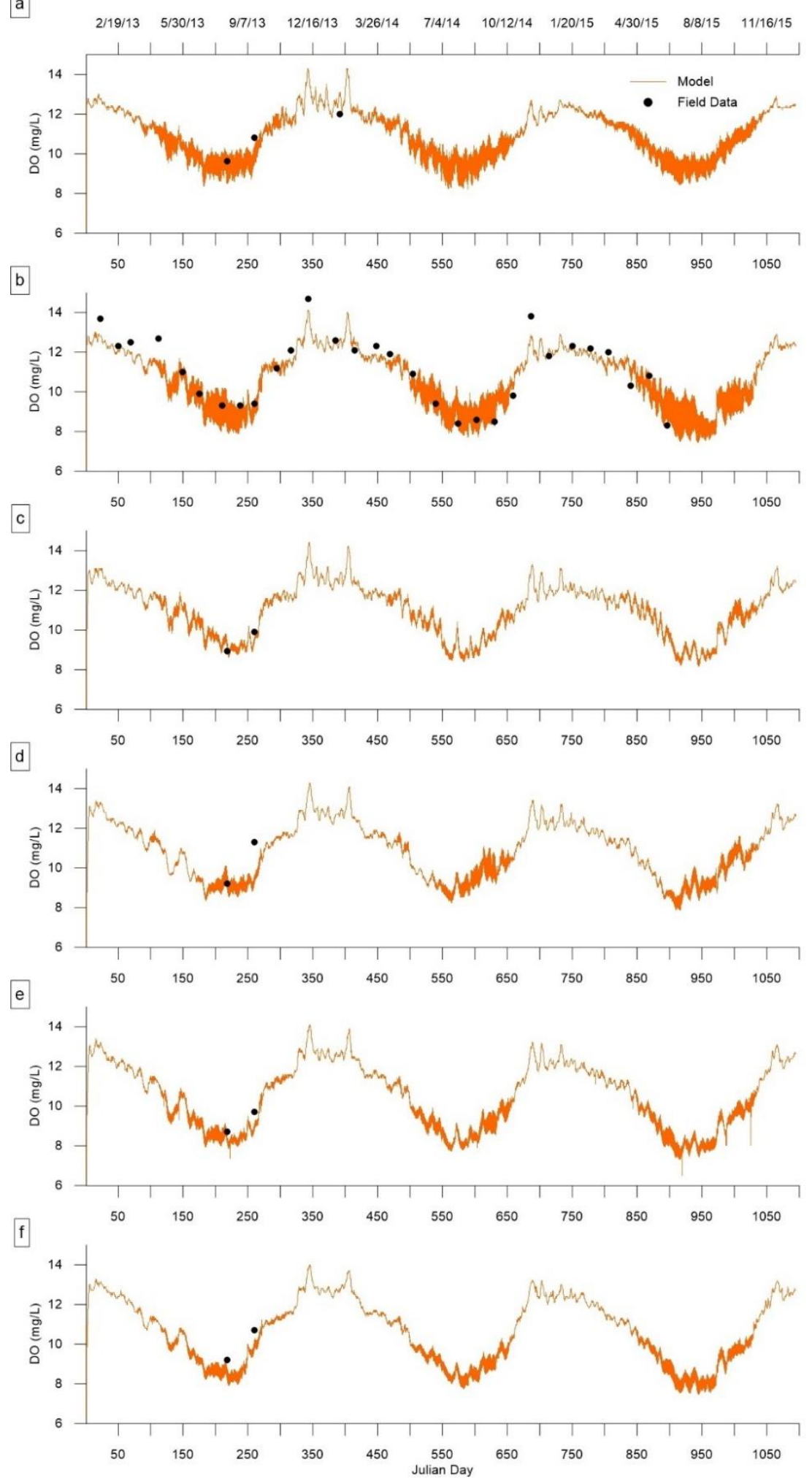

Figure 77. Model dissolved oxygen predictions compared to field data in mainstem Chehalis River at (a) upstream of Pe Ell, (b) Dryad, (c) upstream of South Fork Chehalis River, (d) Adna, (e) upstream of Newaukum River, and (f) Route 6 bridge between 2013-2015. 


\section{a}

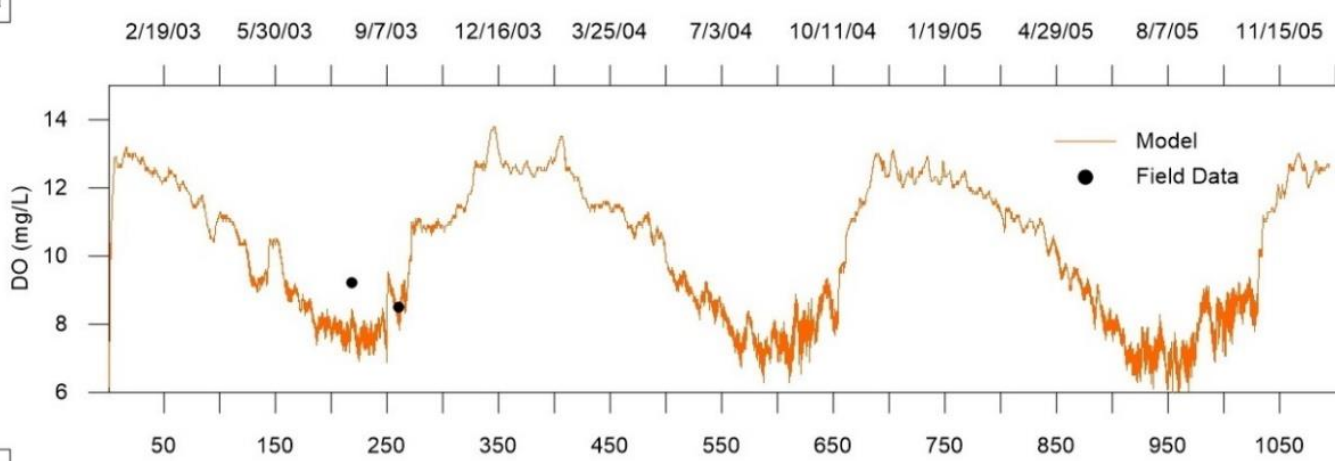

b

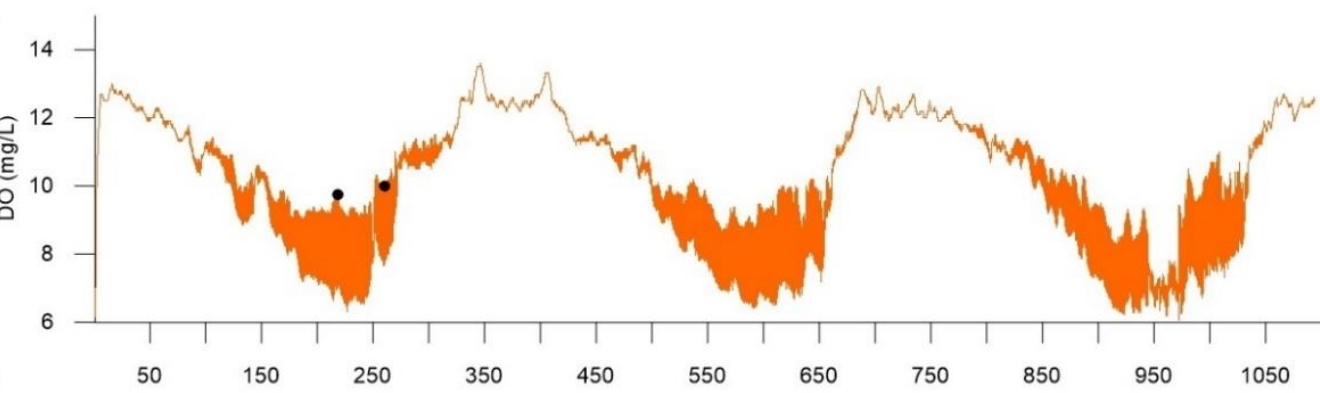

c

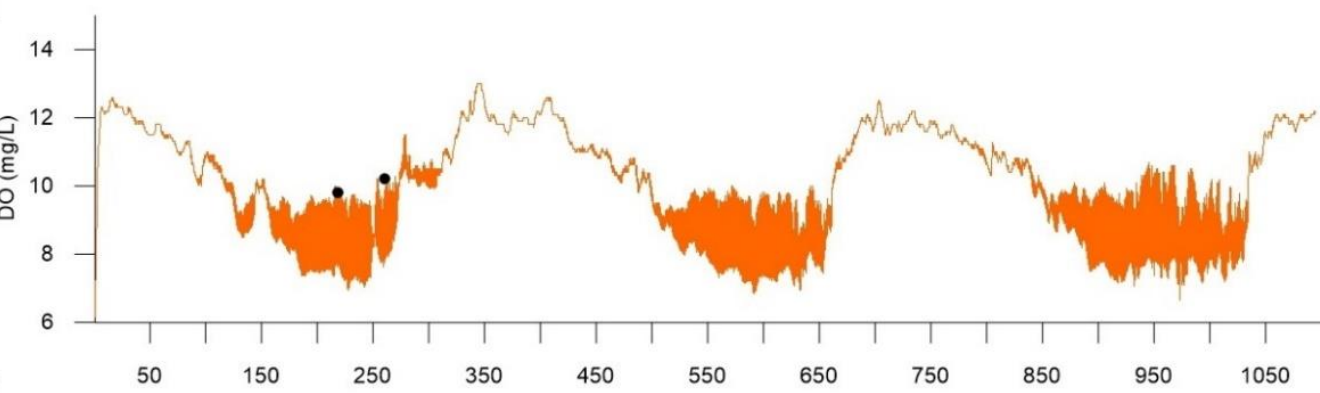

d

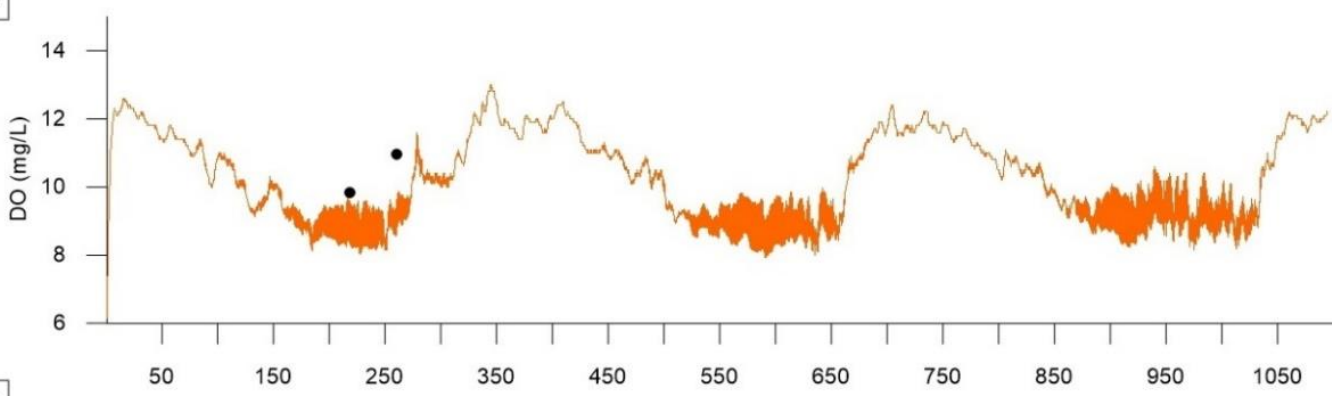

e

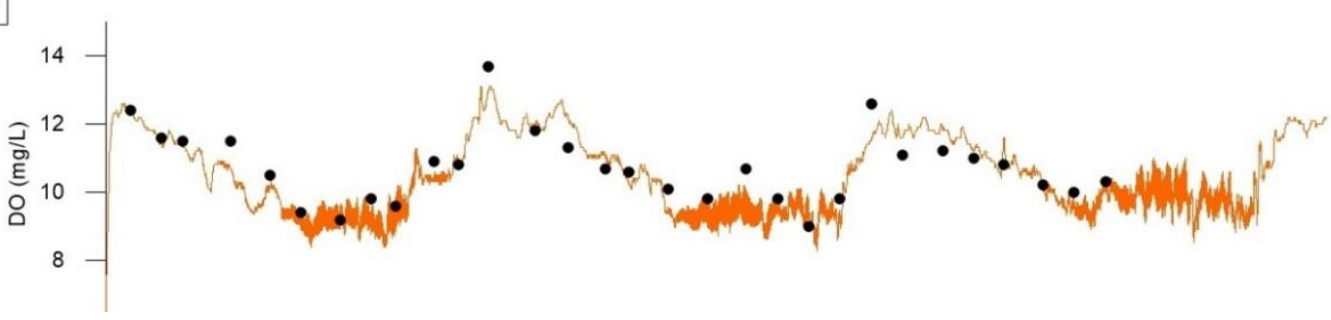

Figure 78. Model dissolved oxygen predictions compared to field data in the mainstem Chehalis River at (a) upstream of Skookumchuck River, (b) Galvin Road bridge, (c) upstream of Black River, (d) Oakville, and (e) Porter between 2013-2015. 
a

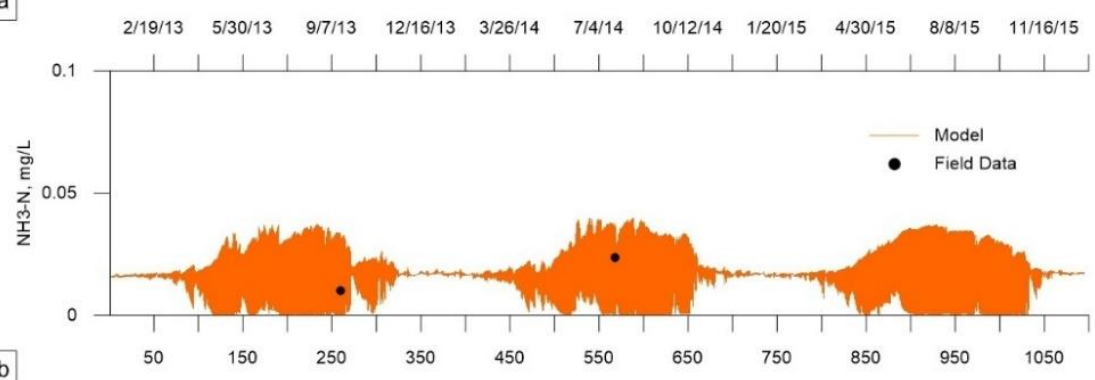

b
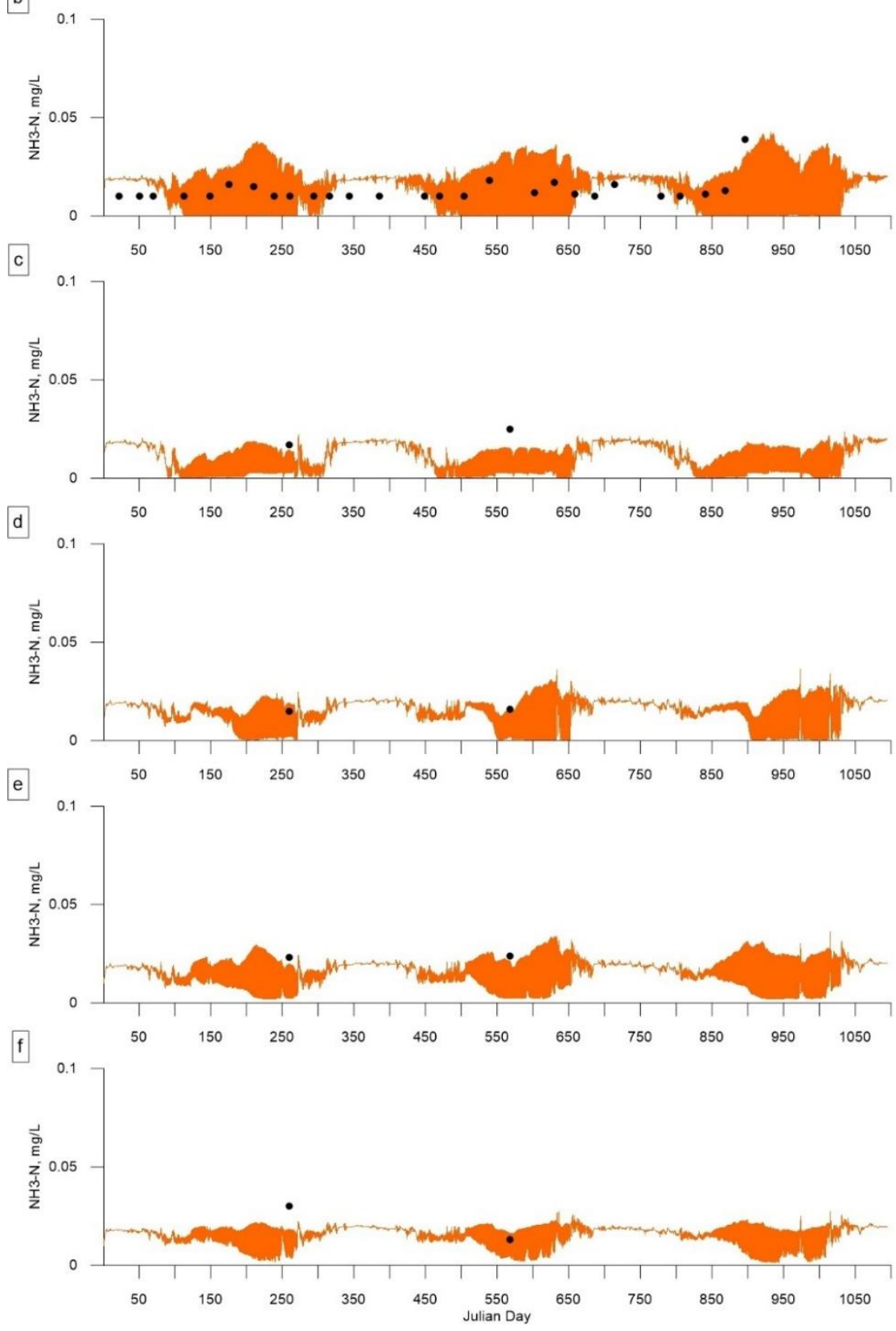

Figure 79. Model ammonia predictions compared to field data in mainstem Chehalis River at (a) upstream of Pe Ell, (b) Dryad, (c) upstream of South Fork Chehalis River, (d) Adna, (e) upstream of Newaukum River, and (f) Route 6 bridge between 2013-2015. 
a

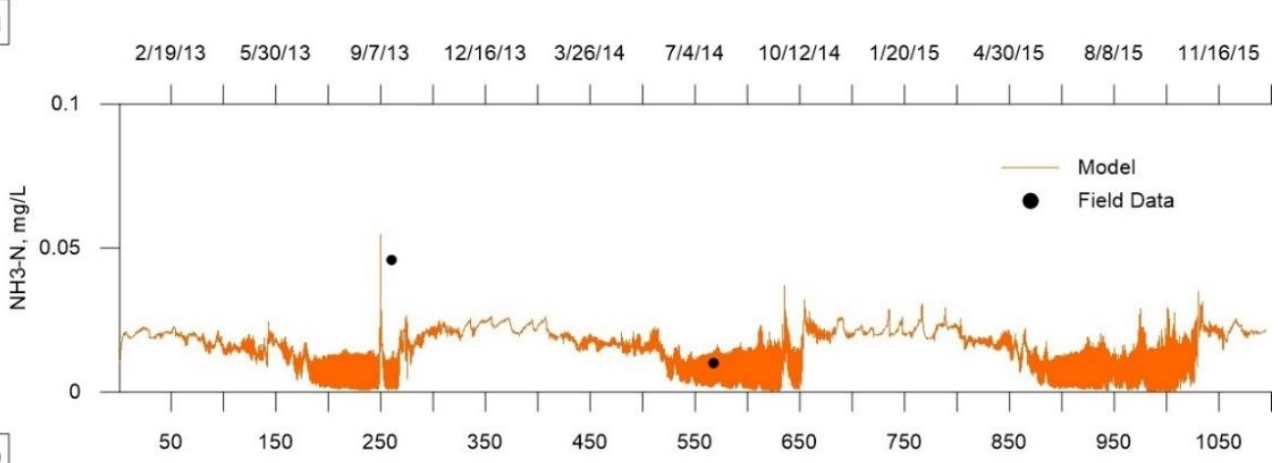

b

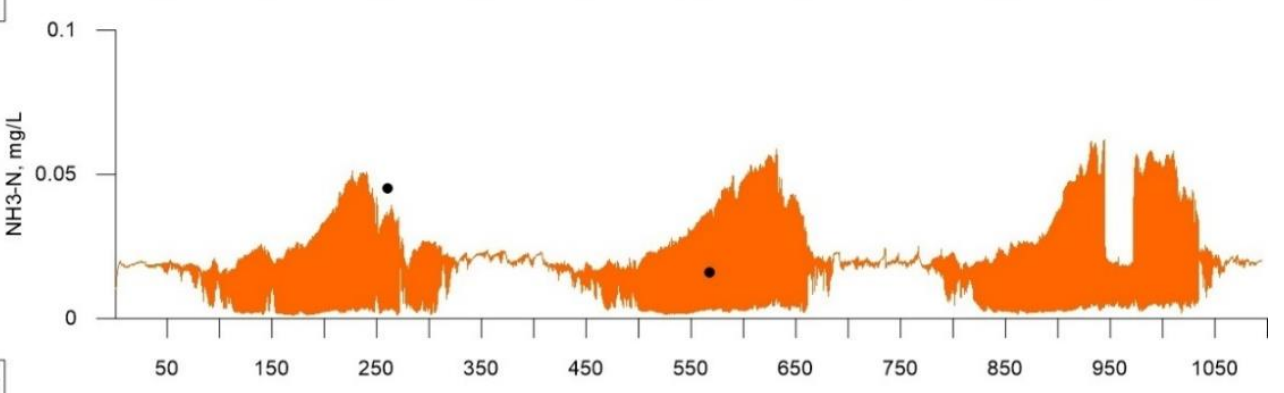

C

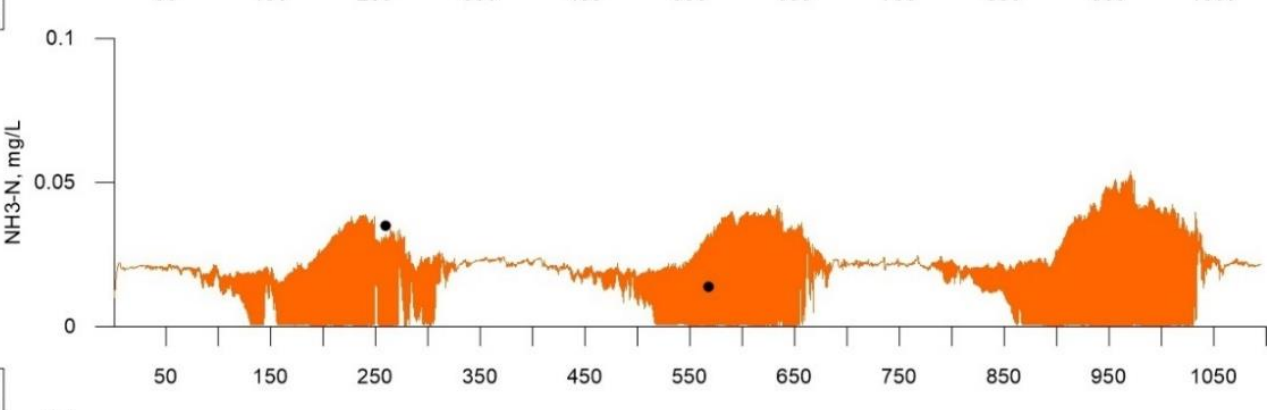

d

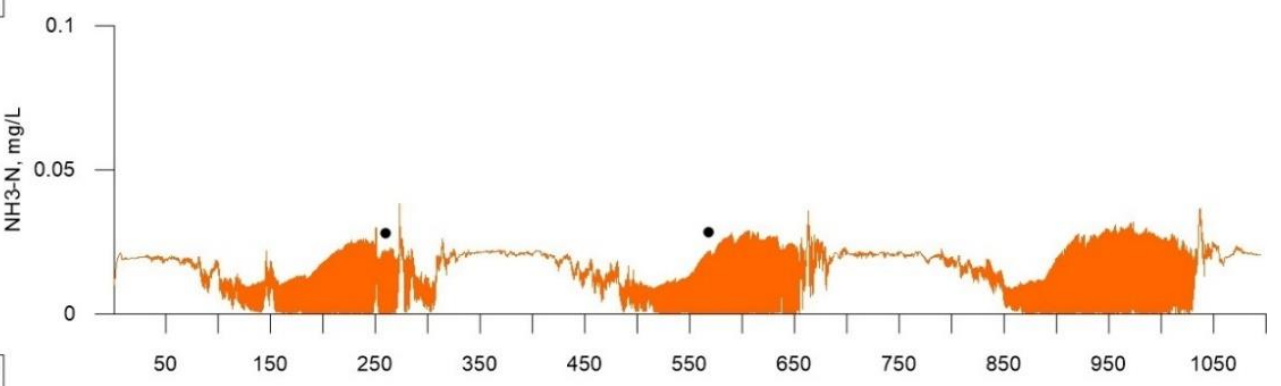

$\mathrm{e}$

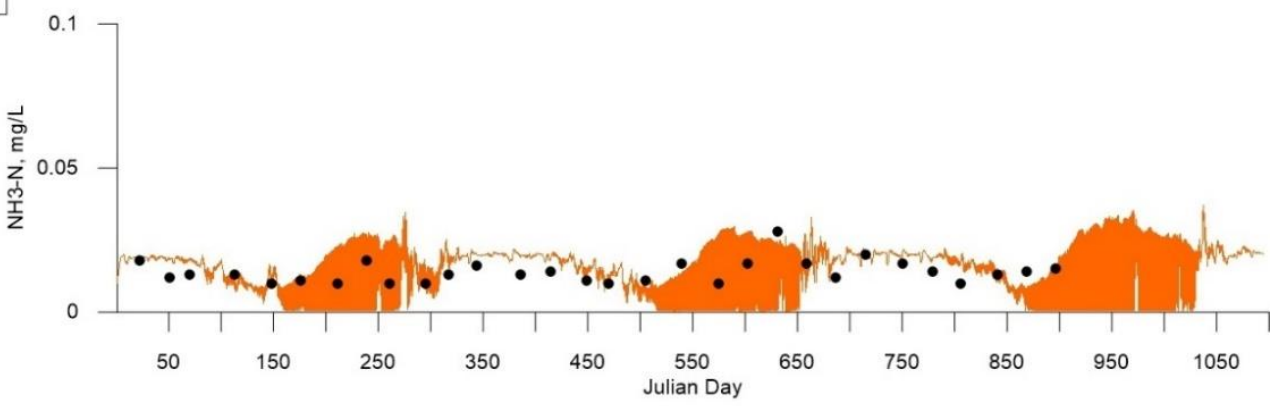

Figure 80. Model ammonia predictions compared to field data in the mainstem Chehalis River at (a) upstream of Skookumchuck River, (b) Galvin Road bridge, (c) upstream of Black River, (d) Oakville, and (e) Porter between 2013-2015. 
a
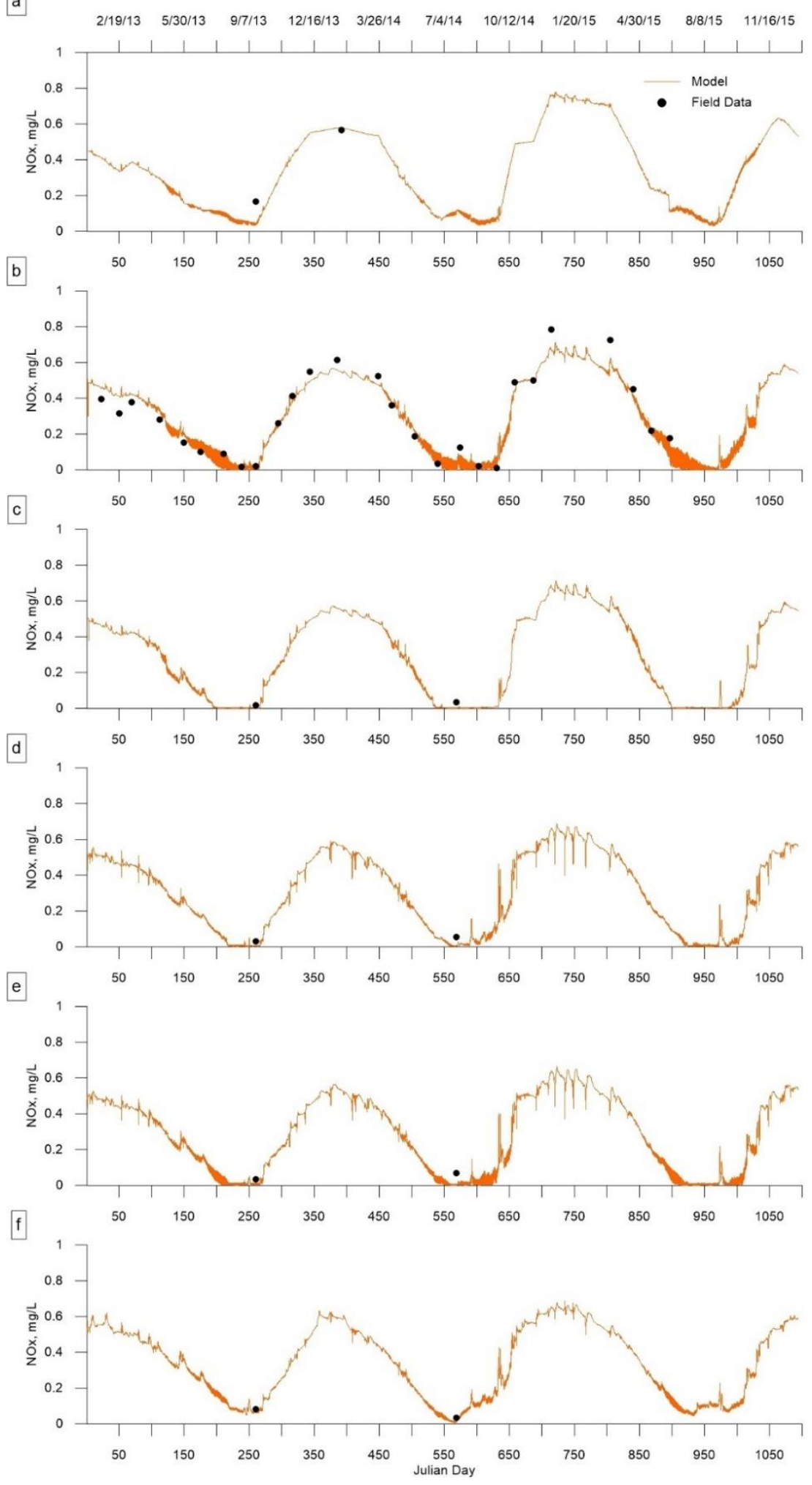

Figure 81. Model NO2-N+NO3-N predictions compared to field data in mainstem Chehalis River at (a) upstream of Pe Ell, (b) Dryad, (c) upstream of South Fork Chehalis River, (d) Adna, (e) upstream of Newaukum River, and (f) Route 6 bridge between 2013-2015. 


\section{a}

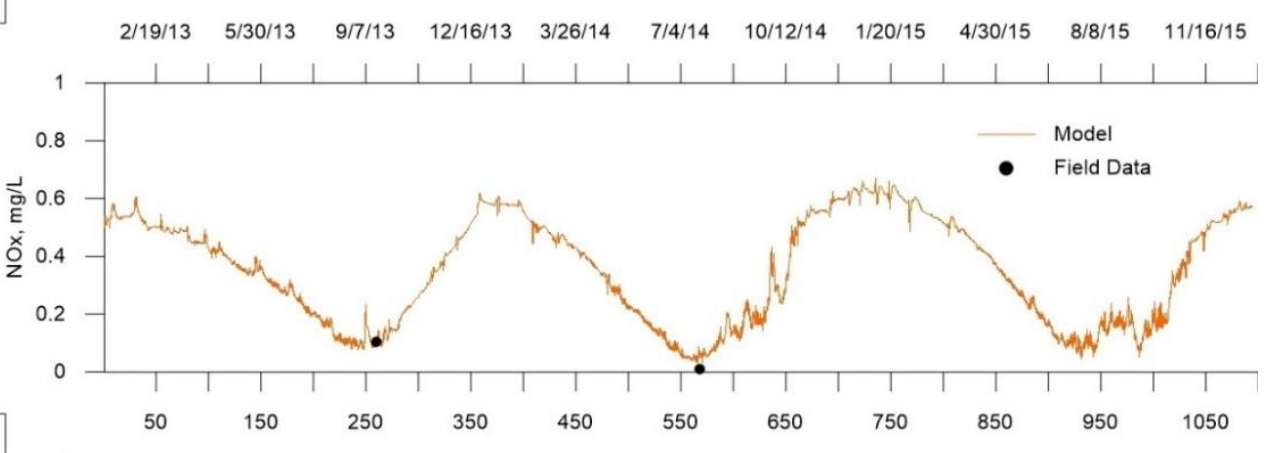

b

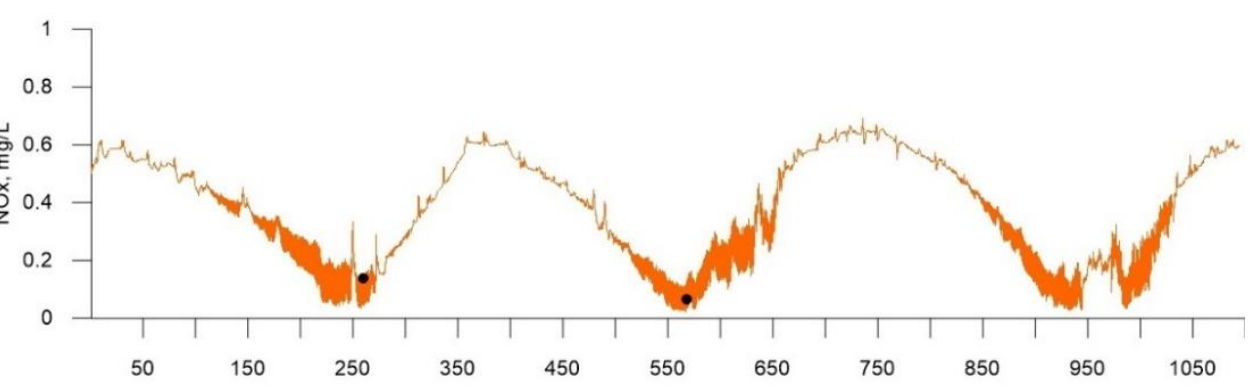

c

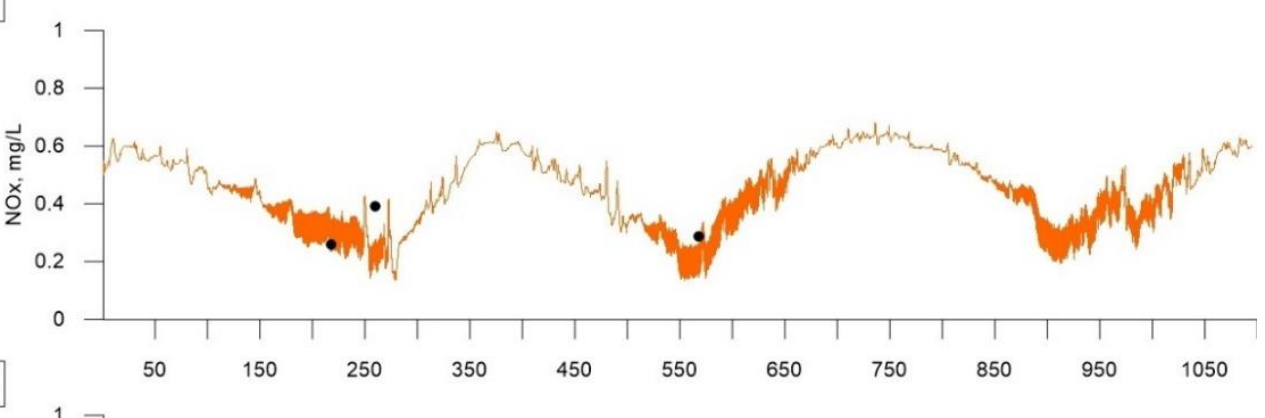

d
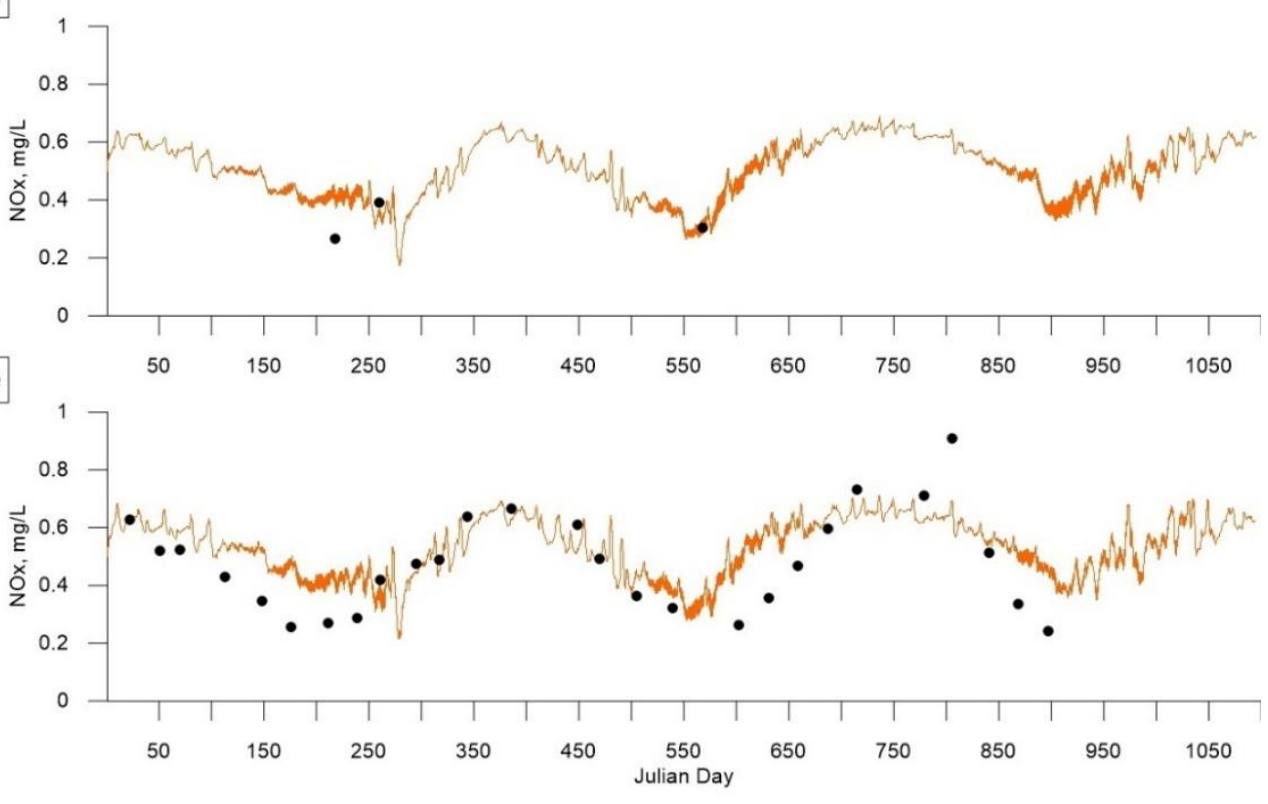

Figure 82. Model NO2-N+NO3-N predictions compared to field data in the mainstem Chehalis River at (a) upstream of Skookumchuck River, (b) Galvin Road bridge, (c) upstream of Black River, (d) Oakville, and (e) Porter between 2013-2015. 
a

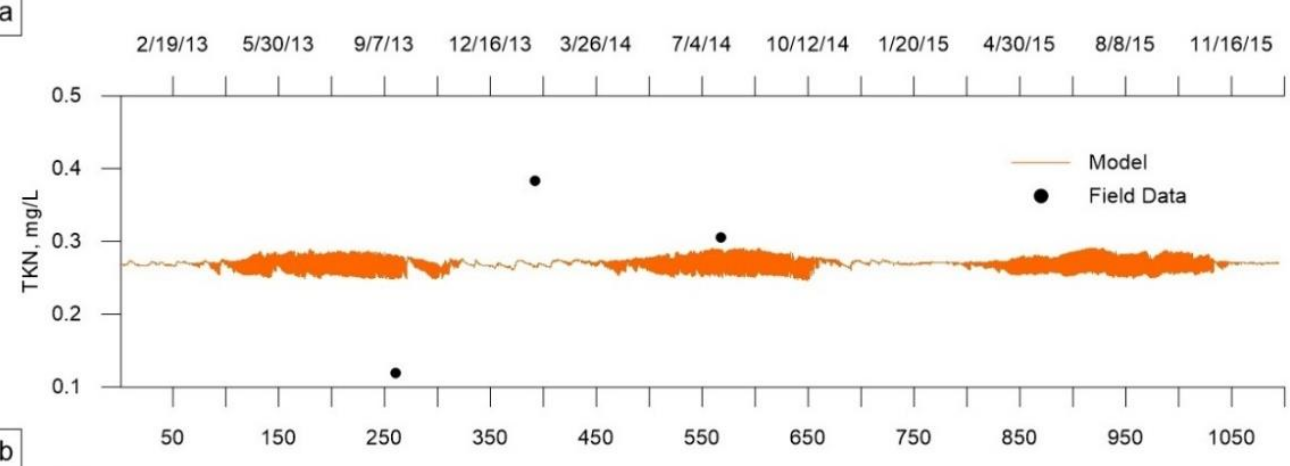

b

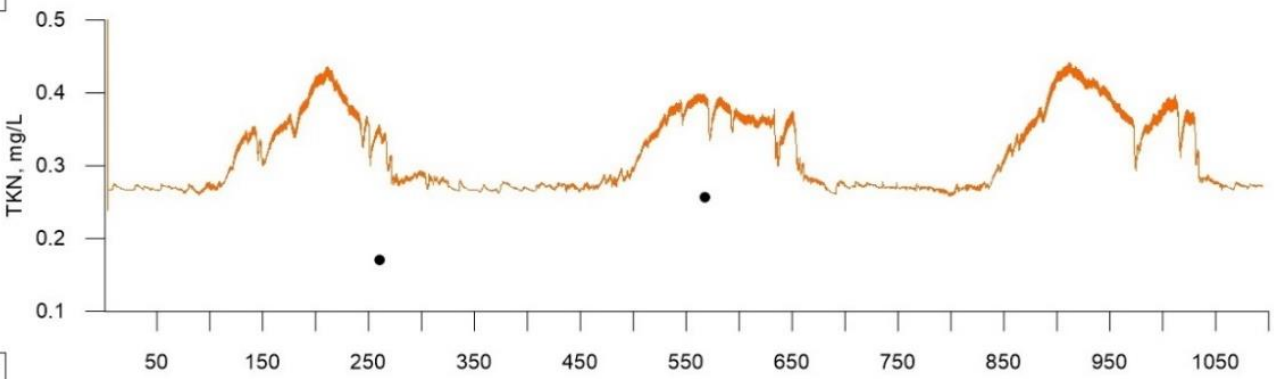

c

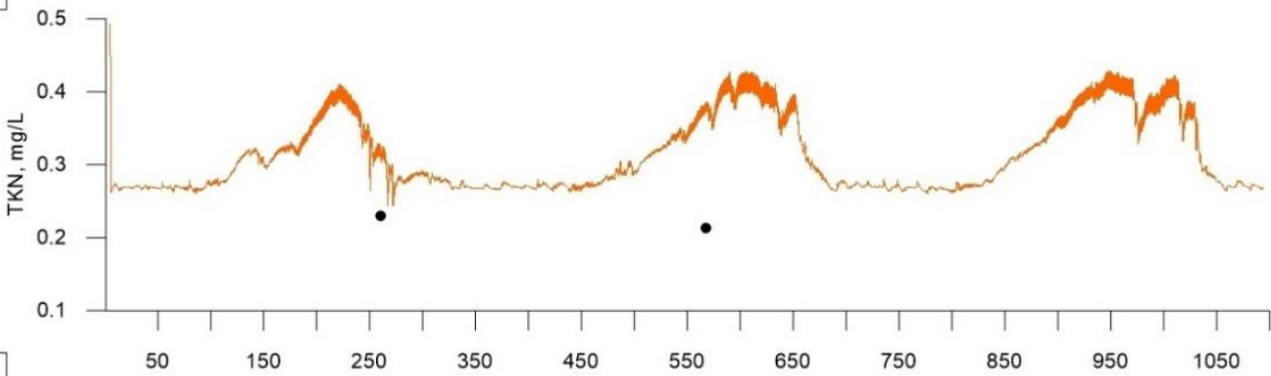

d

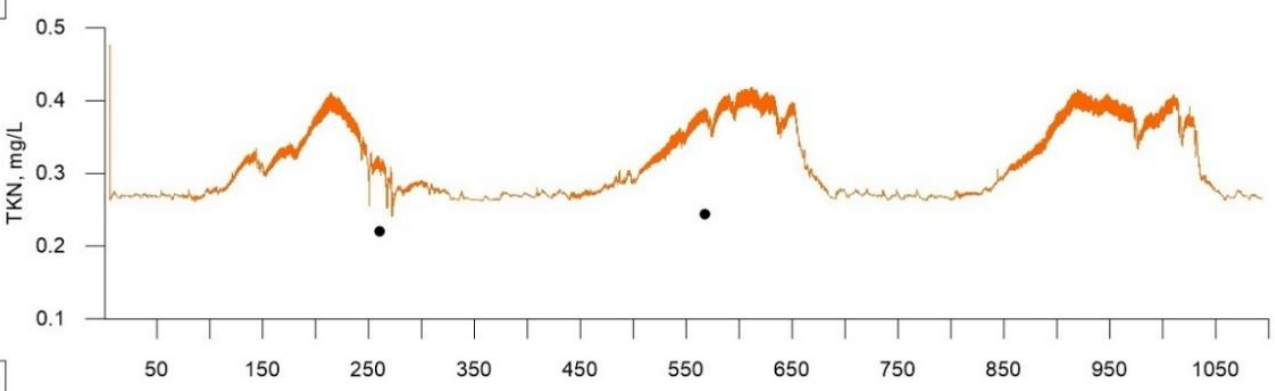

e

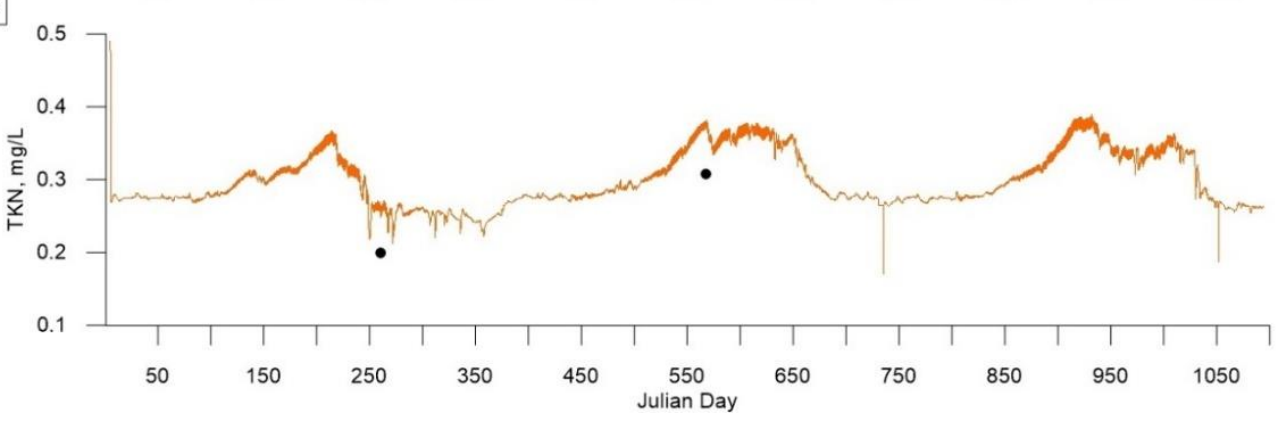

Figure 83. Model TKN predictions compared to field data in the mainstem Chehalis River at (a) upstream of Pe Ell, (b) upstream of South Fork Chehalis River, (c) Adna, (d) upstream of Newaukum River, and (e) Route 6 bridge between 2013-2015. 
a

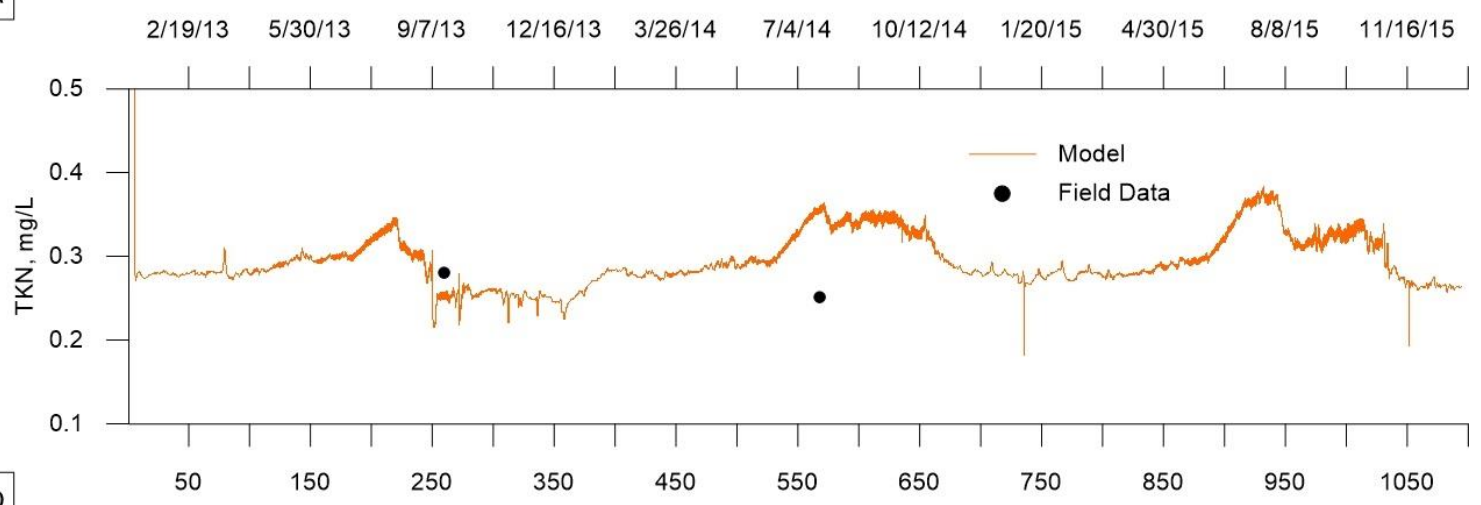

b

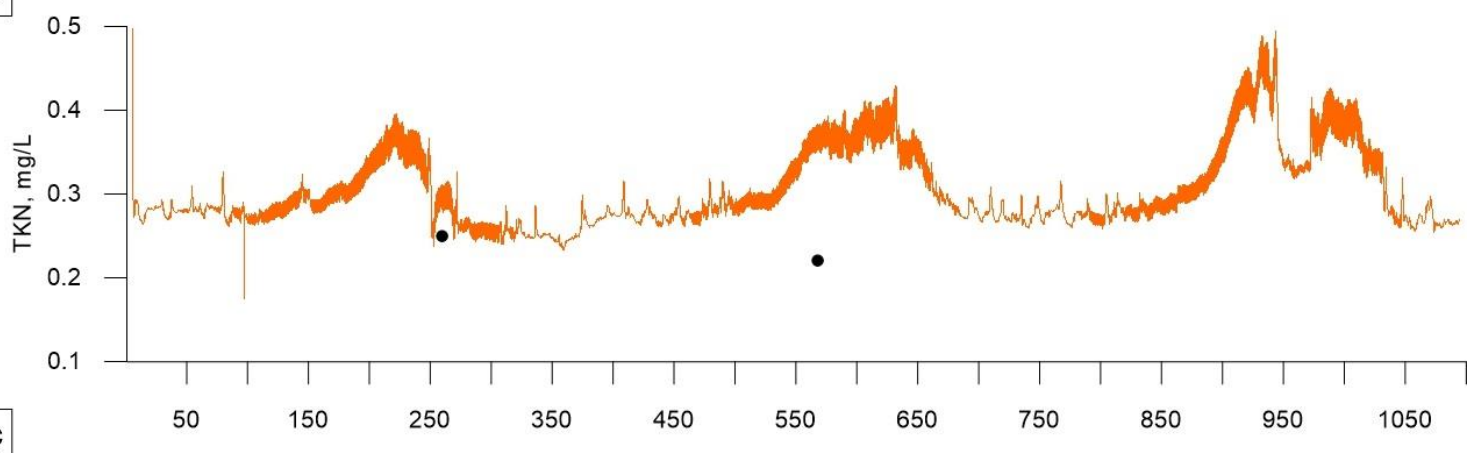

C

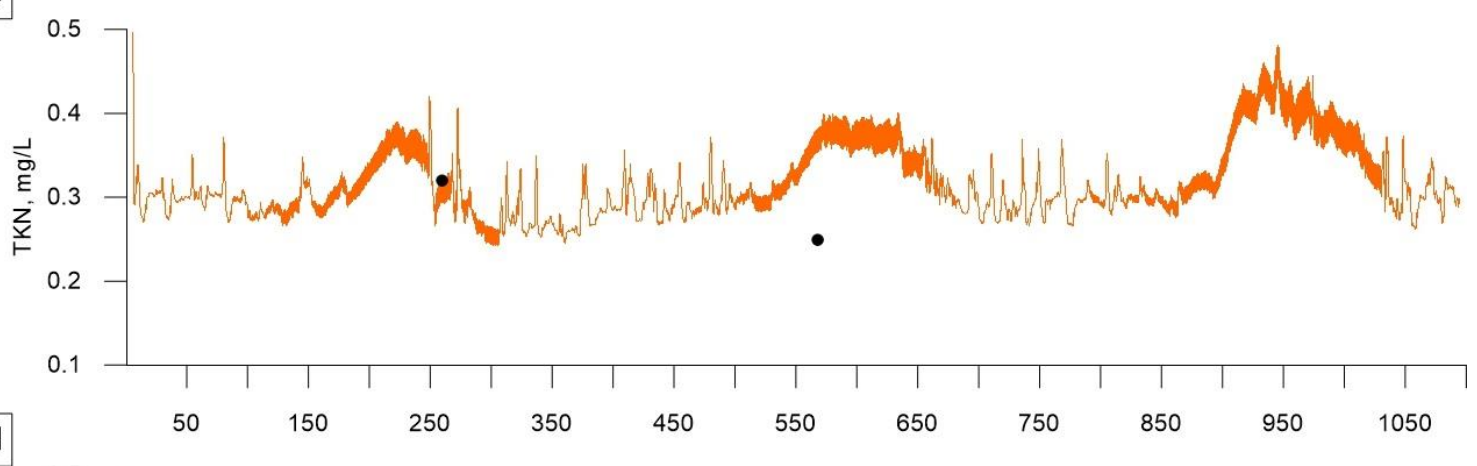

d

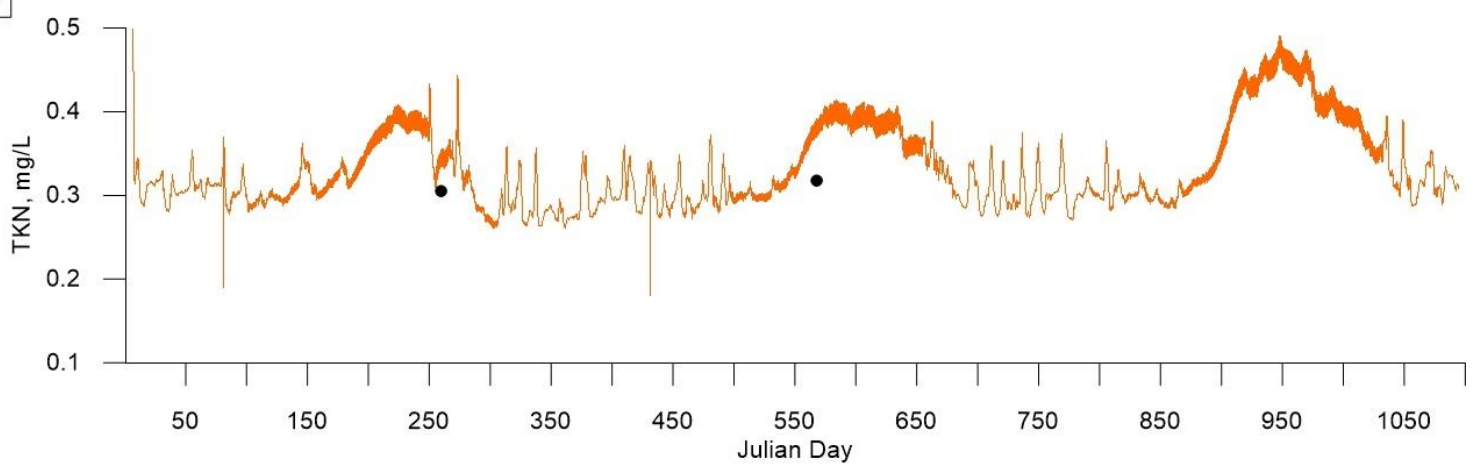

Figure 84. Model TKN predictions compared to field data in the mainstem Chehalis River at (a) upstream of Skookumchuck River, (b) Galvin Road bridge, (c) upstream of Black River, and (d) Oakville between 2013-2015. 
a
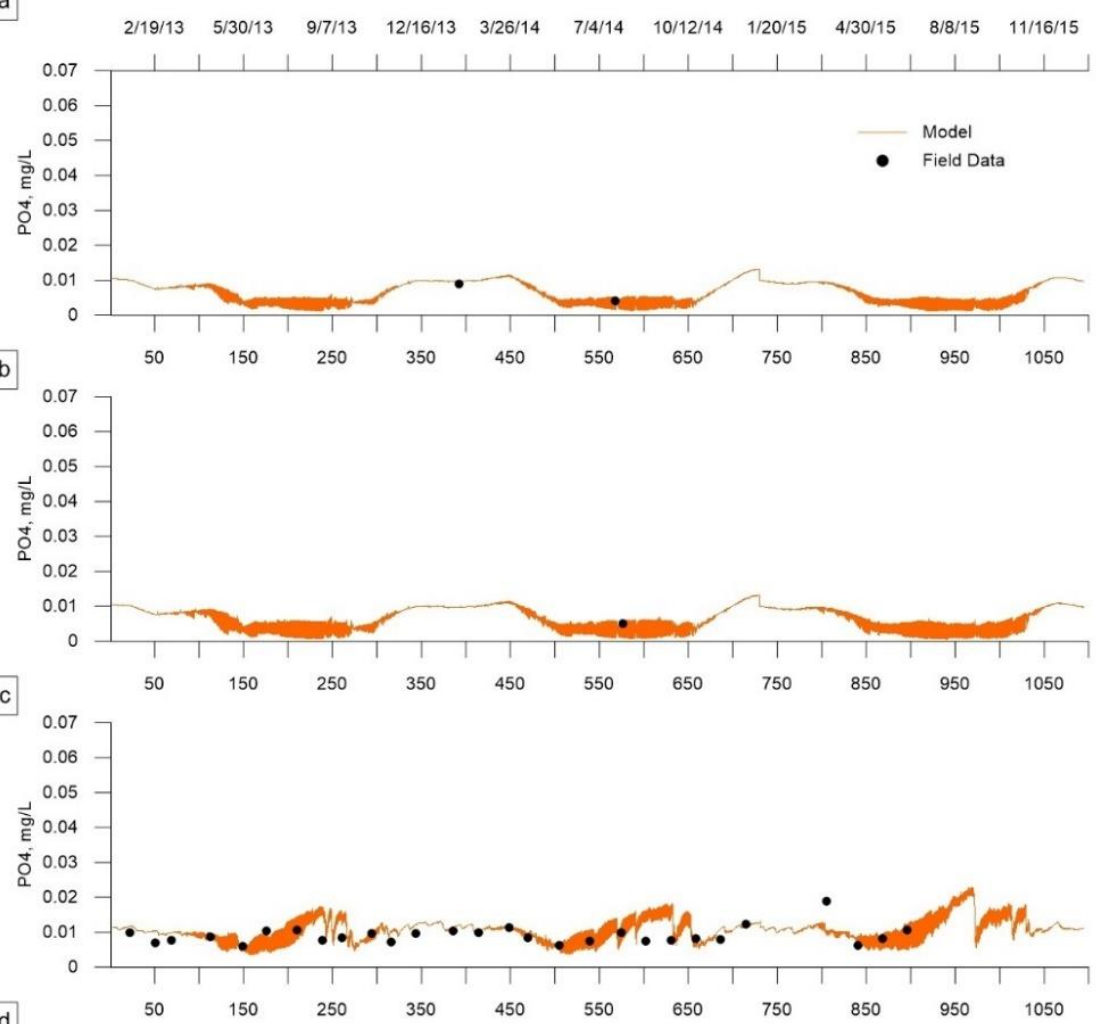

d

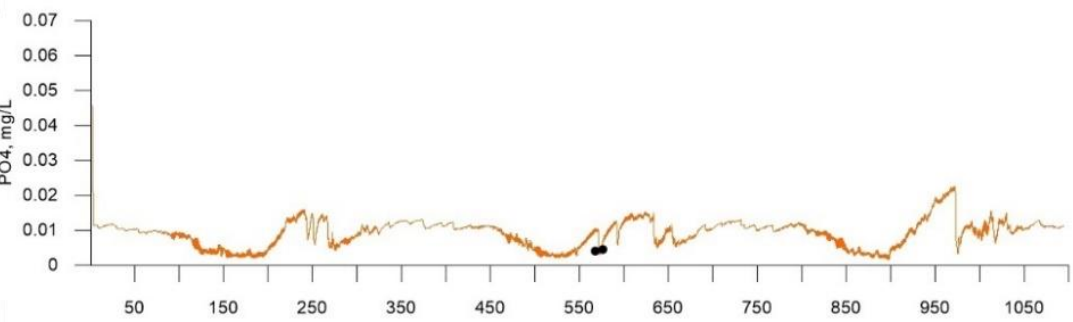

e

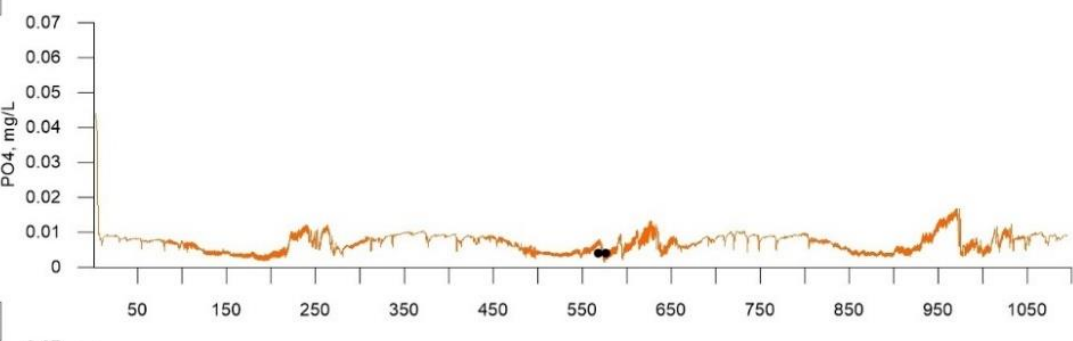

f

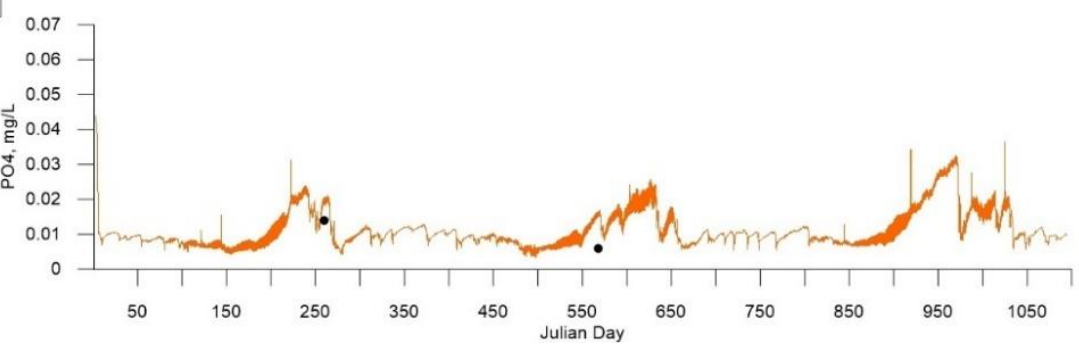

Figure 85. Model P04-P predictions compared to field data in the mainstem Chehalis River at (a) upstream of Pe Ell, (b) downstream of Pe Ell, (c) Dryad, (d) upstream of South Fork Chehalis River, (e)Adna, and (f) upstream of Newaukum River between 2013-2015. 


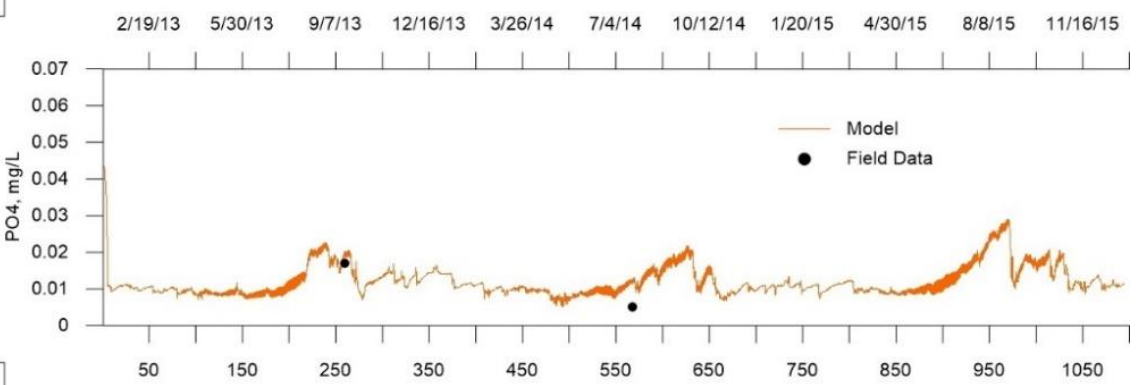

b

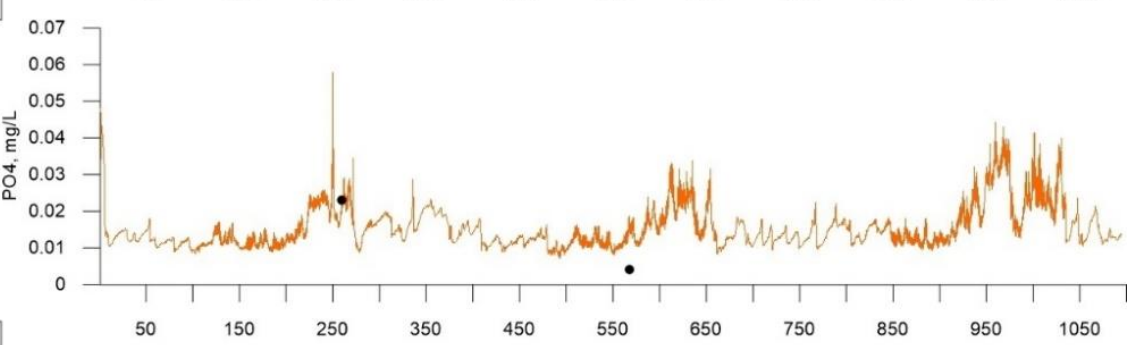

c

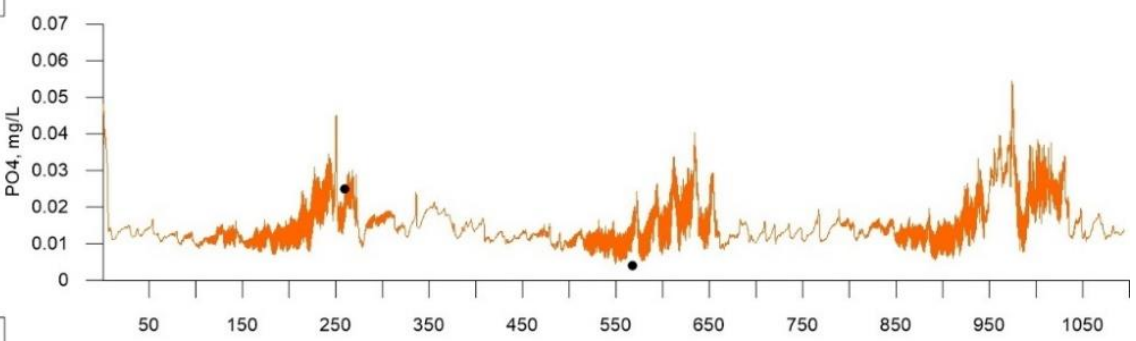

d

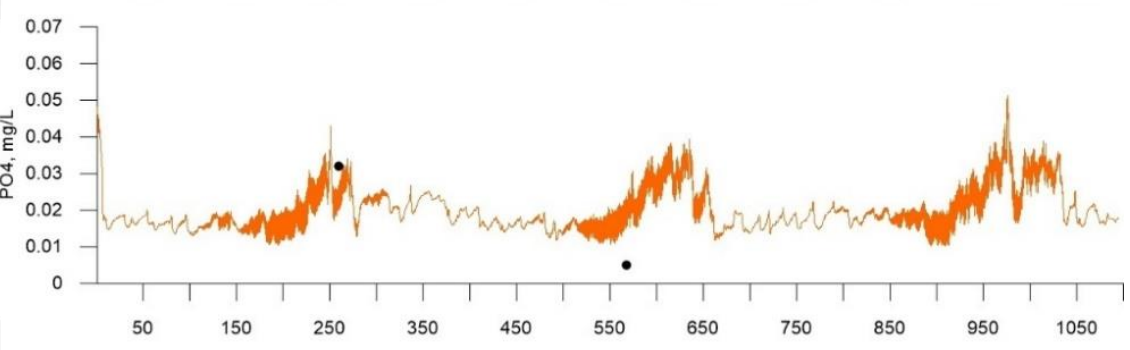

e

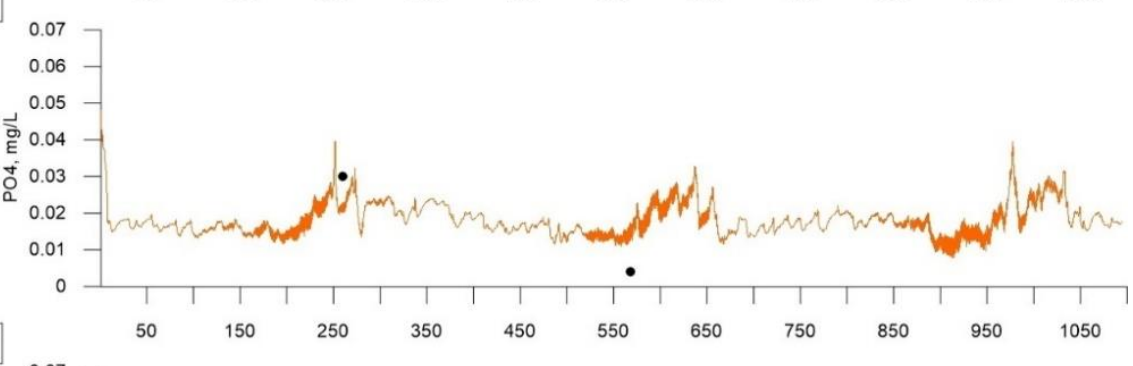

f

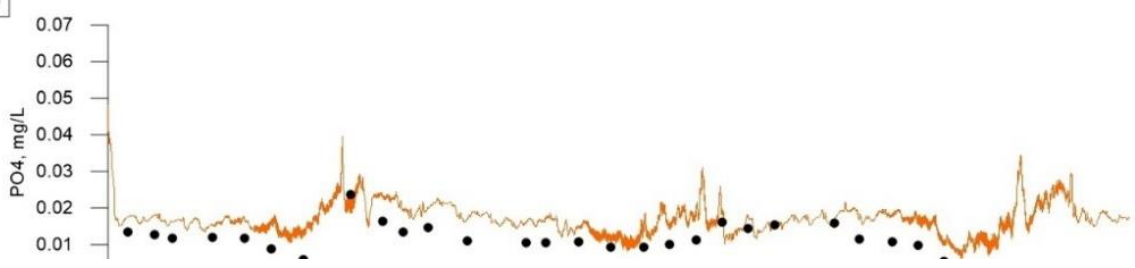

Figure 86. Model P04-P predictions compared to field data in the mainstem Chehalis River at (a) Route 6 bridge, (b) upstream of Skookumchuck River, (c) Galvin Road bridge, (d) upstream of Black River, (e) Oakville, and (f) Porter between 2013-2015. 
a
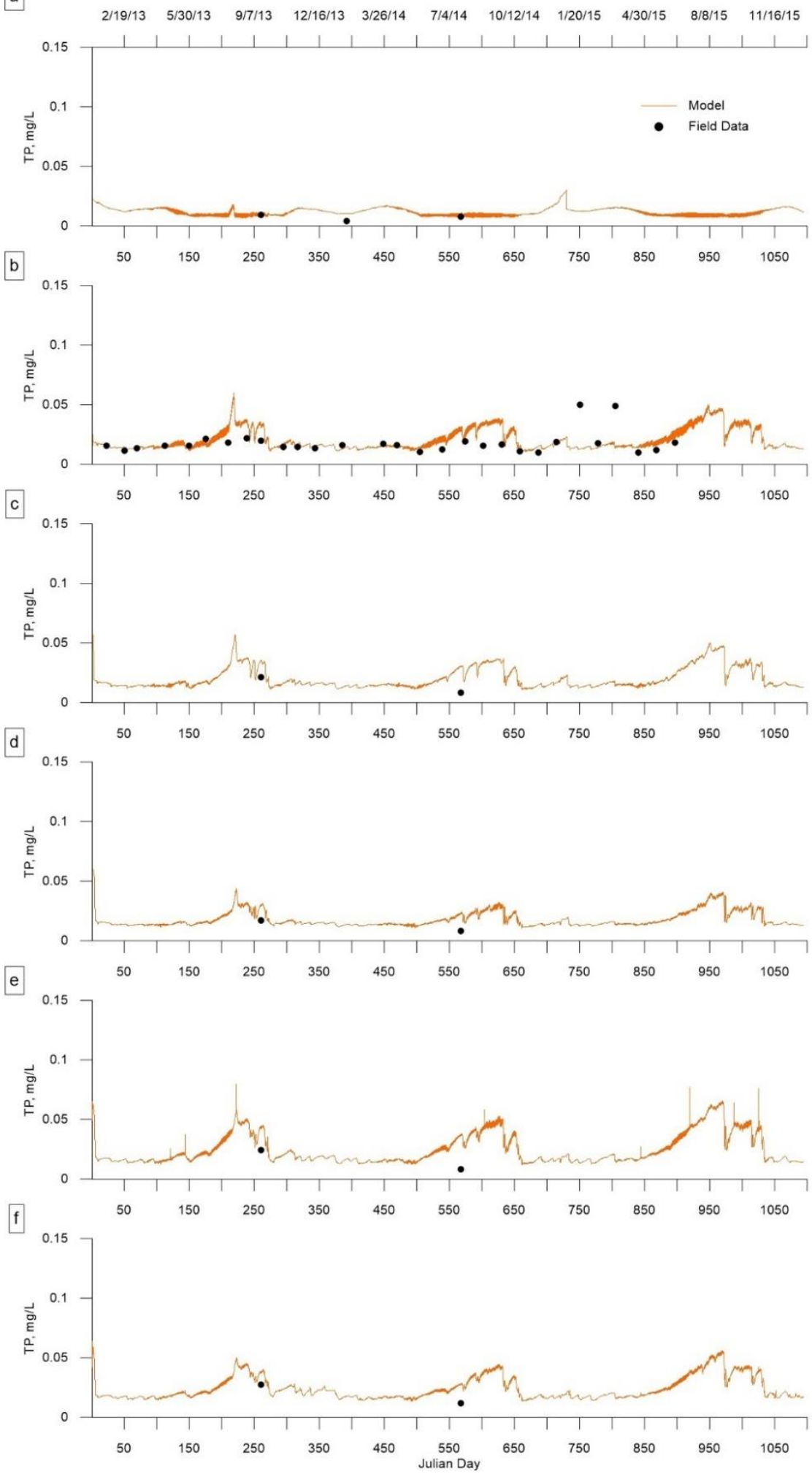

Figure 87. Model total phosphorus predictions compared to field data in the mainstem Chehalis River at (a) upstream of Pe Ell, (b) Dryad, (c) upstream of South Fork Chehalis River, (d) Adna, (e) upstream of Newaukum River, and (f) Route 6 bridge between 2013-2015. 
a

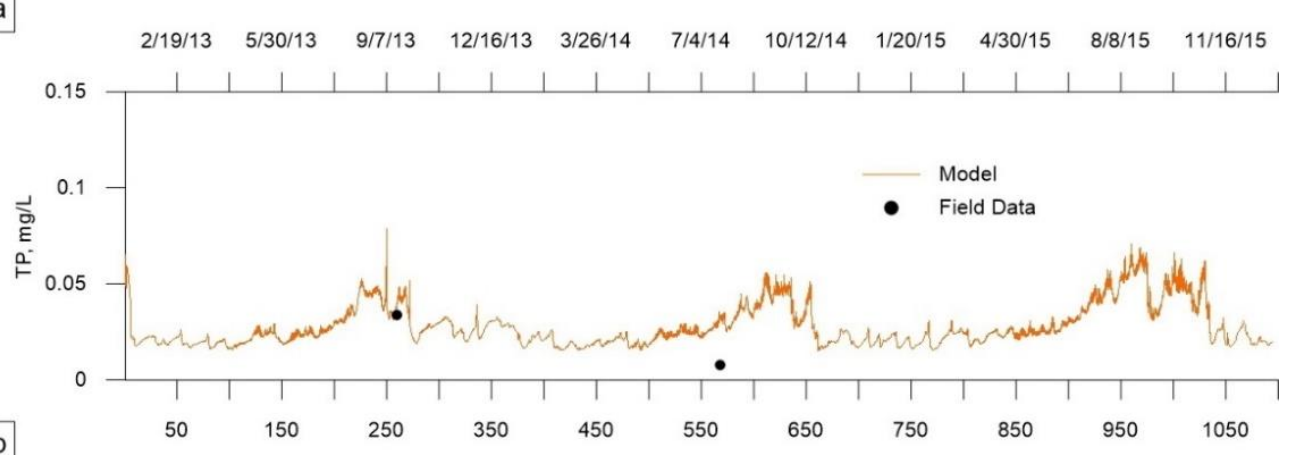

b

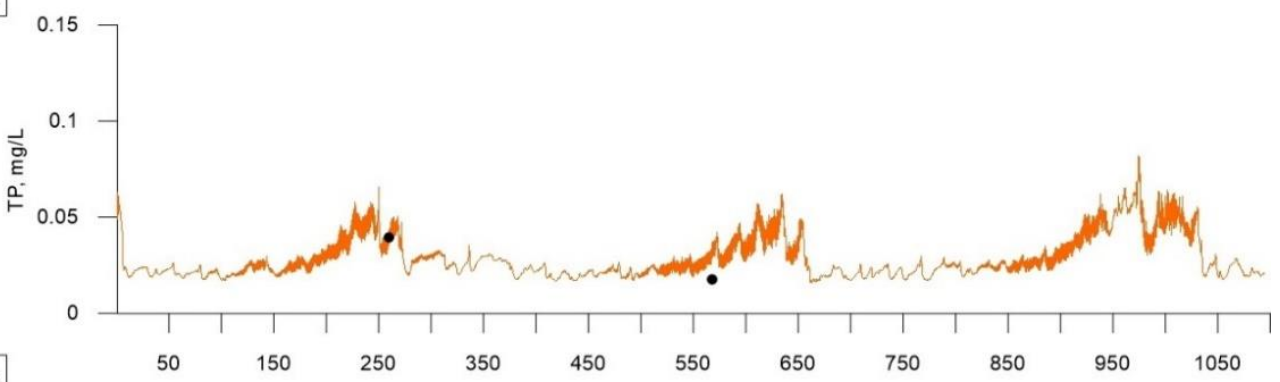

c

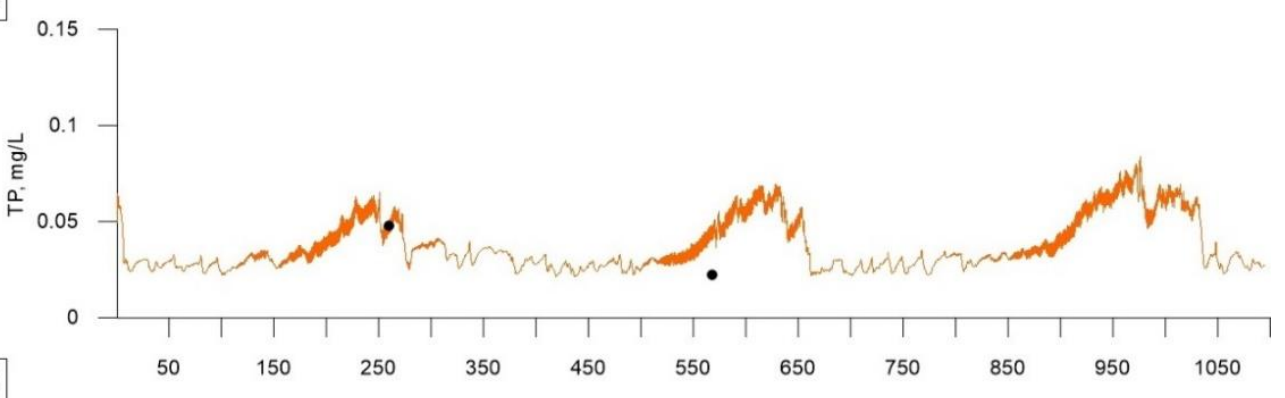

d

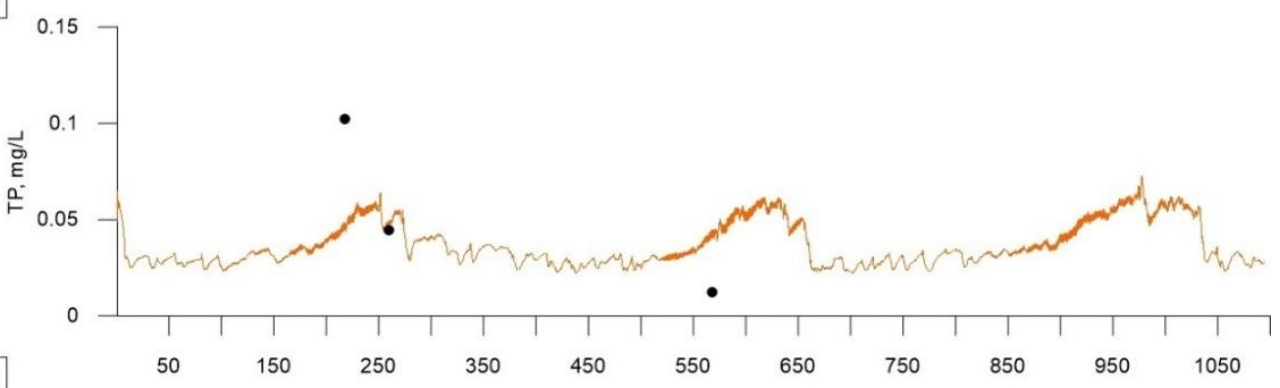

e

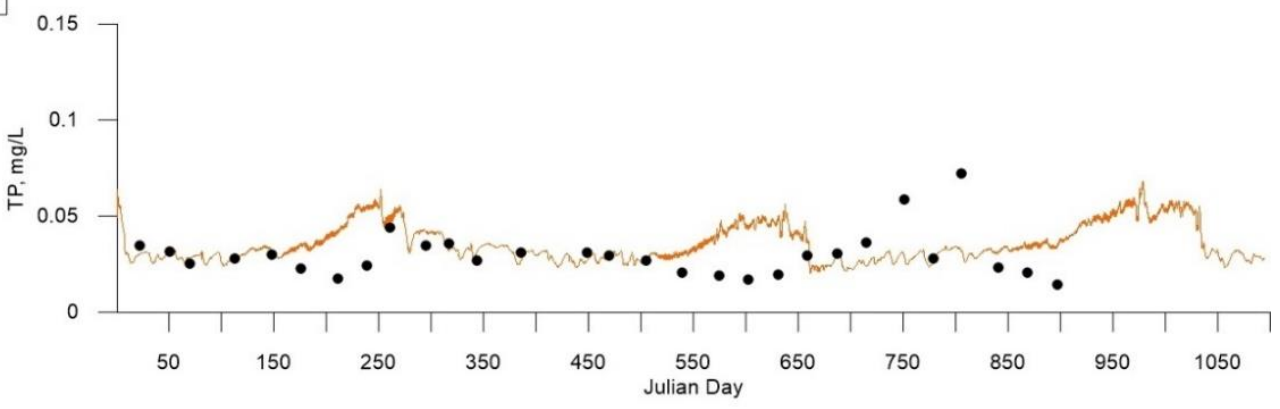

Figure 88. Model total phosphorus predictions compared to field data in the mainstem Chehalis River at (a) upstream of Skookumchuck River, (b) Galvin Road bridge, (c) upstream of Black River, (d) Oakville, and (e) Porter between 2013-2015. 
a

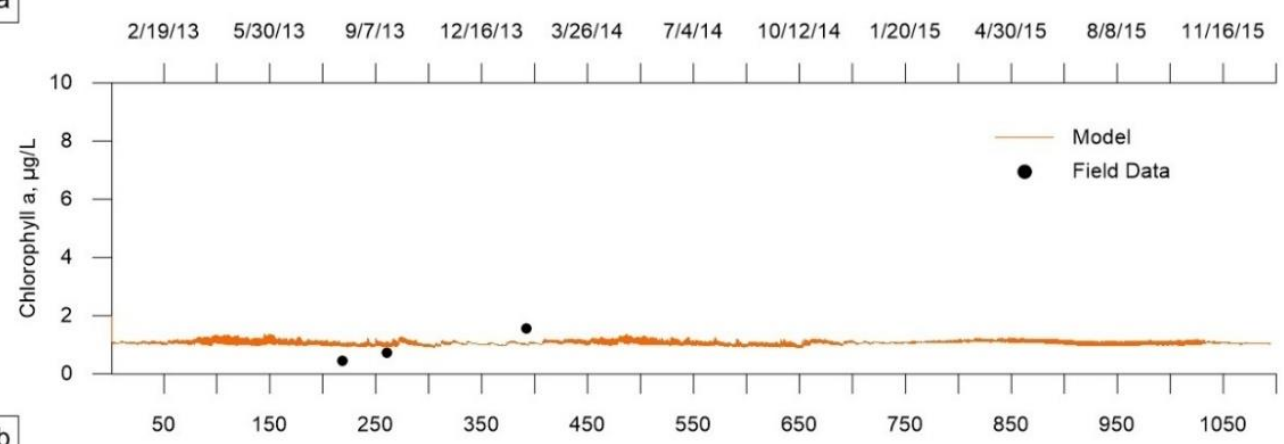

b

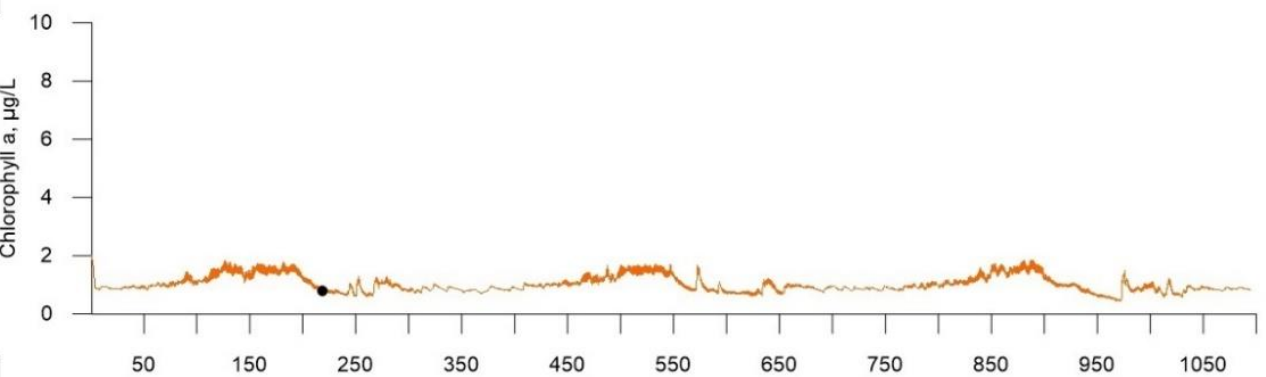

c

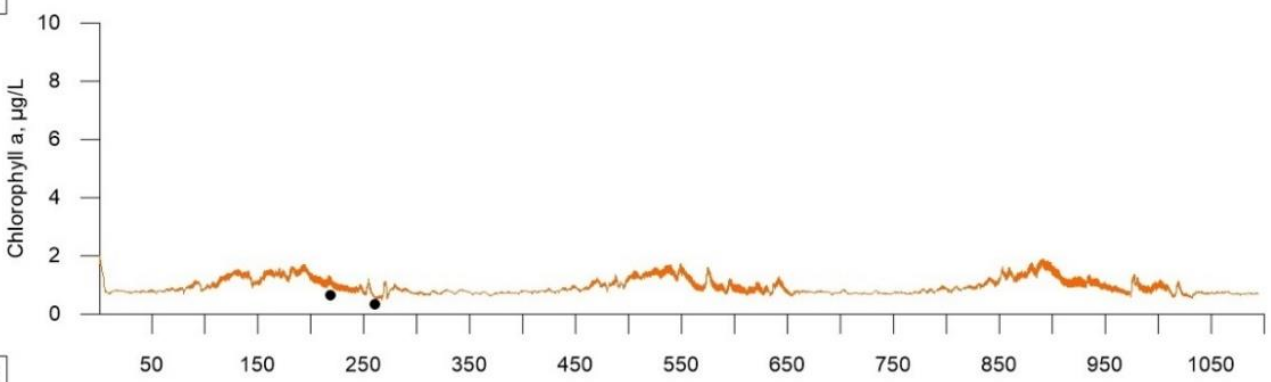

d

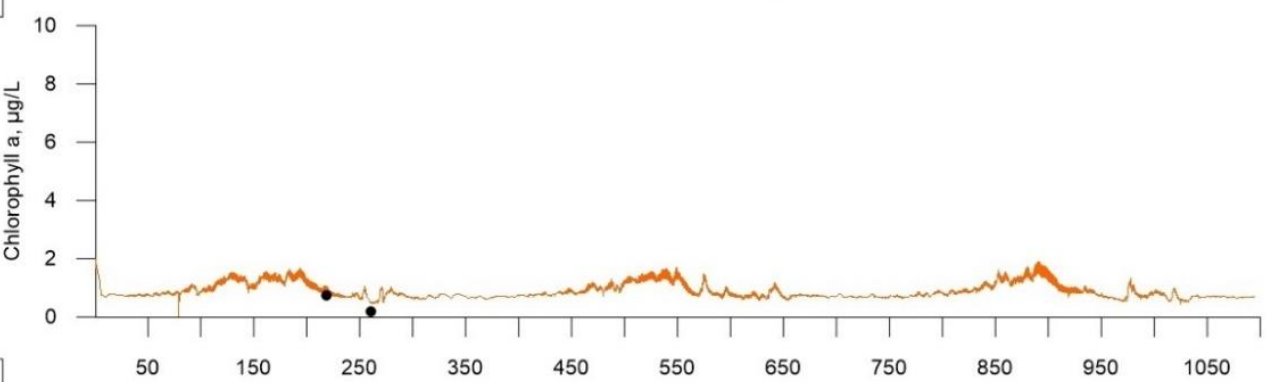

e

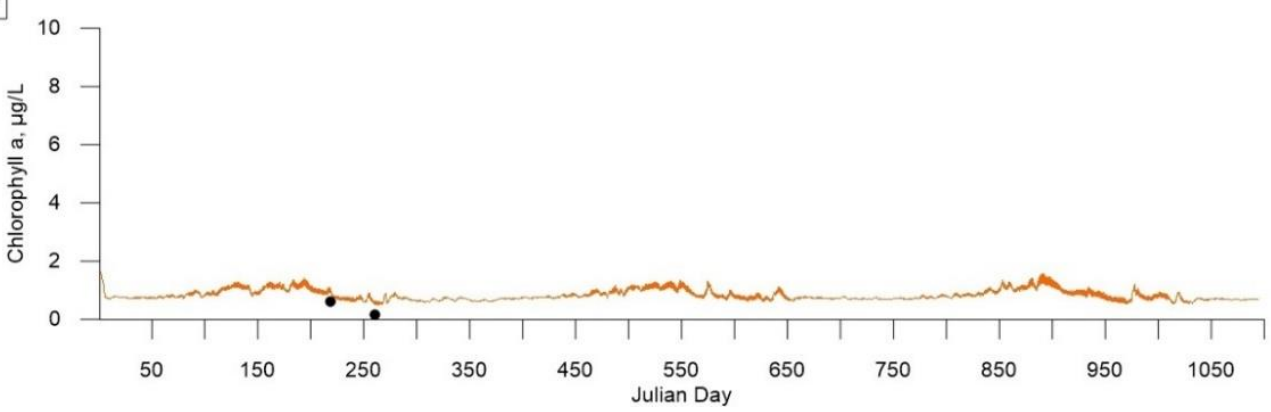

Figure 89. Model chlorophyll a predictions compared to field data in the mainstem Chehalis River at (a) upstream of Pe Ell, (b) upstream of South Fork Chehalis River, (c) Adna, (d) upstream of Newaukum River, and (e) Route 6 bridge between 2013-2015. 
a

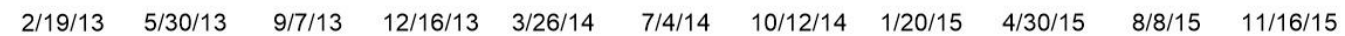

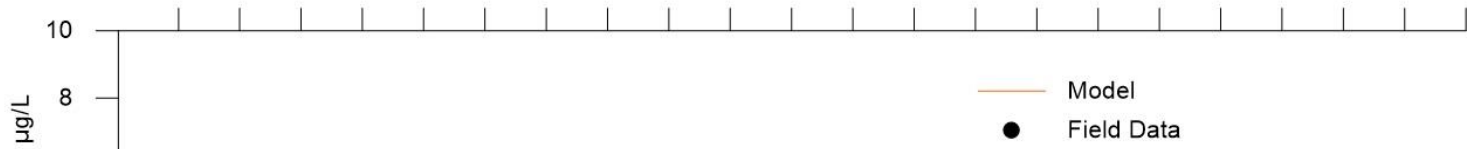

b
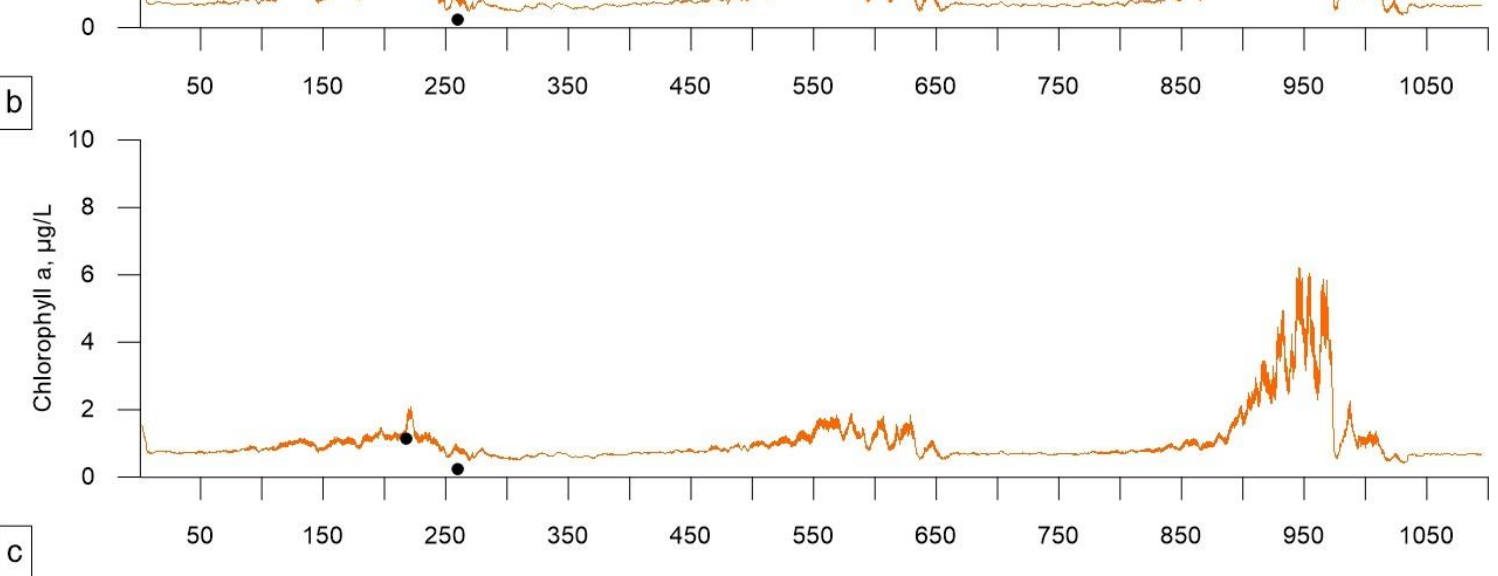

C

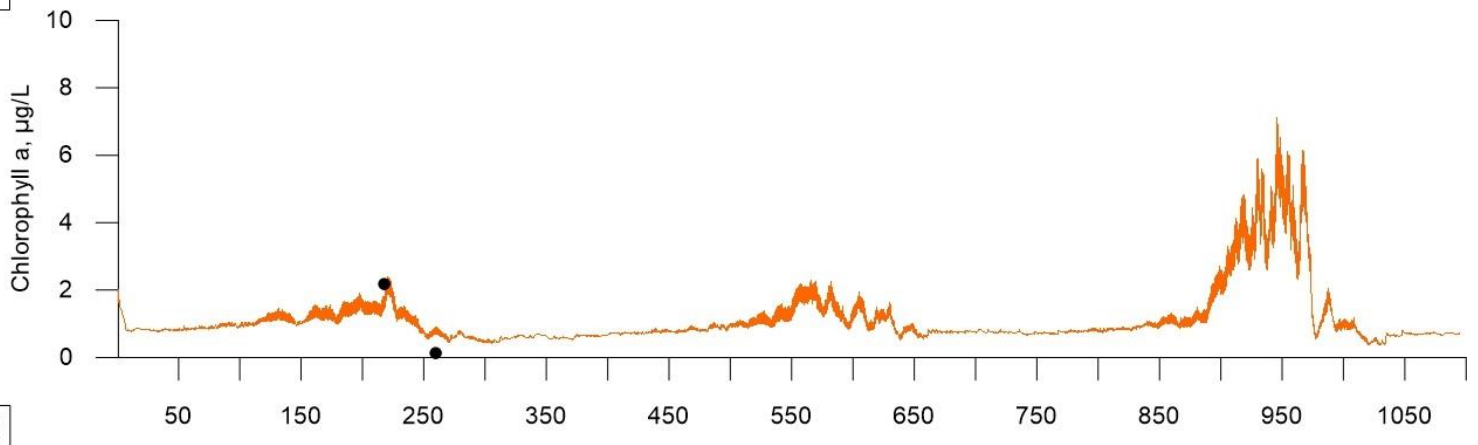

d

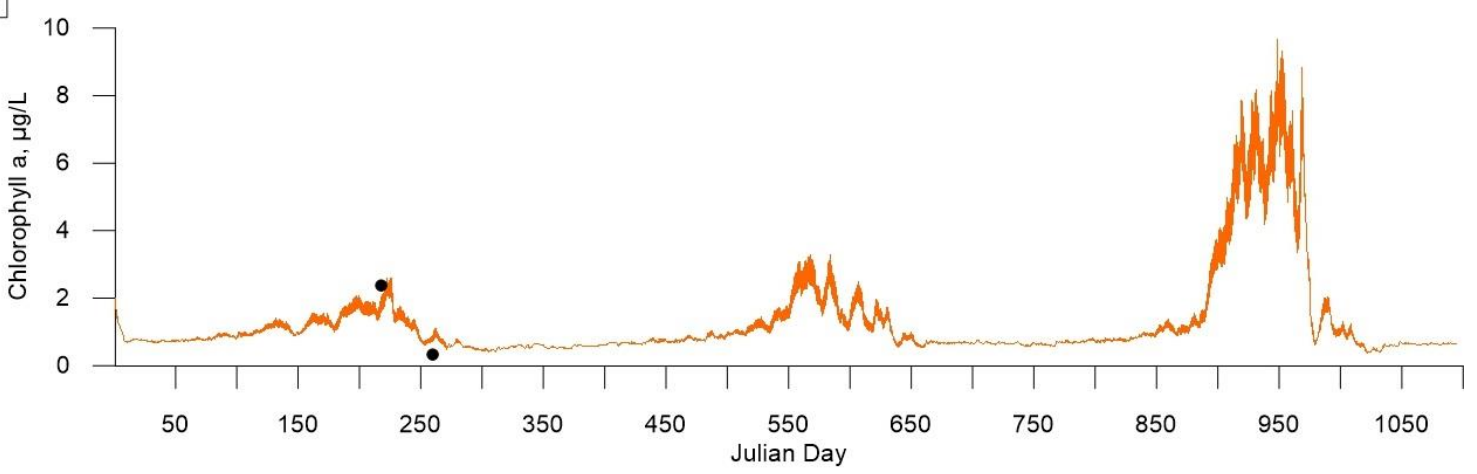

Figure 90. Model chlorophyll a predictions compared to field data in the mainstem Chehalis River at (a) upstream of Skookumchuck River, (b) Galvin Rd bridge, (c) upstream of Black River, and (d) Oakville between 2013-2015. 


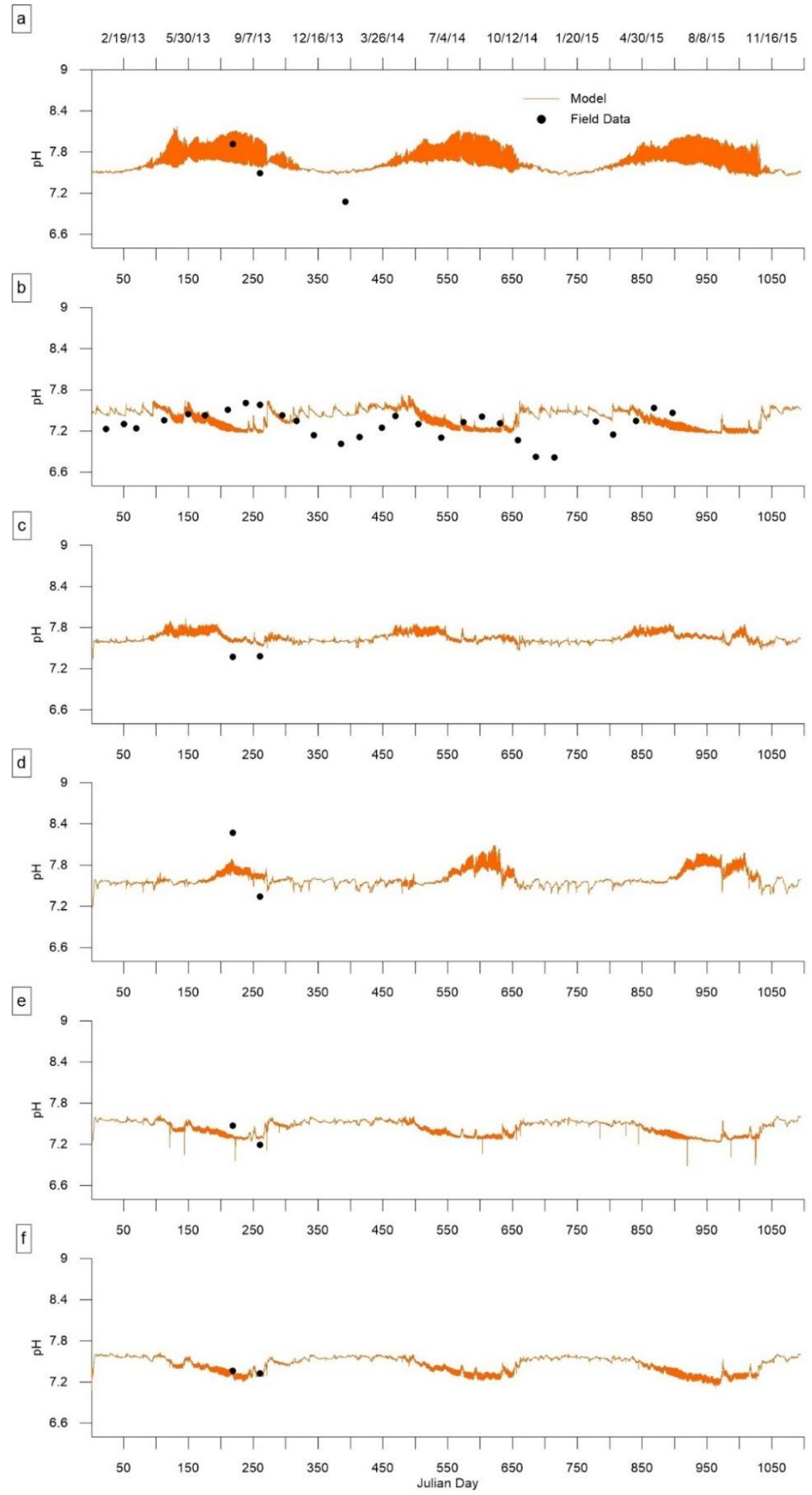

Figure 91. Model pH predictions compared to field data in the mainstem Chehalis River at (a) upstream of Pe Ell, (b) Dryad, (c) upstream of South Fork Chehalis River, (d) Adna, (e) upstream of Newaukum River, and (f) Route 6 bridge between 2013-2015. 


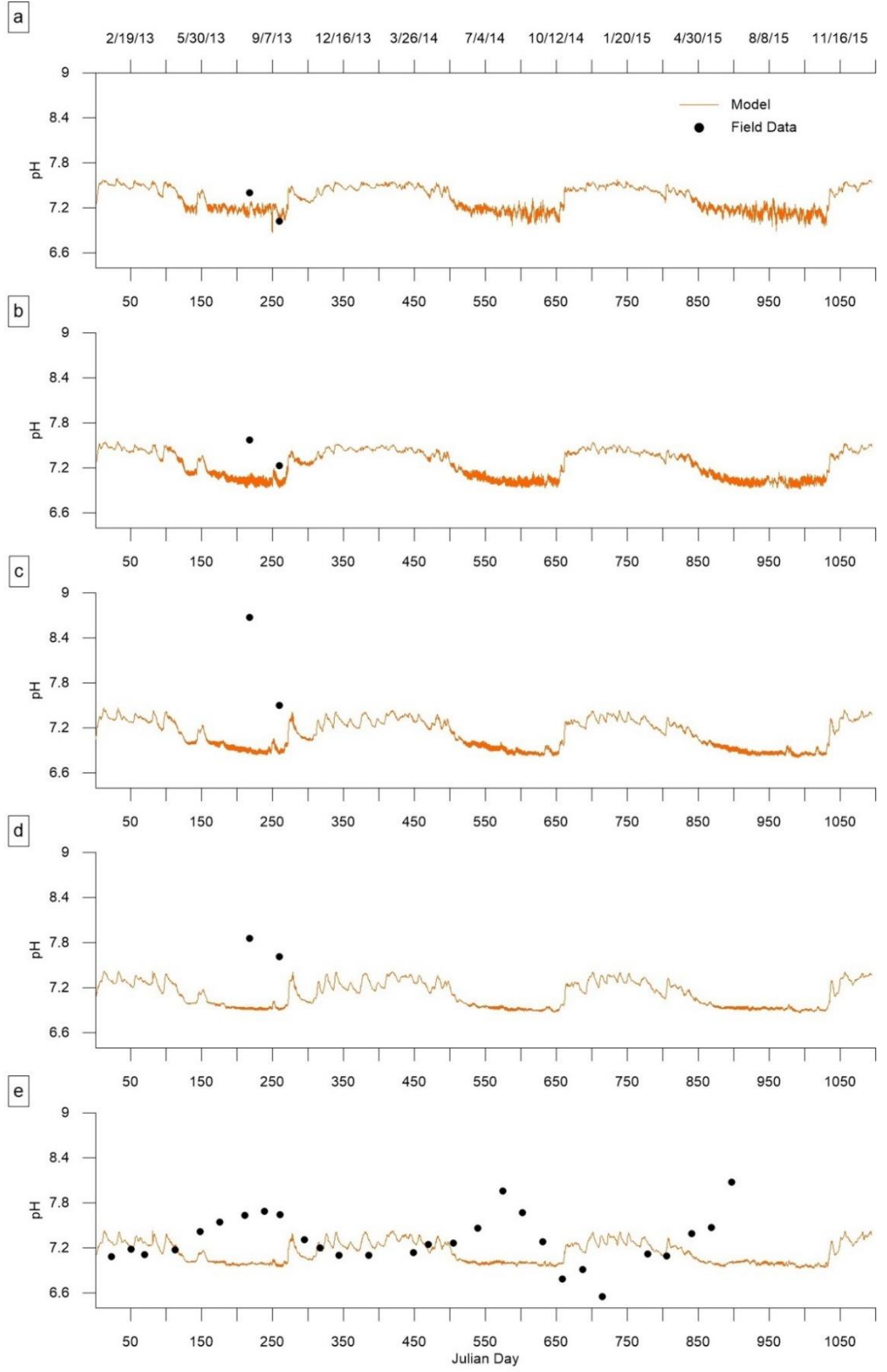

Figure 92. Model pH predictions compared to field data in the mainstem Chehalis River at (a) upstream of Skookumchuck River, (b) Galvin Road bridge, (c) upstream of Black River, (d) Oakville, and (e) Porter between 2013-2015. 
a
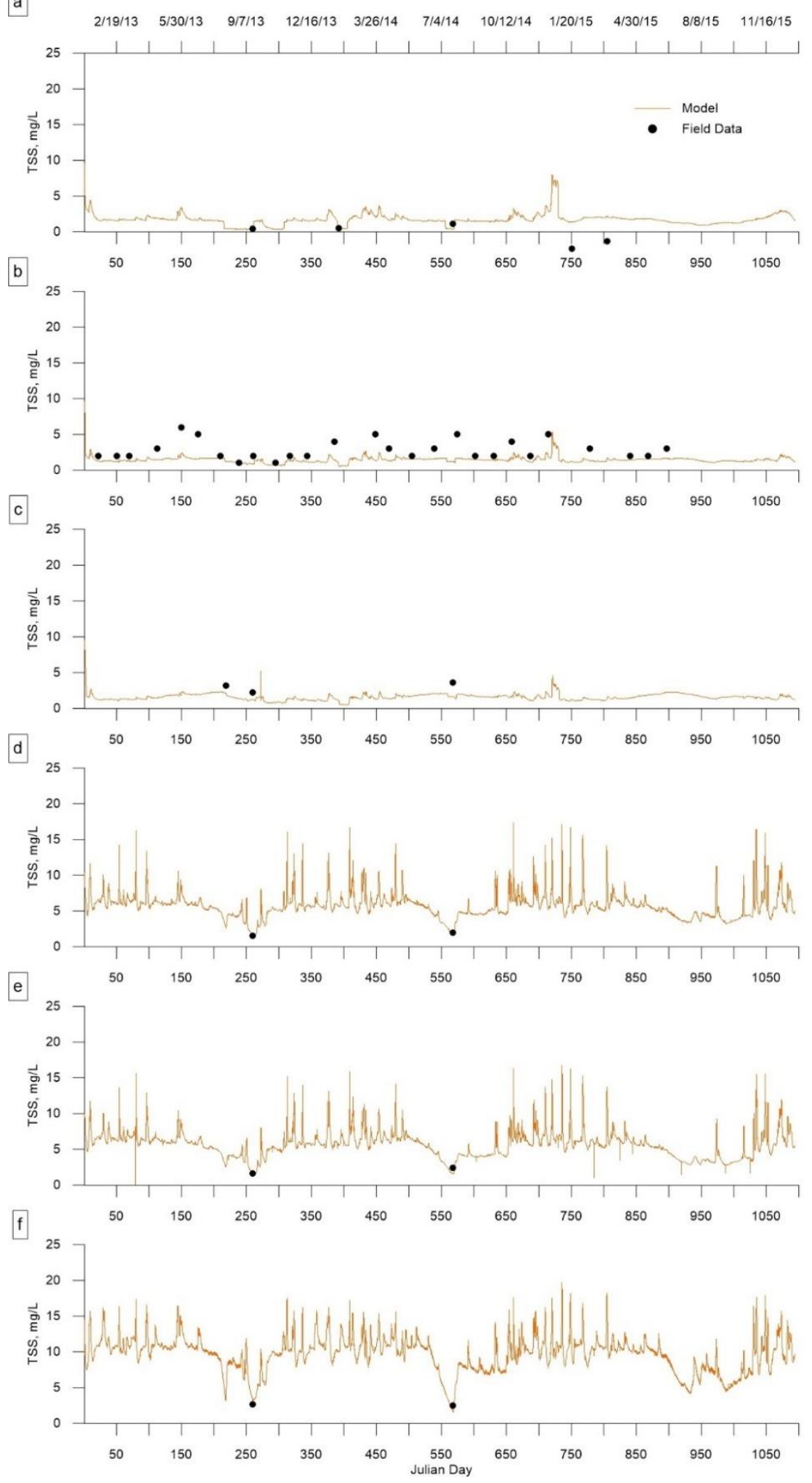

Figure 93. Model total suspended solids predictions compared to field data in the mainstem Chehalis River at (a) upstream of Pe Ell, (b) Dryad, (c) upstream of South Fork Chehalis River, (d) Adna, (e) upstream of Newaukum River, and (f) Route 6 bridge between 2013-2015. 


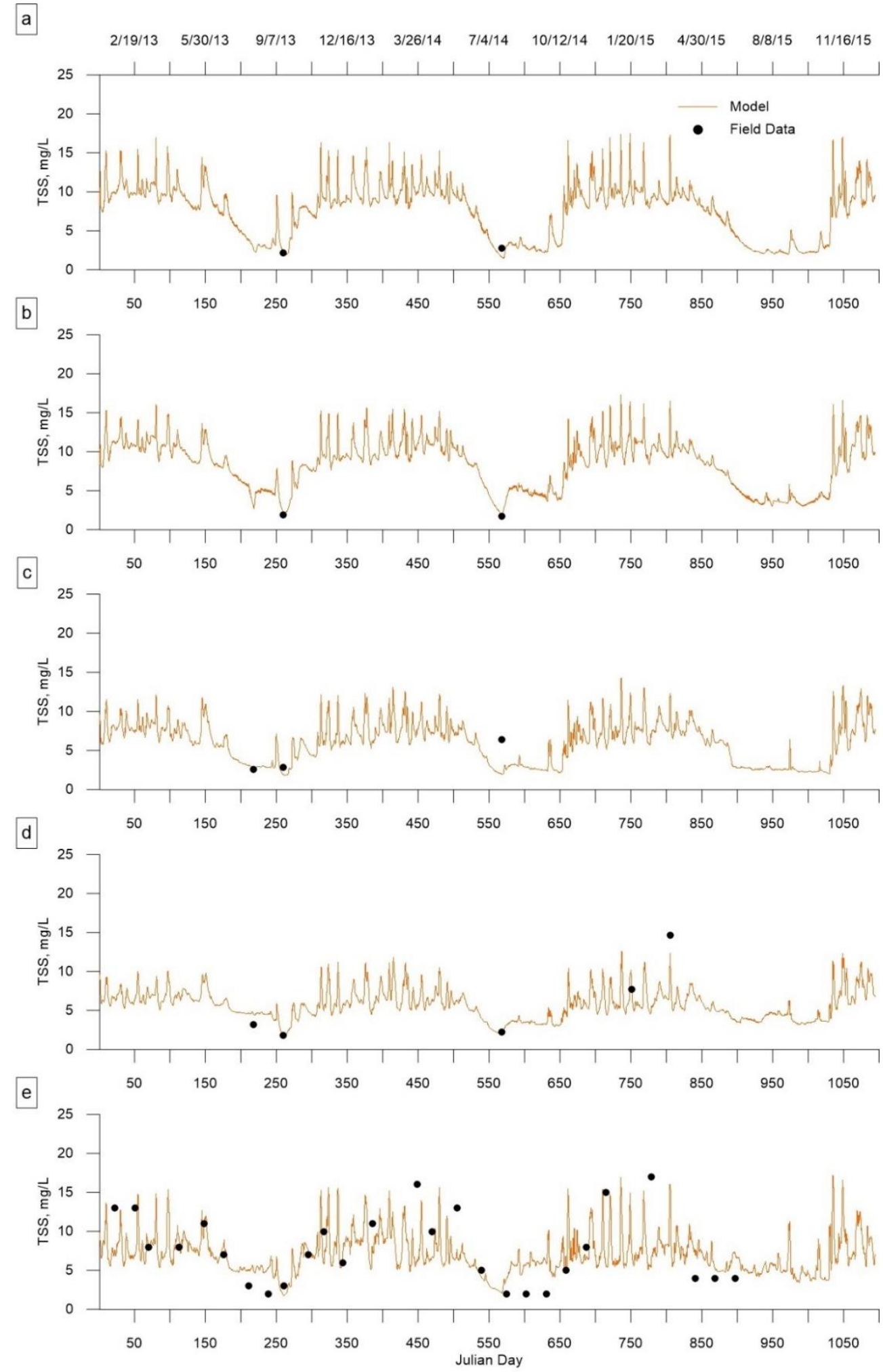

Figure 94. Model total suspended solids predictions compared to field data in the mainstem Chehalis River at (a) upstream of Skookumchuck River, (b) Galvin Road bridge, (c) upstream of Black River, (d) Oakville, and (e) Porter between 2013-2015. 
a

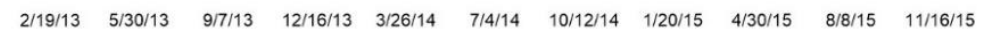

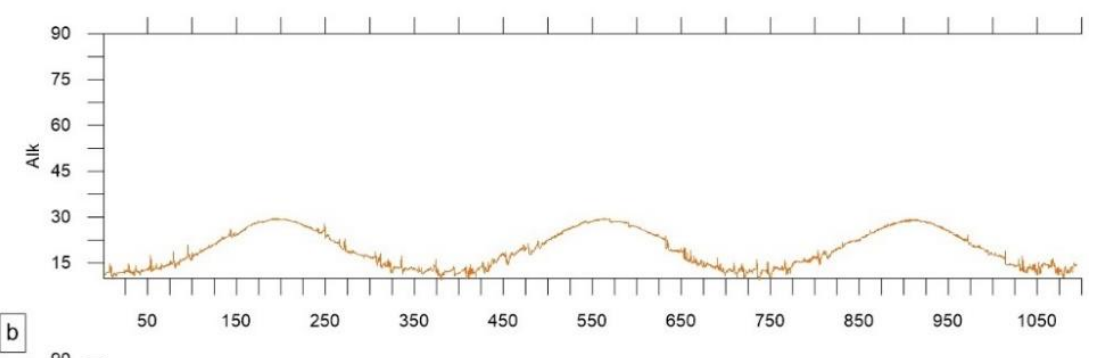

bo

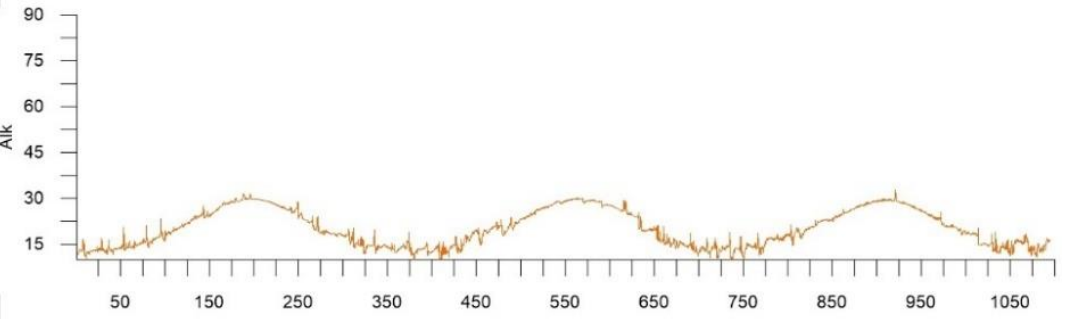

C
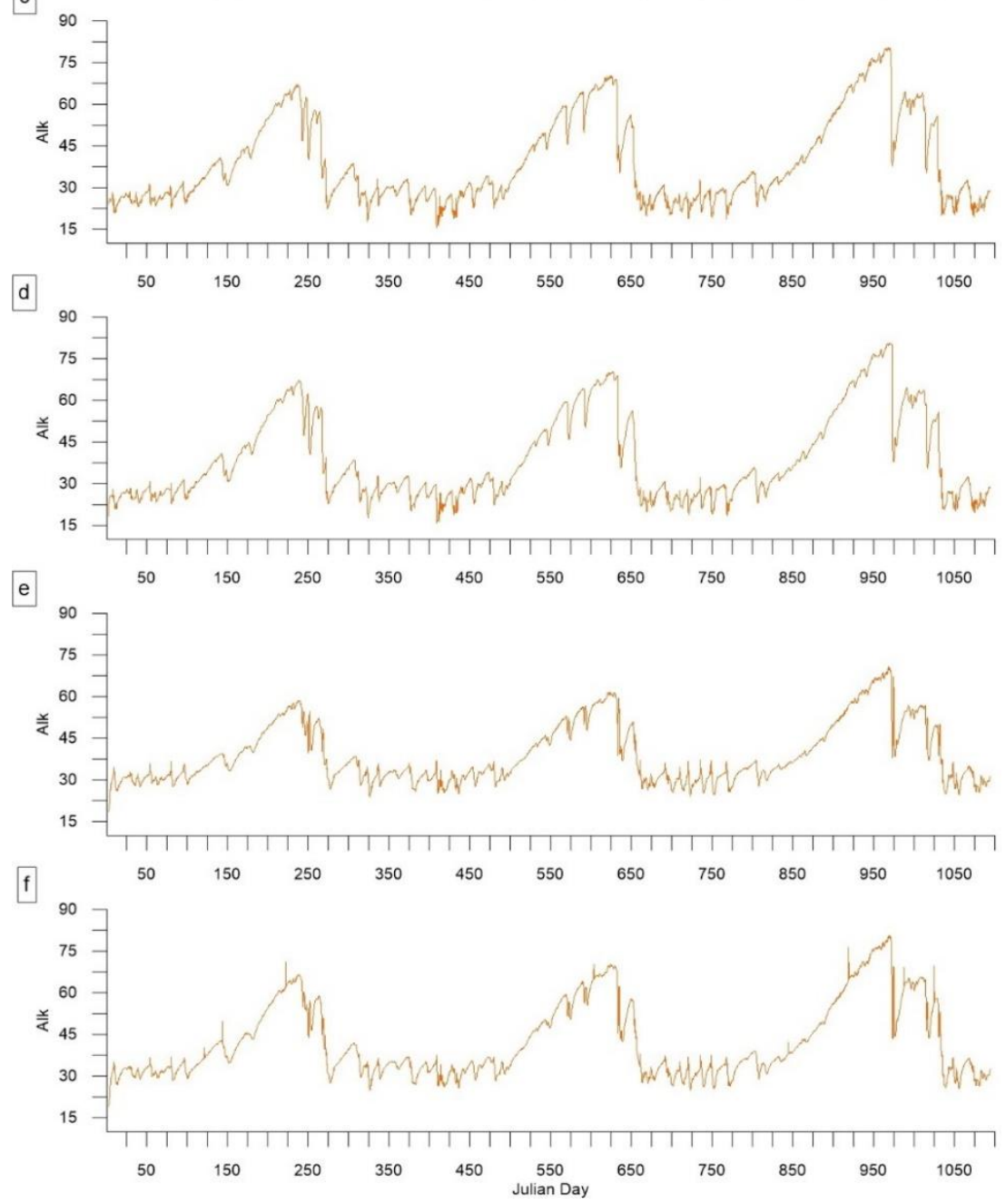

Figure 95. Model alkalinity predictions in the mainstem Chehalis River at (a) downstream of Pe Ell, (b) downstream of Pe Ell, (c) Dryad, (d) upstream of South Fork Chehalis River, (e) Adna, and (f) upstream of Newaukum River between 2013-2015. 
a

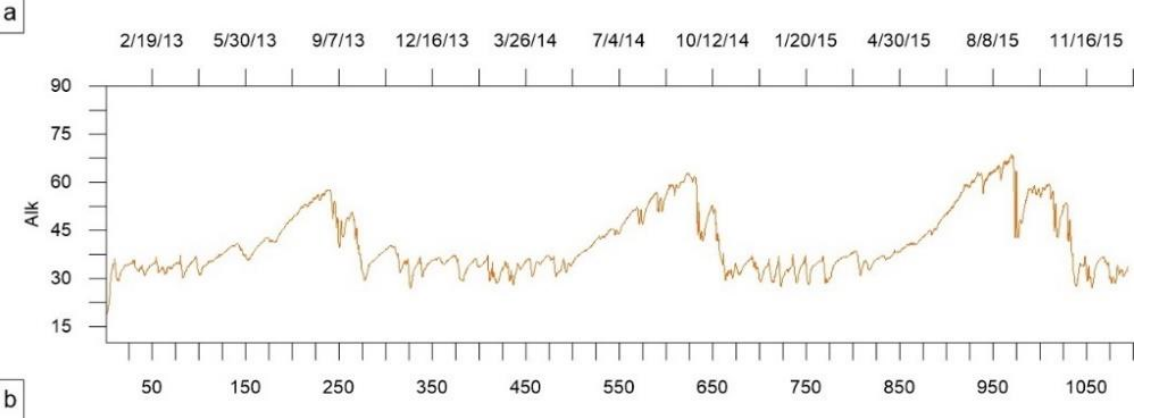

b

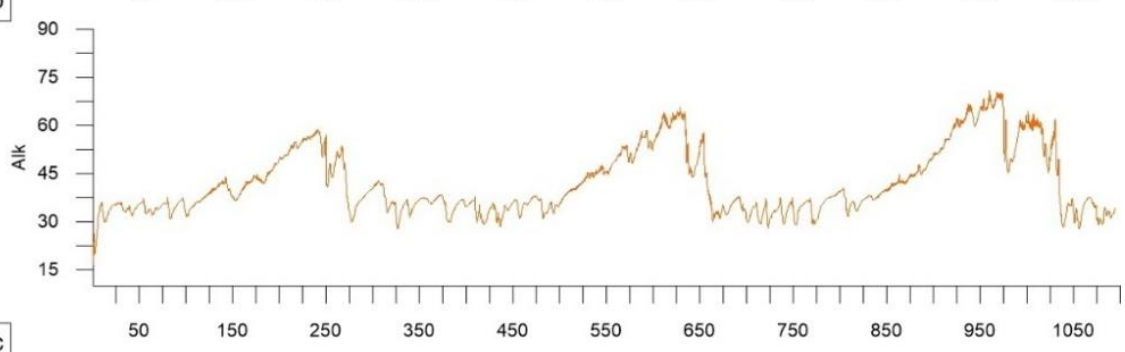

c
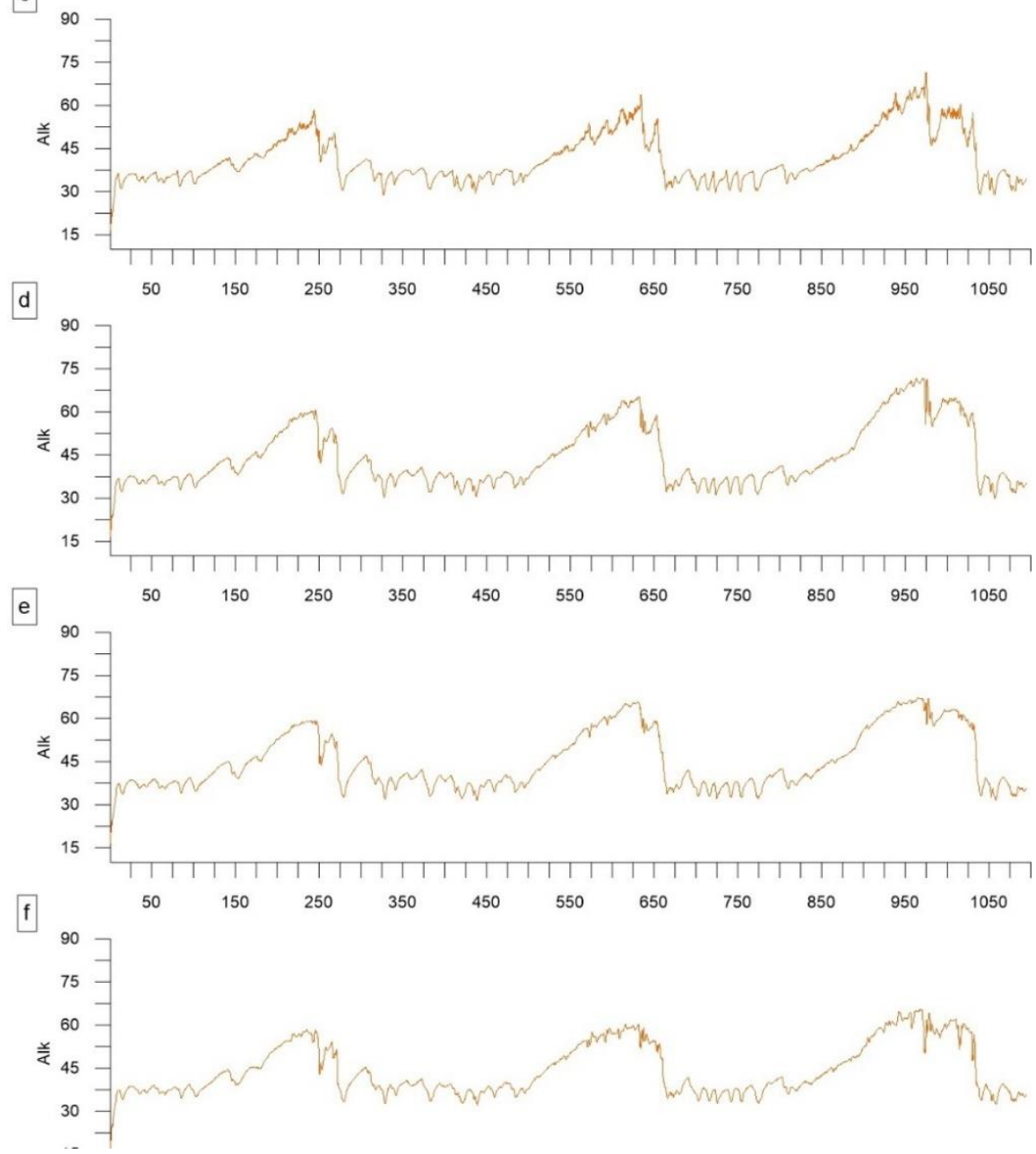

Figure 96. Model alkalinity predictions in the mainstem Chehalis River at (a) Route 6 bridge, (b) upstream of Skookumchuck River, (c) Galvin Road bridge, (d) upstream of Black River, (e) Oakville, and (f) Porter between 2013-2015. 
Continuous dissolved oxygen data

Model predictions compared to continuous DO field data at the Chehalis River mainstem stations downstream of Pe Ell, at Route 6 Bridge, and at Mellen Road Bridge are shown in Figure 97, Figure 98, and Figure 99. The dynamics were reasonable except at Pe Ell around Julian day 260 where our dynamics were low compared to the field data. 

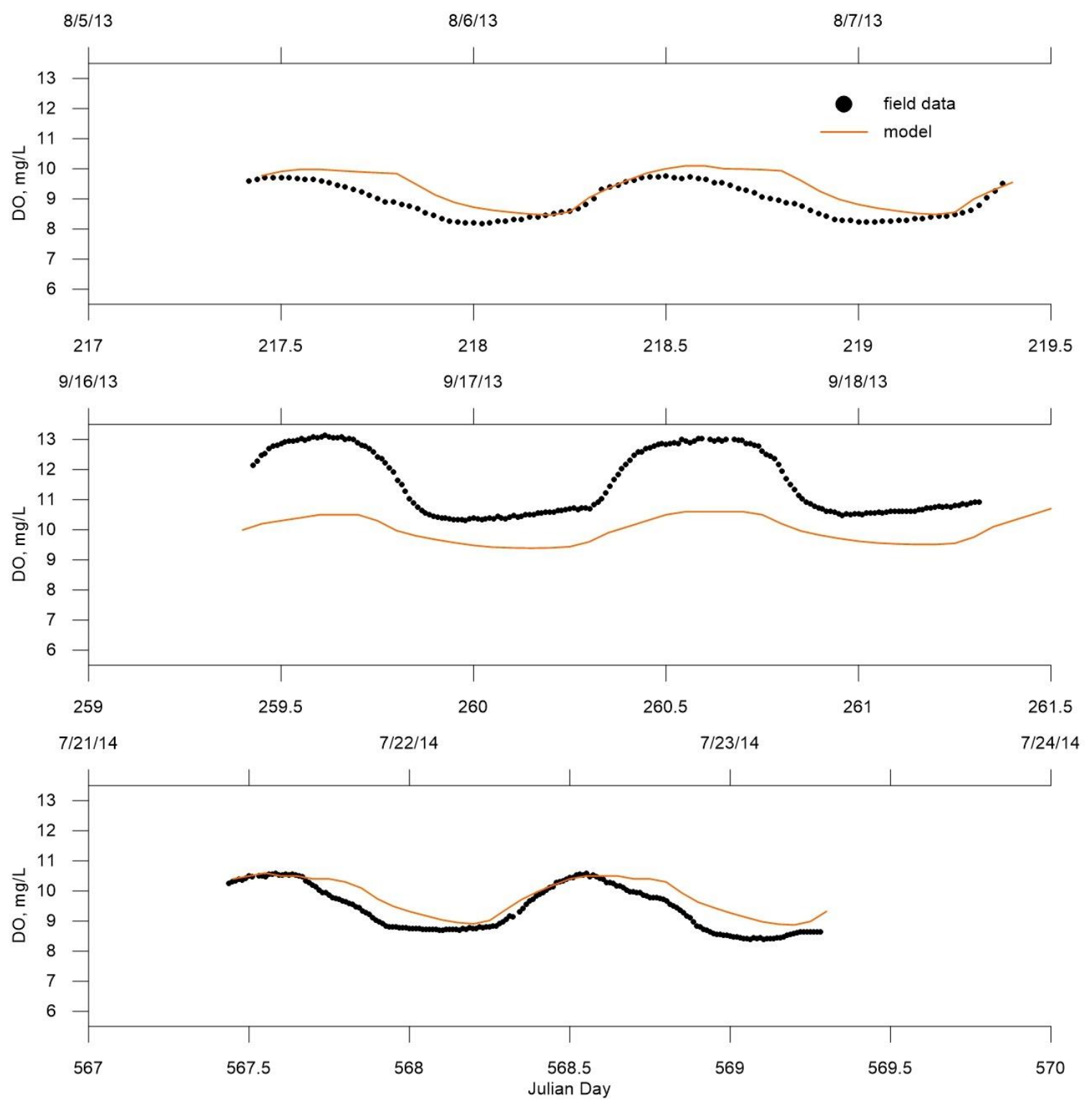

Figure 97. Continuous dissolved oxygen model predictions compared to field data in the mainstem Chehalis River at downstream of Pe Ell between 2013-2015. 

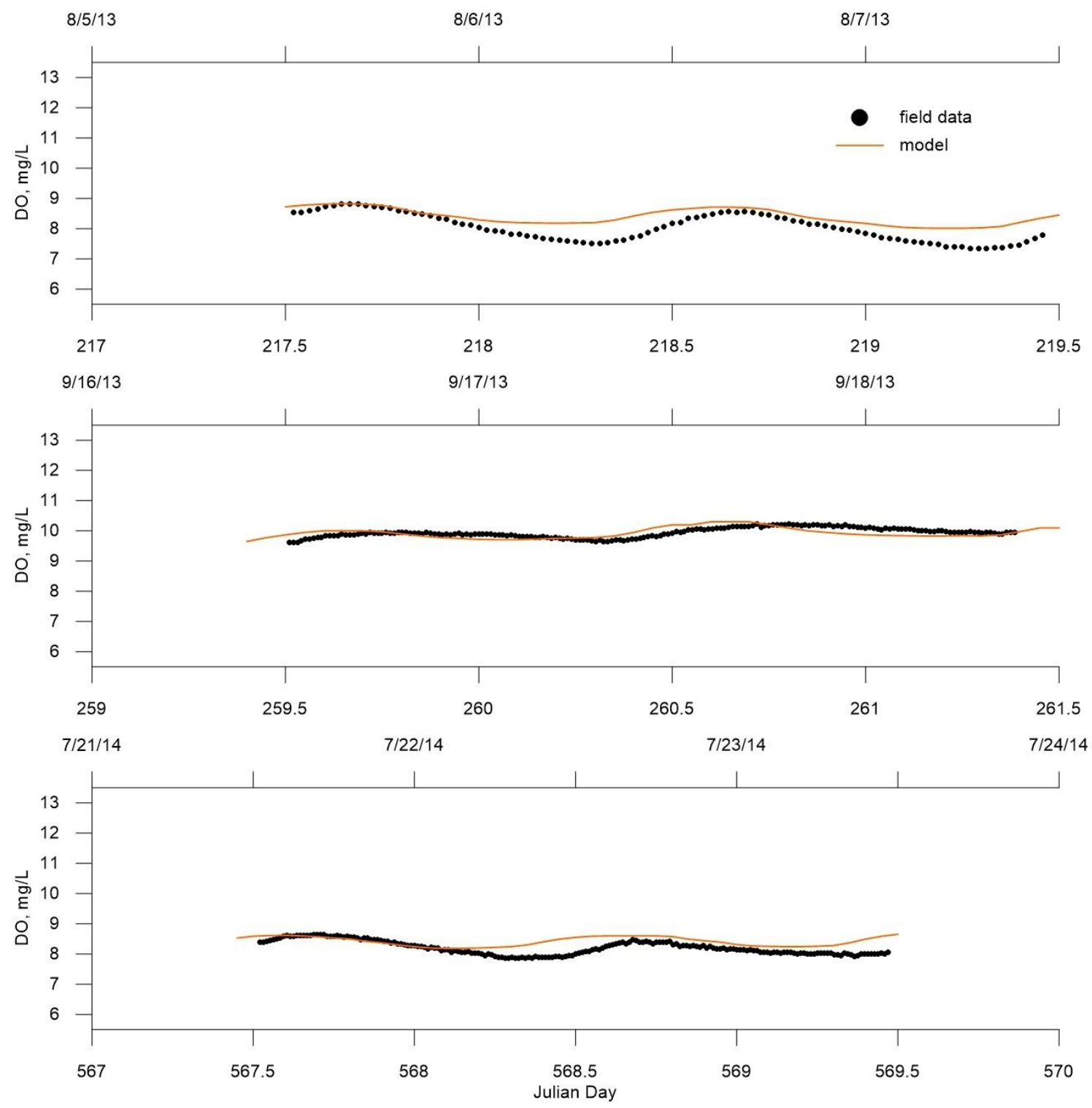

Figure 98. Continuous dissolved oxygen model predictions compared to field data in the mainstem Chehalis River at Route 6 bridge between 2013-2015. 

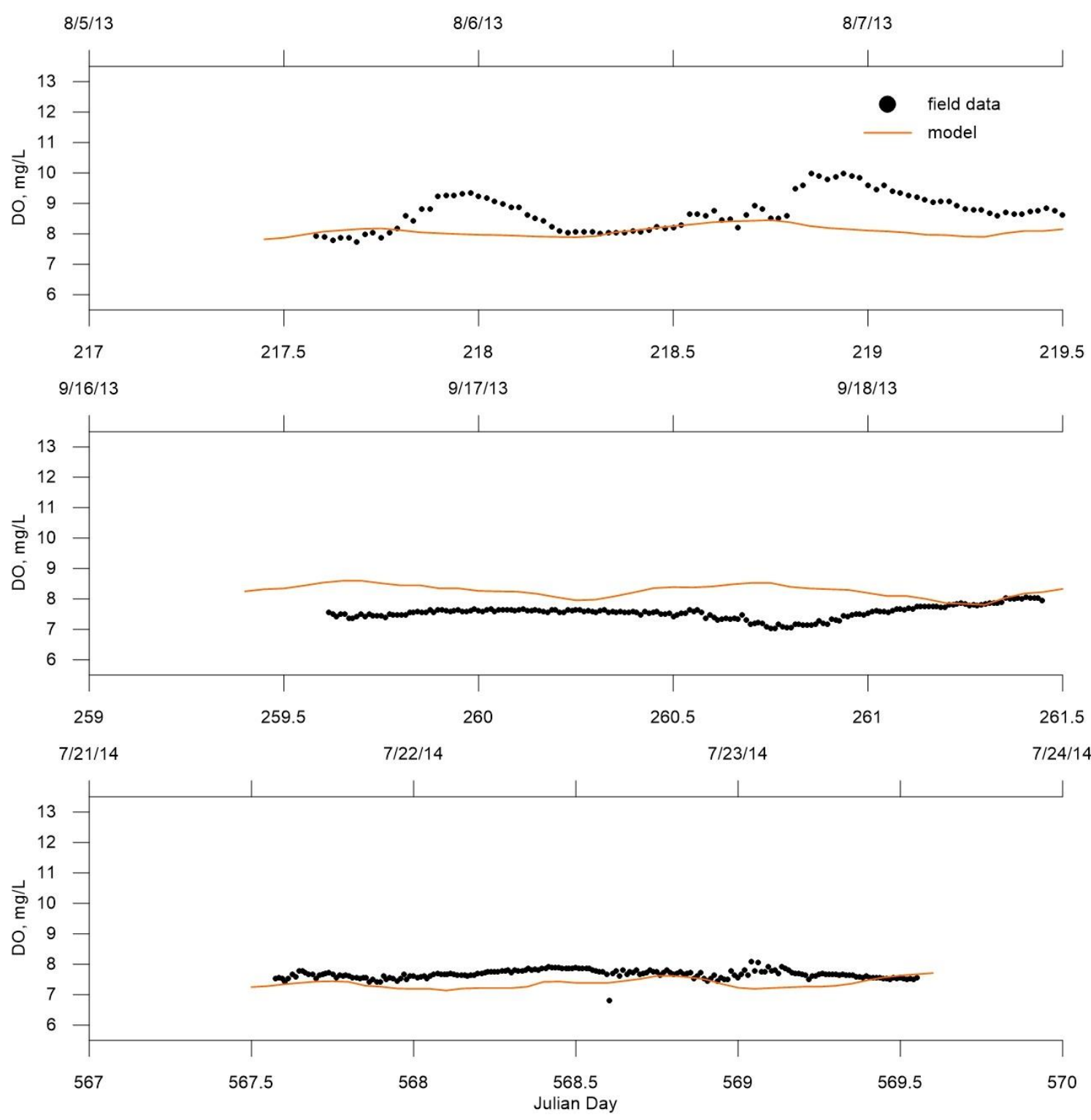

Figure 99. Continuous dissolved oxygen model predictions compared to field data in the mainstem Chehalis River at Mellen Road bridge between 2013-2015.

Vertical dissolved oxygen profiles

Vertical profile data were available at the same locations as temperature.

Comparisons of vertical DO profiles to field data at the mainstem stations at Route 6

Bridge, HL-14, HL-13, HL-12, HL-11, HL-10, HL-9, HL-8, HL-7, HL-6, HL-5, HL-4, HL-

3, HL-2, Mellen Road Bridge, and HL-1 are shown in Figure 100, Figure 101, Figure

102, and Figure 103. As evident from the temperature profile comparisons, if the 
temperature was not simulated correctly, the dissolved oxygen was also not correct as stratification affects the vertical dissolved oxygen distribution.

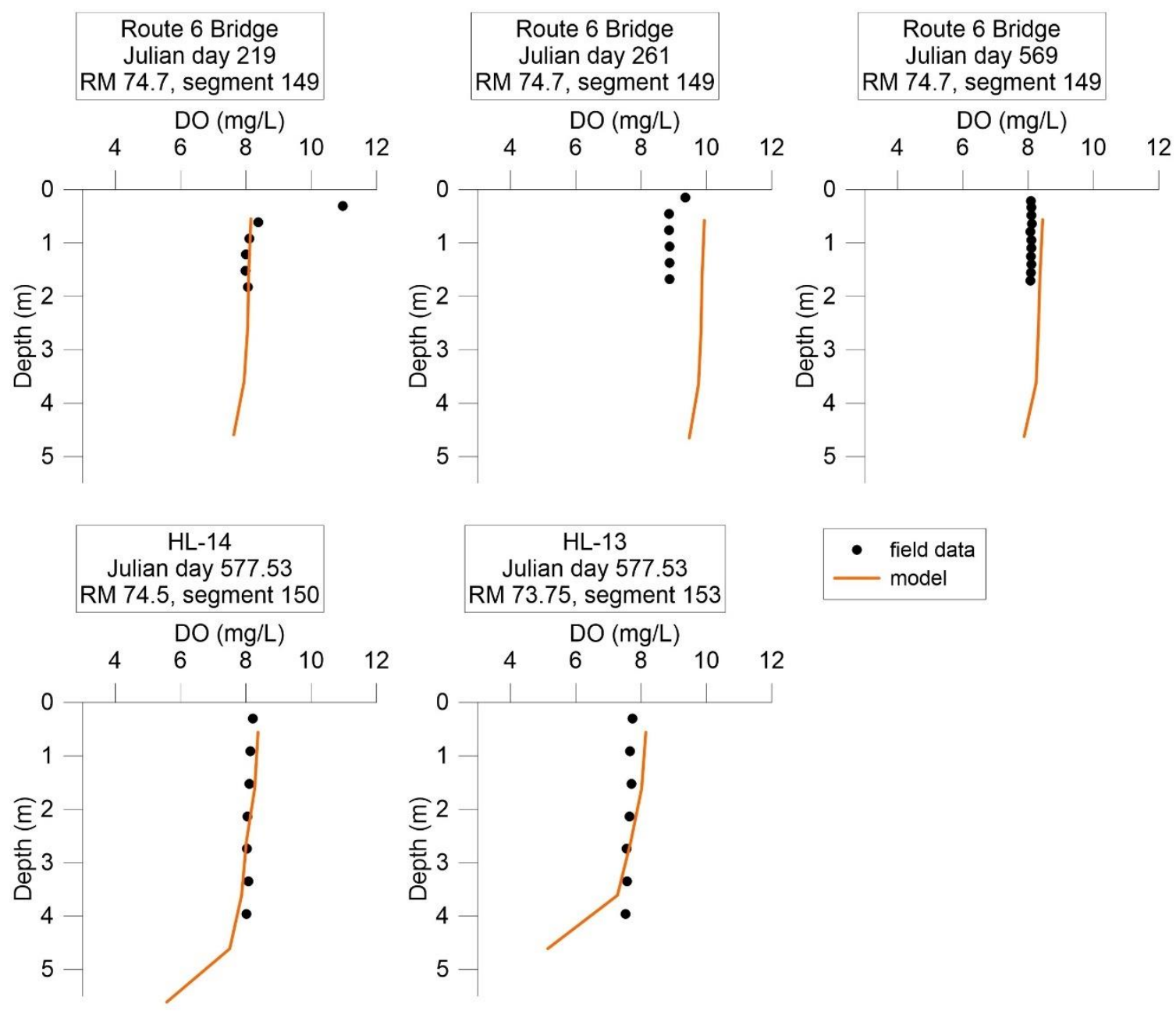

Figure 100. Vertical dissolved oxygen model predictions compared to field data in the mainstem Chehalis River pool area in 2013 and 2014 in the pool area. 


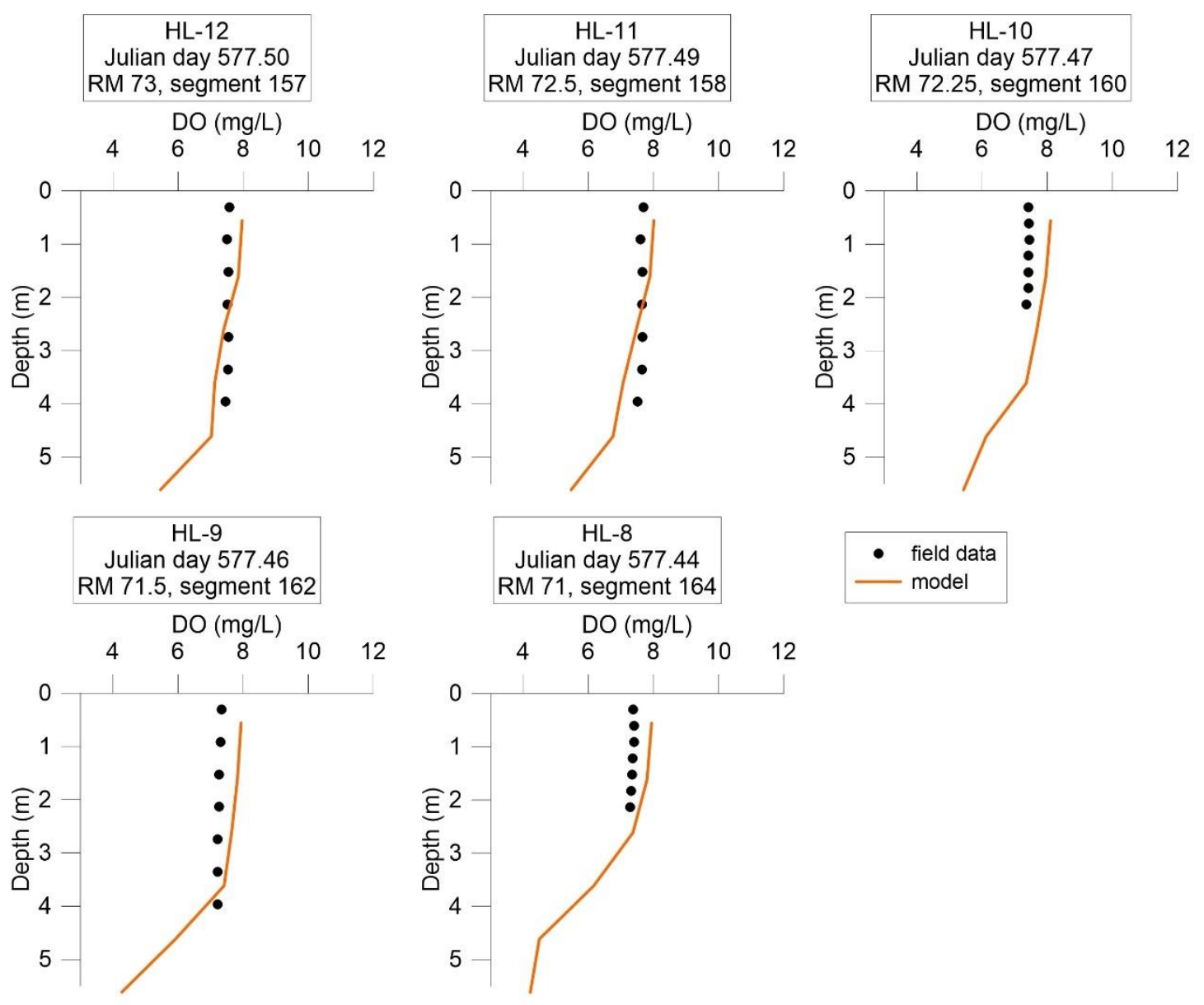

Figure 101. Vertical dissolved oxygen model predictions compared to field data in the mainstem Chehalis River pool area in 2014. 


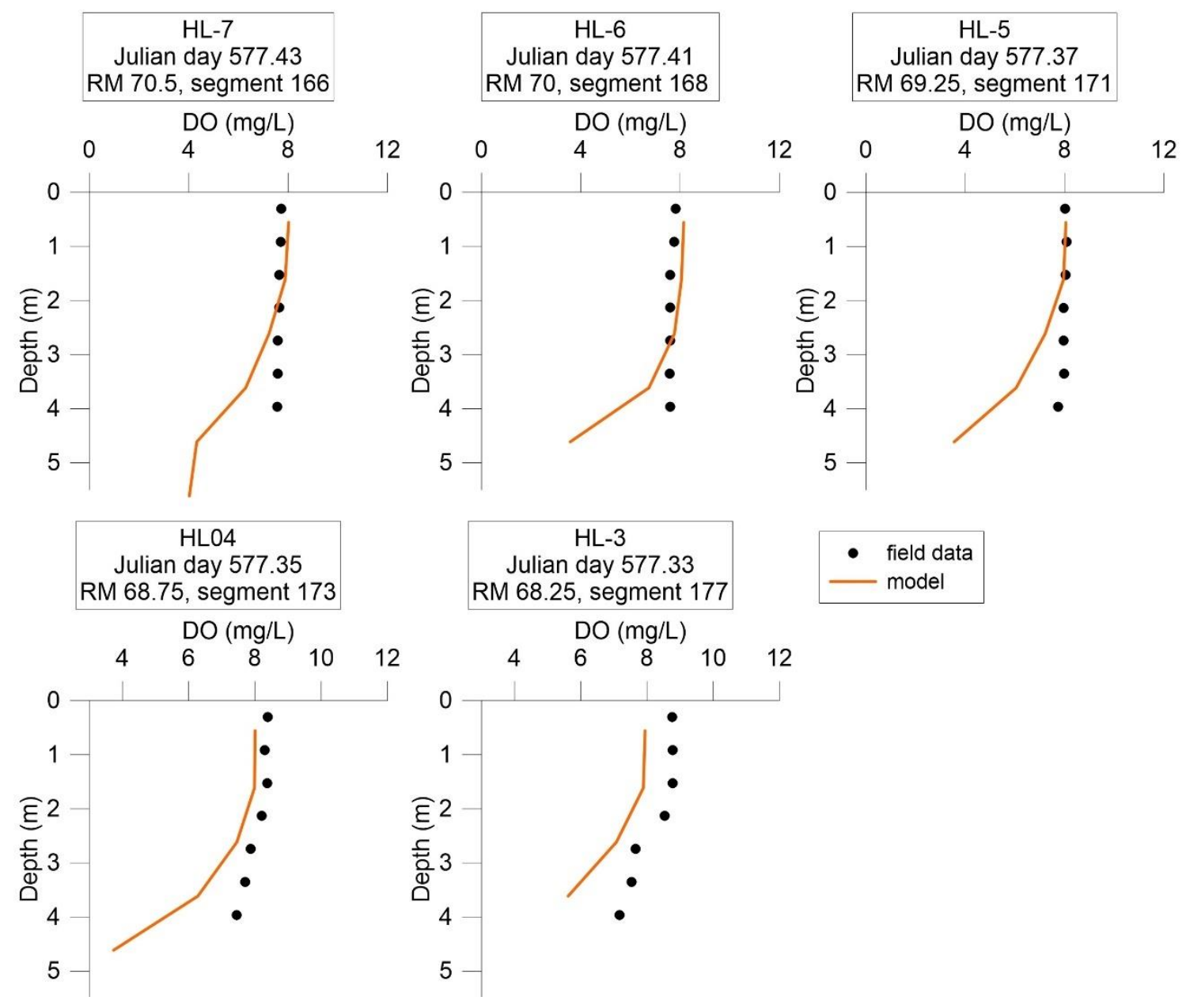

Figure 102. Vertical dissolved oxygen model predictions compared to field data in the mainstem Chehalis River pool area in 2014. 


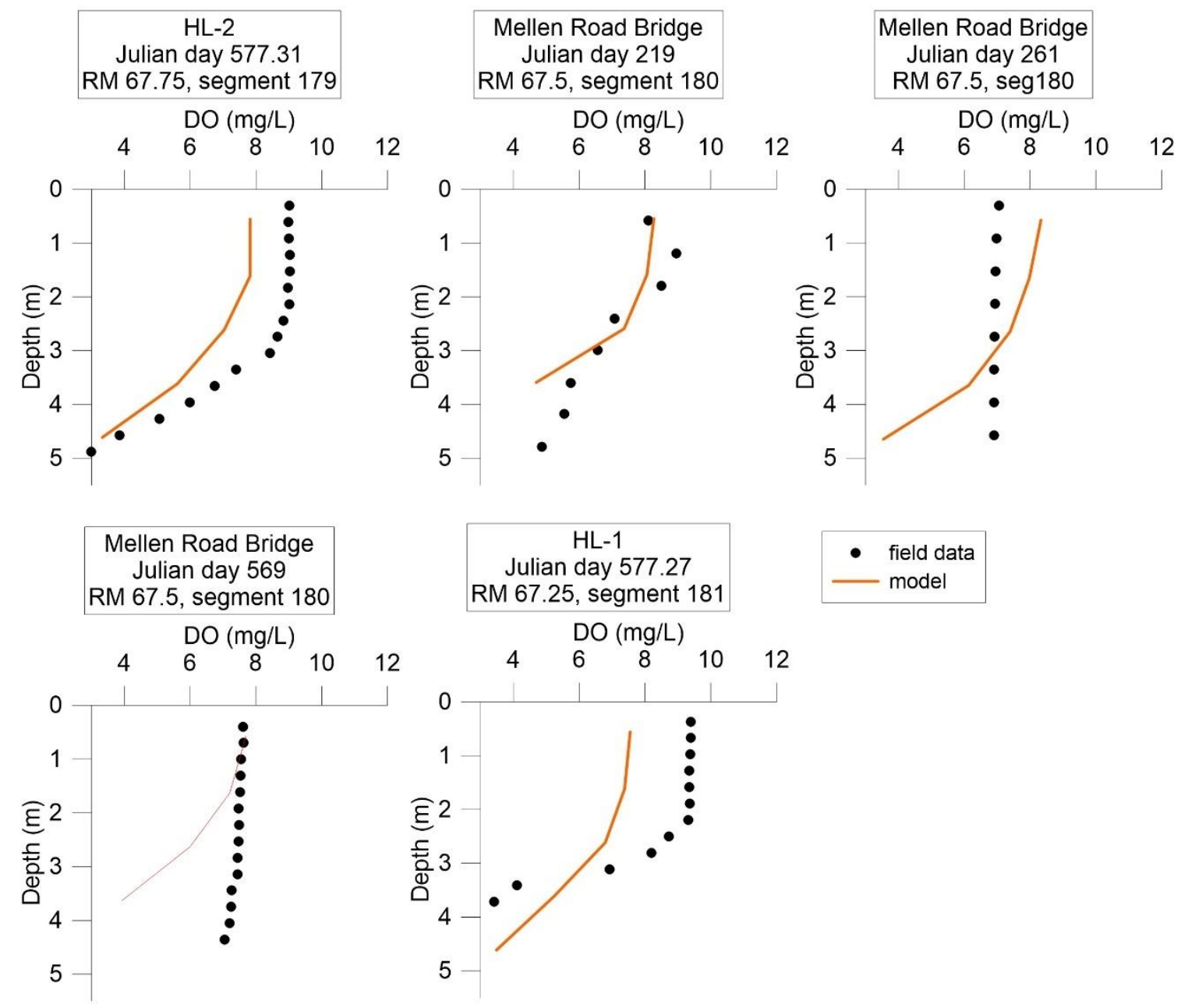

Figure 103. Vertical dissolved oxygen model predictions compared to field data in the mainstem Chehalis River pool area in 2013 and 2014.

\section{Algae Dynamics}

The model prediction of algae growth is largely a function of the limiting nutrient for algae. The model predicted nitrogen and phosphorus limitation (from 0 to 1) at several sampling stations along the mainstem Chehalis River between 2013-2015 as shown in Figure 104 and Figure 105; Figure 106 and Figure 107, respectively. Generally, phosphorus is limiting except between the Dryad and upstream of the Newaukum where nitrogen limits algae growth. 


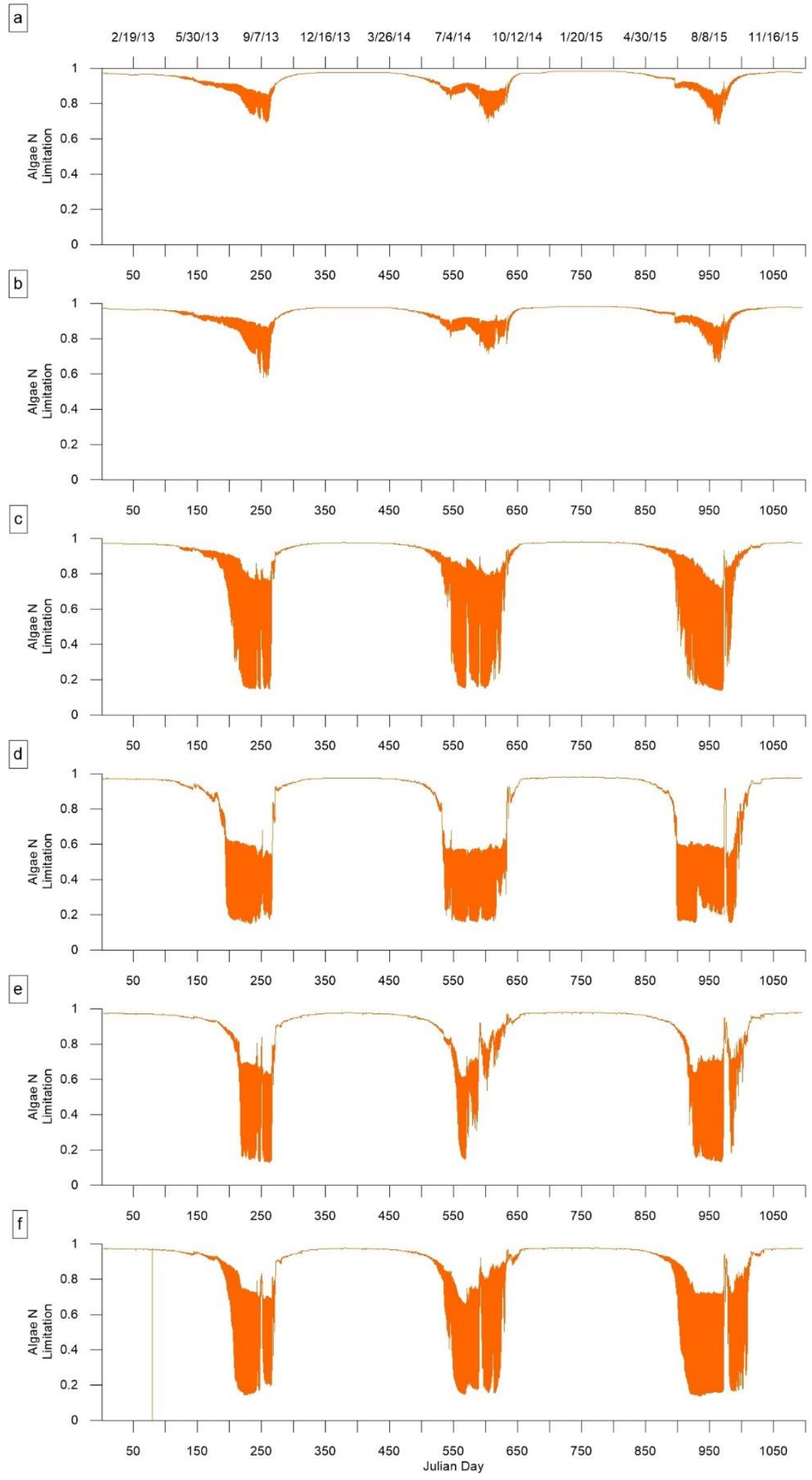

Figure 104. Model predicted nitrogen limitation for algal growth in the mainstem Chehalis River at (a) upstream of Pe Ell, (b) downstream of Pe Ell, (c) Dryad, (d) upstream of South Fork Chehalis River, (e) 
Adna, and (f) upstream of Newaukum River between 2013-2015. A value of 1 shows it is not limiting. Whichever value $(N, P$, or light) is the lowest is the limiting nutrient. 
a

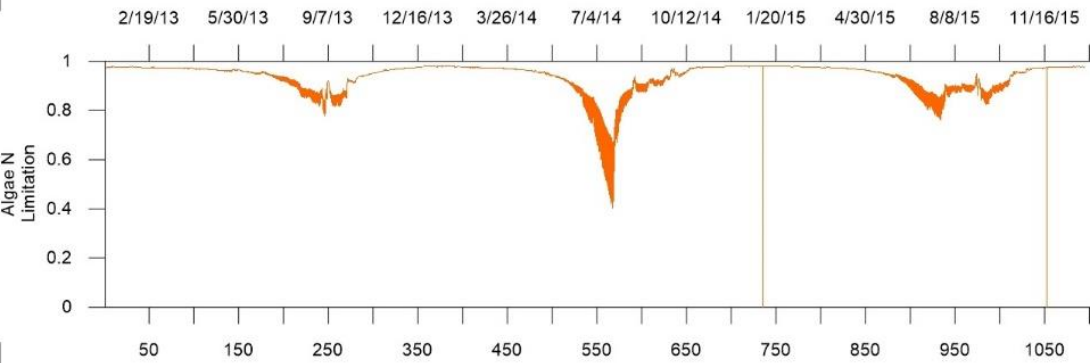

b

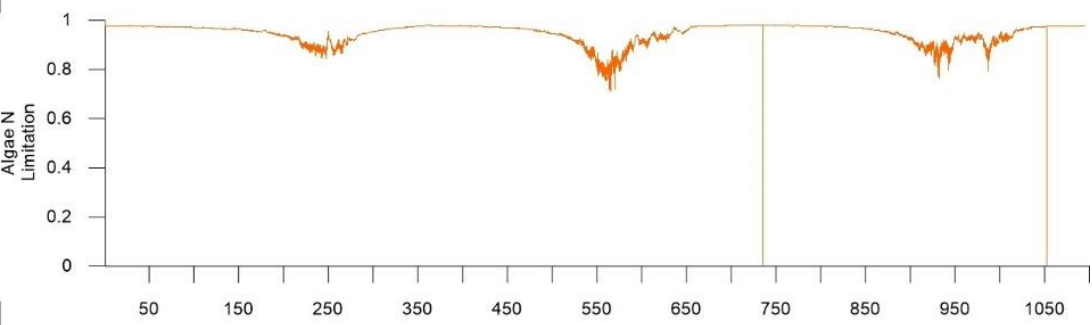

c

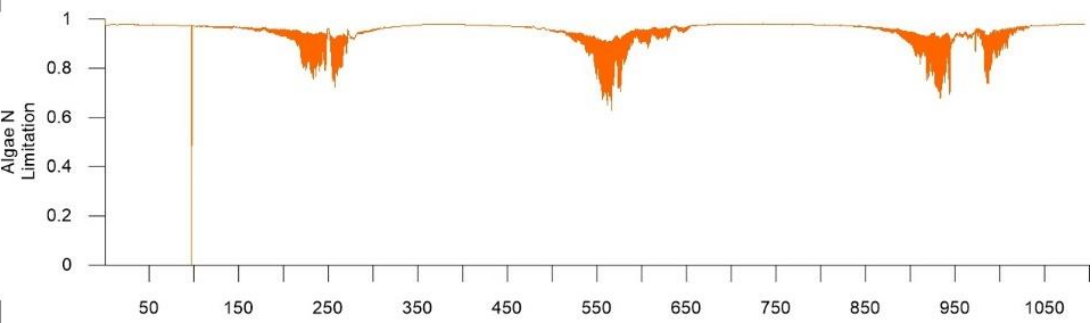

d

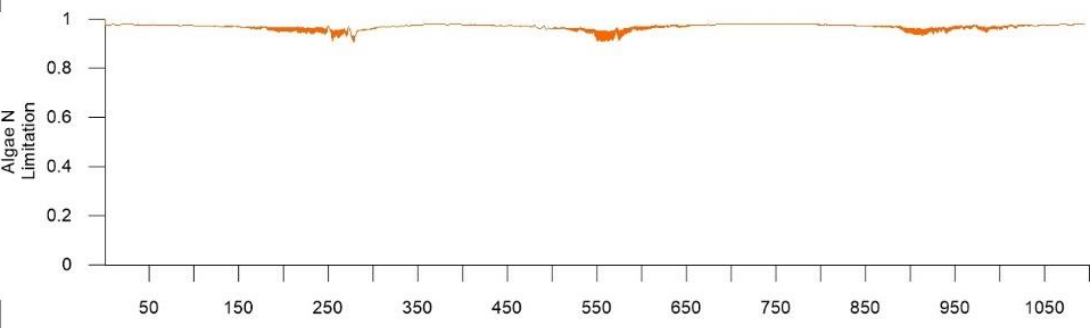

e
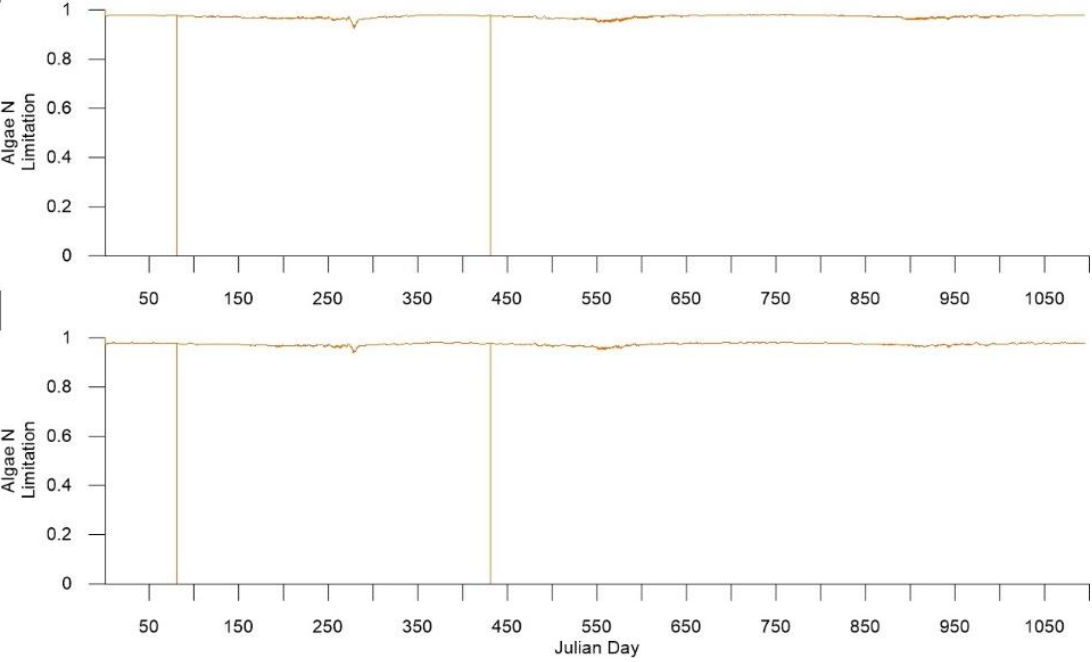

Figure 105. Model predicted nitrogen limitation for algal growth in the mainstem Chehalis River at (a) Route 6 bridge, (b) upstream of Skookumchuck River, (c) Galvin Road bridge, (d) upstream of Black 
River, (e) Oakville, and (f) Porter between 2013-2015. A value of 1 shows it is not limiting. Whichever value $(N, P$, or light) is the lowest is the limiting nutrient. 


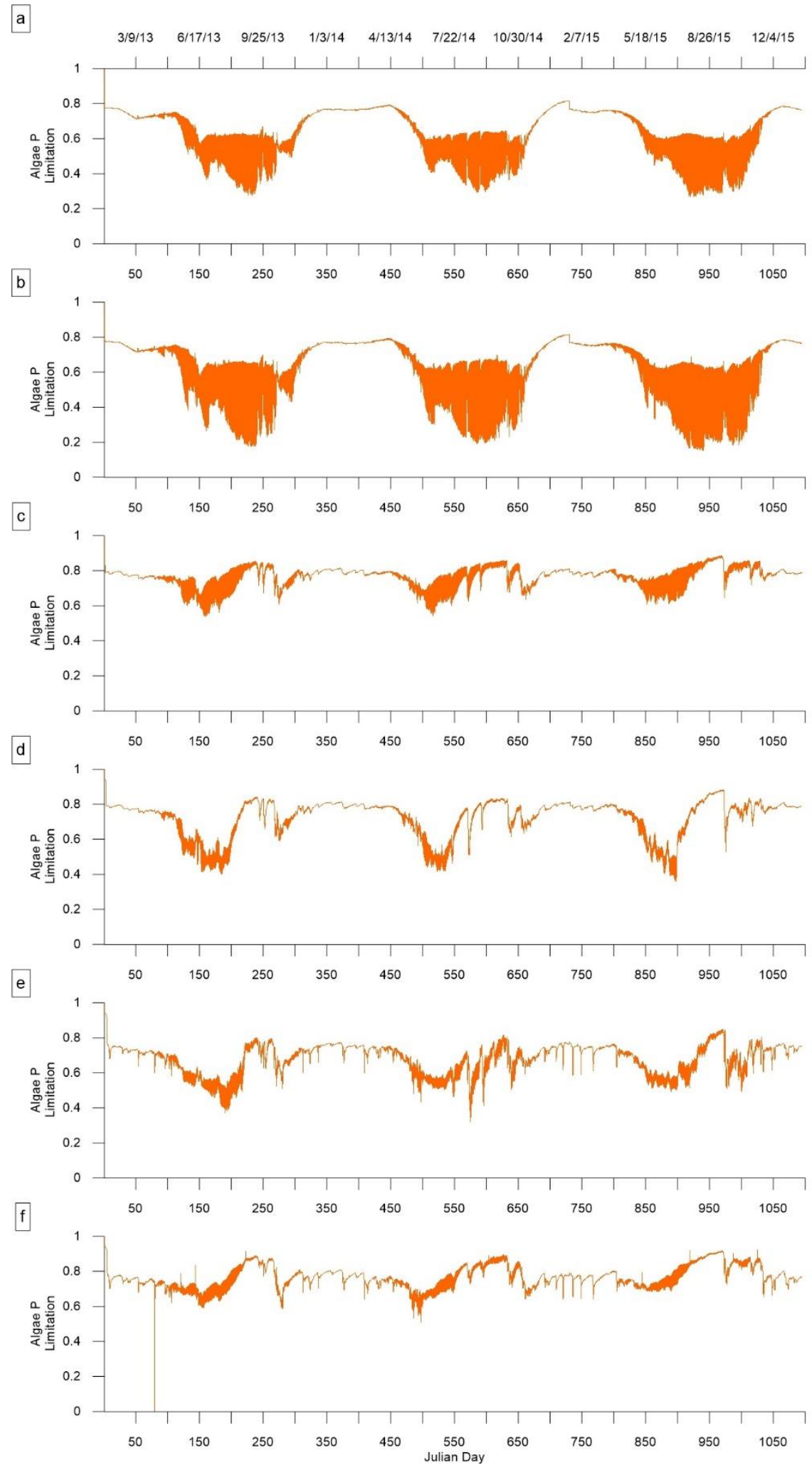

Figure 106. Model predicted phosphorus limitation for algal growth in the mainstem Chehalis River at (a) upstream of Pe Ell, (b) downstream of Pe Ell, (c) Dryad, (d) upstream of South Fork Chehalis River, 
(e) Adna, and (f) upstream of Newaukum River between 2013-2015. A value of 1 shows it is not limiting. Whichever value $(N, P$, or light) is the lowest is the limiting nutrient. 
a

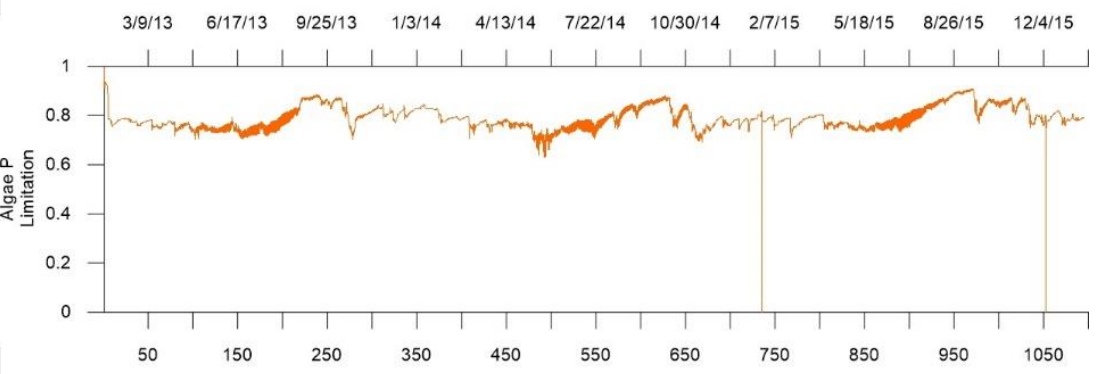

b

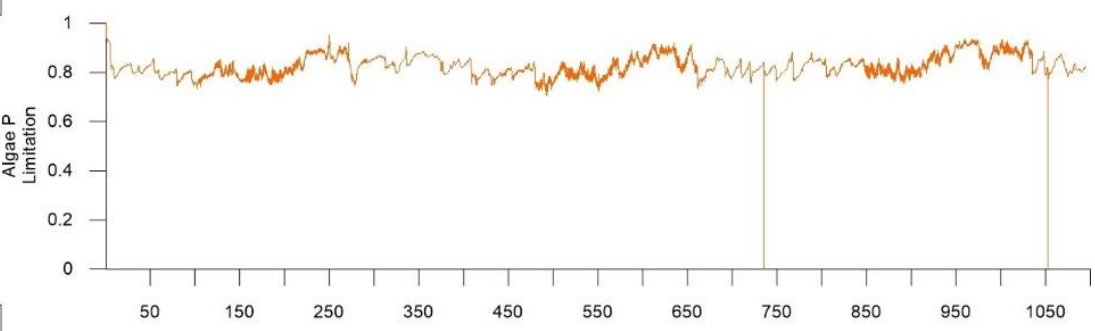

c

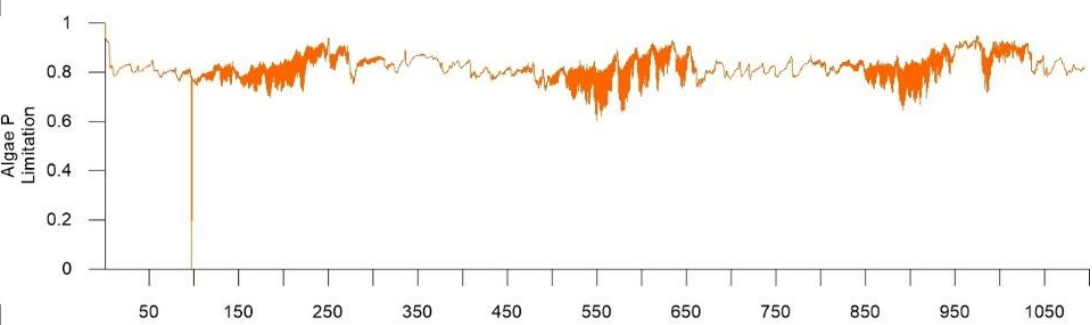

d

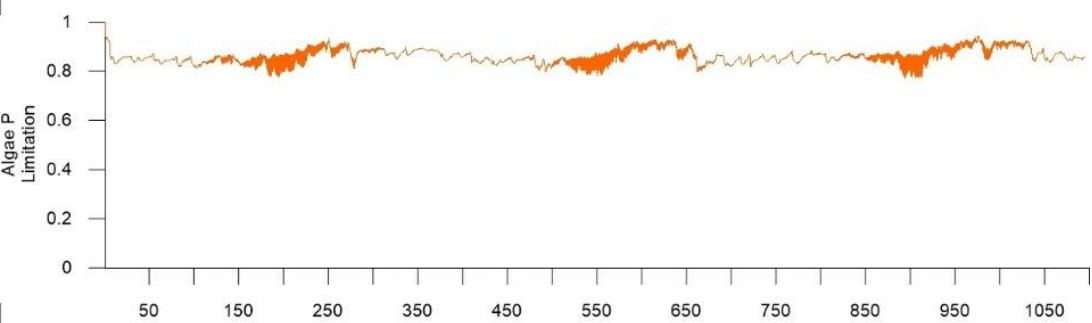

e

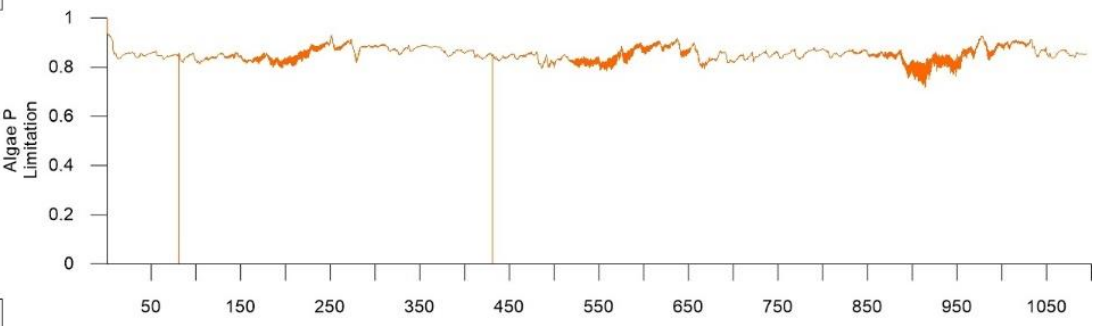

$\mathrm{f}$

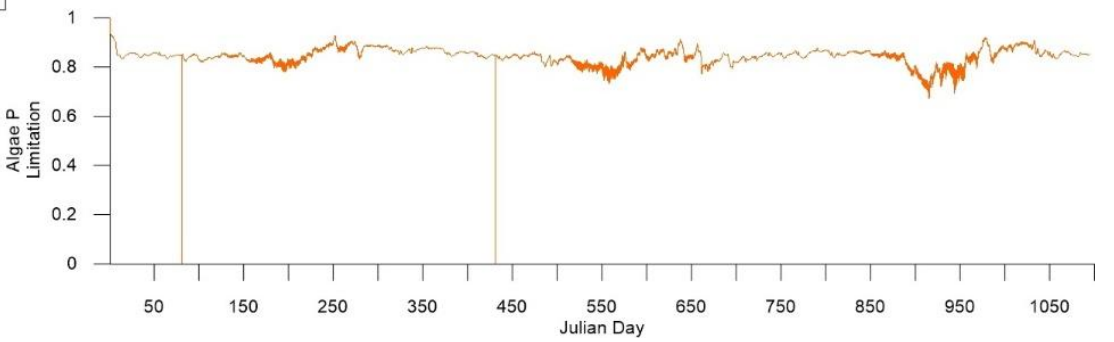

Figure 107. Model predicted phosphorus limitation for algal growth in the mainstem Chehalis River at (a) Route 6 bridge, (b) upstream of Skookumchuck River, (c) Galvin Road bridge, (d) upstream of Black 
River, (e) Oakville, and (f) Porter between 2013-2015. A value of 1 shows it is not limiting. Whichever value $(N, P$, or light) is the lowest is the limiting nutrient.

Periphyton

Model predicted periphyton densities for 2013-2015 at sampling sites along the mainstem Chehalis River are shown in Figure 108 and Figure 109. There were no field data to compare to model results. Upstream of the pool section, phosphorus was often the limiting nutrient for model periphyton growth during spring, while nitrogen was more often limiting during summer. 
a
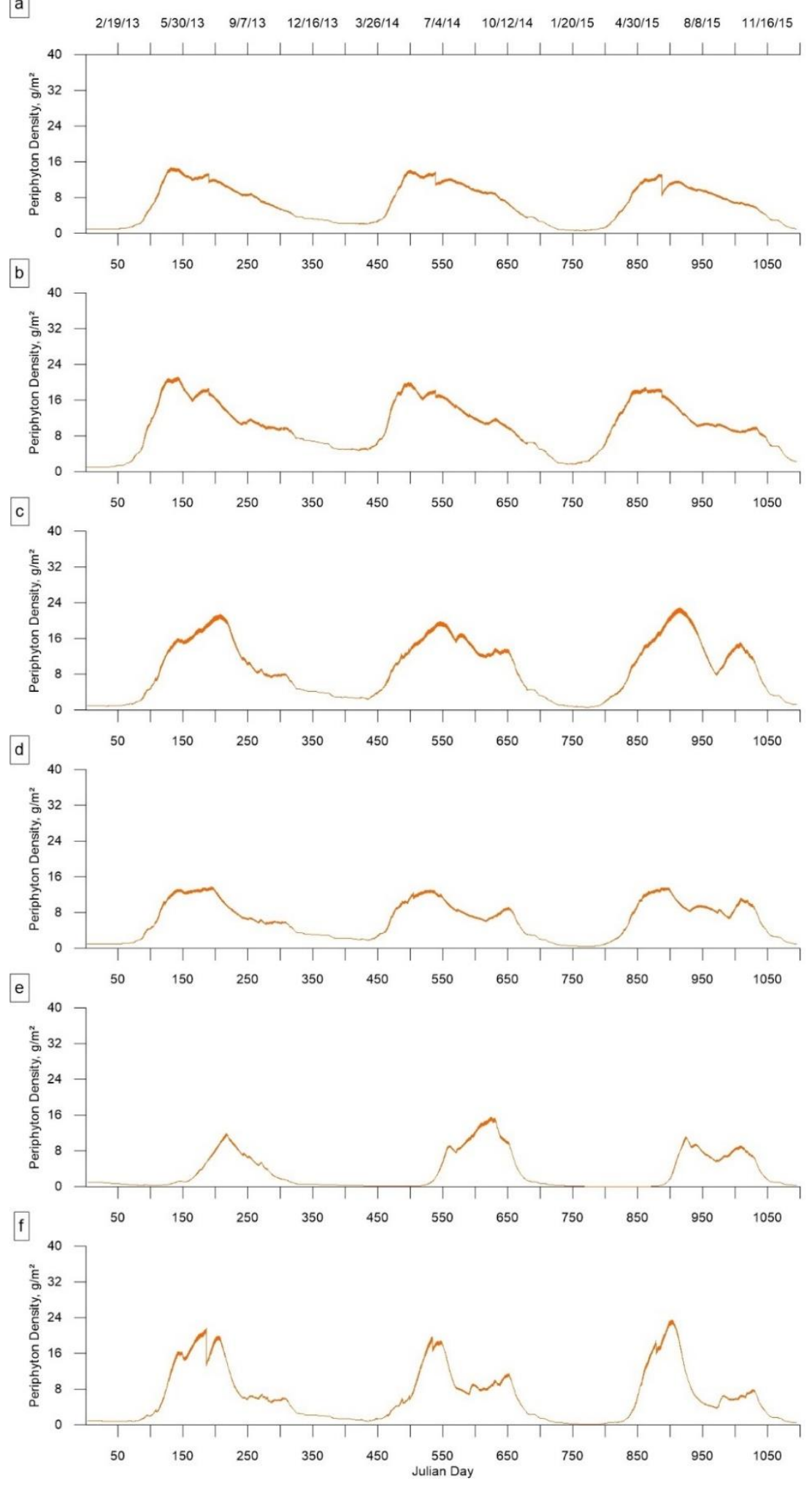

Figure 108. Model periphyton density predictions in the mainstem Chehalis River at (a) upstream of Pe Ell, (b) downstream of Pe Ell, (c) Dryad, (d) upstream of South Fork Chehalis River, (e) Adna, and (f) upstream of Newaukum River between 2013-2015. 


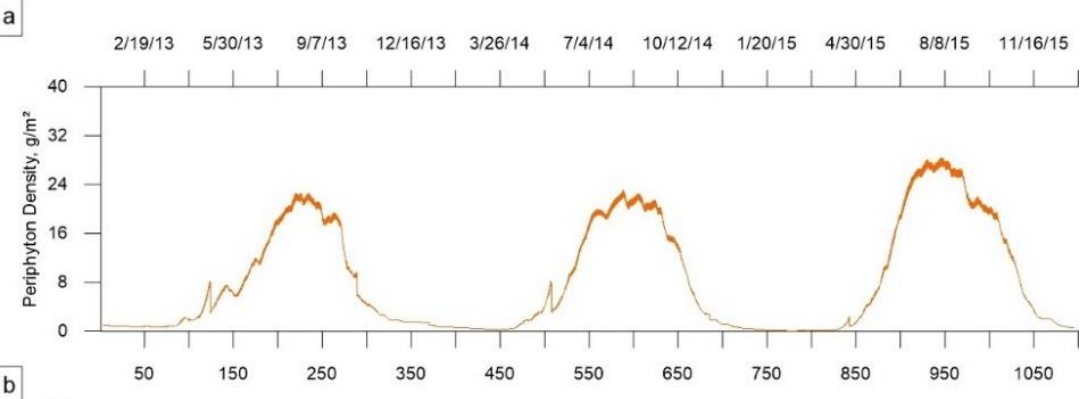

b

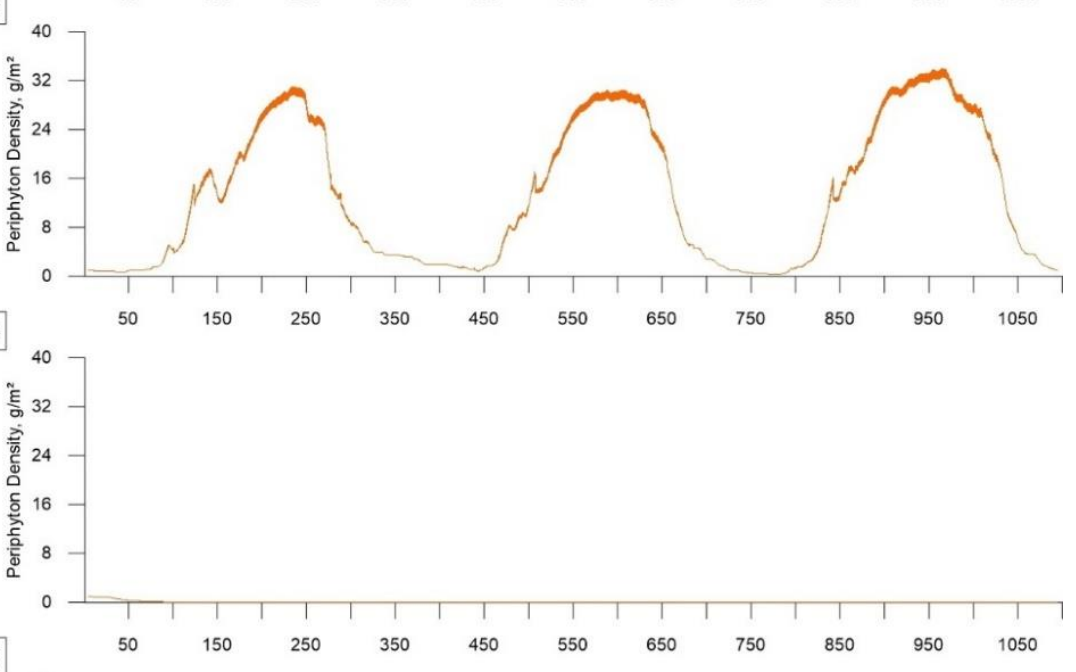

d
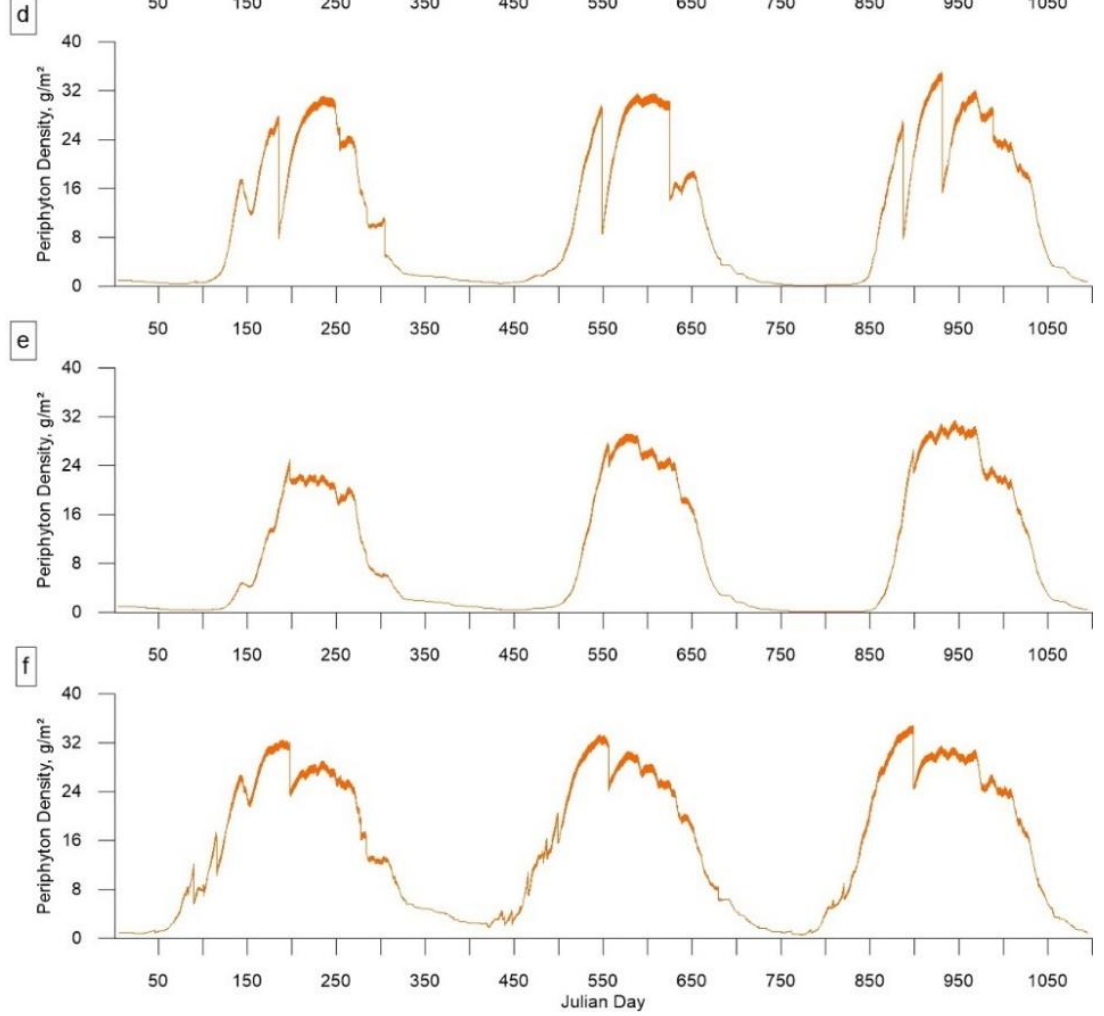

Figure 109. Model periphyton density predictions in the mainstem Chehalis River at (a) Route 6 bridge, (b) upstream of Skookumchuck River, (c) Galvin Road bridge, (d) upstream of Black River, (e) Oakville, and (f) Porter between 2013-2015. 
As a result of this lack of field data, a periphyton study was conducted by the Washington State Department of Ecology between July and September 2018. Three samples were collected from each of six sites between river mile 76.4 and river mile 106.2. Figure 110 shows the three-year average of model results between 20132015 with the 2018 WSDOE field data in order to show that the order of magnitude of the model predictions were reasonable at the 6 sampling sites corresponding to model segments $11,36,59,90,111,137$. In general, the model predicted periphyton densities were of a similar magnitude as the field data. 

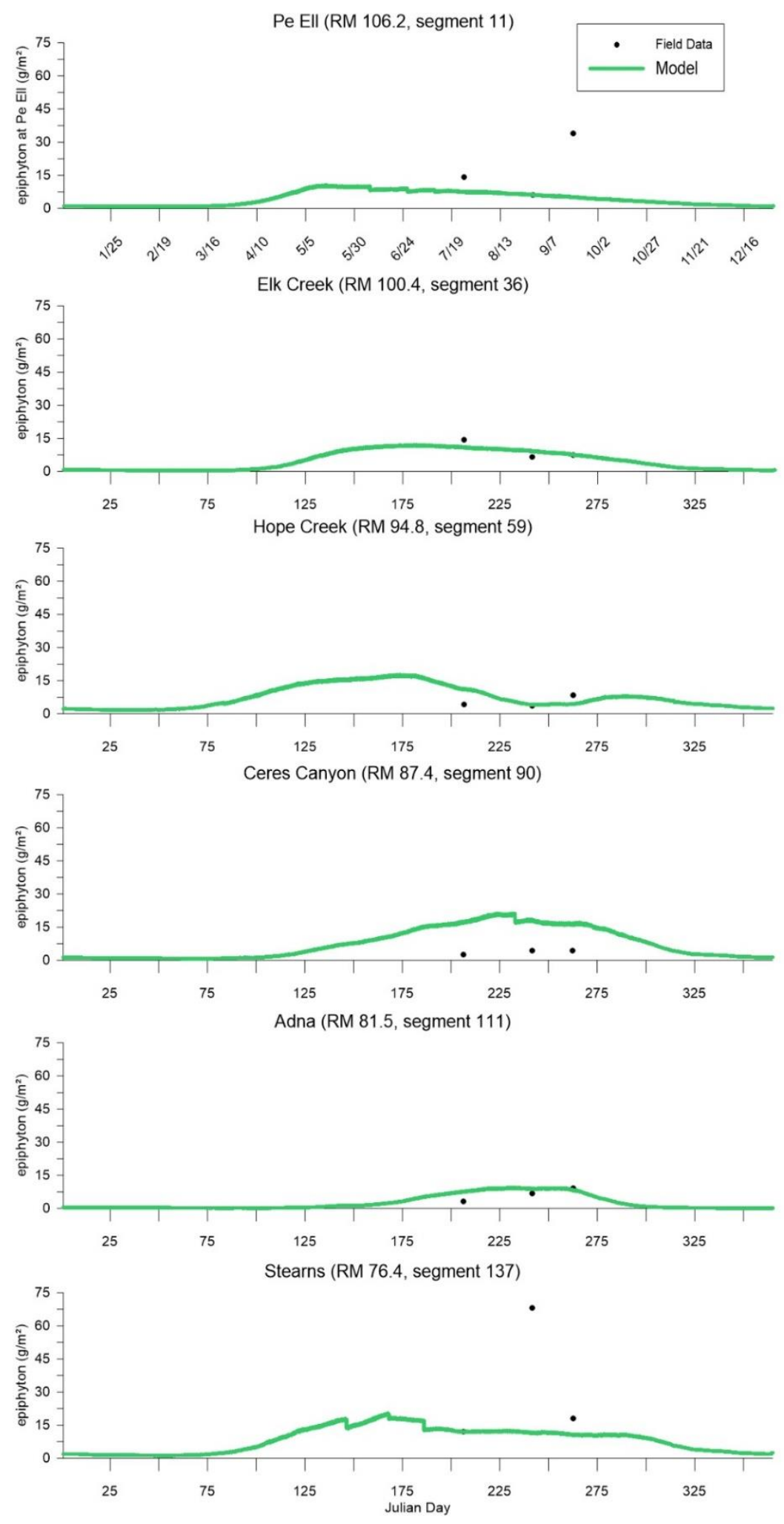

Figure 110. Periphyton field data for 2018 compared with model average periphyton output in the mainstem Chehalis River at model segments 11, 36, 59, 90, 111, and 137 for 2013-2015. 


\section{Summary}

The Chehalis River hydrodynamic and water quality model of Van Glubt et al. (2017)

was updated as follows:

- All model boundary conditions were updated to include 2015 since the original model development only included 2013 and 2014

- New correlations for flow and temperature were made to fill in data gaps for missing flow and temperature at some of the model input locations for 20132015

- A dye study by Mathieu (2018) was used to adjust travel time and dispersion throughout the Chehalis River mainstem. The travel time in the Van Glubt et al. (2017) model was generally too fast with little dispersion. Hence, the travel time was reduced and dispersion increased to match some of the dye study data.

- The model run times were reduced by using a new feature of CE-QUAL-W2 Version 4.2 that allowed the model to run in a cascade of multiple waterbodies. Run times were reduced by up to $90 \%$.

- Tributary models were developed and calibrated for the South Fork Chehalis, Newaukum, Skookumchuck, and Black Rivers for hydrodynamics and temperature.

- Tributary models performed well despite inadequate upstream temperature and flow boundary condition data.

The updated models were then run from January 1, 2013 through December 31, 2015 for flow and temperature. Only the mainstem Chehalis model was run for water quality between 2013-2015.

Tributary model calibration was primarily accomplished with estimates of boundary conditions rather than model coefficients. Model coefficients that were varied included the wind sheltering coefficient (WSC) which reduced wind, a factor that accounts for absorption of heat into the bed sediment (TSEDF), evaporation coefficients (AFW, BFW, CFW), the light extinction for water in $\mathrm{m}^{-1}$ (EXH20), the fraction of short waver solar absorbed on the surface (BETA), and Manning's friction factor (see Table 22). 
Table 22. Model coefficients used in the CE-QUAL-W2 model of the tributaries. WSC is the wind sheltering coefficient, TSEDF is a factor that accounts for absorption of heat into the bed sediment, AFW, $B F W$ and CFW were evaporation coefficients, EXH2O is the light extinction coefficient for water in $\mathrm{m}^{-1}$, and BETA is the fraction of short wave solar absorbed on the surface.

\begin{tabular}{|l|r|r|r|r|r|r|r|r|}
\hline Model & WSC & TSEDF & AFW & BFW & CFW & EXH20 & BETA & Manning's friction \\
\hline South Fork Chehalis & $0.25-1.0$ & 0.125 & 1.2 & 0.46 & 2 & 0.25 & 0.45 & 0.04 \\
\hline Newaukum & 0.5 & 0.5 & 9.2 & 0.46 & 2 & 0.25 & 0.45 & 0.04 \\
\hline Skookumchuck & 0.5 & 0.24 & 7 & 0.46 & 2 & 0.25 & 0.45 & 0.04 \\
\hline Black & 0.75 & 0.1 & 9.2 & 0.46 & 2 & 0.45 & 0.45 & 0.035 \\
\hline
\end{tabular}

The model predictions were compared to flow rate data at gages between 20132015. Generally, the model performed very well in predicting flow rates. This was especially important for the low flow summer flow periods. Flow percent mean error was below $1 \%$ of model average flow at each gage, and absolute mean error was below $4 \%$. Flow root mean square error was below $7 \%$.

In the Chehalis mainstem, the model predicted water levels between 2013-2015 were compared with gage data. In general, the comparisons were reasonable at several stations, even though there was uncertainty in the gage datum. Water level at Grand Mound and Doty could still be refined further with better local bathymetric data.

Model predictions were also compared to nearly 690,000 temperature field data points between 2013-2015 at over 27 monitoring stations along the mainstem Chehalis. For the mainstem Chehalis, the mean error (ME) was $-0.03^{\circ} \mathrm{C}$, and the absolute mean error (AME) was $0.72{ }^{\circ} \mathrm{C}$. Root mean square error was $0.91^{\circ} \mathrm{C}$. For 
the tributaries with no upstream temperature data, the mean errors were all below $\pm 0.5^{\circ} \mathrm{C}$ and the AME varied from 0.89 to $1.27^{\circ} \mathrm{C}$.

In the Chehalis mainstem, the model predicted water quality conditions during 2013-2015. Dissolved oxygen and nutrient levels were well reproduced. The model predicted phosphorus limitation of phytoplankton except between Adna and upstream of the Newaukum River, where it was nitrogen limited.

The periphyton levels predicted from the model were compared to field data from 2018 to see whether periphyton were an important part of the Chehalis ecosystem. The 2018 field data agreed well qualitatively with average model predictions between 2013-2015. Periphyton was phosphorus limited in the first two model waterbodies, and alternated between phosphorus and nitrogen limitation further downstream.

The model can still be improved. The following items would improve the model predictive ability:

- Since there was a lot of uncertainty in water quality boundary conditions, a better understanding of the water quality of the tributaries would improve the water quality predictive ability. Many of the tributaries relied on neighboring tributaries or on sparse data that was interpolated. For 2015, some of the tributaries had no measured water quality data and an average of 2013 and 2014 was used.

- The model geometry used an average hydraulic slope for the upstream segments. In contrast the model could be made more complex by dividing the model into many different pools and riffle elements (many more waterbodies) to more closely describe the water level and flow dynamics in the upper sections

- Even though the model predicted stratification in the pool area, some of the model-data comparisons showed that the model did not capture all of the dynamics. This could be a result of local wind or flow conditions in the pool 
area compared to that used by the model. This could mean that wind data in the pool or a different allocation of distributed flows as a result of performing the water balance may improve the predictive behavior of the model.

- For flood flows, the model could include lateral spillways to flood neighboring fields or oxbow lakes during peak storm events rather than being constrained to the top width of the cross-section. This would allow the model to predict lower peak water levels during large storm events.

- Measurement of flow rate and temperature at tributary model upstream boundaries.

- Tributary flow rates assumed to flow into the mainstem Chehalis River were not always measured at the confluence but were not corrected for this discrepancy. Studying the change between gaged flows and confluences with the mainstem would improve model accuracy.

- As the relationship between flow in a river and any of its tributaries is unlikely to be linear, using linear models used to estimate tributary flows introduces error to the model. Alternative methods of estimating these flows may give better results.

- Shade files should be developed for tributary models to improve temperature calibration.

- Additional adjustments to better replicate the 2018 dye study. 


\section{References}

Adams, E. E. and Wells, S. A. (1984) "Field Measurements on Side Arms of Lake Anna, Virginia," Journal of Hydraulic Engineering, ASCE, Vol. 110, No. 6, 773-793.

Anchor QEA, LLC. 2011. “Appendix A Draft Hydrologic and Hydraulic Modeling Report Chehalis River Fish Study". Prepared for Chehalis River Basin Flood Authority, Chehalis, WA. November, 2011.

Bilhimer, Dustin. 2015. “Chehalis Basin Strategy WQ Technical Tasks”. Water Quality Program, Washington Department of Ecology, Olympia, WA. September 22, 2015.

Cole, T. and Wells, S. 2018. "CE-QUAL-W2: A Two-Dimensional, Laterally Averaged, Hydrodynamic and Water Quality Model, Version 4.1 User Manual", Department of Civil and Environmental Engineering, Portland State University, Portland, OR.

Mathieu, Nuri. 2019. Personnel communication, Olympia, WA.

Pickett, P. 1994. Upper Chehalis Total Maximum Daily Load. Washington Department of Ecology. Publication No. 94-126, Olympia, WA.

Van Glubt, S., C. Berger, S. Wells. 2017. Technical memorandum Chehalis water quality and hydrodynamic modeling: model setup, calibration, and scenario analysis. Technical Report for Washington Department of Ecology, April 2017, 262 pp.

Washington Department of Ecology (WADOE). 2001. Upper Chehalis River Basin Temperature Total Maximum Daily Load. Publication No. 99-52, Olympia, WA.

Wells, S., Jensen, T., and Berger, C. 2019. Chehalis River and Tributary Water Quality and Hydrodynamic Modeling Model Setup, Calibration Analysis for 2013-2015, Technical Report Department of Civil and Environmental Engineering, Portland State University, prepared for Washington Department of Ecology, October 2019, 97 pp. 


\section{Appendix A: Estimating stream temperatures by the filtered equilibrium technique}

Since the inflow temperature records from field data were not available during the model calibration period, a synthetic temperature was determined from meteorological conditions. A filtered equilibrium temperature approach was used based on a technique of Adams and Wells (1984). This section discusses background information on the equilibrium temperature and the filtered equilibrium estimation technique based only on meteorological data, the approximate depth of the stream and the averaging period.

\section{The equilibrium temperature}

The net heat flux entering or leaving the water surface is a function of the incoming short wave solar radiation, the incoming long wave radiation, evaporation, conduction and back radiation. One equation incorporating all of these processes is the following heat balance equation (assuming Ryan-Harleman evaporation equation):

$$
\begin{gathered}
\varphi_{n}\left[W / m^{2}\right]=0.94 \varphi_{s c}\left(1-0.65 C^{2}\right)+5.15 \cdot 10^{-13}\left(T_{a i r}+273\right)^{6}\left(1+0.17 C^{2}\right)-5.51 \cdot 10^{-8}\left(T_{s}+273\right)^{4}- \\
{\left[2.7\left(T_{s v}-T_{a v}\right)^{1 / 3}+3.2 W_{2}\right]\left(e_{s}-e_{2}\right)\left[1+0.61 \frac{T_{s}-T_{2}}{e_{s}-e_{2}}\right]}
\end{gathered}
$$

where $\mathrm{T}_{\text {air }}$ is the air temp in $\operatorname{deg} \mathrm{C}, \mathrm{T}_{\mathrm{s}}$ is the surface temp in $\operatorname{deg} \mathrm{C}$, $\mathrm{e}_{\mathrm{s}}$ is the saturated vapor pressure at water surface temp, $\mathrm{T}_{\mathrm{sv}}$ and $\mathrm{T}_{\mathrm{av}}$ are the virtual surface and air temperatures in deg $\mathrm{K}, \mathrm{C}$ is cloud cover fraction from 0 to 1 . The equilibrium temperature is defines as that value of $\mathrm{T}_{\mathrm{s}}$ (surface temperature) for which the net heat flux, $\phi_{n}$, is zero. Since the equation cannot be solved for explicitly for that temperature, a root finding bi-section technique is used to determine Teq. This is illustrated in Figure A111.

The equilibrium temperature concept was a mathematical approach to surface heat transfer that linearized the $\Phi_{\mathrm{n}}$ term which was a function of $\mathrm{T}_{\text {surface }}$ to the $4^{\text {th }}$ power to a function of $\mathrm{T}_{\text {surface }}$ to the 1 st power. This allowed analytical solutions to temperature models to be used and introduced another term, K called the surface heat transfer coefficient. This term dictates the speed at which the water body responds to the temperature. 


$$
\Phi_{n}=-K\left(T_{s}-T_{E}\right)
$$

Another approach for computing $\mathrm{T}_{\mathrm{E}}$ is to use an approximate technique from Brady et al. (1969):

$$
T_{E}=\frac{\phi_{s n}}{23+f(W)(\beta+0.255)}+T_{d}
$$

where $\varphi_{\text {sn: }}$ net short wave solar in Btu $/ \mathrm{ft}^{2} /$ day

$\mathrm{T}_{\mathrm{d}}$ : dew point temperature $\mathrm{oF}$

$\mathrm{f}(\mathrm{W})$ : wind speed function $=17 \mathrm{~W}_{2}$ Lake Hefner model, in Btu $/ \mathrm{ft}^{2} / \mathrm{day} / \mathrm{mm} \mathrm{Hg}$

$\beta=0.255-0.0085 T^{*}+0.000204 T^{* 2}$

$\mathrm{T}^{*}=0.5\left(\mathrm{~T}_{\mathrm{w}}+\mathrm{T}_{\mathrm{d}}\right)$

Tw: water surface temperature

$\mathrm{T}_{\mathrm{d}}$ : dew point temperature

$\mathrm{W}_{2}$ : wind speed at $2 \mathrm{~m}$ in $\mathrm{mph}$

K can be computed from the slope of net flux vs temperature or can be obtained using an approximate formula (Brady et al., 1969):

$$
K=23+\left(\beta_{w}+0.255\right) 17 W_{2}
$$

where $\beta_{w}=0.255-0.0085 T_{w}+0.000204 T_{w}^{2}$

units of $\mathrm{K}$ are in Btu $/ \mathrm{ft}^{2} /$ day $/{ }^{\circ} \mathrm{F}$

This approximate approach was used to compute TE and K for each hour of the meteorological record. 


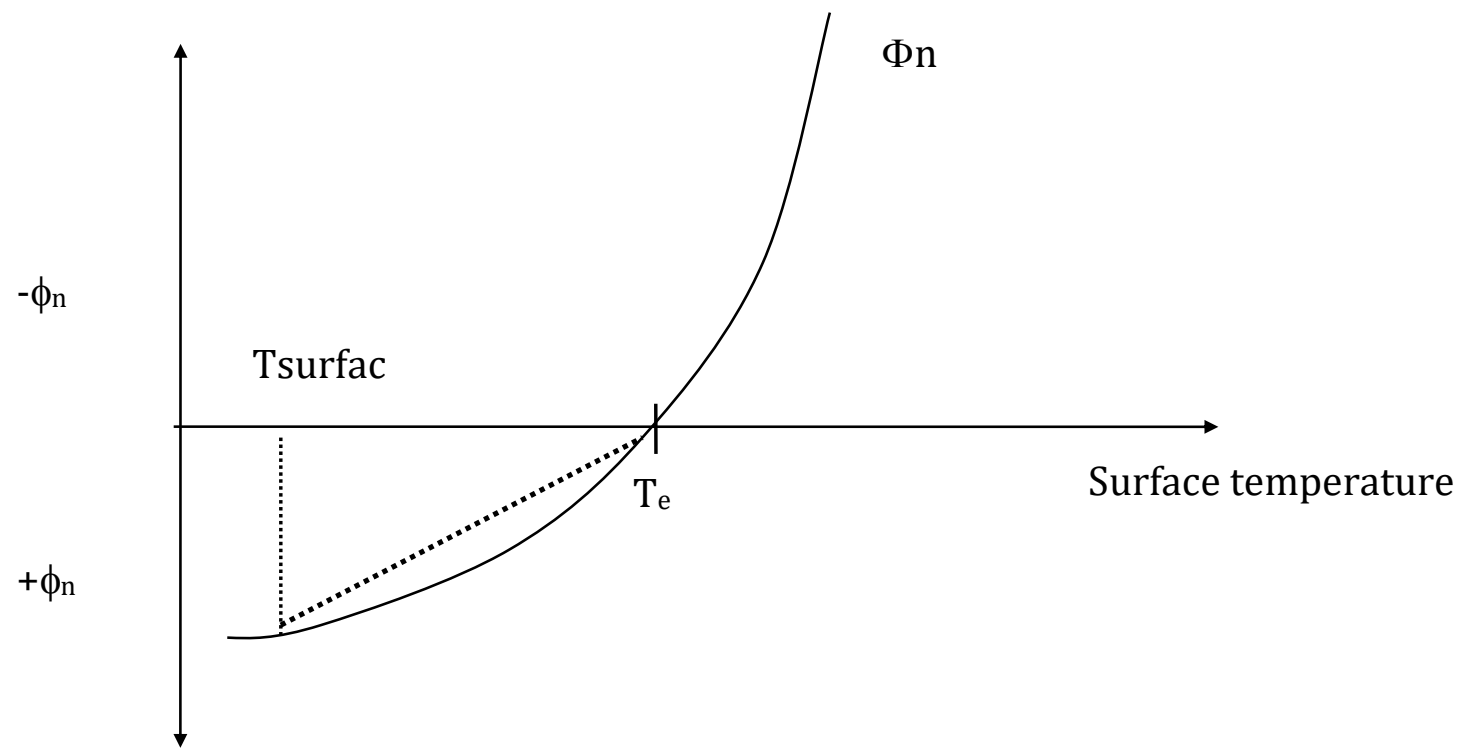

Figure A111. The definition of equilibrium temperature.

\section{The filtered equilibrium temperature}

An approach described in Adams and Wells (1984) was used to predict inflow tributary temperatures. This approach consisted of an exponential filter based on the equilibrium temperature and surface heat exchange coefficient. For example, the

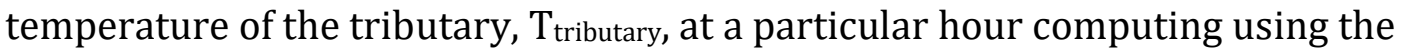
following equation:

$T_{\text {tributary }}=\frac{\sum_{n=1}^{t_{\text {residence }} / \Delta t} T_{e}(t-n \Delta t) \exp (-(n-1) \bar{k} \Delta t)}{\sum_{n=1}^{t_{\text {residence }} / \Delta t} \exp (-(n-1) \bar{k} \Delta t)}$

where $\mathrm{T}_{\mathrm{e}}$ : equilibrium temperature (defined as the value of temperature for which the net surface heat flux is zero)

$\Delta \mathrm{t}$ : time step (usually one hour) 
$\bar{k}:$ kinematic surface heat exchange coefficient (average over preceding residence time)

$=\frac{\bar{K}}{\rho c_{p} h}$ where $\mathrm{K}$ is the surface heat exchange coefficient, $\rho$ is the

density, $c_{p}$ is the specific heat at constant pressure, $h$ is the average depth of the water

tresidence: residence time of fluid exposed to meteorological conditions

n: number of time steps to "average" the meteorological conditions

The kinematic heat exchange coefficient was calculated using the meteorological file for the water body.

\section{Appendix B: Washington Department of Ecology Dye Study 2018}

Mathieu (2018) provided preliminary information on a time-of-travel dye study performed on the Chehalis River in 2018. Even though this was outside the calibration period of the model, the dye information was useful in comparing the movement of water in the Chehalis River to that in the model.

A description of the dye releases in the Chehalis mainstem and the travel time between reaches is shown in Table B23. The times were daylight savings time. The model though used Pacific Standard time for all model inputs.

Table B23. Description of 4 dye releases on the Chehalis River in August 2018 by Mathieu (2018) based on provisional data.

\begin{tabular}{|c|c|c|c|c|c|c|c|c|c|c|c|c|}
\hline Sonde\# & Site & $\begin{array}{c}\sim \text { USGS } \\
\text { RM }\end{array}$ & $\begin{array}{c}\text { Time of Leading } \\
\text { Edge }\end{array}$ & $\begin{array}{c}\text { Time of Peak (or } \\
\text { release) }\end{array}$ & JDAY Peak or release & $\begin{array}{c}\text { Time of Tail (10\% of } \\
\text { peak) }\end{array}$ & $\begin{array}{l}\text { Segment Peak } \\
\text { travel time } \\
\text { (days) }\end{array}$ & $\begin{array}{l}\text { Cumulative } \\
\text { Peak travel time } \\
\text { (days) }\end{array}$ & $\begin{array}{l}\text { Segment Avg } \\
\text { Velocity (ft/s) }\end{array}$ & $\begin{array}{c}\text { Peak } \\
\text { Concentration } \\
\text { (ppb) }\end{array}$ & $\begin{array}{l}\text { Release } \\
\text { Volume } \\
\text { (L) }\end{array}$ & $\begin{array}{l}\text { Mass } \\
\text { added, } \\
\mathrm{gm}\end{array}$ \\
\hline \multicolumn{13}{|c|}{ Release \#4 - Pe EII } \\
\hline $\mathrm{n} / \mathrm{a}$ & SR6-Pe Ell & 106.2 & $\mathrm{n} / \mathrm{a}$ & 8/7/2018 20:33 & 2045.8563 & $\mathrm{n} / \mathrm{a}$ & $n / a$ & 0.0 & $n / a$ & $200,000,000$ & 0.5 & \multirow[t]{4}{*}{100} \\
\hline 26 & Elk Cr Rd & 100.4 & 8/8/2018 17:00 & $8 / 8 / 201822: 15$ & 2046.927 & 8/9/2018 10:00 & 1.1 & 1.1 & 0.33 & 3.16 & & \\
\hline 21 & Hope Creek & 94.8 & $8 / 9 / 201822: 00$ & 8/10/2018 7:15 & $\underline{2048.302}$ & unknown & 1.4 & 2.4 & 0.25 & 0.9 & & \\
\hline 26 & Ceres Canyon & 87.4 & not discernable & 8/12/20189:30 & 2050.396 & unknown & 2.1 & 4.5 & 0.22 & 0.58 & & \\
\hline \multicolumn{13}{|c|}{ Release \#3 - Ceres Canyon } \\
\hline $\mathrm{n} / \mathrm{a}$ & Ceres Canyon & 87.4 & n/a & 8/7/2018 19:50 & 2045.8264 & $n / a$ & $n / a$ & 4.5 & $n / a$ & $200,000,000$ & 0.5 & \multirow[t]{3}{*}{100} \\
\hline 15 & Adna- WH Trail & 81.5 & $8 / 9 / 20185: 00$ & $8 / 9 / 201816: 00$ & $\underline{2047.667}$ & unknown & 1.8 & 6.4 & 0.20 & 0.55 & & \\
\hline 41 & Newaukum/Alexander & 75.1 & $8 / 11 / 20182: 00$ & 8/11/2018 17:30 & $\underline{2049.729}$ & unknown & 2.1 & 8.4 & 0.19 & 0.27 & & \\
\hline \multicolumn{13}{|c|}{ Release \#2 - Newaukum/Alexander Park } \\
\hline$n / a$ & Newaukum/Alexander & 75.1 & $\mathrm{n} / \mathrm{a}$ & 8/6/2018 20:50 & 2044.8681 & $n / a$ & $n / a$ & 8.4 & $n / a$ & $200,000,000$ & 2 & \multirow[t]{2}{*}{400} \\
\hline 37 & Skookumchuck/F.Borst & 67 & 8/11/2018 17:00 & $8 / 13 / 201820: 45$ & $\quad \underline{2051.865}$ & unknown & 7.0 & 15.4 & 0.07 & 0.535 & & \\
\hline \multicolumn{13}{|c|}{ Release \#1 - Skookumchuck/Fort Borst Park } \\
\hline$n / a$ & Skookumchuck & 66.65 & $\mathrm{n} / \mathrm{a}$ & 8/6/2018 20:05 & $\underline{2044.8368}$ & $n / a$ & $n / a$ & 15.4 & $n / a$ & $200,000,000$ & 2 & \multirow[t]{3}{*}{400} \\
\hline 21 & Prather Rd & 59.9 & 8/8/2018 0:30 & $8 / 8 / 201811: 30$ & 2046.479 & unknown & 1.6 & 17.1 & 0.25 & 1.32 & & \\
\hline 33 & Oakville Boat launch & 42.4 & $8 / 10 / 201816: 00$ & 8/11/2018 11:45 & 2049.490 & 8/13/2018 10:00 & 3.0 & 20.1 & 0.36 & 0.32 & & \\
\hline
\end{tabular}

Flow rates during the dye study were very low compared to historical flow rates as shown in Figure B112. After the dye release at Pe Ell (RM 106.2), the resulting provisional measured dye concentrations downstream over time at the sampling 
station Elk Creek (RM 100.4), Hope Creek (RM 94.8) and Ceres Canyon (RM 87.4) are shown in Figure B113, Figure B114, and Figure B115, respectively. Whereas the dye concentrations at Elk Creek and Hope Creek were typical of river systems, the concentrations at Ceres Canyon show that flow dynamics were highly complex. Other dye profiles for the three other dye releases were found in Matheiu (2018).
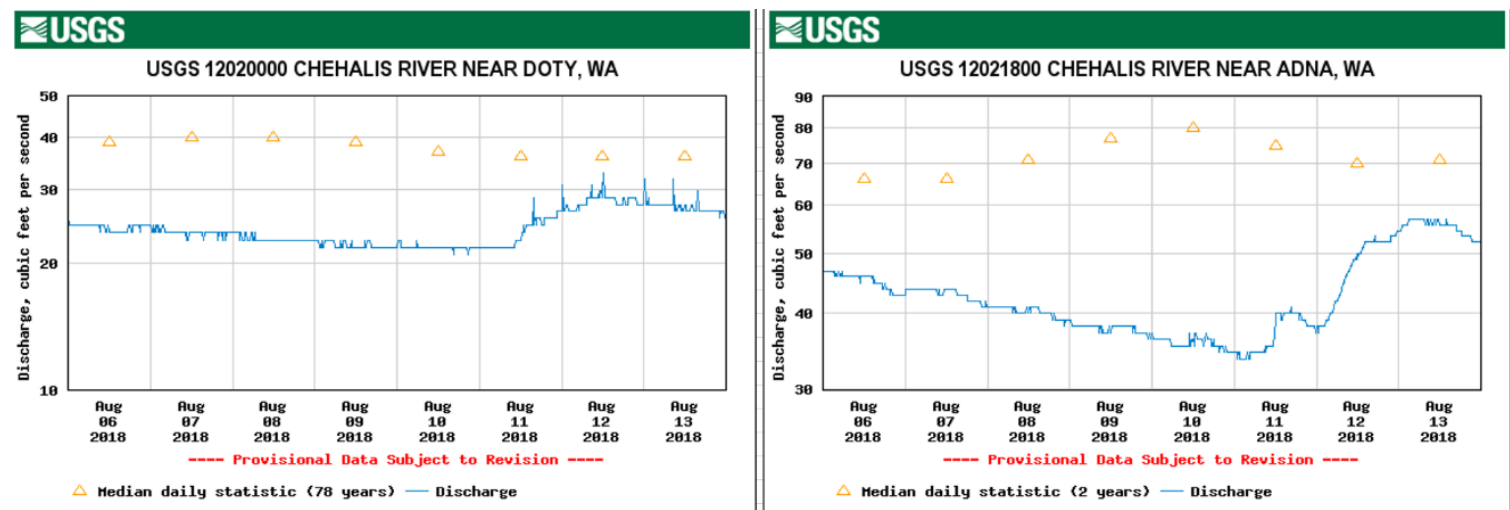

$\triangle$ Median daily statistic (78 years) — Discharge
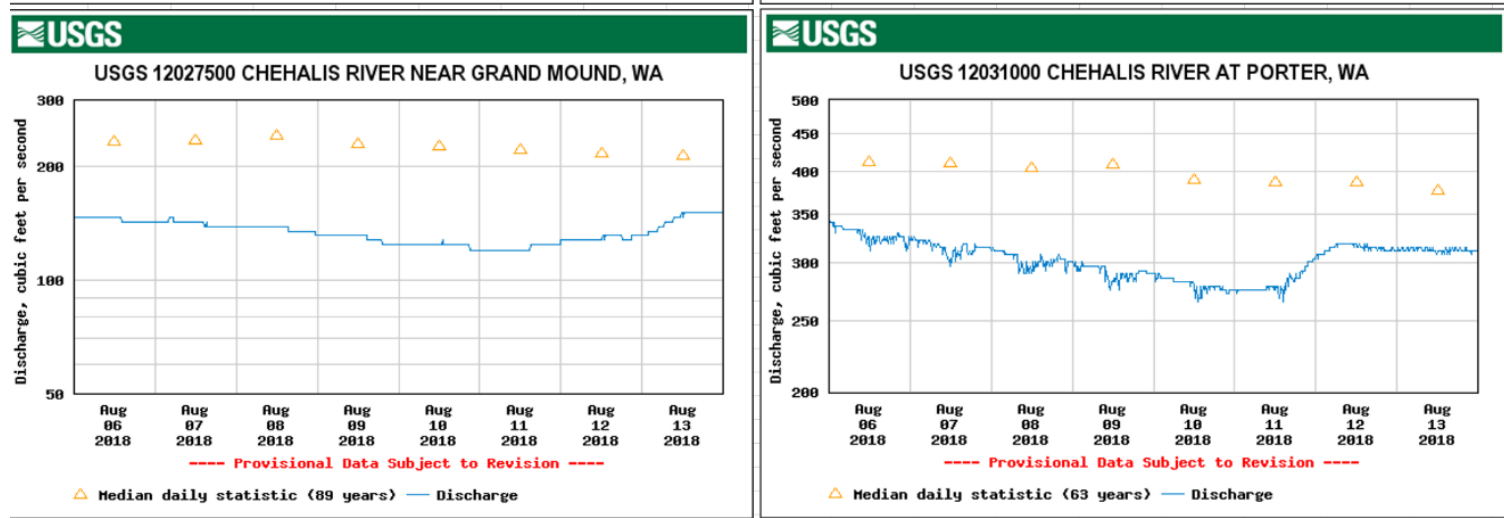

Figure B112. USGS flow rates in the Chehalis mainstem during the August 2018 dye study. 


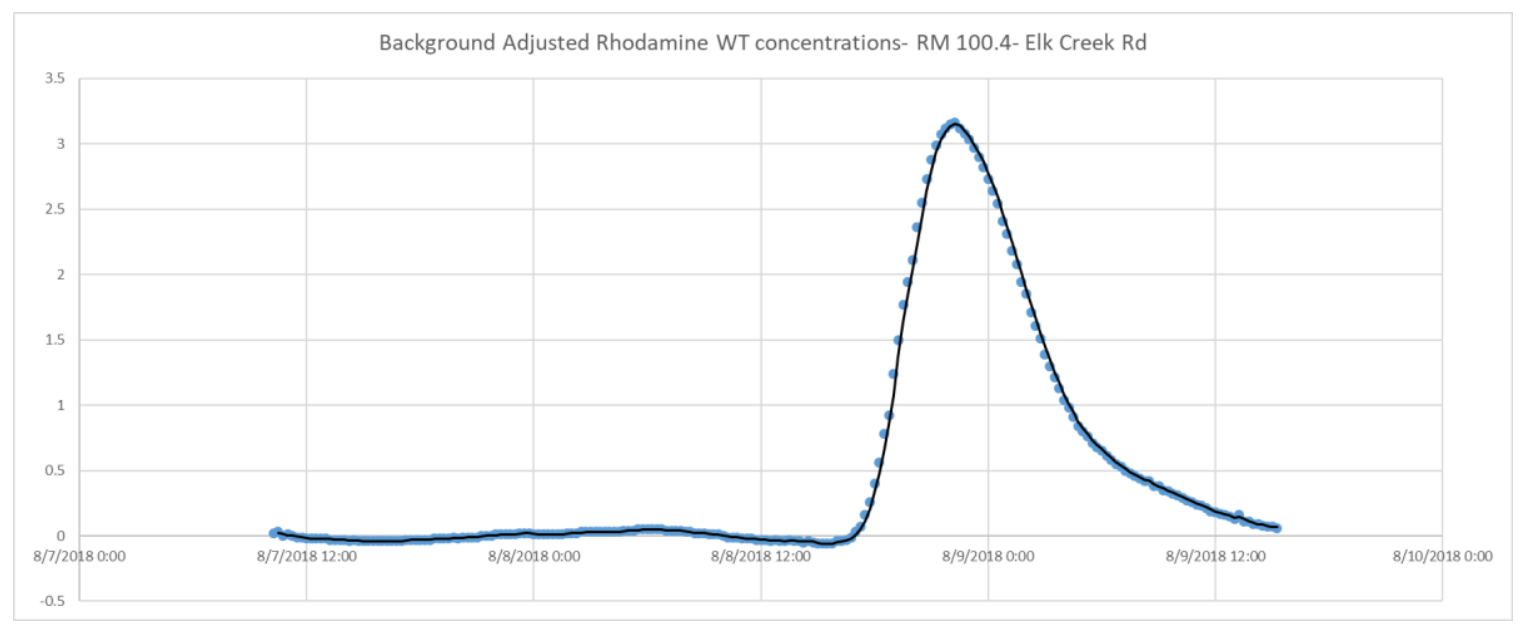

Figure B113. Measured dye concentrations in ppb at Elk Creek RM 100.4 in August 2018 after release at Pe Ell RM 106.2 on 8/7/2018 at 20:33.

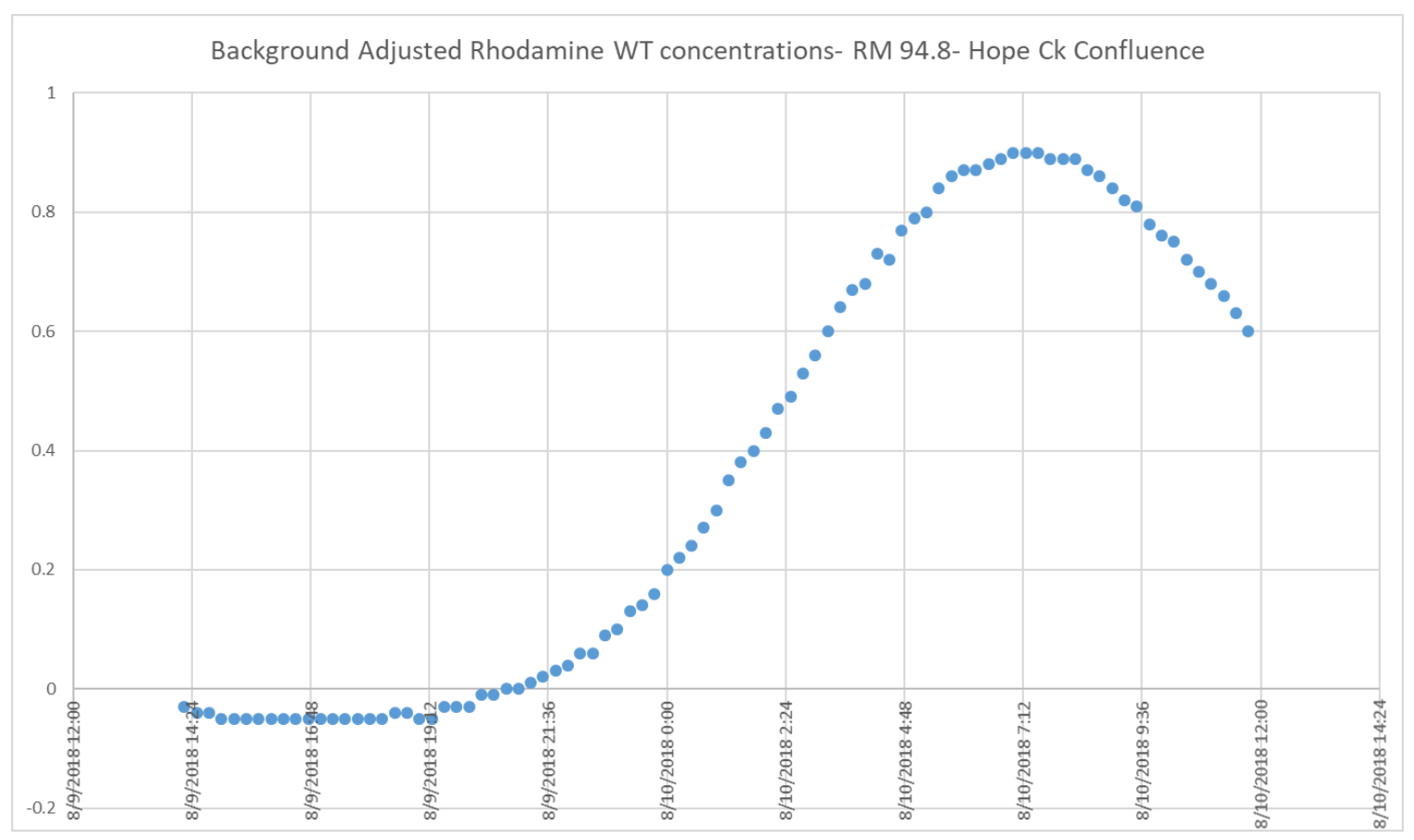

Figure B114 Measured dye concentrations in ppb at Hope Creek RM 94.8 in August 2018 after release at Pe Ell RM 106.2 on 8/7/2018 at 20:33. 


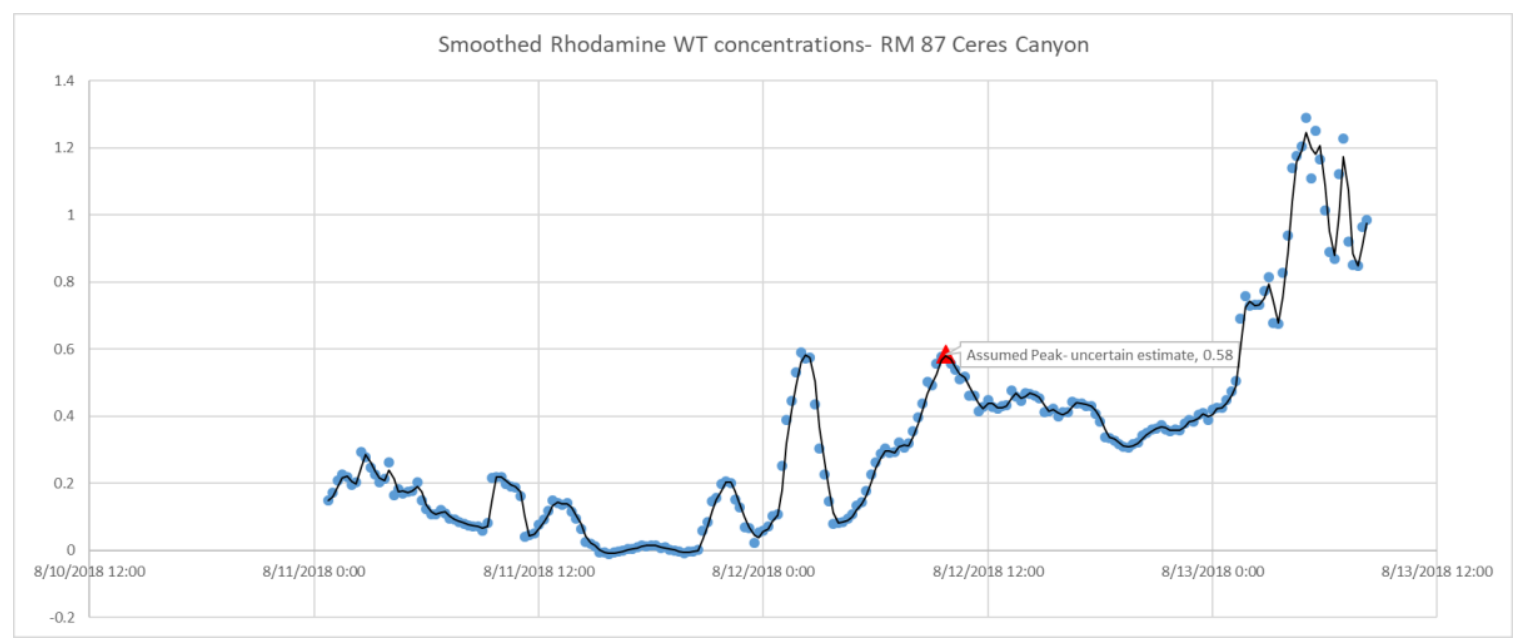

Figure B115. Measured dye concentrations in ppb at Ceres Canyon RM 87 in August 2018 after release at Pe Ell RM 106.2 on 8/7/2018 at 20:33.

Appendix C: Error Statistics

The closeness of model predicted temperature to field data was evaluated with error statistics such as the mean error (ME), absolute mean error (AME), and the root mean square error (RMSE).

These were calculated using the equations described below.

$$
M E=\frac{1}{N} \Sigma\left(Q_{\text {model }}-Q_{\text {field data }}\right)
$$

where $\mathrm{N}$ is the number of model-field data comparisons, Qmodel is the model output value, and $\quad Q_{\text {field data }}$ is the field data value.

$$
\begin{aligned}
& A M E=\frac{1}{N} \Sigma\left|\left(Q_{\text {model }}-Q_{\text {field data }}\right)\right| \\
& R M S=\sqrt{\frac{1}{N} \Sigma\left(Q_{\text {model }}-Q_{\text {field data }}\right)^{2}}
\end{aligned}
$$

Weighted average mean error, absolute mean error, and root mean square error values were computed using 


$$
\begin{aligned}
M E_{\text {weighted }} & =\frac{\Sigma(M E \times N)}{\Sigma N} \\
A M E_{\text {weighted }} & =\frac{\Sigma(A M E \times N)}{\Sigma N} \\
R M S E_{\text {weighted }} & =\frac{\Sigma(R M S E \times N)}{\Sigma N}
\end{aligned}
$$

These weighted errors were used in looking at all model-data errors in aggregate over all model stations.

\section{Appendix D: Using Multiple Processors for a Cascade of Waterbodies}

If the model user has a cascade of waterbodies (see Figure D116), such as reservoirs in series or even a river system with a cascade of reaches where the backwater from a downstream waterbody does not affect an upstream waterbody, then the model user can use a model feature to reduce overall model run time.

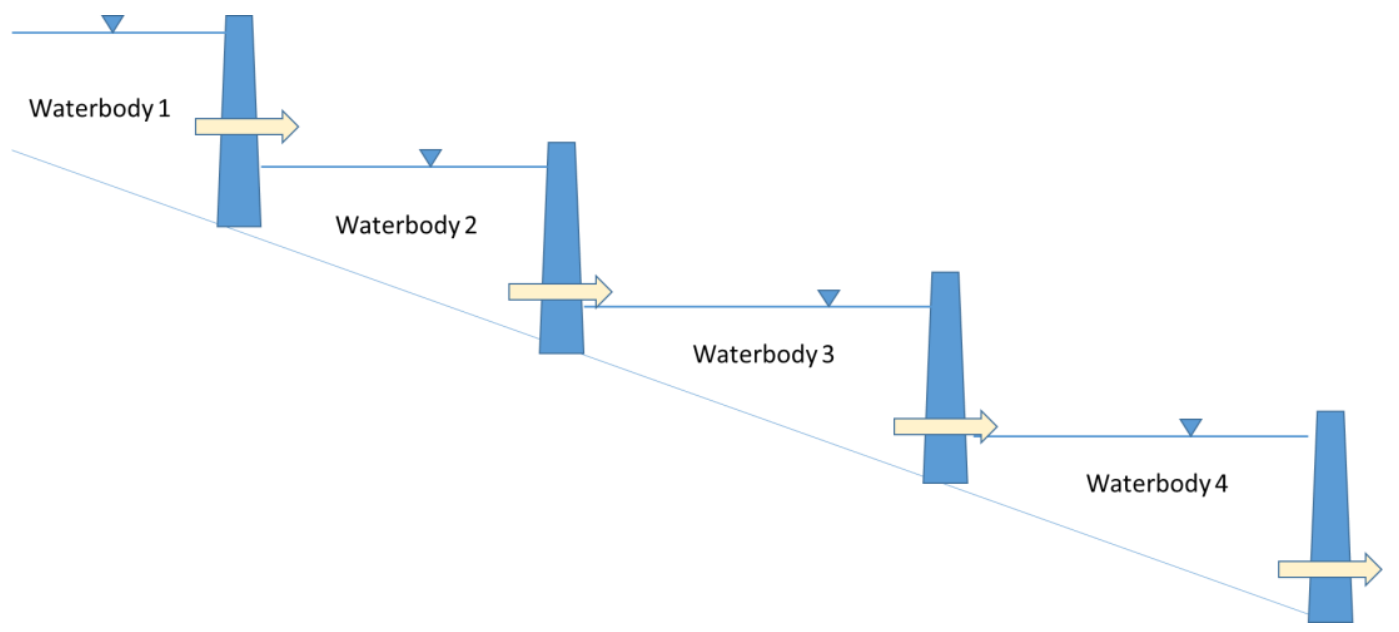

Figure D116. Cascade of reservoirs or multiple waterbodies.

There are 3 options now for simulating this series of waterbodies as shown in Table D24. 
Table D24. Techniques for using CE-QUAL-W2 to simulate a cascade of waterbodies.

\begin{tabular}{|c|c|c|c|}
\hline $\begin{array}{c}\text { Option } \\
\#\end{array}$ & Option Description & Advantages & Disadvantages \\
\hline 1 & $\begin{array}{l}\text { Have one system model } \\
\text { with multiple } \\
\text { waterbodies and one } \\
\text { control file }\end{array}$ & $\begin{array}{l}\text { Entire model is under } \\
\text { one control file, } \\
\text { w2_con.npt, simpler to } \\
\text { manage }\end{array}$ & $\begin{array}{l}\text { The time step for } \\
\text { stability will be } \\
\text { dictated by one of the } \\
\text { waterbodies, causing } \\
\text { other waterbodies to } \\
\text { run at the lowest time } \\
\text { step. Run times may } \\
\text { be long. }\end{array}$ \\
\hline 2 & $\begin{array}{l}\text { Have separate } \\
\text { waterbodies in separate } \\
\text { directories, use a batch } \\
\text { file to automatically } \\
\text { transfer the output from } \\
\text { one waterbody } \\
\text { (withdrawal output files) } \\
\text { as the input to the next } \\
\text { waterbody }\end{array}$ & $\begin{array}{l}\text { Each waterbody runs } \\
\text { according to its own } \\
\text { minimum time step } \\
\text { and hence will result in } \\
\text { faster simulation time } \\
\text { compared to option } 1 . \\
\text { Also, the model user } \\
\text { can tune for faster } \\
\text { DLTMAX in some } \\
\text { waterbodies. }\end{array}$ & $\begin{array}{l}\text { Must break model } \\
\text { into multiple models, } \\
\text { one for each } \\
\text { waterbody. Each } \\
\text { waterbody must wait } \\
\text { until the upper one is } \\
\text { completed before } \\
\text { starting. }\end{array}$ \\
\hline 3 & $\begin{array}{l}\text { Have separate } \\
\text { waterbodies in separate } \\
\text { directories, use the input } \\
\text { file (multiple_WB.npt) } \\
\text { for multiple waterbodies } \\
\text { to point to inflow from } \\
\text { upper waterbody }\end{array}$ & $\begin{array}{l}\text { Each waterbody runs } \\
\text { according to its own } \\
\text { minimum time step } \\
\text { and does not have to } \\
\text { wait until the upper } \\
\text { waterbody is complete } \\
\text { before proceeding. } \\
\text { Hence the model will } \\
\text { run faster compared to } \\
\text { option } 1 \text { and } 2 \text {. Also, } \\
\text { the model user can } \\
\text { tune for faster DLTMAX } \\
\text { in some waterbodies. } \\
\text { Each model will usually } \\
\text { be running on different } \\
\text { cores of a multiple core } \\
\text { processor. }\end{array}$ & $\begin{array}{l}\text { Must break model } \\
\text { into multiple models, } \\
\text { one for each } \\
\text { waterbody. }\end{array}$ \\
\hline
\end{tabular}

The third option shown above allows the downstream model to run even before the upstream model has completed. The downstream model, by means of the input file, 'multiple_WB.npt', which tells the downstream model where to obtain the 
upstream inflow boundary condition. How the CE-QUAL-W2 model processes this is shown in Figure D117. In model tests with multiple waterbodies, speed improvements from $22-90 \%$ have been seen.

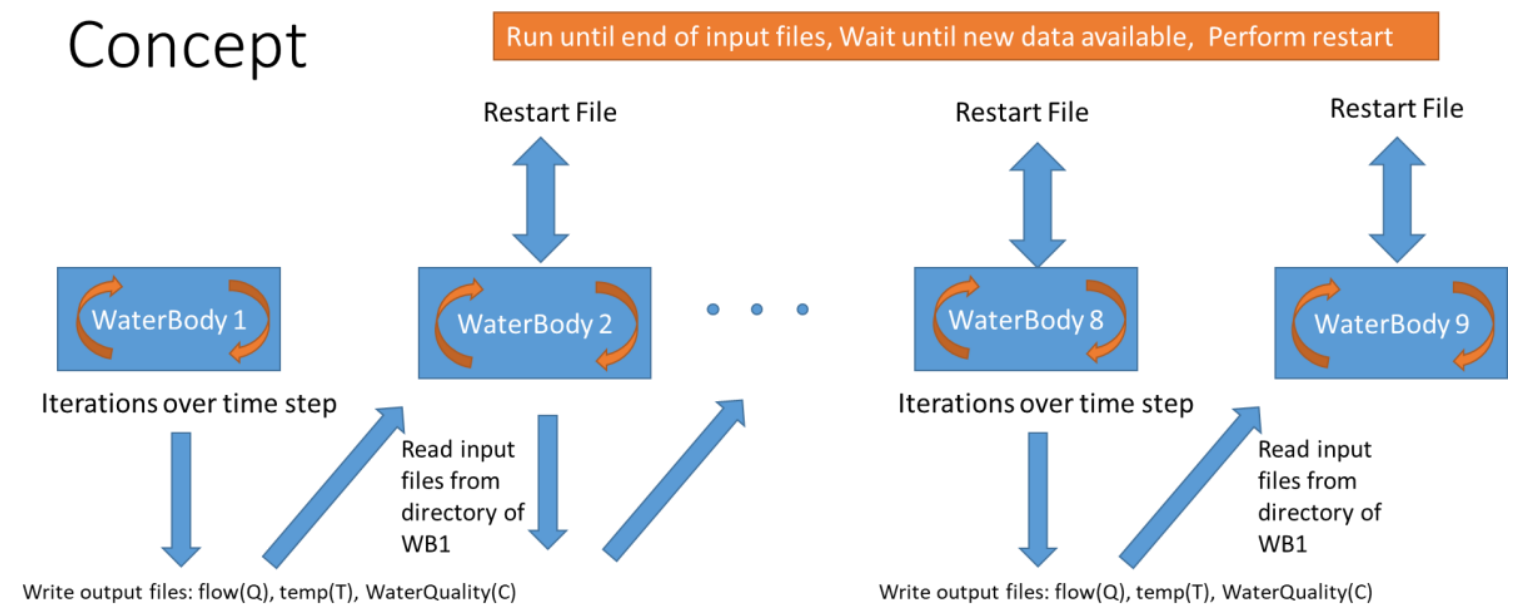

Caveat: This assumes that water level in downstream WB does not influence upstream WB

Figure D117. Concept of running multiple waterbodies simultaneously.

\section{How to Set up a Simulation}

In order to allow this to work, the model user must set up a simulation with multiple waterbodies in separate directories. After this is complete, then the following steps are required:

1. Each waterbody must set up a Withdrawal outflow by setting the withdrawal output control [WDOC] to ON (see 'w2_con.npt') and setting the outlet segment as a withdrawal outflow. These outflow files contain information for the withdrawal flows, temperatures and/or constituent concentrations as a time series. These files will be used as input to the downstream waterbody. Make sure the output frequency is set to a short time since the model is writing out instantaneous flows, temperatures, and concentrations rather than integrated values between output times.

2. The downstream waterbody must set as the inflow flow rate, temperature and concentration, the name of the withdrawal outlet file in the upstream waterbody. Just the filenames are required, one does not set the directory path since these are copied into the directory of the downstream waterbody by the CE-QUAL-W2 model. Hence, if the upstream waterbody has set for the WDOFN 'wdo.csv', and the withdrawal output segment is 6, then the upstream model will write out files: qwo_6.csv, two_6.csv, and cwo_6.csv. The downstream model will use these names as QINFN, TINFN, and CINFN, respectively. When you run the preprocessor for the downstream waterbody, it will give you an 
error, such as 'Could not open branch 1 inflow file qwo_6.csv' since the file does not exist (similarly for the temperature and concentration input files). This can be ignored since the model will supply the file during run time.

3. The downstream model will also have a file called 'multiple_WB.npt' that contains information on running the series of waterbodies. This is described below.

4. Then, the model user starts the upstream waterbody by double-clicking the executable. A dialog box for the first waterbody then starts. Then in the downstream waterbody directory, double click the executable in that directory. Then once, that waterbody starts to run, then start the next downstream W2 executable. You must wait to execute the downstream waterbody exe only after the upstream model starts generating output.

\section{Input File multple_WB.npt}

The input file, multiple_WB.npt, is a text file with the following format:

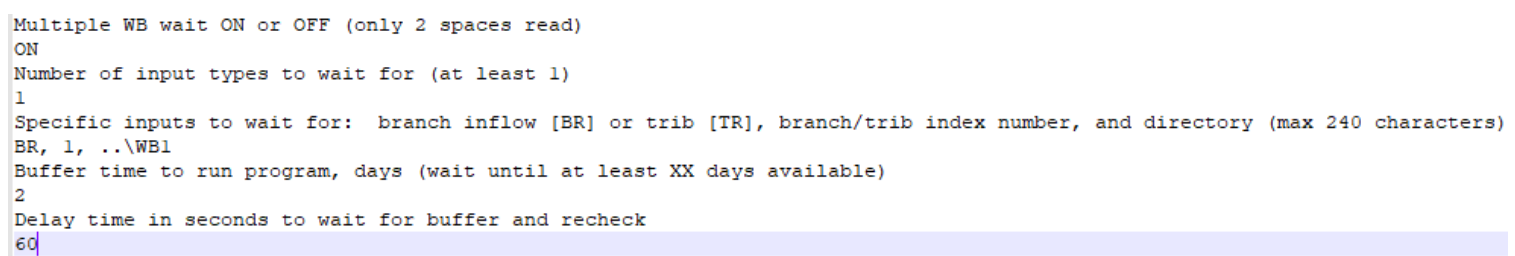

Each header between lines is used for comments and is ignored by the model. Each input field is described below in Table D25.

Table D25. Description of input file multiple_WB.npt.

\begin{tabular}{|c|c|}
\hline Variable & Description \\
\hline Multiple WB wait ON or OFF & $\begin{array}{l}\text { ON or OFF. This turns ON or OFF the multiple } \\
\text { waterbody run. }\end{array}$ \\
\hline Number of input types to wait for (at least 1 ) & $\begin{array}{l}\begin{array}{l}\text { Specifies the number of input file types to wait } \\
\text { for. }\end{array} \\
\end{array}$ \\
\hline $\begin{array}{c}\text { DIRECTORY OF INPUT FILES (MAX } 240 \\
\text { CHARACTERS) }\end{array}$ & $\begin{array}{l}\text { This specifies the directory of the upstream } \\
\text { waterbody and the type of input (branch or } \\
\text { tributary). In the example above, relative } \\
\text { directory path was used. '.. } \backslash \text { WB1' means to go } \\
\text { up one directory to a subdirectory WB1. One } \\
\text { can also give an absolute directory path. }\end{array}$ \\
\hline Buffer Time in days & $\begin{array}{l}\text { How many days of output data from the upper } \\
\text { waterbody is required before you start running } \\
\text { the downstream waterbody. }\end{array}$ \\
\hline $\begin{array}{l}\text { Delay time in s to wait for checking upstream } \\
\text { boundary }\end{array}$ & $\begin{array}{l}\text { This is the time in s for the downstream } \\
\text { waterbody to pause before checking to see if } \\
\text { the buffer time is satisfied. If one chose a } 2 \text { day } \\
\text { buffer time, the downstream model would } \\
\text { check at 'delay time' intervals to see if the }\end{array}$ \\
\hline
\end{tabular}




\begin{tabular}{|c|c|}
\hline Variable & Description \\
\hline & $\begin{array}{c}\text { required number of output days are complete } \\
\text { before continuing to run. }\end{array}$ \\
\hline
\end{tabular}

\section{Output file WaitForRunLog.opt}

An output file 'WaitForRunLog.opt' is produced showing how the downstream model copied files from the upstream waterbody. This is merely for debugging model errors. An example of this file is shown below:

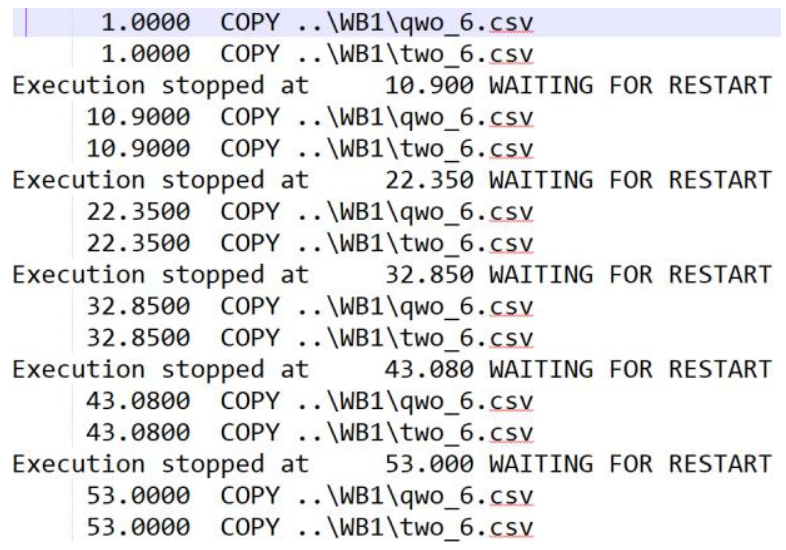

\section{Appendix E: Model files}

Model input and output files are tabulated with brief descriptions below. More detailed descriptions follow.

\section{Mainstem Chehalis River}

The mainstem Chehalis River model is divided into nine folders, one for each waterbody. Table E26 through Table E43 show the input and output filenames for each waterbody with short descriptions of each file. "XX" replaces Julian day or model segment number in filenames that have several to many iterations.

Table E26. Mainstem Chehalis River waterbody 1 model input files.

\begin{tabular}{|l|l|}
\hline Filename & Description \\
\hline bth_wb1.csv & bathymetry \\
\hline cdt_br1.npt & distributed tributary concentrations \\
\hline cin_br1.csv & mainstem Chehalis River inflow concentrations \\
\hline graph.npt & graph input \\
\hline met_wb1.npt & meteorology \\
\hline qdt_br1.csv & distributed tributary flow \\
\hline qin_br1.npt & mainstem Chehalis River inflow \\
\hline shade_WB1.csv & shade file \\
\hline tdt_br1.npt & distributed tributary temperature \\
\hline tin_br1.npt & mainstem Chehalis River inflow temperature \\
\hline w2_con.npt & control file \\
\hline wsc_WB1.csv & wind sheltering coefficients \\
\hline
\end{tabular}


Table E27. Mainstem Chehalis River waterbody 1 model output files.

\begin{tabular}{|l|l|}
\hline Filename & Description \\
\hline cpl_wb1.opt & contour plot \\
\hline cwo_6.csv & withdrawal active concentration \\
\hline cwo_sp1_seg6.csv & spillway active concentration \\
\hline dwo_6.csv & withdrawal derived concentration \\
\hline dwo_sp1_seg6.csv & spillway derived concentration \\
\hline flowbal.csv & flow balance \\
\hline flx_wb1.opt & constituent flux \\
\hline kflux_wb1.csv & constituent kinetic fluxes \\
\hline massbal.csv & nitrogen and phosphorus mass balance \\
\hline pre.opt & preprocessor output \\
\hline pre.wrn & preprocessor warning \\
\hline PREw2CodeCompilerVersion.opt & preprocessor compiler version, build date, and compile date \\
\hline ProfLongJDXX.csv & longitudinal profile plots \\
\hline qwo_6.csv & withdrawal outflow \\
\hline qwo_sp1_seg6.csv & spillway outflow \\
\hline snp_wb1.opt & snapshot \\
\hline tsr_1_seg4.csv & time series \\
\hline two_6.csv & withdrawal temperature \\
\hline two_sp1_seg6.csv & spillway temperature \\
\hline w2.wrn & W2 warning \\
\hline W2CodeCompilerVersion.opt & W2 compiler version, build date, and compile date \\
\hline wl.opt & water level \\
\hline
\end{tabular}

Table E28. Mainstem Chehalis River waterbody 2 model input files.

\begin{tabular}{|l|l|}
\hline Filename & Description \\
\hline bth_wb2.csv & bathymetry \\
\hline cdt_br2.npt & branch distributed tributary concentrations \\
\hline ctr_tr1.npt & Pe Ell WWTP concentrations \\
\hline cwo_6.csv & branch inflow concentrations \\
\hline graph.npt & graph input \\
\hline met_wb2.npt & meteorology \\
\hline multiple_WB.npt & multiple waterbody control \\
\hline qdt_br2.csv & branch distributed tributary inflow \\
\hline qtr_tr2.npt & Pe Ell WWTP inflow \\
\hline qwo_6.csv & branch inflow \\
\hline shade_WB2.csv & shade file \\
\hline tdt_br2.npt & distribute tributary temperature \\
\hline ttr_tr1.npt & Pe Ell WWTP temperature \\
\hline two_6.csv & branch inflow temperature \\
\hline w2_con.npt & control file \\
\hline wsc_WB2.csv & wind sheltering coefficients \\
\hline
\end{tabular}


Table E29. Mainstem Chehalis River waterbody 2 model output files.

\begin{tabular}{|l|l|}
\hline Filename & Description \\
\hline cpl_wb2.opt & contour plot \\
\hline cwo_21.csv & withdrawal active concentrations \\
\hline cwo_sp1_seg21.csv & spillway active concentrations \\
\hline dwo_21.csv & withdrawal derived concentrations \\
\hline dwo_sp1_seg21.csv & spillway derived concentrations \\
\hline flowbal.csv & flow balance \\
\hline flx_wb2.opt & constituent flux \\
\hline kflux_wb1.csv & constituent kinetic fluxes \\
\hline massbal.csv & nitrogen and phosphorus mass balance \\
\hline pre.opt & preprocessor output \\
\hline pre.wrn & preprocessor warning \\
\hline PREw2CodeCompilerVersion.opt & preprocessor compiler version, build date, and compile date \\
\hline ProfLongJDXX.csv & longitudinal profile plots \\
\hline qwo_21.csv & withdrawal outflow \\
\hline qwo_sp1_seg21.csv & spillway outflow \\
\hline snp_wb2.opt & snapshot \\
\hline tsr_X_segX.csv & time series \\
\hline two_21.csv & withdrawal temperature \\
\hline two_sp1_seg21.csv & spillway temperature \\
\hline w2.wrn & W2 warning \\
\hline W2CodeCompilerVersion.opt & W2 compiler version, build date, and compile date \\
\hline WaitForRunLog.opt & multiple waterbody wait log \\
\hline wl.opt & water level \\
\hline &
\end{tabular}

Table E30. Mainstem Chehalis River waterbody 3 model input files.

\begin{tabular}{|l|l|}
\hline Filename & Description \\
\hline bth_wb3.csv & bathymetry \\
\hline cdt_br3.npt & branch distributed tributary concentrations \\
\hline ctr_tr2.npt & Elk Creek concentrations \\
\hline $\begin{array}{l}\text { ctr_tr27.npt- } \\
\text { ctr_tr51.npt }\end{array}$ & groundwater concentrations \\
\hline cwo_21.csv & branch inflow concentrations \\
\hline graph.npt & graph input \\
\hline met_wb3.npt & meteorology \\
\hline multiple_WB.npt & multiple waterbody control \\
\hline qdt_br3.npt & branch distributed tributary inflow \\
\hline qtr_tr2.npt & Elk Creek inflow \\
\hline qtr_tr27.npt- \\
qtr_tr51.npt & groundwater inflow \\
\hline qwo_21.csv & branch inflow \\
\hline shade_WB3.csv & shade file \\
\hline tdt_br3.npt & branch distributed tributary temperature \\
\hline ttr_tr2.npt & Elk Creek temperature \\
\hline ttr_tr27.npt- & groundwater temperature \\
ttr_tr51.npt & branch inflow temperature \\
\hline two_21.csv & control file \\
\hline w2_con.npt &
\end{tabular}


\begin{tabular}{|l|l}
\hline wsc_WB3.csv & wind sheltering coefficients
\end{tabular}

Table E31. Mainstem Chehalis River waterbody 3 model output files.

\begin{tabular}{|l|l|}
\hline Filename & Description \\
\hline cpl_wb3.opt & contour plot \\
\hline cwo_30.csv & withdrawal active concentrations \\
\hline cwo_sp1_seg30.csv & spillway active concentrations \\
\hline dwo_30.csv & withdrawal derived concentrations \\
\hline dwo_sp1_seg30.csv & spillway derived concentrations \\
\hline flowbal.csv & flow balance \\
\hline flx_wb3.opt & constituent flux \\
\hline kflux_wb1.csv & constituent kinetic fluxes \\
\hline massbal.csv & nitrogen and phosphorus mass balance \\
\hline pre.opt & preprocessor output \\
\hline pre.wrn & preprocessor warning \\
\hline PREw2CodeCompilerVersion.opt & preprocessor compiler version, build date, and compile date \\
\hline ProfLongJDXX.csv & longitudinal profile plots \\
\hline qwo_30.csv & withdrawal outflow \\
\hline qwo_sp1_seg30.csv & spillway outflow \\
\hline snp_wb3.opt & snapshot \\
\hline tsr_X_segX.csv & time series \\
\hline two_30.csv & withdrawal temperature \\
\hline two_sp1_seg30.csv & spillway temperature \\
\hline w2.wrn & W2 warning \\
\hline W2CodeCompilerVersion.opt & W2 compiler version, build date, and compile date \\
\hline WaitForRunLog.opt & multiple waterbody wait log \\
\hline wl.opt & water level \\
\hline &
\end{tabular}

Table E32. Mainstem Chehalis River waterbody 4 model input files.

\begin{tabular}{|l|l|}
\hline Filename & Description \\
\hline bth_wb4.csv & bathymetry \\
\hline cdt_br4.npt & branch distributed tributary concentrations \\
\hline ctr_tr3.npt & South Fork Chehalis River concentrations \\
\hline ctr_tr13.npt & Bunker Creek concentrations \\
\hline $\begin{array}{l}\text { ctr_tr52.npt- } \\
\text { ctr_tr118.npt }\end{array}$ & groundwater concentrations \\
\hline cwo_30.csv & branch inflow concentrations \\
\hline graph.npt & graph input \\
\hline met_wb4.npt & meteorology \\
\hline multiple_WB.npt & multiple waterbody control \\
\hline qdt_br4.npt & branch distributed tributary inflow \\
\hline qtr_tr3.npt & South Fork Chehalis River inflow \\
\hline qtr_tr13.npt & Bunker Creek inflow \\
\hline $\begin{array}{l}\text { qtr_tr52.npt- } \\
\text { qtr_tr118.npt }\end{array}$ & groundwater inflow \\
\hline qwo_30.csv & branch inflow \\
\hline shade_WB4.csv & shade file \\
\hline tdt_br4.npt & branch distributed tributary temperature \\
\hline
\end{tabular}




\begin{tabular}{|l|l|}
\hline$t t r \_t r 3 . n p t$ & South Fork Chehalis River temperature \\
\hline ttr_tr13.npt & Bunker Creek temperature \\
\hline $\begin{array}{l}\text { ttr_tr52.npt- } \\
\text { ttr_tr118.npt }\end{array}$ & groundwater temperature \\
\hline two_30.csv & branch inflow temperature \\
\hline w2_con.npt & control file \\
\hline wsc_WB4.csv & wind sheltering coefficients \\
\hline
\end{tabular}

Table E33. Mainstem Chehalis River waterbody 4 model output files.

\begin{tabular}{|l|l|}
\hline Filename & Description \\
\hline cpl_wb4.opt & contour plot \\
\hline cwo_68.csv & withdrawal active concentrations \\
\hline cwo_sp1_seg68.csv & spillway active concentrations \\
\hline dwo_68.csv & withdrawal derived concentrations \\
\hline dwo_sp1_seg68.csv & spillway derived concentrations \\
\hline flowbal.csv & flow balance \\
\hline flx_wb4.opt & constituent flux \\
\hline kflux_wb1.csv & constituent kinetic fluxes \\
\hline massbal.csv & nitrogen and phosphorus mass balance \\
\hline pre.opt & preprocessor output \\
\hline pre.wrn & preprocessor warning \\
\hline PREw2CodeCompilerVersion.opt & preprocessor compiler version, build date, and compile date \\
\hline ProfLongJDXX.csv & longitudinal profile plots \\
\hline qwo_68.csv & withdrawal outflow \\
\hline qwo_sp1_seg68.csv & spillway outflow \\
\hline snp_wb4.opt & snapshot \\
\hline tsr_X_segX.csv & time series \\
\hline two_68.csv & withdrawal temperature \\
\hline two_sp1_seg68.csv & spillway temperature \\
\hline w2.wrn & W2 warning \\
\hline W2CodeCompilerVersion.opt & W2 compiler version, build date, and compile date \\
\hline WaitForRunLog.opt & multiple waterbody wait log \\
\hline wl.opt & water level \\
\hline &
\end{tabular}

Table E34. Mainstem Chehalis River waterbody 5 model input files.

\begin{tabular}{|l|l|}
\hline Filename & Description \\
\hline bth_wb5.csv & bathymetry \\
\hline ctr_tr4.npt & Newaukum River concentrations \\
\hline ctr_tr14.npt & Stearns Creek concentrations \\
\hline $\begin{array}{l}\text { ctr_tr119.npt- } \\
\text { ctr_tr133.npt }\end{array}$ & groundwater concentrations \\
\hline cwo_68.csv & branch inflow concentrations \\
\hline graph.npt & graph input \\
\hline met_wb5.npt & meteorology \\
\hline multiple_WB.npt & multiple waterbody control \\
\hline qtr_tr4.npt & Newaukum River inflow \\
\hline qtr_tr14.npt & Stearns Creek inflow \\
\hline qtr_tr119.npt- & groundwater inflow \\
\hline
\end{tabular}




\begin{tabular}{|l|l|}
\hline qtr_tr133.npt & \\
\hline qwo_68.csv & branch inflow \\
\hline shade_WB5.csv & shade file \\
\hline ttr_tr4.npt & Newaukum River temperature \\
\hline ttr_tr14.npt & Stearns Creek temperature \\
\hline $\begin{array}{l}\text { ttr_tr119.npt- } \\
\text { ttr_tr133.npt }\end{array}$ & groundwater temperature \\
\hline two_68.csv & branch inflow temperature \\
\hline w2_con.npt & control file \\
\hline wsc_WB5.csv & wind sheltering coefficients \\
\hline
\end{tabular}

Table E35. Mainstem Chehalis River waterbody 5 model output files.

\begin{tabular}{|l|l|}
\hline Filename & Description \\
\hline cpl_wb5.opt & contour plot \\
\hline cwo_16.csv & withdrawal active concentrations \\
\hline cwo_sp1_seg16.csv & spillway active concentrations \\
\hline dwo_16.csv & withdrawal derived concentrations \\
\hline dwo_sp1_seg16.csv & spillway derived concentrations \\
\hline flowbal.csv & flow balance \\
\hline flx_wb5.opt & constituent flux \\
\hline kflux_wb1.csv & constituent kinetic fluxes \\
\hline massbal.csv & nitrogen and phosphorus mass balance \\
\hline pre.opt & preprocessor output \\
\hline pre.wrn & preprocessor warning \\
\hline PREw2CodeCompilerVersion.opt & preprocessor compiler version, build date, and compile date \\
\hline ProfLongJDXX.csv & longitudinal profile plots \\
\hline qwo_16.csv & withdrawal outflow \\
\hline qwo_sp1_seg16.csv & spillway outflow \\
\hline snp_wb5.opt & snapshot \\
\hline tsr_X_segX.csv & time series \\
\hline two_16.csv & withdrawal temperature \\
\hline two_sp1_seg16.csv & spillway temperature \\
\hline w2.wrn & W2 warning \\
\hline W2CodeCompilerVersion.opt & W2 compiler version, build date, and compile date \\
\hline WaitForRunLog.opt & multiple waterbody wait log \\
\hline wl.opt & water level \\
\hline &
\end{tabular}

Table E36. Mainstem Chehalis River waterbody 6 model input files.

\begin{tabular}{|l|l|}
\hline Filename & Description \\
\hline bth_wb6.csv & bathymetry \\
\hline ctr_tr5.npt & Darigold WWTP concentrations \\
\hline ctr_tr6.npt & Chehalis WWTP concentrations \\
\hline ctr_tr8.npt & Skookumchuck River concentrations \\
\hline $\begin{array}{l}\text { ctr_tr134.npt- } \\
\text { ctr_tr177.npt }\end{array}$ & groundwater concentrations \\
\hline cwo_16.csv & branch inflow concentrations \\
\hline graph.npt & graph input \\
\hline met_wb6.npt & meteorology \\
\hline
\end{tabular}




\begin{tabular}{|l|l|}
\hline multiple_WB.npt & multiple waterbody control \\
\hline qtr_tr5.npt & Darigold WWTP inflow \\
\hline qtr_tr6.npt & Chehalis WWTP inflow \\
\hline qtr_tr8.npt & Skookumchuck River inflow \\
\hline $\begin{array}{l}\text { qtr_tr134.npt- } \\
\text { qtr_tr177.npt }\end{array}$ & groundwater inflow \\
\hline qwo_16.csv & branch inflow \\
\hline shade_WB6.csv & shade file \\
\hline ttr_tr5.npt & Darigold WWTP temperature \\
\hline ttr_tr6.npt & Chehalis WWTP temperature \\
\hline ttr_tr8.npt & Skookumchuck River temperature \\
\hline $\begin{array}{l}\text { ttr_tr134.npt- } \\
\text { ttr_tr177.npt }\end{array}$ & groundwater temperature \\
\hline two_16.csv & branch inflow temperature \\
\hline w2_con.npt & control file \\
\hline wsc_WB6.csv & wind sheltering coefficients \\
\hline
\end{tabular}

Table E37. Mainstem Chehalis River waterbody 6 model output files.

\begin{tabular}{|l|l|}
\hline Filename & Description \\
\hline cpl_wb6.opt & contour plot \\
\hline cwo_28.csv & withdrawal active concentrations \\
\hline cwo_47.csv & withdrawal active concentrations \\
\hline cwo_sp1_seg47.csv & spillway active concentrations \\
\hline dwo_28.csv & withdrawal derived concentrations \\
\hline dwo_47.csv & withdrawal derived concentrations \\
\hline dwo_sp1_seg47.csv & spillway derived concentrations \\
\hline flowbal.csv & flow balance \\
\hline flx_wb6.opt & constituent flux \\
\hline kflux_wb1.csv & constituent kinetic fluxes \\
\hline massbal.csv & nitrogen and phosphorus mass balance \\
\hline pre.opt & preprocessor output \\
\hline pre.wrn & preprocessor warning \\
\hline PREw2CodeCompilerVersion.opt & preprocessor compiler version, build date, and compile date \\
\hline ProfLongJDXX.csv & longitudinal profile plots \\
\hline qwo_28.csv & withdrawal outflow \\
\hline qwo_47.csv & withdrawal outflow \\
\hline qwo_sp1_seg47.csv & spillway outflow \\
\hline snp_wb6.opt & snapshot \\
\hline tsr_X_segX.csv & time series \\
\hline two_28.csv & withdrawal temperature \\
\hline two_47.csv & withdrawal temperature \\
\hline two_sp1_seg47.csv & spillway temperature \\
\hline w2.wrn & W2 warning \\
\hline W2CodeCompilerVersion.opt & W2 compiler version, build date, and compile date \\
\hline WaitForRunLog.opt & multiple waterbody wait log \\
\hline wl.opt & water level \\
\hline
\end{tabular}


Table E38. Mainstem Chehalis River waterbody 7 model input files.

\begin{tabular}{|l|l|}
\hline Filename & Description \\
\hline bth_wb7.csv & bathymetry \\
\hline cdt_br8.npt & distributed tributary concentrations \\
\hline ctr_tr7.npt & Centralia WWTP concentrations \\
\hline ctr_tr17.npt & Lincoln Creek concentrations \\
\hline $\begin{array}{l}\text { ctr_tr178.npt- } \\
\text { ctr_tr196.npt }\end{array}$ & groundwater concentrations \\
\hline cwo_47.csv & branch inflow concentrations \\
\hline graph.npt & graph input \\
\hline met_wb7.npt & meteorology \\
\hline multiple_WB.npt & multiple waterbody control \\
\hline qdt_br8.npt & distributed tributary inflow \\
\hline qtr_tr7.npt & Centralia WWTP inflow \\
\hline qtr_tr17.npt & Lincoln Creek inflow \\
\hline $\begin{array}{l}\text { qtr_tr178.npt- } \\
\text { qtr_tr196.npt }\end{array}$ & groundwater inflow \\
\hline qwo_47.csv & branch inflow \\
\hline shade_WB7.csv & shade file \\
\hline tdt_br8.npt & distributed tributary temperature \\
\hline ttr_tr7.npt & Centralia WWTP temperature \\
\hline ttr_tr17.npt & Lincoln Creek temperature \\
\hline $\begin{array}{l}\text { ttr_tr178.npt- } \\
\text { ttr_tr196.npt }\end{array}$ & groundwater temperature \\
\hline two_47.csv & branch inflow temperature \\
\hline w2_con.npt & control file \\
\hline wsc_WB7.csv & wind sheltering coefficients \\
\hline
\end{tabular}

Table E39. Mainstem Chehalis River waterbody 7 model output files.

\begin{tabular}{|l|l|}
\hline Filename & Description \\
\hline cpl_wb7.opt & contour plot \\
\hline cwo_20.csv & withdrawal active concentrations \\
\hline cwo_sp1_seg20.csv & spillway active concentrations \\
\hline dwo_20.csv & withdrawal derived concentrations \\
\hline dwo_sp1_seg20.csv & spillway derived concentrations \\
\hline flowbal.csv & flow balance \\
\hline flx_wb7.opt & constituent flux \\
\hline kflux_wb1.csv & constituent kinetic fluxes \\
\hline massbal.csv & nitrogen and phosphorus mass balance \\
\hline pre.opt & preprocessor output \\
\hline pre.wrn & preprocessor warning \\
\hline PREw2CodeCompilerVersion.opt & preprocessor compiler version, build date, and compile date \\
\hline ProfLongJDXX.csv & longitudinal profile plots \\
\hline qwo_20.csv & withdrawal outflow \\
\hline qwo_sp1_seg20.csv & spillway outflow \\
\hline snp_wb7.opt & snapshot \\
\hline tsr_X_segX.csv & time series \\
\hline two_20.csv & withdrawal temperature \\
\hline two_sp1_seg20.csv & spillway temperature \\
\hline
\end{tabular}




\begin{tabular}{|l|l|}
\hline w2.wrn & W2 warning \\
\hline W2CodeCompilerVersion.opt & W2 compiler version, build date, and compile date \\
\hline WaitForRunLog.opt & multiple waterbody wait log \\
\hline wl.opt & water level \\
\hline
\end{tabular}

Table E40. Mainstem Chehalis River waterbody 8 model input files.

\begin{tabular}{|l|l|}
\hline Filename & Description \\
\hline bth_wb8.csv & bathymetry \\
\hline ctr_tr9.npt & Grand Mound WWTP concentrations \\
\hline ctr_tr10.npt & Scatter Creek concentrations \\
\hline ctr_tr11.npt & Black River concentrations \\
\hline ctr_tr18.npt & Independence Creek concentrations \\
\hline ctr_tr19.npt & Garrard Creek concentrations \\
\hline ctr_tr25.npt & Prairie Creek concentrations \\
\hline $\begin{array}{l}\text { ctr_tr197.npt- } \\
\text { ctr_tr262.npt }\end{array}$ & groundwater concentrations \\
\hline cwo_20.csv & branch inflow concentrations \\
\hline graph.npt & graph input \\
\hline met_wb8.npt & meteorology \\
\hline multiple_WB.npt & multiple waterbody control \\
\hline qtr_tr9.npt & Grand Mound WWTP inflow \\
\hline qtr_tr10.npt & Scatter Creek inflow \\
\hline qtr_tr11.npt & Black River inflow \\
\hline qtr_tr18.npt & Independence Creek inflow \\
\hline qtr_tr19.npt & Garrard Creek inflow \\
\hline qtr_tr25.npt & Prairie Creek inflow \\
\hline $\begin{array}{l}\text { qtr_tr197.npt- } \\
\text { qtr_tr262.npt }\end{array}$ & groundwater inflow \\
\hline qwo_20.csv & branch inflow \\
\hline shade_WB8.csv & shade file \\
\hline ttr_tr9.npt & Grand Mound WWTP temperature \\
\hline ttr_tr10.npt & Scatter Creek temperature \\
\hline ttr_tr11.npt & Black River temperature \\
\hline ttr_tr18.npt & Independence Creek temperature \\
\hline ttr_tr19.npt & Garrard Creek temperature \\
\hline ttr_tr25.npt & Prairie Creek temperature \\
\hline $\begin{array}{l}\text { ttr_tr197.npt- } \\
\text { ttr_tr262.npt }\end{array}$ & groundwater temperature \\
\hline two_20.csv & branch inflow temperature \\
\hline w2_con.npt & control file \\
\hline wsc_WB8.csv & wind sheltering coefficients \\
\hline
\end{tabular}

Table E41. Mainstem Chehalis River waterbody 8 model output files.

\begin{tabular}{|l|l|}
\hline Filename & Description \\
\hline cpl_wb8.opt & contour plot \\
\hline cwo_67.csv & withdrawal active concentrations \\
\hline cwo_sp1_seg67.csv & spillway active concentrations \\
\hline dwo_67.csv & withdrawal derived concentrations \\
\hline
\end{tabular}




\begin{tabular}{|l|l|}
\hline dwo_sp1_seg67.csv & spillway derived concentrations \\
\hline flowbal.csv & flow balance \\
\hline flx_wb8.opt & constituent flux \\
\hline kflux_wb1.csv & constituent kinetic fluxes \\
\hline massbal.csv & nitrogen and phosphorus mass balance \\
\hline pre.opt & preprocessor output \\
\hline pre.wrn & preprocessor warning \\
\hline PREw2CodeCompilerVersion.opt & preprocessor compiler version, build date, and compile date \\
\hline ProfLongJDXX.csv & longitudinal profile plots \\
\hline qwo_67.csv & withdrawal outflow \\
\hline qwo_sp1_seg67.csv & spillway outflow \\
\hline snp_wb8.opt & snapshot \\
\hline tsr_X_segX.csv & time series \\
\hline two_67.csv & withdrawal temperature \\
\hline two_sp1_seg67.csv & spillway temperature \\
\hline w2.wrn & W2 warning \\
\hline W2CodeCompilerVersion.opt & W2 compiler version, build date, and compile date \\
\hline WaitForRunLog.opt & multiple waterbody wait log \\
\hline wl.opt & water level \\
\hline
\end{tabular}

Table E42. Mainstem Chehalis River waterbody 9 model input files.

\begin{tabular}{|l|l|}
\hline Filename & Description \\
\hline bth_wb9.csv & bathymetry \\
\hline cdt_br10.npt & distributed tributary concentrations \\
\hline ctr_tr12.npt & Rock Creek concentrations \\
\hline ctr_tr20.npt & Cedar Creek concentrations \\
\hline ctr_tr21.npt & Porter Creek concentrations \\
\hline ctr_tr26.npt & Gibson Creek concentrations \\
\hline $\begin{array}{l}\text { ctr_tr263.npt- } \\
\text { ctr_tr299.npt }\end{array}$ & groundwater concentrations \\
\hline cwo_67.csv & branch inflow concentrations \\
\hline graph.npt & graph input \\
\hline met_wb9.npt & meteorology \\
\hline multiple_WB.npt & multiple waterbody control \\
\hline qdt_br10.npt & distributed tributary inflow \\
\hline qtr_tr12.npt & Rock Creek inflow \\
\hline qtr_tr20.npt & Cedar Creek inflow \\
\hline qtr_tr21.npt & Porter Creek inflow \\
\hline qtr_tr26.npt & Gibson Creek inflow \\
\hline $\begin{array}{l}\text { qtr_tr263.npt- } \\
\text { qtr_tr299.npt }\end{array}$ & groundwater inflow \\
\hline qwo_67.csv & branch inflow \\
\hline shade_WB9.csv & shade file \\
\hline tdt_br10.npt & distributed tributary temperature \\
\hline ttr_tr12.npt & Rock Creek temperature \\
\hline ttr_tr20.npt & Cedar Creek temperature \\
\hline ttr_tr21.npt & Porter Creek temperature \\
\hline ttr_tr26.npt & Gibson Creek temperature \\
\hline $\begin{array}{l}\text { ttr_tr263.npt- } \\
\text { ttr_tr299.npt }\end{array}$ & groundwater temperature \\
\hline
\end{tabular}




\begin{tabular}{|l|l|}
\hline two_67.csv & branch inflow temperature \\
\hline w2_con.npt & control file \\
\hline wsc_WB9.csv & wind sheltering coefficients \\
\hline
\end{tabular}

Table E43. Mainstem Chehalis River waterbody 9 model output files.

\begin{tabular}{|l|l|}
\hline Filename & Description \\
\hline cpl_wb9.opt & contour plot \\
\hline cwo_38.csv & withdrawal active concentrations \\
\hline cwo_sp1_seg38.csv & spillway active concentrations \\
\hline dwo_38.csv & withdrawal derived concentrations \\
\hline dwo_sp1_seg38.csv & spillway derived concentrations \\
\hline flowbal.csv & flow balance \\
\hline flx_wb9.opt & constituent flux \\
\hline kflux_wb1.csv & constituent kinetic fluxes \\
\hline massbal.csv & nitrogen and phosphorus mass balance \\
\hline pre.opt & preprocessor output \\
\hline pre.wrn & preprocessor warning \\
\hline PREw2CodeCompilerVersion.opt & preprocessor compiler version, build date, and compile date \\
\hline ProfLongJDXX.csv & longitudinal profile plots \\
\hline qwo_38.csv & withdrawal outflow \\
\hline qwo_sp1_seg38.csv & spillway outflow \\
\hline snp_wb9.opt & snapshot \\
\hline tsr_X_segX.csv & time series \\
\hline two_38.csv & withdrawal temperature \\
\hline two_sp1_seg38.csv & spillway temperature \\
\hline w2.wrn & W2 warning \\
\hline W2CodeCompilerVersion.opt & W2 compiler version, build date, and compile date \\
\hline WaitForRunLog.opt & multiple waterbody wait log \\
\hline wl.opt & water level \\
\hline &
\end{tabular}

\section{South Fork Chehalis River}

Table E44 and Table E45 show South Fork Chehalis River model input and output filenames, respectively, with brief descriptions of each. "XX" replaces the Julian day of output in longitudinal profile plot filenames.

Table E44. South Fork Chehalis River model input files.

\begin{tabular}{|l|l|}
\hline Filename & Description \\
\hline bth_wb1.csv & bathymetry \\
\hline graph.npt & graph input \\
\hline met_wb9.npt & meteorology \\
\hline qdt_br1.csv & distributed tributary inflow \\
\hline qin_br1.npt & branch inflow \\
\hline shade.csv & shade file \\
\hline tdt_br1.csv & distributed tributary temperature \\
\hline tin_br1.csv & branch inflow temperature \\
\hline w2_con.npt & control file \\
\hline wsc.csv & wind sheltering coefficients \\
\hline
\end{tabular}


Table E45. South Fork Chehalis River model output files.

\begin{tabular}{|l|l|}
\hline Filename & Description \\
\hline pre.opt & preprocessor output \\
\hline pre.wrn & preprocessor warning \\
\hline PREW2CodeCompilerVersion.opt & preprocessor compiler version, build date, and compile date \\
\hline prf_wb1.opt & profile plot \\
\hline ProfLongJDXX.csv & longitudinal profile plots \\
\hline qwo_38.opt & withdrawal outflow \\
\hline qwo_sp1_seg38.opt & spillway outflow \\
\hline snp_wb1.opt & snapshot file \\
\hline tsr_X_segX.csv & time series \\
\hline two_38.opt & withdrawal temperature \\
\hline two_sp1_seg38.opt & spillway temperature \\
\hline w2.wrn & W2 warning \\
\hline W2CodeCompilerVersion.opt & W2 compiler version, build date, and compile date \\
\hline wl.opt & water level \\
\hline
\end{tabular}

\section{Newaukum River}

Table E46 and Table E47 show Newaukum River model input and output filenames, respectively, with brief descriptions of each. "XX" replaces the Julian day of output in longitudinal profile plot filenames.

Table E46. Newaukum River model input files.

\begin{tabular}{|l|l|}
\hline Filename & Description \\
\hline bth_wb1.csv & bathymetry \\
\hline graph.npt & graph input \\
\hline met_wb1.npt & meteorology \\
\hline qdt_br1.csv & distributed tributary inflow \\
\hline qdt_br2.csv & distributed tributary inflow \\
\hline qin_br1.npt & branch inflow \\
\hline shade.csv & shade file \\
\hline tdt_br1.npt & distributed tributary temperature \\
\hline tdt_br2.npt & distributed tributary temperature \\
\hline tin_br1.csv & branch inflow temperature \\
\hline w2_con.npt & control file \\
\hline wsc.npt & wind sheltering coefficients \\
\hline
\end{tabular}

Table E47. Newaukum River model output files.

\begin{tabular}{|l|l|}
\hline Filename & Description \\
\hline pre.opt & preprocessor output \\
\hline pre.wrn & preprocessor warning \\
\hline PREW2CodeCompilerVersion.opt & preprocessor compiler version, build date, and compile date \\
\hline prf_wb1.opt & profile plot \\
\hline ProfLongJDXX.csv & longitudinal profile plots \\
\hline qwo_23.opt & withdrawal outflow \\
\hline
\end{tabular}




\begin{tabular}{|l|l|}
\hline qwo_60.opt & withdrawal outflow \\
\hline qwo_93.opt & withdrawal outflow \\
\hline qwo_sp1_seg93.opt & spillway outflow \\
\hline snp_wb1.opt & snapshot file \\
\hline tsr_X_segX.csv & time series \\
\hline two_23.opt & withdrawal temperature \\
\hline two_60.opt & withdrawal temperature \\
\hline two_93.opt & withdrawal temperature \\
\hline two_sp1_seg93.opt & spillway temperature \\
\hline w2.wrn & W2 warning \\
\hline W2CodeCompilerVersion.opt & W2 compiler version, build date, and compile date \\
\hline wl.opt & water level \\
\hline
\end{tabular}

\section{Skookumchuck River}

Table E48 and Table E49 show Skoookumchuck River model input and output filenames, respectively, with brief descriptions of each. "XX" replaces the Julian day of output in longitudinal profile plot filenames.

Table E48. Skookumchuck River model input files.

\begin{tabular}{|l|l|}
\hline Filename & Description \\
\hline bth_wb1.csv & bathymetry \\
\hline graph.npt & graph input \\
\hline met_wb9.npt & meteorology \\
\hline qdt_br1.csv & distributed tributary inflow \\
\hline qin_br1.npt & branch inflow \\
\hline shade.csv & shade file \\
\hline tdt_br1.npt & distributed tributary temperature \\
\hline tin_br1.csv & branch inflow temperature \\
\hline w2_con.npt & control file \\
\hline wsc.csv & wind sheltering coefficients \\
\hline
\end{tabular}

Table E49. Skookumchuck River model output files.

\begin{tabular}{|l|l|}
\hline Filename & Description \\
\hline pre.opt & preprocessor output \\
\hline pre.wrn & preprocessor warning \\
\hline PREW2CodeCompilerVersion.opt & preprocessor compiler version, build date, and compile date \\
\hline prf_wb1.opt & profile plot \\
\hline ProfLongJDXX.csv & longitudinal profile plots \\
\hline qwo_156.opt & withdrawal outflow \\
\hline qwo_sp1_seg156.opt & spillway outflow \\
\hline snp_wb1.opt & snapshot file \\
\hline tsr_X_segX.csv & time series \\
\hline two_156.opt & withdrawal temperature \\
\hline two_sp1_seg156.opt & spillway temperature \\
\hline w2.wrn & W2 warning \\
\hline W2CodeCompilerVersion.opt & W2 compiler version, build date, and compile date \\
\hline wl.opt & water level \\
\hline
\end{tabular}




\section{Black River}

Table E50 and Table E51 show Black River model input and output filenames, respectively, with brief descriptions of each. "XX" replaces the Julian day of output in longitudinal profile plot filenames.

Table E50. Black River model input files.

\begin{tabular}{|l|l|}
\hline Filename & Description \\
\hline bth_wb1.csv & bathymetry \\
\hline graph.npt & graph input \\
\hline met_wb9.npt & meteorology \\
\hline qdt_br1.csv & distributed tributary inflow \\
\hline qin_br1.npt & branch inflow \\
\hline shade.csv & shade file \\
\hline tdt_br1.npt & distributed tributary temperature \\
\hline tin_br1.csv & branch inflow temperature \\
\hline w2_con.npt & control file \\
\hline wsc.csv & wind sheltering coefficients \\
\hline
\end{tabular}

Table E51. Black River model output files.

\begin{tabular}{|l|l|}
\hline Filename & Description \\
\hline cpl_wb1.opt & contour plot \\
\hline pre.opt & preprocessor output \\
\hline pre.wrn & preprocessor warning \\
\hline PREW2CodeCompilerVersion.opt & preprocessor compiler version, build date, and compile date \\
\hline prf_wb1.opt & profile plot \\
\hline ProfLongJDXX.csv & longitudinal profile plots \\
\hline snp_wb1.opt & snapshot file \\
\hline tsr_X_segX.csv & time series \\
\hline w2.wrn & W2 warning \\
\hline W2CodeCompilerVersion.opt & W2 compiler version, build date, and compile date \\
\hline wl.opt & water level \\
\hline
\end{tabular}

Input file descriptions

bth_wb1.csv: Bathymetry file. Includes segment length [DLX], initial water surface elevation [ELWS], segment orientation angle in radians [PHIO], segment Manning's friction factor [FRICT], layer height in meters, and layer width in meters.

cdt_br1.npt: Branch distributed tributary concentration file. Contains a time series of water quality constituent concentrations for a branch's distributed tributary.

cin_br1.npt: Branch inflow concentration file. Contains a time series of water quality constituent concentrations for a branch's inflow. 
ctr_tr1.npt: Tributary inflow concentration file. Contains a time series of water quality constituent concentrations for a tributary's inflow.

cwo_1.csv: Withdrawal outflow active concentration file. Contains a time series of active constituent concentrations output by the model at the downstream end of each waterbody. Used as an upstream boundary condition for the next waterbody.

graph.npt: Graph input file. Controls output formats for the model output variables. Includes hydraulic variables and concentration multipliers for each active and derived constituent.

met_wb1.npt: Waterbody meteorology file. Contains a time series of meteorology data: air temperature, ${ }^{\circ} \mathrm{C}$ [TAIR]; dewpoint temperature, ${ }^{\circ} \mathrm{C}$ [TDEW]; wind speed, $\mathrm{m}$ $\mathrm{s}^{-1}$ [WIND]; wind direction, radians [PHI]; cloud cover, 0 to 10 [CLOUD]; and incident short wave solar radiation, $\mathrm{W} \mathrm{m}^{-2}$ [SRO].

multiple_WB.npt: Multiple waterbody control file. Contains a switch for the Multiple WB wait function and fields for input file directory, buffer time in days, and delay time to wait for buffer in seconds.

preW2-V41_64.exe: W2 preprocessor.

qdt_br1.csv: Branch distributed tributary inflow file. Contains a time series of flow rates for a branch's distributed tributary in $\mathrm{m}^{3} \mathrm{~s}^{-1}$.

qin_br1.npt: Branch inflow file. Contains a time series of flow rates for a branch's inflow in $\mathrm{m}^{3} \mathrm{~s}^{-1}$.

qtr_tr1.npt: Tributary inflow file. Contains a time series of flow rates for a tributary's inflow in $\mathrm{m}^{3} \mathrm{~s}^{-1}$.

qwo_1.csv: Withdrawal outflow file. Contains a time series of flow rates output by the model at the downstream end of each waterbody. Used as an upstream boundary condition for the next waterbody.

shade_WB1.csv: Waterbody shade input file. Contains the following data: segment number [SEG]; dynamic shading or static shading [DYNSH]; vegetative elevation left bank, meters [VEL]; vegetative elevation right bank, meters [VER]; distance to vegetation left bank, meters [DL]; distance to vegetation right bank, [DR]; shade reduction factor \#1 left bank [SRFL1]; shade reduction factor \#2 left bank [SRFL2]; shade reduction factor \#1 right bank [SRFR1]; shade reduction factor \#2 right bank [SRFR2]; topographic angle \#1 at $0^{\circ}$, radians [TOP01]; topographic angle \#2 at $20^{\circ}$, radians [TOPO2]; topographic angle \#3 at $40^{\circ}$, radians [TOP03]; topographic angle $\# 4$ at $60^{\circ}$, radians [TOPO4]; topographic angle \#5 at $80^{\circ}$, radians [TOP05]; topographic angle \#6 at $100^{\circ}$, radians [TOP06]; topographic angle \#7 at $120^{\circ}$, radians [TOP07]; topographic angle \#8 at $140^{\circ}$, radians [TOP08]; topographic angle 
$\# 9$ at $160^{\circ}$ [TOP09]; topographic angle \#10 at $180^{\circ}$, radians [TOP010]; topographic angle \#11 at $200^{\circ}$, radians [TOP011]; topographic angle \#12 at $220^{\circ}$, radians [TOP012]; topographic angle \#13 at $240^{\circ}$, radians [TOP013]; topographic angle \#14 at $260^{\circ}$, radians [TOP014]; topographic angle \#15 at $280^{\circ}$, radians [TOP015]; topographic angle \#16 at $300^{\circ}$, radians [TOP016]; topographic angle \#17 at $320^{\circ}$, radians [TOP017]; topographic angle \#18 at 340 , radians [TOP018]; starting date for SRF\#1, Julian day [JDSRF1]; and starting date for SRF\#2, Julian day [JDSRF2].

tdt_br1.npt: Branch distributed tributary temperature file. Contains a time series of temperatures for a branch's distributed tributary in ${ }^{\circ} \mathrm{C}$.

tin_br1.npt: Branch inflow temperature file. Contains a time series of temperatures for a branch's inflow in ${ }^{\circ} \mathrm{C}$.

ttr_tr1.npt: Tributary inflow temperature file. Contains a time series of temperatures for a tributary's inflow in ${ }^{\circ} \mathrm{C}$.

two_1.csv: Withdrawal outflow temperature file. Contains a time series of temperatures output by the model at the downstream end of each waterbody. Used as an upstream boundary condition for the next waterbody.

w2_con.npt: Control file.

wSc_WB1.csv: Wind sheltering coefficient file. Specifies wind-sheltering as a function of model segment and time.

\section{Output file descriptions}

cwo_1.csv: Withdrawal outflow active concentration file.

cwo_sp1_seg1.csv: Spillway outflow active concentration file. For this model, this file contains the same time series as cwo_1.csv.

dwo_1.csv: Withdrawal outflow derived concentration file.

dwo_sp1_seg1.csv: Spillway outflow derived concentration file. For this model, this file contains the same time series as dwo_1.csv.

flowbal.csv: Flow balance output file. Contains a time series of inflow volume to waterbody from qin files in $\mathrm{m}^{3}$, inflow volume from precipitation in $\mathrm{m}^{3}$, outflow volume from outlet structures in $\mathrm{m}^{3}$, output volume from withdrawals in $\mathrm{m}^{3}$, output volume from evaporation in $\mathrm{m}^{3}$, input volume from distributed tributaries in $\mathrm{m}^{3}$, input volume from tributaries in $\mathrm{m}^{3}$, and the volume of ice formation/ice melting in $\mathrm{m}^{3}$ (this is zero if [ICEC] is OFF). Volumes between Julian days are cumulative.

flx_wb1.opt: Kinetic flux file. Contains a time series of fluxes for active constituents at each segment in a waterbody in $\mathrm{kg} \mathrm{day}^{-1}$ averaged over the time interval of flux output. 
kflux_wb1.csv: Waterbody kinetic flux file. Contains a time series of fluxes for active constituents summed over the entire water body in $\mathrm{kg} \mathrm{day}^{-1}$ averaged over the time interval of flux output.

massbal.csv: Waterbody nutrient mass balance file. Contains a time series of nitrogen and phosphorus sources and sinks summed over the entire waterbody in $\mathrm{kg}$. Masses are cumulative between Julian days.

pre.err: Preprocessor error file.

pre.opt: Preprocessor output file.

pre.wrn: Preprocessor warning file.

ProfLongJD1.00.csv: Longitudinal profile plot file. Contains, for each segment in a waterbody at the specified Julian day, water surface elevation in meters, flow rate in $\mathrm{m}^{3} \mathrm{~s}^{-1}$, temperature of the surface layer in ${ }^{\circ} \mathrm{C}$, depth in meters, volume weighted temperature in ${ }^{\circ} \mathrm{C}$, and concentrations of state variables and derived variables at the surface layer.

qwo_1.csv: Withdrawal outflow file.

qwo_sp1_seg1.csv: Spillway outflow file. Contains the same time series as qwo_1.csv.

rso.opt: Restart file.

snp_wb1.opt: Snapshot file. Contains information about timestep, meteorology, and inflow/outflow parameters; balances, geometry, water surface, and temperature/water quality at intervals specified in w2_con.npt.

tsr_1_seg1.csv: Time series file. A time series output for the specified model segment of timestep (s), water surface elevation $(\mathrm{m})$, temperature $\left({ }^{\circ} \mathrm{C}\right)$, flow rate $\left(\mathrm{m}^{3} \mathrm{~s}^{-1}\right)$, shortwave solar radiation incident on the surface $\left(\mathrm{W} \mathrm{m}^{-2}\right)$, light extinction coefficient $\left(\mathrm{m}^{-1}\right)$, depth to bottom of channel $(\mathrm{m})$, surface width $(\mathrm{m})$, shade fraction (0 to 1 ), vertically volume-weighted temperature $\left({ }^{\circ} \mathrm{C}\right.$ ), net radiation at surface of segment $\left(\mathrm{W} \mathrm{m}^{-2}\right)$, evaporative heat flux at surface $\left(\mathrm{W}^{-2}\right)$, net long wave radiation at surface $\left(\mathrm{W} \mathrm{m}^{-2}\right)$, active constituents, derived constituents, kinetic fluxes $\left(\mathrm{kg} \mathrm{day}^{-1}\right)$, and algae growth limitation fraction for phosphorus, nitrogen, and light (0 to 1) for each algae group.

two_1.csv: Withdrawal outflow temperature file.

two_sp1_seg1: Spillway outflow temperature file.

w2.err: W2 error file.

w2.wrn: W2 warning file. 
WaitForRunLog.opt: A log of model wait actions output when the multiple waterbody wait function is used.

wl.opt: Water level output file. Records the water surface elevation of every model segment at intervals specified for time series output. 